\title{
Development of Precipitation $\delta^{18}$ O Isoscapes for Canada and Application within a Tracer-Aided Hydrological Model
}

\author{
by \\ Carly J. Delavau \\ A Thesis submitted to the Faculty of Graduate Studies of \\ The University of Manitoba \\ in partial fulfilment of the requirements of the degree of
}

DOCTORATE OF PHILOSOPHY

Department of Civil Engineering

University of Manitoba

Winnipeg

Copyright (C 2016 by Carly J. Delavau 


\begin{abstract}
Delineating spatial patterns of precipitation isotopes ("isoscapes") is important for studies including the hydrology of terrestrial systems, present and past interpretations of climate, and tracer-aided hydrological modelling, among others. However, the extent to which precipitation isoscapes can be predicted across Canada has not been fully articulated. This thesis combines isotopes in precipitation $\left(\delta^{18} \mathrm{O}_{\mathrm{ppt}}\right)$ observations from two regional and one global network to create long term and time series precipitation isoscapes for Canada and the northern United States. Multi-linear regressions of a small suite of geographic and climate variables generate the best performing long-term and seasonal models of $\delta^{18} \mathrm{O}_{\mathrm{ppt}}$. These models are used to develop long term isoscapes for Canada, which capture the general spatial and seasonal trends in $\delta^{18} \mathrm{O}_{\mathrm{ppt}}$, showing an improvement upon results from previous studies using global models. Building upon long-term $\delta^{18} \mathrm{O}_{\mathrm{ppt}}$ prediction, $\delta^{18} \mathrm{O}_{\mathrm{ppt}}$ observations alongside climatological and geographic predictors are used to create empirical time series prediction models. Five regionalization approaches are used to separate the study domain into isotope zones to explore the effect of spatial grouping on simulations. Generally, the models capture the timing and magnitude of intra-annual (seasonal) $\delta^{18} \mathrm{O}_{\mathrm{ppt}}$ cycles across the study domain while simulating moderate interannual variation; however often fail to capture the anomalies in observed $\delta^{18} \mathrm{O}_{\mathrm{ppt}}$. Uncertainty in predictions is quantified spatially and temporally, and the Köppen-Geiger (Kpn) regionalization is selected as the preferred regionalization scheme for future applications due to adequate model performance and lack of border issues at regional boundaries. Finally, estimates of monthly $\delta^{18} \mathrm{O}_{\mathrm{ppt}}$ from Kpn models, long term annual averages, and daily REMOiso output are used to force an isotope-enabled hydrological model, isoWATFLOOD, in the Fort Simpson Basin, NWT, Canada. Results show streamflow simulations are not significantly impacted by choice of
\end{abstract}


$\delta^{18} \mathrm{O}_{\mathrm{ppt}}$ input; however, oxygen-18 in streamflow and the internal apportionment of water (and model parameterizations) are impacted, particularly during large precipitation and snowmelt events. This work shows how isoWATFLOOD can be used in regions with limited $\delta^{18} \mathrm{O}_{\mathrm{ppt}}$ observations, and that the model can be of value in such regions. This study reinforces that a tracer-aided modelling approach works towards diagnosing issues surrounding model equifinality. 


\section{ACKNOWLEDGEMENTS}

There are many people and institutions that supported me over the past years that I would like to acknowledge. First and foremost - I would like to thank my thesis advisor, Dr. Trish Stadnyk.

Over these past seven years she has provided me with extensive opportunities to learn, collaborate and succeed in my research. Trish is more to me than an advisor, she is also a friend. I have been invited into her life over these past years, and she has provided me with emotional support through many thesis-related and personal ups and downs, for which I am very grateful.

I would also like to thank the rest of my thesis committee - Dr. Peter Rasmussen, Dr. Bill Buhay and Dr. Jean Birks. They are a patient and understanding group, and I am very thankful for all of their support. I would also like to take this opportunity to thank Peter specifically. Peter has not only taught me how to use Matlab (which has saved my life), but also is one of the kindest and most genuine people I have had the pleasure to work with. His outlook on life is inspirational, and he has provided me with much needed perspective.

Thank you to all of my research collaborators. I have been so extremely lucky to meet both incredibly smart and unbelievably kind people to work with that have taught me so much and provided me with indispensible guidance. I am so thankful that our paths have crossed and I know you have all helped to improve the quality of this research substantially. Specifically, this includes Dr. Nick Kouwen - WATFLOOD creator and guru. I cannot count the number of times I have e-mailed Nick in a panic and he has responded promptly with a solution, even from his sailboat on vacation. Also related to WATFLOOD, I would like to thank Tegan Holmes for her help with isoWATFLOOD code development and troubleshooting. Thank you to Dr. John 
Gibson, Dr. Jean Birks and Dr. Yi Yi with Alberta Innovates Technology Futures (AITF), as well as Dr. Tom Edwards. My time with you in Victoria was completely wonderful, and I am so thankful for the opportunity to work with you all. Specifically to Jean - thank you so much for all the expertise and support you've provided me over the years. It's been a pleasure working with you on the CNIP dataset. Many thanks to Dr. Sun Chun for both the knowledge and camaraderie over these past years. Additional thanks to Dr. Julian Klaus for manuscript feedback and friendship. I can always count on you to tell it like it is! Many thanks to Manitoba Hydro, in particular Kristina Koenig, for their support.

I would like to thank all of the students I have worked with over the years, including: Phil, Martin, Alex, Melissa, Aaron, Bill, Milan, Andrew, Scotty, Kian, Greg, Parsa, Steve, Dave, Shane, Andrea, Kevin, Tegan, Mitch, and others. Some of my fondest memories happened in the HRTF (and at our grad student parties and canoe trips!) and I sincerely treasure those years. The ridiculous jokes and stories will live on! I hope our paths cross again sometime soon. Thanks to Trish and Dr. Shawn Clark for putting up with all of us. :) I hope we provided you with at least some semblance of entertainment. Additional thanks to Shawn for all of the knowledge and support over all these years as well.

I would like to thank those organizations that have funded me during my time in graduate studies. This includes NSERC, the University of Manitoba, the Faculty of Engineering, and Manitoba Hydro. I could not have completed this degree without your monetary support, and I am extremely grateful.

Special thanks to Mark Lee and Nicole Armstrong with Manitoba Sustainable Development's Water Science and Management Branch for all their support in these last final months. I am so 
lucky to have such supportive supervisors. I could not have made this final push without your support, and I am incredibly grateful.

And finally, I would like to thank my friends and my family - specifically my Mom and Dad, Laura, Kathryn, and my partner John. Whether you were cooking me meals, mowing my lawn, or providing me emotional support over these past several years while I was working a full time job and finishing my thesis on evenings and weekends, I deeply appreciate it all. During those very stressful times, thank you for giving me a shoulder to lean (or cry) on, and giving me the perspective and motivation to get it done. This has honestly been the hardest challenge I have faced, and I know I could not have completed it without your love and encouragement. 


\section{DEDICATION}

This thesis is dedicated to my mom, Elaine, my dad, Randy, and my sister, Laura. Thank you from the bottom of my heart for everything you have done to help me succeed over these past seven years (and of course, prior to that!). There is no doubt in my mind that I could not have completed this work without your support and encouragement. I am so incredibly lucky to have such a wonderful and supportive family.

Much love and many thanks.

$-\mathrm{C}$

(ن) 


\section{TABLE OF CONTENTS}

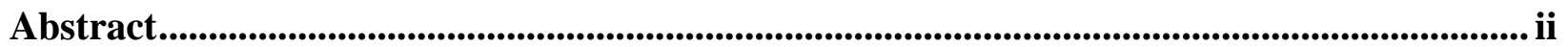

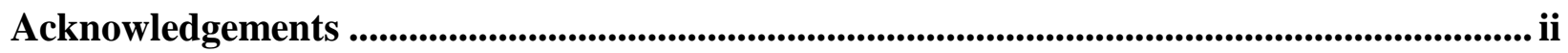

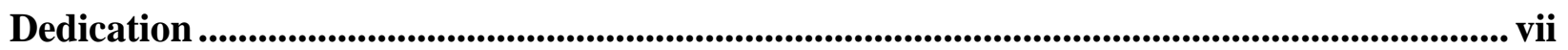

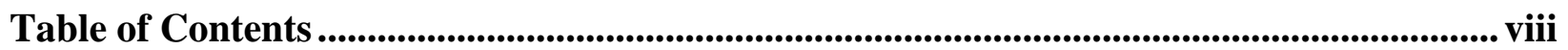

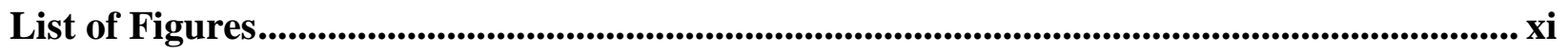

List of Tables ................................................................................................................................. $\times 1$

Use of Copyrighted Material....................................................................................................... xvii

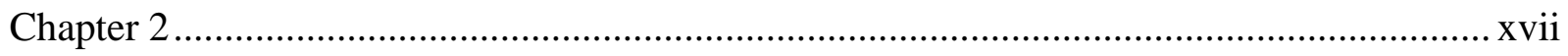

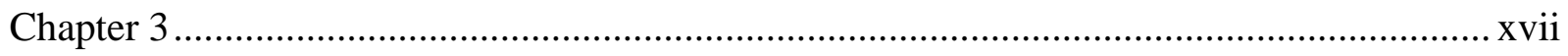

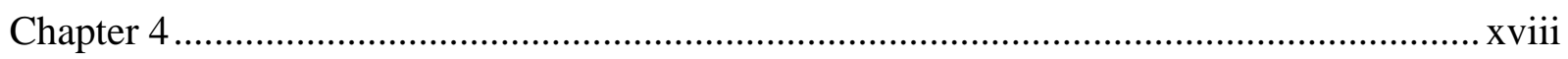

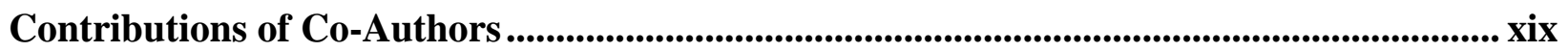

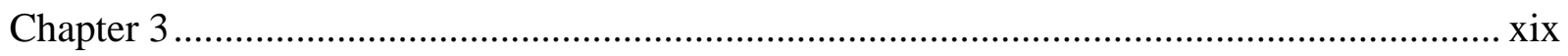

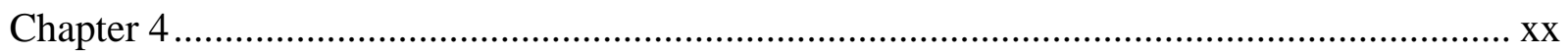

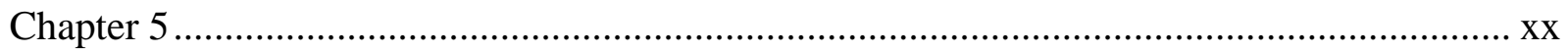

CHAPTER 1： Introduction ................................................................................................ 1

1.1 Project Background and Motivation ................................................................. 1

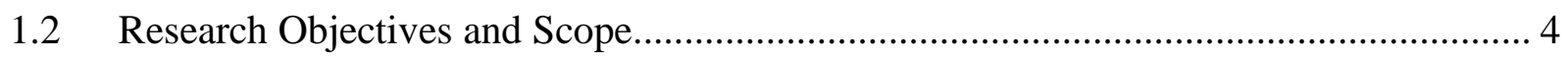

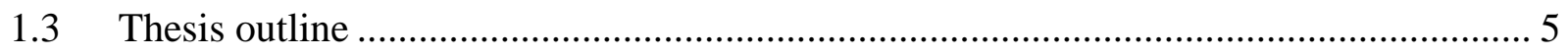

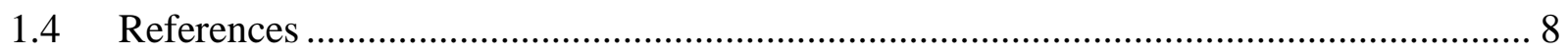

CHAPTER 2: Background and Relevant Literature......................................................... 13

2.1 Stable Water Isotopes in the Hydrological Cycle .................................................... 13

2.2 Stable Water Isotopes in Precipitation ................................................................. 16

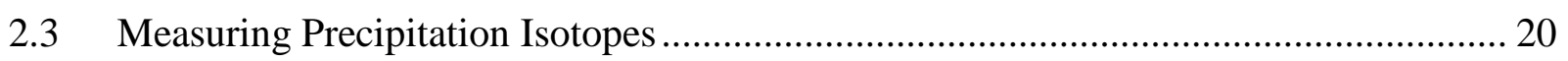

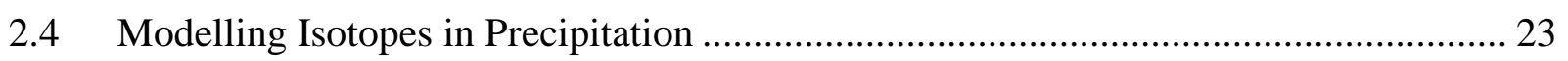

2.4.1 Utility of Precipitation Isoscapes .................................................................. 23

2.4.2 Empirical Methods............................................................................................ 25

2.4.3 Isotope-enabled Climate Models .................................................................... 28

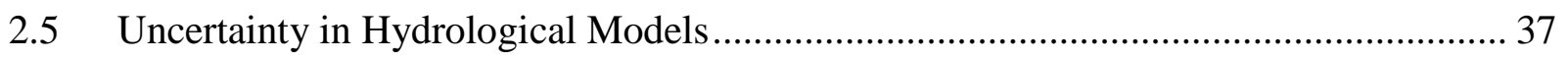

2.5.1 Estimating Predictive Uncertainty ......................................................... 40

2.5.2 Incorporation of Alternative Data Sources ('Data Assimilation') ........................ 44

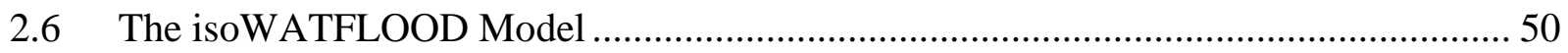

2.7 Chapter Summary and Gaps in Existing Research.................................................. 56 
2.8 References.

CHAPTER 3: Model based spatial distribution of oxygen-18 isotopes in precipitation

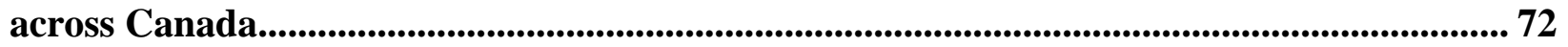

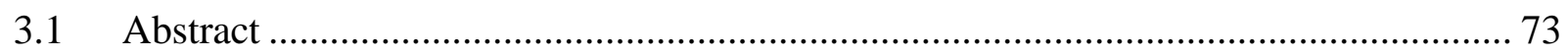

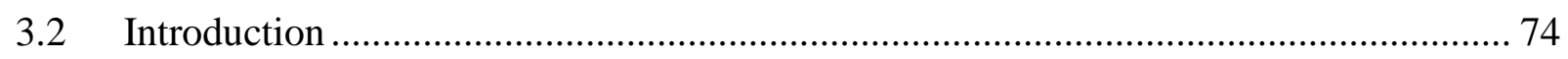

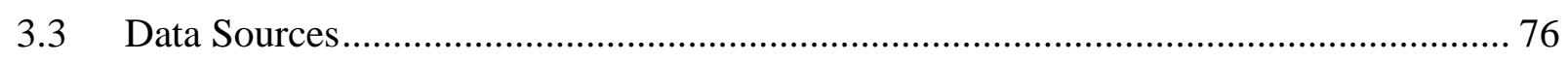

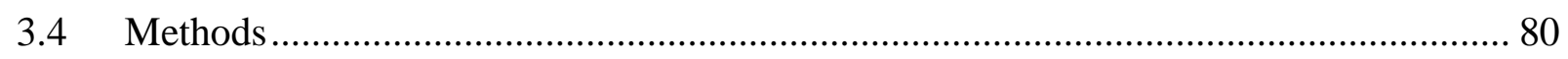

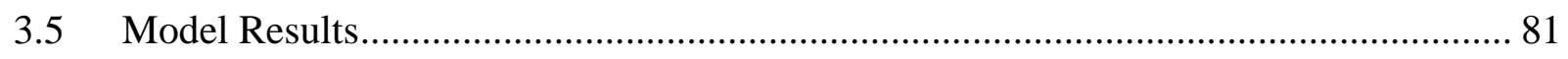

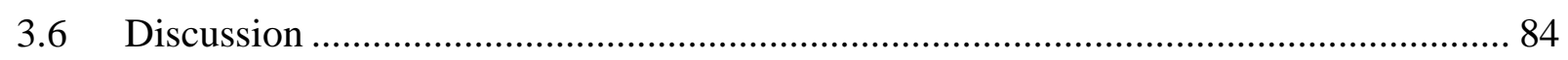

3.7 Spatial Distribution of Annual and Seasonal $\delta^{18} \mathrm{O}_{\mathrm{ppt}}$ over Canada ............................. 94

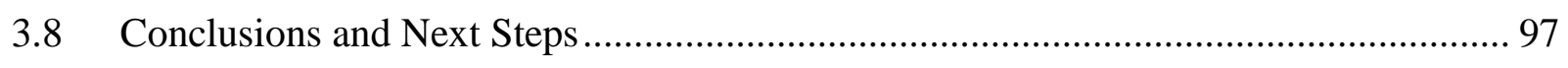

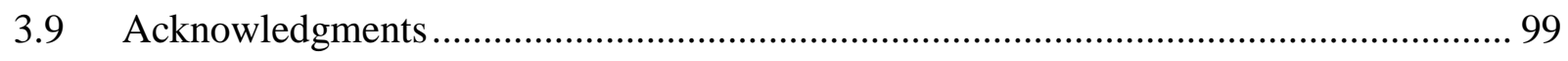

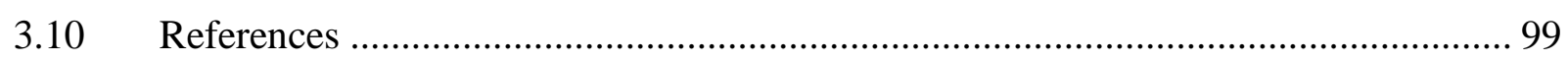

CHAPTER 4: North American precipitation isotope $\left(\delta^{18} O\right)$ zones revealed in time-series modelling across Canada and northern United States ......................................................... 103

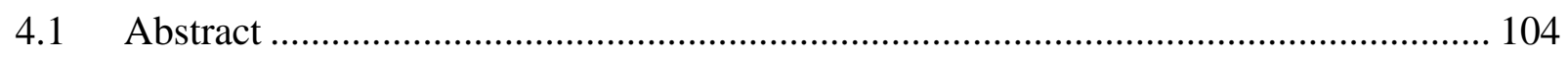

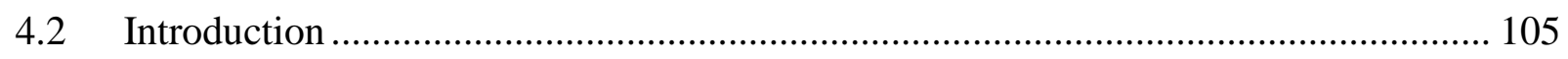

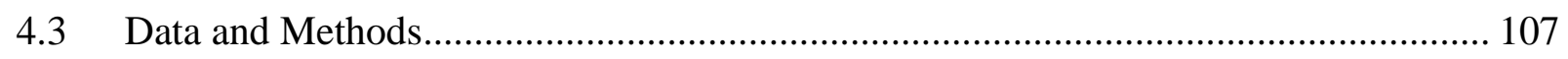

4.3.1 Observations and Gridded Products................................................................. 107

4.3.2 Climate and Geographic Data .................................................................... 109

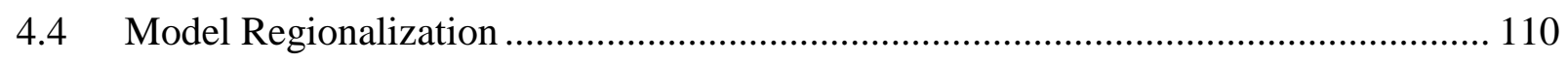

4.5 Regression Model Development ..................................................................... 114

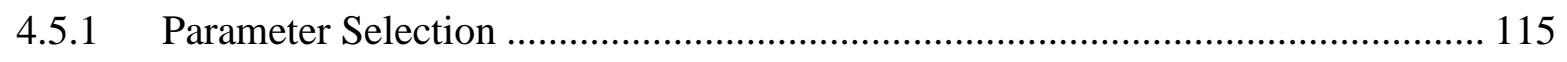

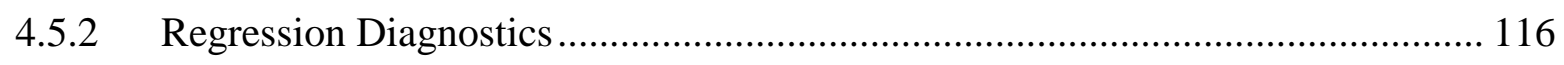

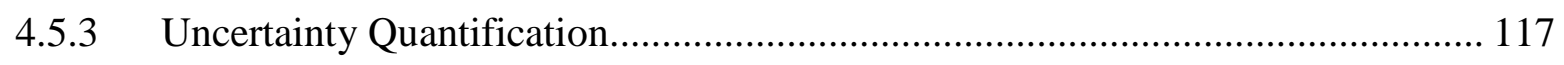

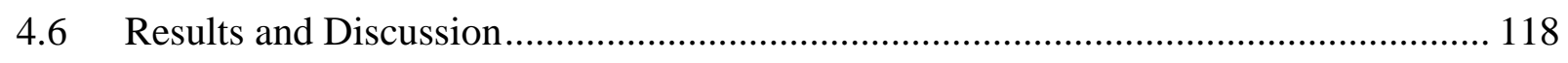

4.6.1 Model Performance, Parameterization, and Diagnostics ................................. 118

4.7 Time-series Ensemble Simulations ................................................................. 126

4.8 Long-Term Spatial Mapping .............................................................................. 129

C.9 Conclusions and Next Steps ............................................................................... 132

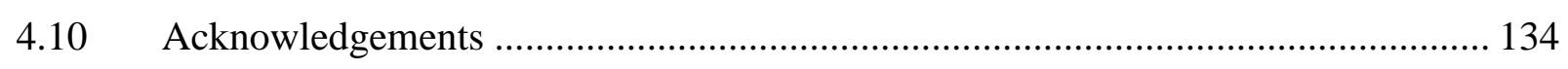

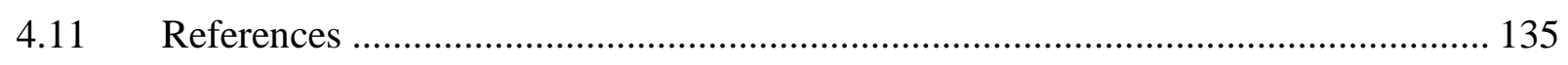

CHAPTER 5: Examining the impacts of Estimated precipitation isotope $\left(\delta^{18} \mathrm{O}\right)$ inputs on distributed tracer-aided hydrological modelling ..................................................................... 139

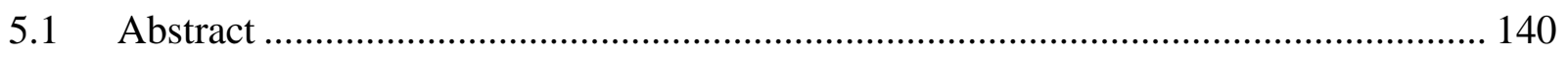




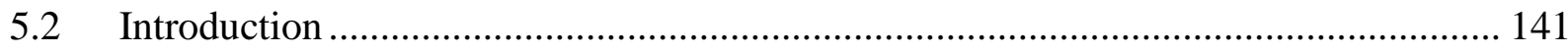

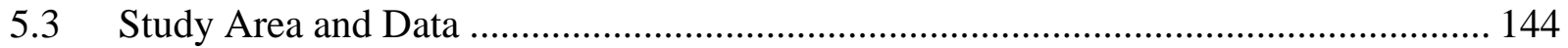

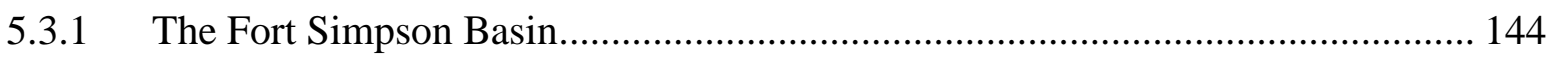

5.3.2 Meteorological and Hydrometric Data ............................................................. 146

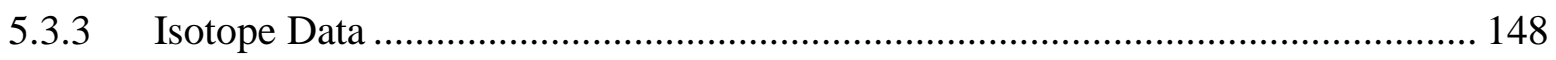

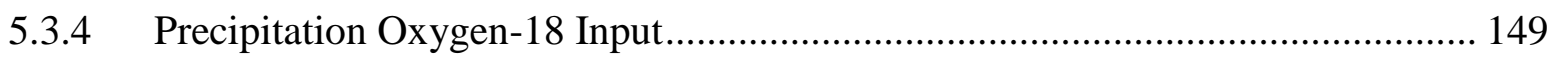

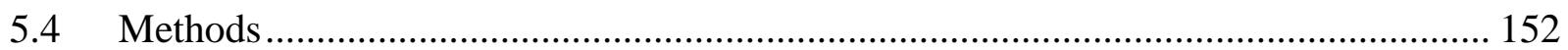

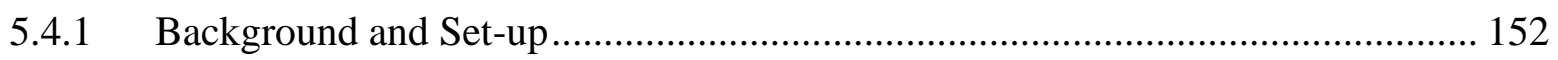

5.4.2 Calibration and Parameter Uncertainty......................................................... 153

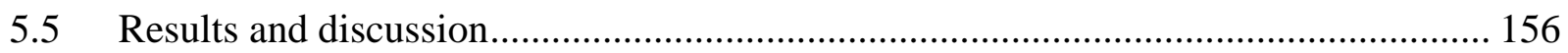

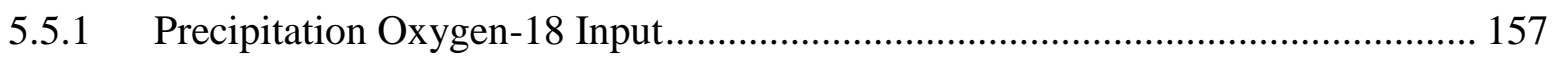

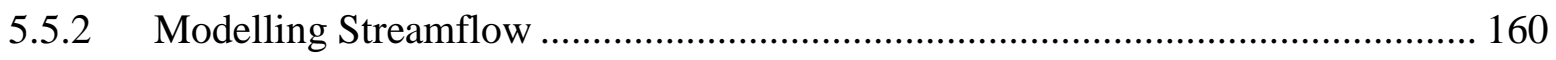

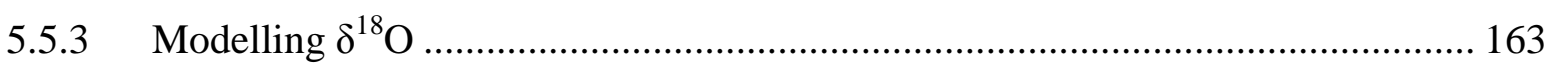

5.5.4 Hydrograph Component Analysis and Parameter Distributions............................ 168

5.6 Conclusion and Recommendations ................................................................... 172

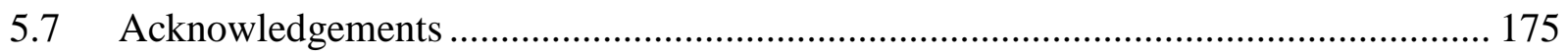

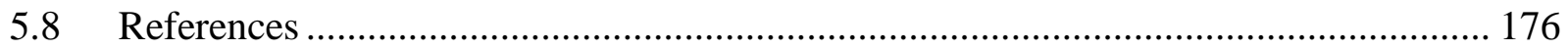

CHAPTER 6: Summary and Conclusions ................................................................................... 181

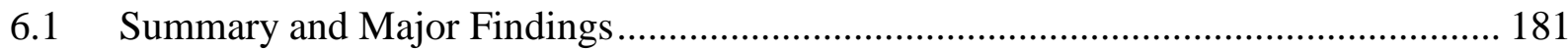

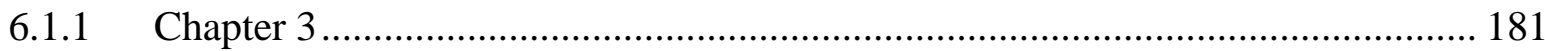

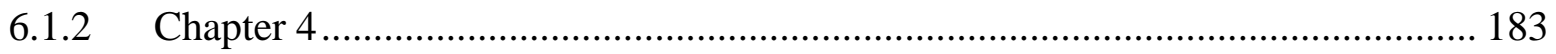

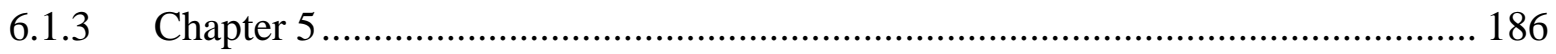

6.2 Limitations and Future Work ……………………......................................... 188

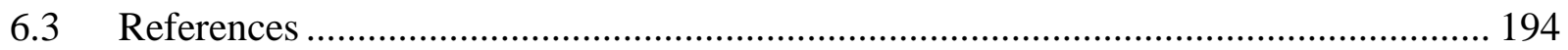

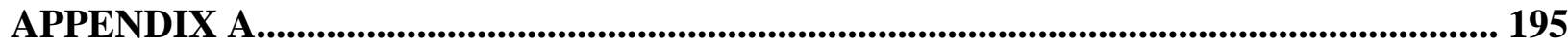

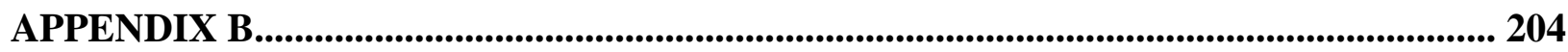

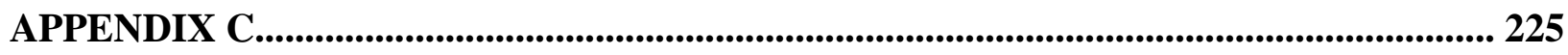

APPENDIX D.............................................................................................................................................. 269

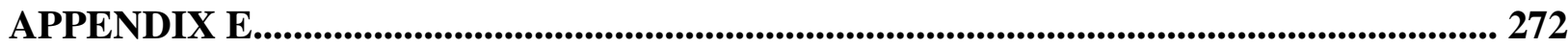




\section{LIST OF TABLES}

Table 1: Stable isotopes of hydrogen and oxygen. ………........................................................ 13

Table 2: Selected isotope-enabled GCMs, their resolution, previous versions, and main

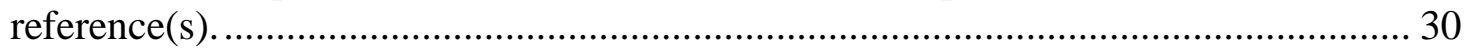

Table 3: Isotope-enabled RCMs, their resolution, main reference(s), and if applicable, the GCM they are nested within........................................................................................... 33

Table 4: Summary of isoWATFLOOD isotope-mass balances and assumptions for each hydrological storage compartment (From Stadnyk et al., 2013 @ John Wiley \& Sons, Ltd.. Reproduced with permission). 54

Table 5: $\delta^{18} \mathrm{O}_{\mathrm{ppt}}$ Period of Record and Sampling Site Geographic Information. 78

Table 6: Summary of variance inflation factor results for simple linear regression (SIM) and stepwise regression (SW) models. A VIF greater than 10 is indicated with a (Y) while a VIF less than 10 is indicated by a $(\mathrm{N})$. 83

Table 7: Annual model parameterization and summary statistics. Bowen and Wilkinson and simple regression parameterizations indicated by an (X). Stepwise regression retained parameters indicated by an $(\mathrm{R})$. 83

Table 8: Seasonal model parameterization and summary statistics. Parameters included in each of the models are indicated with an (X). Stepwise regression retained parameters indicated by an $(\mathrm{R})$. 84

Table 9: Variables included in regression model development. 110

Table 10: Basin characteristics, including land cover classification, area, and average basin slope (recreated from data provided in St Amour et al., 2005) 146

Table 11: Data summary for the study period (SP) and period of record (PoR). The coefficient of variation $(\mathrm{CV})$ is calculated as the ratio of the standard deviation to the mean. 147

Table 12: Static $\delta 180 p p t$ input compositions of annual rainfall and snowfall oxygen-18 for isoWATFLOOD.

Table 13: Seasonal REMOiso bias correction. 151

Table 14: Initialization values for FSB isoWATFLOOD simulations. 153

Table 15: Parameters included in the Monte Carlo calibration, alongside a description of what the parameter represents and the algorithm it is used within. 154 
Table 16: Average simulation statistics from $\mathrm{n}$ behavioural simulations for streamflow and $\delta^{18} \mathrm{O}_{\mathrm{SF}}$ for the three model calibrations (using KPN43, REMOiso, and static inputs).

Table 17: Allowable parameter ranges and resulting averaged parameter characteristics for behavioural simulations retained from the three model calibrations (KPN43, REMOiso, and static inputs). Parameters are summarized as: median (minimum, maximum). 159

Table A-1: Supplementary information for CNIP, GNIP and USNIP measurement

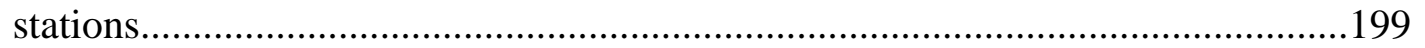

Table A-2: Number of observations (n) included in: (a) calibration and, (b) validation subsets for each seasonal model within the five regionalization schemes. 


\section{LIST OF FIGURES}

Figure 1: Theoretic isotope framework (i.e., 'delta-delta space).(From Froehlich et al,. 2002, (C) International Atomic Energy Agency. Reproduced with permission). 17

Figure 2: $\quad$ Precipitation $\delta^{18} \mathrm{O}$ isoscapes for: (a) long-term, precipitation-amount weighted annual average $\delta^{18} \mathrm{O}$ of precipitation, and (b) intra-annual range of precipitation $\delta^{18}$ O. (From Bowen, 2010, (C) Annual Review of Earth and Planetary Sciences. Reproduced with permission). 19

Figure 3: CNIP, GNIP (yellow symbols) and USNIP (red symbols) isotopes in precipitation $\left(\delta^{18} \mathrm{O}, \delta^{2} \mathrm{H}\right)$ sampling locations. Note that only USNIP stations for the upper tier of

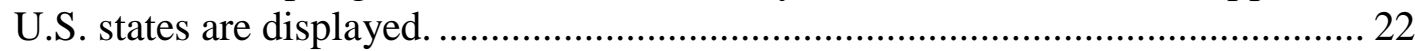

Figure 4: Temporal and spatial distribution of CNIP/GNIP and USNIP monthly observations 23

Figure 5: $\quad$ Simulations of precipitation $\delta^{18} \mathrm{O}$ from (a) the GNIP observation-based regression model (Buenning., N., and D. Noone, Role of local and nonlocal processes in the seasonal cycle and interannual variability of the isotopic composition of precipitation deduced through observations and models, submitted to Journal of Geophysical Research, 2008), and three GCMs: (b) MUGCM, (c) ECHAM and (d) GISS, as part of the first phase of the Stable Water-isotope Intercomparison Group (SWING). Colour shading in (b - d) dictates where the models deviate from GNIP observations by more than 1\%. (red represents positive deviation, blue is negative deviation) with error gradations of 1\%o. (From None and Sturm, 2010, C Springer International Publishing. Reproduced with permission). 32

Figure 6: REMOiso simulations across a southern Canadian transect (a) compared with CNIP and GNIP (b) long-term average and (c \& d) monthly observations (Reproduced with permission from S. J. Birks). 35

Figure 7: $\quad$ REMOiso simulations across a northern Canadian transect (a) compared with CNIP and GNIP (b) long-term average and (c \& d) monthly observations (Reproduced with permission from S. J. Birks) 36

Figure 8: $\quad$ Illustration of isoWATFLOOD hydrology (From Stadnyk et al., 2013 @ John Wiley $\&$ Sons, Ltd.. Reproduced with permission). 51

Figure 9: Spatial Distribution of CNIP/GNIP Stations across Canada. Smaller circles indicate locations where the CNIP station is located at an elevation lower than $200 \mathrm{~m}$ while larger circles indicate stations located at elevations higher than $200 \mathrm{~m}$. 77

Figure 10: Seasonal variations in simulated $\delta^{18} \mathrm{O}_{\mathrm{ppt}}$ from six select CNIP stations. Measured $\delta^{18} \mathrm{O}_{\mathrm{ppt}}$ is indicated by the solid black lines. 87 
Figure 11: Regression model residuals for the DJF model series. Negative residuals (measured $<$ modelled) are shown in black and positive residuals (measured > modelled) are shown in light gray. Residuals are calculated by subtracting modelled $\delta^{18} \mathrm{O}_{\mathrm{ppt}}$ from measured $\delta^{18} \mathrm{O}_{\mathrm{ppt}}$. The size of the circles represents the relative magnitude of the residuals. 89

Figure 12: Residuals from seasonal regression models plotted against longitude for each of the five model types. 92

Figure 13: Regression model residuals for the annual, DJF, MAM, JJA and SON SIM3 models. Negative residuals (measured<modelled) are shown in black and positive residuals (measured $>$ modelled) are shown in light gray. Residuals are arrived at by

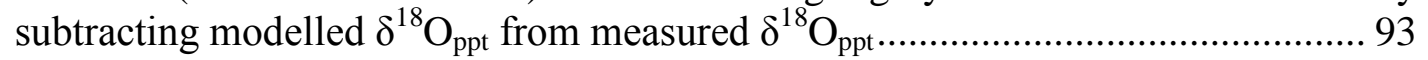

Figure 14: $\quad$ SIM3 annual and seasonal $\delta^{18} \mathrm{O}_{\mathrm{ppt}}$ patterns across Canada................................... 96

Figure 15: SIM3 annual and seasonal residual contours................................................ 97

Figure 16: Distribution of CNIP/GNIP and USNIP monthly $\delta^{18} \mathrm{O}_{\mathrm{ppt}}$ compositions at each station. Number of monthly observations within each decade is specified.......... 108

Figure 17: Study domain regionalization into isotope zones: (a) SSC, (b) Kpn, (c) RCWIP, and (d) 2-Zone. The CNIP, GNIP and USNIP stations included in each zone are indicated, alongside the number of years of data at each station, represented by the magnitude of the symbol. 112

Figure 18: (a) Average number of parameters retained within each model, and (b) overall seasonal parameter retention frequency for all models. 119

Figure 19: Residual box and whisker plots for the (a) calibration and (b) validation subsets of each regionalization. 120

Figure 20: Seasonal MSE (bar chart), for all model residuals at each station, and excess kurtosis and IQR's for individual regionalizations (scatter plots) at each station. Stations are grouped into two subsets: (a) stations located south of $55^{\circ}$ latitude, ordered from west to east; (b) stations located north of $55^{\circ}$ latitude, ordered some south to north. Variance in observed $\delta^{18} \mathrm{O}_{\mathrm{ppt}}$ is indicated by the black line. Star symbols indicate stations displayed in further detail below on Figure 21............ 124

Figure 21: Ten year monthly time-series simulations for five stations throughout the study domain. Ensemble means are indicated by the solid lines. $\delta^{18} \mathrm{O}_{\mathrm{ppt}}$ observations are denoted as black diamonds. The gray shaded region represents the envelope of bootstrapped $90 \%$ prediction intervals for all regionalizations. 128

Figure 22: Long-term precipitation amount weighted annual average $\delta^{18} \mathrm{O}_{\mathrm{ppt}}$ simulations (units of \%o) for: (a) SSC, (b) Kpn, (c) RCWIP, (d) 2-Zone, and (e) 1-Zone regionalizations. The gridded range in long-term simulations is displayed on Figure $22 \mathrm{f}$. 130 
Figure 23: Fort Simpson River Basin (all other tributaries of the Liard and Mackenzie Rivers have been removed for ease of viewing). 145

Figure 24: Comparison of raw and corrected REMOiso $\delta^{18} \mathrm{O}_{\mathrm{ppt}}$ output with CNIP monthly compositions at Snare Rapids, NWT. 151

Figure 25: Input and behavioural simulations for Jean Marie, including: (a) KPN43, REMOiso and static $\delta^{18} \mathrm{O}_{\mathrm{ppt}}$ input time series and daily precipitation; and simulated (b) mean daily streamflow and uncertainty bounds and (c) mean daily $\delta^{18} \mathrm{O}_{\mathrm{SF}}$ and uncertainty bounds, for KPN43, REMOiso and static driven model calibrations. $\delta^{18} \mathrm{O}_{\mathrm{ppt}}$ inputspecific uncertainty bounds are represented as the shaded regions, with shading colour corresponding to $\delta^{18} \mathrm{O}_{\mathrm{ppt}}$ type. 161

Figure 26: Input and behavioural simulations for Blackstone, including: (a) KPN43, REMOiso and static $\delta^{18} \mathrm{O}_{\mathrm{ppt}}$ input time series and daily precipitation; and simulated (b) mean daily streamflow and uncertainty bounds and (c) mean daily $\delta^{18} \mathrm{O}_{\mathrm{SF}}$ and uncertainty bounds, for KPN43, REMOiso and static driven model calibrations. $\delta^{18} \mathrm{O}_{\mathrm{ppt}}$ inputspecific uncertainty bounds are represented as the shaded regions, with shading colour corresponding to $\delta^{18} \mathrm{O}_{\mathrm{ppt}}$ type. 162

Figure 27: Precipitation-weighted $\delta^{18} \mathrm{O}$ of snowpack $\left(\delta^{18} \mathrm{O}_{\mathrm{SNW}}\right)$ for KPN43, REMOiso and static inputs from January to the end of melt for each year of the study period. Snow water equivalent (SWE), snowfall (gray line) and rainfall (blue line) are also shown. $\delta^{18} \mathrm{O}_{\mathrm{ppt}}$ input-specific uncertainty bounds are represented as the shaded regions. 166

Figure 28: Percent seasonal volume contributing to total streamflow from surface runoff, interflow and baseflow storages for each season. Cross symbols represent the $5^{\text {th }}$ and $95^{\text {th }}$ percentiles for each forcing method, and circle symbols signify the mean values. The combined uncertainty bounds representing the $5^{\text {th }}$ and $95^{\text {th }}$ simulations from all three $\delta^{18} \mathrm{O}_{\mathrm{ppt}}$ input types are shaded in gray. 169

Figure 29: Probability distributions for select parameters, as indicated in the bottom right corner of each panel. Parameters are from behavioural simulations, and (a), (b), (e) and (f) have been weighted to the land cover distribution within Jean Marie and Blackstone, as outlined in Table 10. Panels (c) and (d) and river class parameters within Jean Marie, and panels (g) and (h) contain river class parameters for Blackstone. 171

Figure B-1: Incorporation of isoP folder within overall WATFLOOD folder structure..........206

Figure B-2: Folder structure required by the isoP program, and the files housed in the isoP_Code folder on local drive:ISPLlisoP_Code............................................. 207

Figure B-3: Locations of comparison between NARR and ERA-40 data. ........................... 209

Figure B-4: Proportionality plots of NARR (x-axis) vs. ERA-40 (y-axis) precipitable water at 13 locations located throughout the study domain. 210 
Figure B-5: (a) The five Köppen Zones for which $\delta^{18} \mathrm{O}_{\text {ppt }}$ prediction models are developed, and (b) the ten Köppen Zones located within Canadian river basins......................... 214

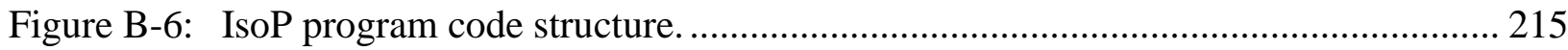

Figure B-7: The WATFLOOD grid for the Lower Nelson River watershed.......................... 217 


\section{USE OF COPYRIGHTED MATERIAL}

\section{Chapter 2}

Figure 1: Theoretic isotope framework (i.e., 'delta-delta space).(From Froehlich et al. 2002, () International Atomic Energy Agency. Reproduced with permission)........................................................................................... 17

Figure 2: Precipitation $\delta^{18} \mathrm{O}$ isoscapes for: (a) long-term, precipitation-amount weighted annual average $\delta^{18} \mathrm{O}$ of precipitation, and (b) intra-annual range of precipitation $\delta^{18} \mathrm{O}$. (From Bowen, 2010, () Annual Review of Earth and Planetary Sciences. Reproduced with permission). 19

Figure 5: Simulations of precipitation $\delta^{18} \mathrm{O}$ from (a) the GNIP observation-based regression model (Buenning., N., and D. Noone, Role of local and nonlocal processes in the seasonal cycle and interannual variability of the isotopic composition of precipitation deduced through observations and models, submitted to Journal of Geophysical Research, 2008), and three GCMs: (b) MUGCM, (c) ECHAM and (d) GISS, as part of the first phase of the Stable Water-isotope Intercomparison Group (SWING). Colour shading in $(b-d)$ dictates where the models deviate from GNIP observations by more than $1 \%$. (red represents positive deviation, blue is negative deviation) with error gradations of 1\%. (From None and Sturm, 2010, () Springer International Publishing. Reproduced with permission). 32

Figure 6: REMOiso simulations across a southern Canadian transect (a) compared with CNIP and GNIP (b) long-term average and (c \& d) monthly observations (Reproduced with permission from S. J. Birks) 35

Figure 7: REMOiso simulations across a northern Canadian transect (a) compared with CNIP and GNIP (b) long-term average and (c \& d) monthly observations (Reproduced with permission from S. J. Birks) 36

Figure 8: Illustration of isoWATFLOOD hydrology (From Stadnyk et al., 2013 @ John Wiley $\&$ Sons, Ltd.. Reproduced with permission) 51

Table 4: Summary of isoWATFLOOD isotope-mass balances and assumptions for each hydrological storage compartment (From Stadnyk et al., 2013 @ John Wiley \& Sons, Ltd.. Reproduced with permission). 54

\section{Chapter 3}

Chapter 3 of this thesis is reproduced with minor modifications from Delavau et al. (2011, Model based distribution of oxygen-18 isotopes in precipitation across Canada, Cdn. Water Resour. J., 36(4), 313-330, doi: 10.4296/cwrj3604875), @ Canadian Water Resources Journal. 
Reprinted with permission. The article can be found on the Taylor and Francis website as follows: http://www.tandfonline.com/; http://dx.doi.org/10.4296/cwrj3604875.

\section{Chapter 4}

Chapter 4 of this thesis is reproduced with minor modifications from Delavau et al. (2015, North American precipitation isotope ( $\mathrm{d} 18 \mathrm{O})$ zones revealed in time series modeling across Canada and

northern United States, Water Resour. Res., 51, doi:10.1002/2014WR015687), () American Geophysical Union. Reprinted with permission. 


\section{CONTRIBUTIONS OF CO-AUTHORS}

This thesis benefitted immensely from the help of numerous co-authors, the contributions from which are outlined below. However, it should be stated that the overall analysis, summary and presentation of results, alongside the general discussion of findings from Chapters 3,4 and 5 were largely completed on my own. Additionally, unless stated otherwise, the computer code required to complete the research in this thesis was personally developed and implemented.

\section{Chapter 3}

Model based spatial distribution of oxygen-18 isotopes in precipitation across Canada (Delavau, C., Stadnyk, T., and Birks, S. J.)

Dr. Tricia Stadnyk provided financial support and organized the logistics for me to re-locate to Victoria, British Columbia for four months in 2011 to work closely with Dr. Jean Birks, Dr. John Gibson, and other post-doctoral and visiting researchers in the Alberta Innovates Technology Futures (AITF) Victoria office. This gave me exposure and opportunity to collaborate with some of the foremost Canadian isotope hydrologists. Dr. Stadnyk provided some guidance with interpretation of the modelling results for this manuscript, in addition to editing of the

manuscript text. Dr. Jean Birks provided access to the Canadian Network for Isotopes in Precipitation (CNIP) data, and provided expertise and discussion on analysis of CNIP data, modelling results and made general suggestions for the modelling methods used. Dr. Birks also provided edits to the manuscript before it went to publication. 


\section{Chapter 4}

North American precipitation isotope $\left(\delta^{18} \mathrm{O}\right)$ zones revealed in time-series modelling across Canada and northern United States (Delavau, C., Chun, K.P., Stadnyk, T., Birks, S.J., and Welker, J.M.)

Dr. Kwok Pan Chun provided indispensable guidance and expertise on the statistical components of this work - specifically on the methods used to develop the multivariate regression models. He also provided technical assistance by conducting some preliminary statistical analysis on the spatial attributes and correlation of the CNIP data and completed some statistical checks on my model results. Dr. Chun was also involved in providing feedback for manuscript drafts throughout all stages of writing, and helped shape the outline of the manuscript. Dr. Stadnyk provided expertise and discussion on the modelling results for this manuscript. Dr. Jean Birks supplied access to CNIP data, and provided expertise and discussion on the modelling results. Dr. Jeffrey Welker supplied access to United States Network for Isotopes in Precipitation (USNIP) data. All authors contributed to editing and discussion of the manuscript text.

\section{Chapter 5}

Examining the impacts of precipitation isotope $\left(\delta^{18} \mathrm{O}\right)$ inputs on distributed tracer-aided hydrological modelling (Delavau, C., Stadnyk, T., and Holmes, T.)

Dr. Stadnyk provided the isoWATFLOOD model set-up that was used in this study. She provided guidance and expertise on analysis and discussion of modelling results. Dr. Stadnyk was also involved in providing feedback for manuscript drafts throughout all stages of writing, and helped shape the presentation and discussion of the results. Ms. Tegan Holmes was helpful in diagnosing and implementing isoWATFLOOD code enhancements related to this research, specifically regarding the isotopic evolution of snowpack. Ms. Holmes also created relative 
humidity and some other required files for isoWATFLOOD modelling, and provided edits to the manuscript. 


\section{Chapter 1}

\section{CHAPTER 1: INTRODUCTION}

\subsection{Project Background and Motivation}

The stable isotopes of precipitation $\left(\delta^{18} \mathrm{O}_{\mathrm{ppt}}\right.$ and $\left.\delta^{2} \mathrm{H}_{\mathrm{ppt}}\right)$ are natural tracers providing diverse attributes for understanding processes characterizing the water cycle at local, regional, and continental scales. This understanding is of paramount importance today as water resources provide the basis of rural and urban community sustainability, commercial industries, and the delivery of essential ecosystem services. While precipitation amounts and patterns are relatively well quantified, it is only over the last 25 years that we have begun to rigorously explore the spatial patterns of water cycle isotopes (termed 'isoscapes') at the continental and global scales. Precipitation isoscapes have helped researchers to understand large-scale water cycle dynamics and hydrologic fluxes (e.g. Gibson et al., 2010; Jasechko et al., 2013), investigate the movement and origins of animals and products (e.g. Bowen et al., 2007; Ehleringer et al., 2010; Hobson et al., 2010), develop paleoclimate proxies (e.g. Rowley and Garzione, 2007, Bowen, 2010), and they are required meteorological forcing data for tracer-aided hydrological modelling applications (e.g. Fekete et al., 2006).

Past efforts to predict oxygen-18 and deuterium distributions in precipitation have typically focused on creating isoscapes of long-term annual or seasonal averages at the global scale (Birks et al., 2002; Bowen and Wilkinson, 2002; Bowen and Revenaugh, 2003, Van der Veer et al., 2009; Terzer et al., 2013). More recently, researchers have refined the spatial extent to regional or continental scales for the United States (Dutton et al., 2005), China (Liu et al., 2008; Zhao et 


\section{Chapter 1}

al., 2011), Austria (Liebminger et al., 2006), Ireland (Fischer and Baldini, 2011), New Zealand (Baisden, et al., 2016), and the eastern Mediterranean (Lykoudis and Argiriou, 2007). The development of regional models has provided better approximations of the spatial and temporal distributions of $\delta^{18} \mathrm{O}_{\mathrm{ppt}}$, likely due to the inclusion of additional predictor variables than those typically incorporated within global-scale studies, and the smaller scale of application. The poor performance of global-based models over north central Canada (Bowen and Wilkinson, 2002, Noone and Sturm, 2010) indicates a regional model capable of better representing the controls on isotopic labeling of precipitation is needed for this region.

These empirical approaches have provided useful depictions of long-term annual and seasonal averages of $\delta^{18} \mathrm{O}_{\mathrm{ppt}}$ for many regions and have wide applicability as input or complementary data for many studies. They also provide valuable insight on the continental and regional controls on the isotopic composition of precipitation. Most of these estimates, however, are not suitable for predicting precipitation isotope compositions on the time scale necessary for many hydrological applications, such as tracer-aided hydrological modeling, where a time series monthly (or finer) compositions are required for model forcing (Stadnyk et al., 2013). This identifies a need not only to generate long-term Canadian isoscapes, but to also create models that are capable of simulating time series ${ }^{18} \mathrm{O}_{\mathrm{ppt}}$ at the monthly time scale.

Hydrological models are required for the planning, development, design, operation and sustainable management of our water resources (Singh and Frevert, 2006), particularly within regional-scale basins $\left(\geq 1000 \mathrm{~km}^{2}\right)$ where models are applied operationally and policy decisions are made. Large amounts of uncertainty in model output, however, can exist due to a lack of 


\section{Chapter 1}

available data at sufficient resolutions, over-parameterization and issues with nonuniqueness (i.e., equifinality). Equifinality is based on the concept that there are a multitude of model structures or parameter combinations that lead to the same end result (i.e., model output) due to the uncertainty involved with the various stages of the modelling process (Beven and Binley, 1992; Kirchner, 2006; Beven 2006; 2008). This concept of equifinality becomes increasingly significant when changes in climate or land-use effecting future streamflow are evaluated. If a hydrological model is unable to achieve the right answers for the right reasons during calibration conditions, the reliability surrounding the model's future predictions of streamflow is highly questionable (Beven, 2008).

One such tool to improve calibration and constrain uncertainty within hydrological models is to use a tracer-aided modelling approach, whereby an environmental tracer (for the purpose of this research, the tracer is stable water isotopes, SWIs) is simulated in conjunction with streamflow. This approach allows for multi-objective calibration and validation, whereby both streamflow and isotope simulations are used to constrain model structure and parameters. Modelling at the regional-scale typically requires a distributed approach to capture the heterogeneity in meteorological inputs, basin characteristics, and runoff response, resulting in more complex, highly parameterized models (e.g. Michaud and Sorooshian, 1994; Carpenter and Georgakakos, 2006; Her and Chaubey, 2015), further justifying the need for a multi-objective approach. Currently, isoWATFLOOD (Stadnyk-Falcone, 2008; Stadnyk et al., 2013) is the only distributed tracer-aided hydrological model that has been applied at regional or operational scales, where most other tracer-aided models are simple, lumped models that have only been applied on small, highly instrumented catchments. 


\section{CHAPTER 1}

Simulation of isotopes within tracer-aided models requires $\delta^{18} \mathrm{O}_{\mathrm{ppt}}$ observations as input data to force the model. Unfortunately, throughout much of the world, and particularly in sparsely populated mid- to high-latitude regions (such as the vast majority of Canada), these data are not widely available. The lack of spatial and temporal density of $\delta^{18} \mathrm{O}_{\mathrm{ppt}}$ observations highlights the need for alternative methods to provide estimates of stable isotopes in precipitation for traceraided model forcing. Options include empirically-based models generating gridded time series estimates of precipitation isotopes and isotope-enabled climate model output (e.g. REMOiso; Sturm et al., 2005; 2007).

Stadnyk et al. (2013) suggest well defined compositions of precipitation are instrumental to the accurate replication of inter-seasonal variation of isotopes in streamflow. For this reason, there is

a considerable need to assess and improve upon the current $\delta^{18} \mathrm{O}_{\mathrm{ppt}}$ input utilized by isoWATFLOOD (alongside other tracer-aided models), in addition to achieving an in-depth understanding of how the uncertainty due to $\delta^{18} \mathrm{O}_{\mathrm{ppt}}$ input propagates through the model and translates into uncertainty in model simulations and parameterizations. Improving $\delta^{18} \mathrm{O}_{\mathrm{ppt}}$ input and assessing the uncertainty attributable to $\delta^{18} \mathrm{O}_{\mathrm{ppt}}$ forcing is an important step towards utilizing isoWATFLOOD to constrain model parameterizations (i.e., reduce equifinality), and work towards the end goal of reducing uncertainty in WATFLOOD streamflow simulations.

\subsection{Research Objectives and Scope}

The over-arching goals of this research are to generate Canadian $\delta^{18} \mathrm{O}_{\mathrm{ppt}}$ isoscapes, and incorporate and evaluate these isoscapes as input for tracer-aided hydrological modelling. These goals will be achieved through the following objectives: 


\section{Chapter 1}

1. Develop new methods for the prediction of long-term average and monthly time series regional $\delta^{18} \mathrm{O}_{\mathrm{ppt}}$ isoscapes and their uncertainty throughout Canada, while concurrently enhancing our understanding of isotope-climate relations across the country;

2. Integrate $\delta^{18} \mathrm{O}_{\mathrm{ppt}}$ isoscapes as forcing for regional-scale tracer-aided hydrological models, enabling the application of such models within poorly gauged, remote basins where $\delta^{18} \mathrm{O}_{\mathrm{ppt}}$ observations are not available for model input, and;

3. Evaluate the uncertainty in tracer-aided model output and parameterizations due to estimated $\delta^{18} \mathrm{O}_{\mathrm{ppt}}$ inputs of differing temporal and spatial variability, thus informing the over-arching goal of quantifying and reducing uncertainty (and equifinality) in isoWATFLOOD streamflow simulations.

As the intended primary application of this research is $\delta^{18} \mathrm{O}_{\mathrm{ppt}}$ estimation and use in operational tracer-aided modelling at regional-scales, there are numerous constraints requiring consideration so as to not limit the applicability of this work. The main considerations are outlined below to aid in further defining the scope of this thesis:

- The $\delta^{18} \mathrm{O}_{\mathrm{ppt}}$ estimation method(s) must utilize publically available data that are temporally and spatially available throughout Canada. To create models requiring data that are typically unavailable in sparsely gauged, remote areas would restrict the models use;

- The $\delta^{18} \mathrm{O}_{\mathrm{ppt}}$ estimation method(s) should incorporate data that can account for temporally and spatially varying patterns of isotopes in precipitation. The timescale for which the $\delta^{18} \mathrm{O}_{\mathrm{ppt}}$ models are developed should be in line with the required temporal resolution of 


\section{ChAPTER 1}

tracer-aided hydrological models for successful prediction of the isotopic composition of streamflow. This timescale, however, is dictated by the monthly sampling frequency of the Canadian and Global Networks for Isotopes in Precipitation (CNIP, GNIP) data, and;

- The $\delta^{18} \mathrm{O}_{\mathrm{ppt}}$ estimation method(s) must be simplistic enough to be easily and seamlessly implemented within tracer-aided hydrological models with minimal or no additional parameterization. This consideration will also ensure that the $\delta^{18} \mathrm{O}_{\mathrm{ppt}}$ estimation methods are computationally efficient, and do not cause any drastic increases in pre-processing or hydrological model run times. This is particularly critical for operational tracer-aided hydrological modelling, as excessive run-times would prohibit use for this type of application.

\subsection{Thesis outline}

This thesis is comprised of six chapters. Chapter 1 provides a brief background of the thesis topic alongside the motivation and scope for the work completed in this thesis. Chapter 2 summarizes the theory and current state of research relating to stable water isotopes in the hydrologic cycle, with a specific focus on the creation of precipitation isoscapes and estimation of time series $\delta^{18} \mathrm{O}_{\mathrm{ppt}}$ through empirical and climate model approaches. The chapter concludes with how tracers

can help address uncertainty in hydrological modelling and how estimates of $\delta^{18} \mathrm{O}_{\mathrm{ppt}}$ are a critical component of using tracer-aided models in large-scale and/or remote and poorly gauged applications. The remaining chapters (with the exception of Chapter 6) are composed of manuscripts, forming the main portion of the thesis. 


\section{Chapter 1}

The first manuscript (Chapter 3) investigates the predictability of long term seasonal averages of oxygen-18 precipitation isotopes across Canada. Long-term average climate data and geographic information are used as predictor variables to generate seasonal maps of $\delta^{18} \mathrm{O}_{\mathrm{ppt}}$ for Canada. These maps are useful inputs for climatological, ecological, hydrological and hydrogeological studies requiring information on the long-term seasonal and annual labeling of precipitation. This work is the first step in achieving Objective 1, and has been peer-reviewed and published in the Canadian Water Resources Journal:

Delavau, C., T. A. Stadnyk, and S. J. Birks, (2011), Model based distribution of oxygen-18 isotopes in precipitation across Canada, Cdn. Water Resour. J., 36(4), 313-330, doi: $10.4296 /$ cwrj3604875.

The second manuscript (Chapter 4) investigates the predictability of monthly time series $\delta^{18} \mathrm{O}_{\mathrm{ppt}}$ by creating a suite of multivariate regression models using re-analysis climate data, geographic information and teleconnection indices. The effect of spatial grouping on model performance and model structure uncertainty is explored. Both time series monthly $\delta^{18} \mathrm{O}_{\mathrm{ppt}}$ simulations (and uncertainty bounds) at select locations and long-term annual average maps of $\delta^{18} \mathrm{O}_{\mathrm{ppt}}$ for the study domain are developed and analyzed. This work is the final step in achieving Objective 1, and has been peer-reviewed and featured in Water Resources Research:

Delavau, C., K. P. Chun, T. Stadnyk, S. J. Birks, and J. M. Welker, (2015), North American precipitation isotope $(\mathrm{d} 180)$ zones revealed in time series modeling across Canada and northern United States, Water Resour. Res., 51, doi: 10.1002/2014WR015687. 


\section{Chapter 1}

The third manuscript (Chapter 5) uses three types of $\delta^{18} \mathrm{O}_{\mathrm{ppt}}$ estimates as input for the traceraided isoWATFLOOD model and investigates how selection of $\delta^{18} \mathrm{O}_{\mathrm{ppt}}$ input impacts simulations, internal apportionment of water, and the resulting model parameterizations. A multicriteria, multi-objective multi- approach is used, and parameter uncertainty is accounted for using a GLUE-based methodology. This work is the final step in achieving Objectives 2 and 3, and the manuscript is currently ready for submission to Hydrology and Earth System Sciences.

The final chapter (Chapter 6) summarizes the research completed within this thesis, and outlines the major conclusions and recommendations for future work. Finally, Appendix B outlines the development of a pre-processing program (isoP) in Matlab that automates the process of developing gridded $\delta^{18} \mathrm{O}_{\text {ppt }}$ input for isoWATFLOOD modelling applications. This addresses Objective 2 .

Overall, this thesis makes a significant contribution to understanding the controls on and predictability of $\delta^{18} \mathrm{O}_{\mathrm{ppt}}$ throughout Canada at various temporal scales. Additionally, this work makes substantial strides in understanding how estimates of $\delta^{18} \mathrm{O}_{\mathrm{ppt}}$ impact distributed traceraided hydrological modelling, while making this modelling approach more accessible for poorly gauged regional basins across Canada.

\subsection{References}

Baisden, W. T., E. D. Keller, R. Van Hale, R. D. Frew, and L. I. Wassenaar, (2016), Precipitation isoscapes for New Zealand: enhanced temporal detail using precipitationweighted daily climatology, Isot. Environ. Health Stud., 23, 1-10, doi: 10.1080/10256016.2016.1153472.

Beven, K. (2008), On doing better hydrological science, Hydrol. Process., 22(17), 3549-3553, doi: 10.1002/hyp.7108. 


\section{Chapter 1}

Beven, K. J. (2006), A manifesto for the equifinality thesis, J. Hydrol., 320(1-2), 18-36, doi: 10.1016/j.jhydrol.2005.07.007.

Beven, K. And A. Binley (1992), The future of distributed models: Model calibration and uncertainty prediction. Hydrol. Process., 6: 279-298. doi: 10.1002/hyp.3360060305.

Birks, S. J., J. J. Gibson, L. Gourcy, P. K. Aggarwal, and T. W. D. Edwards (2002), Maps and animations offer new opportunities for studying the global water cycle, Eos Trans. AGU, 83(37), 406, doi: 10.1029/2002EO000298.

Birks, S. J., and T. W. D. Edwards (2009), Atmospheric circulation controls on precipitation isotope-climate relations in western Canada, Tellus Ser. B, 61B(3), 566-576, doi: 10.1111/j.1600-0889.2009.00423.x.

Bowen, G.J. (2010), Isoscapes: Spatial pattern in isotopic biogeochemistry, Annu. Rev. Earth Planet. Sci., 38, 161-187, doi:10.1146/annurev-earth-040809-152429.

Bowen, G. J., J. R. Ehleringer, L. A. Chesson, E. Stange, and T. E. Cerling, (2007), Stable isotope ratios of tap water in the contiguous United States, Water Resour. Res., 43, W03419, doi:10.1029/2006WR005186.

Bowen, G. J. and J. Revenaugh (2003), Interpolating the isotopic composition of modern meteoric precipitation, Water Resour. Res., 39(10), 1299-1311, doi: 10.1029/2003WR002086.

Bowen, G. J. and B. H. Wilkinson (2002), Spatial distribution of $\delta 180$ in meteoric precipitation, Geology, 30(4), 315-318, doi: 10.1130/0091-7613(2002)030<0315:SDOOIM>2.0.CO;2.

Carpenter, T. M., K. P. Georgakakos (2006), Intercomparison of lumped versus distributed hydrologic model ensemble simulations on operational forecast scales, J. Hydrol., 329(1-2), 174-185, doi: 10.1016/j.jhydrol.2006.02.013.

Dunn, S. M., J. Freer, M. Weiler, M. J. Kirkby, J. Seibert, P. F. Quinn, G. Lischeid, D. Tetzlaff, and C. Soulsby (2008), Conceptualization in catchment modelling: simply learning?. Hydrol. Process., 22, 2389-2393, doi: 10.1002/hyp.7070.

Dutton, A. L., B. H. Wilkinson, G. Bowen, J. M. Welker, and K. C. Lohmann (2005), Comparison of river water and precipitation $\delta 180$ across the 48 contiguous United States, Hydrol. Process., 19, 3551-3572, doi: 10.1002/hyp.5876.

Ehleringer, J. R., A. H. Thompson, D. W. Podlesak, G. J. Bowen, L. A. Chesson, T. E. Cerling, T. Park, P. Dostle, and H. Schwarcz, (2010), A framework for the incorporation of isotopes and isoscapes in geospatial forensic investigations, in: Isoscapes: Understanding movement, pattern, and process on Earth through isotope mapping, edited by: West, J. B., G. J. Bowen, T. E. Dawson, and K. P. Tu, Springer, London, 357-387.

Fekete, B. M., J. J. Gibson, P. Aggarwal, C .J Vorosmarty (2006), Application of isotope tracers in continental scale hydrological modeling, J. Hydrol., 330(3-4), 444-456, doi: doi:10.1016/j.jhydrol.2006.04.029. 


\section{Chapter 1}

Fenicia, F., J. J. McDonnell, and H. H. G. Savenije (2008), Learning from model improvement: On the contribution of complementary data to process understanding, Water Resour. Res., 44, W06419, doi: 10.1029/2007WR006386.

Fischer M. J., and L. M. Baldini (2011), A climate-isotope regression model with seasonallyvarying and time-integrated relationships, Clim. Dyn., 37(11-12), 2235-2251, doi: 10.1007/s00382-011-1009-1.

Gat J. R., C. J. Bowser, and C. Kendall (1994), The contribution of evaporation from the Great Lakes to the continental atmosphere: estimate based on stable isotope data, Geophys. Res. Lett., 21, 557-560, doi: 10.1029/94GL00069.

Gibson, J. J, B. M. Fekete, and G. J. Bowen, (2010), Stable isotopes in large scale hydrological applications, in: Isoscapes: Understanding movement, pattern, and process on Earth through isotope mapping, edited by: West, J. B., G. J. Bowen, T. E. Dawson, and K. P. Tu, Springer, London, 389-405.

Her, Y., and I. Chaubey (2015), Impact of the numbers of observations and calibration parameters on equifinality, model performance, and output and parameter uncertainty. Hydrol. Process., 29, 4220-4237, doi: 10.1002/hyp.10487.

Hobson, K. A., R. Barnett-Johnson, and T. Cerling, (2010), Using isoscapes to track animal migration, in: Isoscapes: Understanding movement, pattern, and process on Earth through isotope mapping, edited by: West, J. B., G. J. Bowen, T. E. Dawson, and K. P. Tu, Springer, London, 273-298.

Jasechko, S., Z. D. Sharp, J. J. Gibson, S. J. Birks, Y. Yi, and P. J. Fawcett, (2013), Terrestrial water fluxes dominated by transpiration, Nature, 496(7445), 347-350, doi: doi:10.1038/nature11983.

Kirchner, J. (2006), Getting the right answers for the right reasons: Linking measurements, analyses, and models to advance the science of hydrology, Water Resour. Res., 42(3), W03S04, doi:10.1029/2005WR004362.

Kohn, M. J. and J. M. Welker (2005), On the temperature correlation of $\delta^{18} \mathrm{O}$ in modern precipitation, Earth Planet. Sci. Lett., 231(1-2), 87-96, doi: 10.1016/j.epsl.2004.12.004.

Kuczera, G. (1983), Improved parameter inference in catchment models: 2. Combining different kinds of hydrologic data and testing their compatibility, Water Resour. Res., 19(5), 11631172, doi:10.1029/WR019i005p01163.

Kuczera, G. and M. Mroczkowski (1998), Assessment of hydrologic parameter uncertainty and the worth of multiresponse data, Water Resour. Res., 34(6), 1481-1489, doi:10.1029/98WR00496.

Lawrence, J. R. and J. W. C. White (1991), The elusive climate signal in the isotopic composition of precipitation, Stable Isotope Geochemistry: A Tribute to Samuel Epstein, 3, $169-185$. 


\section{Chapter 1}

Liebminger, A., G. Haberhauer, K. Varmuza, W. Papesch, and G. Heiss (2006), Modeling the oxygen 18 concentration in precipitation with ambient climatic and geographic parameters, Geophys. Res. Lett., 33(5), doi:10.1029/2005GL025049.

Liu, Z., T. Lide, X. Chai, and T. Yao (2008), A model-based determination of spatial variation of precipitation $\delta 18 \mathrm{O}$ over China, Chem. Geol., 249, 203-212, doi:10.1016/j.chemgeo.2007.12.011.

Lykoudis, S. P. and A. A. Argiriou (2007), Gridded data set of the stable isotopic composition of precipitation over the eastern and central Mediterranean, J. Geophys. Res., 112(D18107), doi:10.1029/2007JD008472.

Michaud, J. and S. Sorooshian (1994), Comparison of simple versus complex distributed runoff models on a midsized semiarid watershed, Water Resour. Res., 30(3), 593-605, doi:10.1029/93WR03218

Moran, T. A., S. J. Marshall, E. C. Evans, and K. E. Sinclair (2007), Altitudinal gradients of stable isotopes in lee-slope precipitation in the Canadian Rocky Mountains, Arctic Antarctic Alpine Research, 39(3), 455-467, http://www.jstor.org/stable/20181717.

Noone, D., and C. Sturm, (2010), Comprehensive dynamical models of global and regional water isotope distributions, in: Isoscapes: Understanding movement, pattern, and process on Earth through isotope mapping, edited by: West, J. B., G. J. Bowen, T. E. Dawson, and K. P. Tu, Springer, London, 195-219.

Rowley, D. B. And C. N. Garzione, (2007), Stable isotope-based paleoaltimetry, Annu. Rev. Earth Planet. Sci., 35, 463-508, doi: 10.1146/annurev.earth.35.031306.140155.

Seibert, J., and J. J. McDonnell (2002), On the dialog between experimentalist and modeler in catchment hydrology: Use of soft data for multicriteria model calibration, Water Resour. Res., 38(11), 1241, doi:10.1029/2001WR000978.

Simpkins, W. W. (1995), Isotopic composition of precipitation in central Iowa, Journal of Hydrology, 172, 185-207, doi: 10.1016/0022-1694(95)02694-K.

Singh, V.P., and D. K. Frevert, (2006), Watershed models. CRC Taylor \& Francis, Boca Raton.

Stadnyk, T. A., C. Delavau, N. Kouwen, and T. W. D. Edwards (2013), Towards hydrological model calibration and validation: simulation of stable water isotopes using the isoWATFLOOD model. Hydrol. Process., 27, 3791-3810, doi: 10.1002/hyp.9695.

Stadnyk-Falcone, T. A., (2008), Mesoscale Hydrological Model Validation and Verification using Stable Water Isotopes: The isoWATFLOOD Model. Ph.D. Thesis, University of Waterloo, Waterloo, 386 pp., http://hdl.handle.net/10012/3970.

Sturm, K., G. Hoffmann, and B. Langmann (2007), Simulation of the stable water isotopes in precipitation over South America: Comparing regional to global circulation models, J. Clim., 20(15), 3730-3750, doi: 10.1175/JCLI4194.1. 


\section{Chapter 1}

Sturm, K., G. Hoffmann, B. Langmann, and W. Stichler (2005), Simulation of d18O in precipitation by the regional circulation model REMOiso, Hydrol. Process., 19(17), 34253444, doi: 10.1002/hyp.5979.

Terzer, S., L. I. Wassenaar, L. J. Araguás-Araguás, and P. K. Aggarwal (2013), Global isoscapes for $\delta 18 \mathrm{O}$ and $\delta 2 \mathrm{H}$ in precipitation: improved prediction using regionalized climatic regression models, Hydrol. Earth Syst. Sci., 17, 4713-4728, doi:10.5194/hess-17-4713-2013.

Van der Veer, G., S. Voerkelius, G. Lorentz, G. Heiss, and J. A. Hoogewerff (2009), Spatial interpolation of the deuterium and oxygen-18 composition of global precipitation using temperature as ancillary variable, J. Geochem. Explor., 101, 175-184, doi: 10.1016/j.gexplo.2008.06.008.

Zhao, L., H. Xiao, M. Zhou, G. Cheng, L. Wang, L. Yin, and J. Ren (2011), Factors controlling spatial and seasonal distributions of precipitation d180 in China, Hydrol. Processes, 26, 143152, doi:10.1002/hyp.8118. 


\section{Chapter 2}

\section{CHAPTER 2: BACKGROUND AND RELEVANT LITERATURE}

This chapter provides a background of the relevant concepts relating to stable water isotopes in the hydrologic cycle and the controls on $\delta^{18} \mathrm{O}_{\text {ppt }}$ The state of research regarding the creation of precipitation isoscapes and estimation of time series $\delta^{18} \mathrm{O}_{\mathrm{ppt}}$ through empirical and climate model approaches is summarized. The chapter concludes with how tracers can help address uncertainty in hydrological modelling, particularly in large-scale and/or remote and poorly gauged applications, and how estimates of $\delta^{18} \mathrm{O}_{\mathrm{ppt}}$ are a critical component of using tracer-aided models.

\subsection{Stable Water Isotopes in the Hydrological Cycle}

The water molecule $\left(\mathrm{H}_{2} \mathrm{O}\right)$ is composed of both hydrogen $(\mathrm{H})$ and oxygen $(\mathrm{O})$ elements. Both hydrogen and oxygen have a number of isotopes, both stable and non-stable (i.e., radioactive). An isotope is two or more atoms of the same element that have an identical number of protons but a different number of neutrons and therefore differing atomic weights (Table 1). These differences in mass between isotopes allow for their use as tracers in hydrological studies (Gat $e t$ al., 2001).

Table 1: Stable isotopes of hydrogen and oxygen.

\begin{tabular}{|c|c|c|c|c|}
\hline Symbol & $\begin{array}{c}\text { Number of } \\
\text { Protons }\end{array}$ & $\begin{array}{c}\text { Number of } \\
\text { Neutrons }\end{array}$ & $\begin{array}{c}\text { Atomic } \\
\text { Mass }\end{array}$ & $\begin{array}{c}\text { Natural } \\
\text { Abundance } \\
(\%)\end{array}$ \\
\hline \multicolumn{5}{|c|}{ Hydrogen } \\
\hline${ }^{1} \mathrm{H}$ & 1 & 0 & 1 & 99.985 \\
\hline${ }^{2} \mathrm{H} ; \mathrm{D}$ & 1 & 1 & 2 & 0.0155 \\
\hline \multicolumn{5}{|c}{ Oxygen } \\
\hline${ }^{16} \mathrm{O}$ & 8 & 8 & 16 & 99.759 \\
\hline${ }^{17} \mathrm{O}$ & 8 & 9 & 17 & 0.037 \\
\hline${ }^{18} \mathrm{O}$ & 8 & 10 & 18 & 0.204 \\
\hline
\end{tabular}




\section{Chapter 2}

Isotopic values are reported in units of per mille (\%o) and utilize the delta $(\delta)$ notation relative to the VSMOW (Vienna Standard Mean Ocean Water) standard (Craig, 1961):

$\delta=\left(R_{\text {sample }}-R_{\text {standard }}\right) / R_{\text {standard }} * 1000$

(Equation 1)

where: $\mathrm{R}=\frac{{ }^{18} \mathrm{O}}{{ }^{16} \mathrm{O}}$ or $\mathrm{R}=\frac{{ }^{18} \mathrm{O}}{{ }^{16} \mathrm{O}}$

The notation to represent the abundance of heavy isotopes $\left({ }^{2} \mathrm{H},{ }^{18} \mathrm{O}\right)$ within a sample of water for hydrogen and oxygen are: $\delta^{2} \mathrm{H}$ (deuterium), and $\delta^{18} \mathrm{O}$ (oxygen-18), respectively.

As water moves from one phase to another throughout the hydrologic cycle (e.g. from liquid to vapour during evaporation, from vapour to liquid during condensation, etc.), mass-dependent isotopic fractionation occurs. There are two types of fractionation, equilibrium $\left(\varepsilon^{*}\right)$ and kinetic $\left(\varepsilon_{\mathrm{K}}\right)$. Equilibrium fractionation is a two-way thermodynamic exchange, with $\varepsilon^{*}=\left(\alpha^{*}-1\right)$. For freshwater oxygen-18 liquid to vapour (and vapour to liquid) equilibrium fractionation, Horita and Wesolowski (1994) defined the fractionation factor, $\alpha^{*}$, for oxygen-18 (in decimal notation) as:

$\ln \alpha_{L / V}^{*}=-\ln \alpha_{V / L}^{*}=0.35041 * 10^{6} / T^{3}-1.6664 * 10^{3} / T^{2}+6.7123 / T-7.685 * 10^{-3}$

(Equation 2)

where $T$ is temperature in units of Kelvin [K]. Conversely, kinetic fractionation is a one-way (i.e., irreversible) reaction where molecular bonds are broken, whose effects are generally larger than those from equilibrium fractionation (Gat et al., 2001). Kinetic fractionation is dependent on relative humidity and diffusivity of the evaporating molecules (Gat, 1995; 1996): 


\section{Chapter 2}

$\varepsilon_{K}=(1-h) * \theta * n * C_{D}$

(Equation 3)

Where $1-h$ is the humidity gradient, $n$ is the turbulence parameter where: $0.5 \leq \mathrm{n} \leq 1, \mathrm{C}_{\mathrm{D}}$ is equal to $28.55 \%$ based on laboratory studies (Gat, 1996), and $\theta$ is the weighting term whereby $\theta=(1-$ $\left.h^{\prime}\right) /(1-h) . \theta$ can be assumed approximately equal to 1 for a small body of water whose evaporation flux does not significantly change the isotopic composition of ambient moisture, or for water evaporating from soils (Barnes and Allison, 1988); however, this weighting term was found to be lower for larger water bodies such as the Great Lakes ( $\theta=0.88$; Gat et al., 1994).

Evaporation from the oceans is the primary source of water in the atmosphere (Gat, 1996). The isotopic fractionation that occurs during evaporation is an important factor in the variability and labelling of isotopic compositions within the water cycle. As water evaporates, the remaining liquid is then left enriched in heavy isotopes $\left({ }^{2} \mathrm{H},{ }^{18} \mathrm{O}\right)$, as the lighter isotopes $\left({ }^{1} \mathrm{H},{ }^{16} \mathrm{O}\right)$ are preferentially moved into the vapour phase due to their lighter mass. This leaves the evaporated vapour relatively depleted in heavy isotopes. Conversely, during transpiration, the isotopic fractionation is small relative to that during evaporation, and therefore is typically assumed to be negligible (Dawson and Ehleringer, 1998). Craig and Gordon (1965) proposed a linear resistance model to determine the composition of the evaporated water flux utilizing a three layer approach:

1. air/water interface layer: equilibrium conditions $\left(\varepsilon^{*}\right)$ assumed, therefore vapour is in equilibrium with the water (relative humidity $=100 \%$ );

2. laminar layer: molecular diffusion dominates $\left(\varepsilon_{\mathrm{K}}\right)$, equilibrium fraction still occurs (relative humidity < $100 \%$ ), and;

3. turbulent layer: eddy diffusion or turbulent transport dominates and it is assumed that no isotopic fractionation is occurring. 


\section{Chapter 2}

This results in the following equation for the isotopic composition of evaporated moisture $\left(\delta_{\mathrm{E}}\right.$; Craig and Gordon, 1965):

$\delta_{E}=\left(\alpha^{*} \delta_{L}-h \delta_{A}-\varepsilon^{*}-\varepsilon_{K}\right) /(1-h)$

(Equation 4)

where $\delta_{\mathrm{L}}$ is the isotopic composition of the surface waters, $h$ is the relative humidity, and $\delta_{\mathrm{A}}$ is the isotopic composition of atmospheric moisture. Typically, $\delta_{\mathrm{A}}$ is assumed to be in equilibrium with local meteoric water $\left(\delta_{\mathrm{P}}\right)$, whereby $\delta_{\mathrm{A}}$ is commonly defined as (Gibson et al., 2008):

$$
\delta_{A}=\delta_{P}-\varepsilon^{*} / \alpha^{*}
$$

(Equation 5)

However, the assumption of $\delta_{\mathrm{A}}$ being in equilibrium with meteoric water is not justified when large lakes or bodies of water are contributing excess moisture to the atmosphere. If this situation is occurring, $\delta_{\mathrm{A}}$ is better represented by an evaporation flux-weighted $\delta_{\mathrm{A}}$ value (Gibson et al., 2008).

\subsection{Stable Water Isotopes in Precipitation}

In a generalized sense, once the evaporated moisture disconnects from its source waters (i.e., the oceans), it mixes with the surrounding parcels of (marine) air, resulting in a homogenized precipitation composition, close to that of the Global Meteoric Water Line, GMWL (Figure 1; Craig, 1961; Dansgaard, 1964; Yurtsever, 1975). The GMWL is derived from the global average relationship between oxygen-18 and deuterium in precipitation $\left(\delta^{18} \mathrm{O}_{\mathrm{ppt}} / \delta^{2} \mathrm{H}_{\mathrm{ppt}}\right)$, represented as:

$\delta^{2} H_{p p t}=8 * \delta^{18} O_{p p t}+10$

where the intercept of the above equation is termed deuterium excess ( $d$-excess); and for the GMWL, is equal to 10\% (Figure 1; Dansgaard, 1964). The $d$-excess value (i.e., the offset from 


\section{Chapter 2}

the GMWL) is due to conditions controlling kinetic fractionation at the source of the evaporation, such as humidity, air and sea-surface temperatures, and wind speed (Merlivat and Jouzel, 1979, Froehlich et al., 2002). These differences in $d$-excess are one of the reasons behind unique meteoric water lines throughout different parts of the world, termed Local Meteoric Water Lines (LMWLs; Figure 1).

Figure 1: Theoretic isotope framework (i.e., 'delta-delta space).(From Froehlich et al,. 2002, (C) International Atomic Energy Agency. Reproduced with permission).

$\delta^{2} \mathrm{H}(\% \mathrm{~V}$-SMOW)

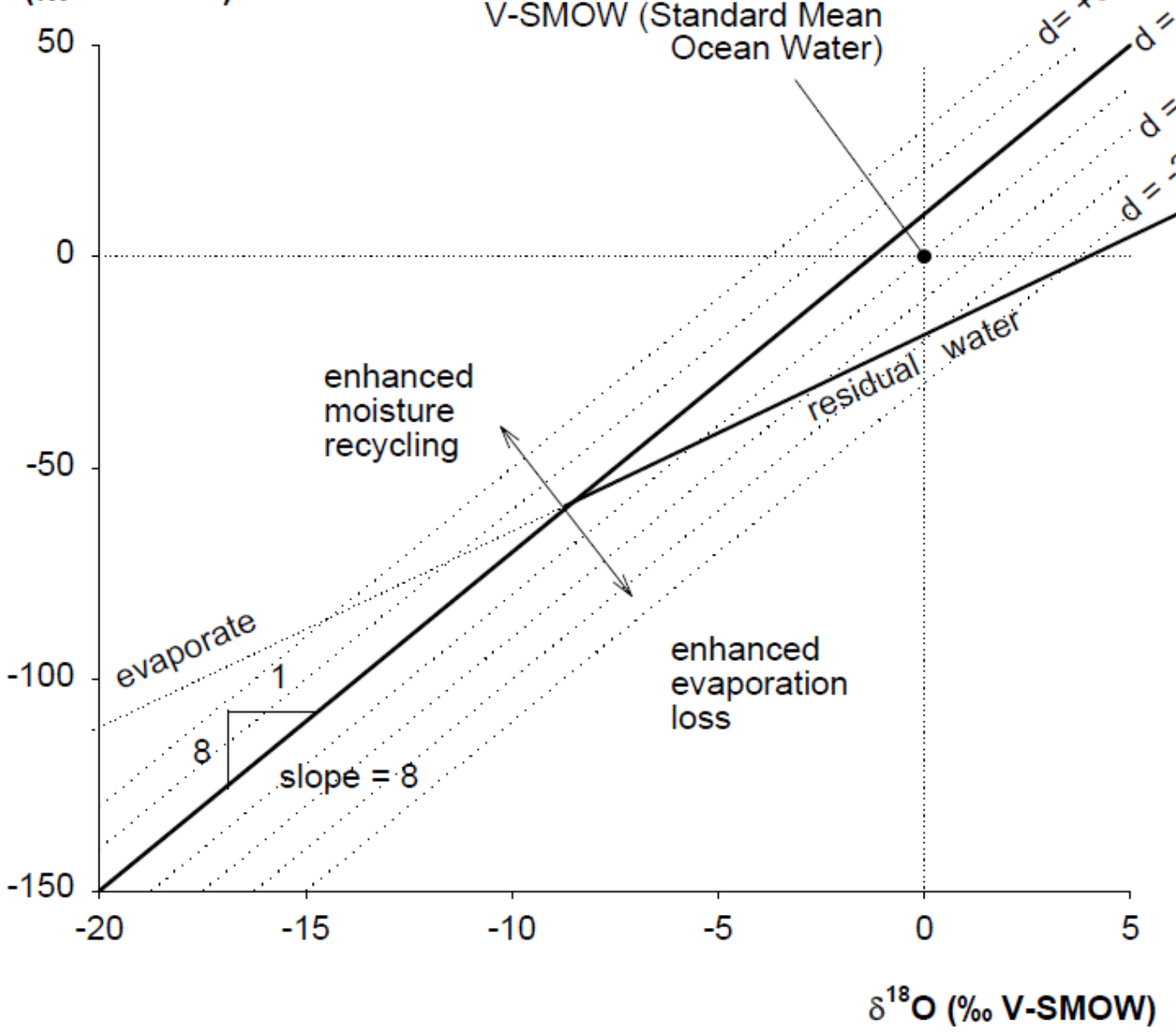

The primary process labelling the isotopic composition of oxygen-18 and deuterium in precipitation is the preferential loss of heavy isotopes during condensation and precipitation. 


\section{ChAPTER 2}

This fractionation process leaves the residual vapour in the air mass, and any subsequent precipitation that forms from it, depleted in heavy isotopes (Dansgaard, 1964). This process is termed 'Rayleigh distillation', and is described by the following equation:

$R_{v}=R_{v}^{o} f^{\alpha-1}$

(Equation 7)

where: $R_{v}=$ isotope ratio of the vapour remaining in the air mass, $R_{v}{ }^{\circ}=$ isotope ratio of the initial vapor, $f=$ the fraction of vapor remaining, and $\alpha=$ the temperature-dependent isotopic fractionation factor between condensation and vapour. The isotope ratio of the initial vapour is defined by the meteorological conditions of the vapour source and therefore the magnitude of kinetic effects as waters are evaporated from the ocean (Merlivat and Jouzel, 1979).

Once moisture has been evaporated into the atmosphere, changes in the fraction of vapour remaining within an airmass are driven by changes in temperature and pressure that generate strong spatial patterns in $\delta^{18} \mathrm{O}_{\mathrm{ppt}}$ and $\delta^{2} \mathrm{H}_{\mathrm{ppt}}$ associated with the following well-known 'effects', resulting in a depletion in heavy isotopes due to increasing: latitude ('latitude effect'), altitude ('altitude effect'), distance inland form the coast ('continentality effect'), and in tropical or subtropical areas, amount of precipitation ('amount effect') (Dansgaard 1964; Yurtsever, 1975; Araguás-Araguás et al., 2000). In northern climates, changes in season also bring along marked changes in isotopic composition of precipitation due to changes in temperature, type of precipitation (i.e., rainfall vs. snowfall), and vapour source. These effects can be visualized in the global long-term annual and intra-annual range $\delta^{18} \mathrm{O}$ precipitation isoscapes displayed on Figure 2. 


\section{Chapter 2}

Figure 2: Precipitation $\delta^{18} O$ isoscapes for: (a) long-term, precipitation-amount weighted annual average $\delta^{18} O$ of precipitation, and $(b)$ intra-annual range of precipitation $\delta^{18} O$. (From Bowen, 2010, () Annual Review of Earth and Planetary Sciences. Reproduced with permission).
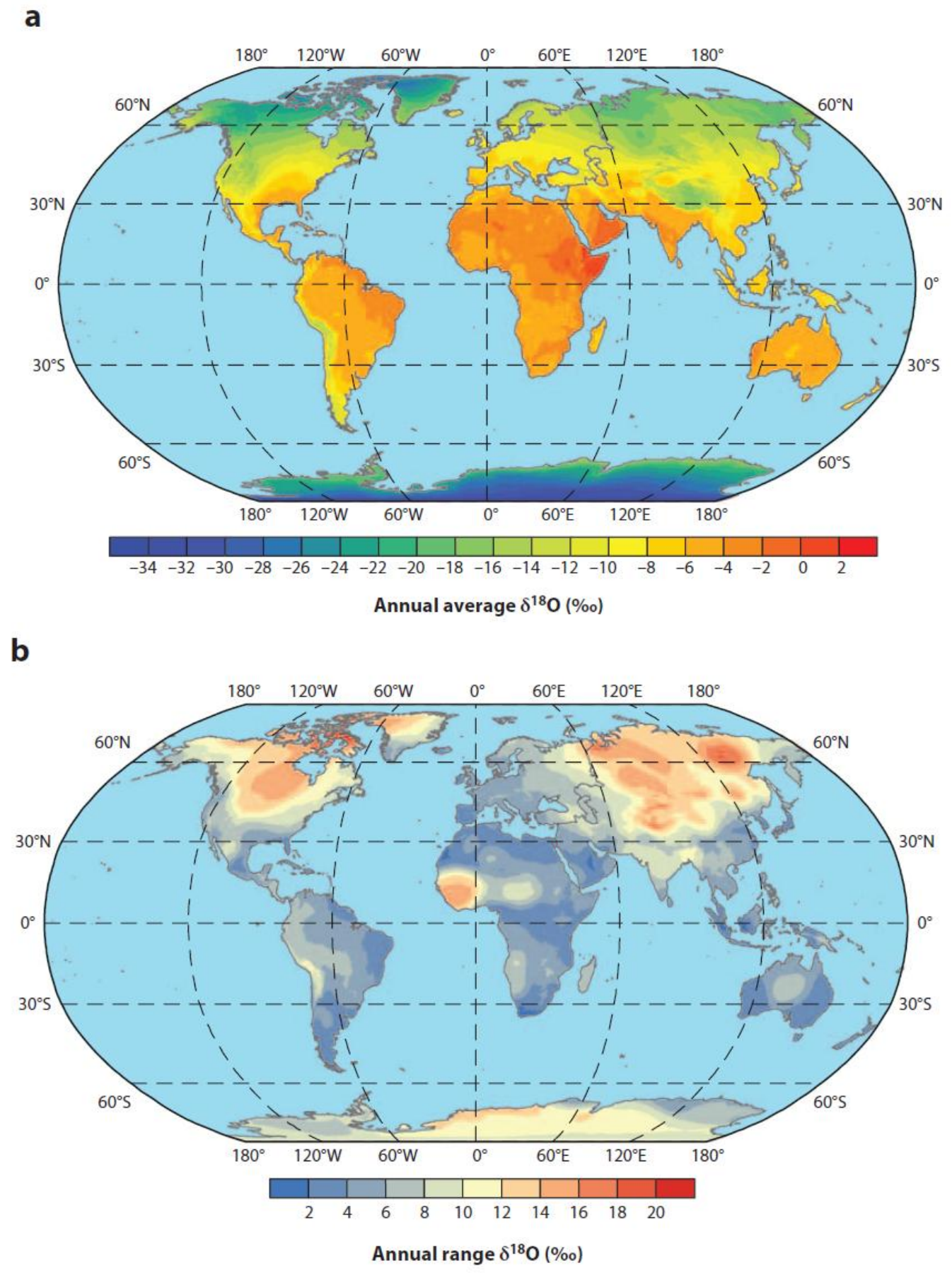

The Rayleigh distillation process dominates changes in $\delta^{18} \mathrm{O}_{\mathrm{ppt}}$ and $\delta^{2} \mathrm{H}_{\mathrm{ppt}}$ as long as secondary processes do not play a large roll. However, this only occurs under simplified conditions, when 


\section{ChAPTER 2}

in reality secondary processes are occurring, resulting in an inherently more complex evolution in $\delta^{18} \mathrm{O}_{\mathrm{ppt}}$ and $\delta^{2} \mathrm{H}_{\mathrm{ppt}}$ (Araguás-Araguás et al., 2000). Secondary processes are those that in addition to Rayleigh distillation have an additional effect on the composition of heavy isotopes within precipitation. Two commonly observed secondary effects include second-order kinetic effects, and mixing of different air masses. Second order kinetic effects include the additional kinetic fractionation that occurs due to snow formation at very low temperatures $\left(<-10^{\circ} \mathrm{C}\right)$ or the evaporation of falling raindrops through an under saturated atmosphere, resulting in a significant change in the d-excess of precipitation (Figure 1; e.g. Dansgaard, 1964; Stewart, 1975; Jouzel and Merlivat 1984; Araguás-Araguás et al., 2000; Lee and Fung 2007). The mixing of air masses from different sources and with different degrees of rainout, replenishment of moisture via evapotranspiration from the land surface or ocean, in addition to continental moisture recycling due to evaporation from large water bodies also can play a large role in defining the isotopic composition of an air mass and its resulting precipitation (e.g. Gat et al., 1994; Araguás-Araguás et al., 2000; Birks and Edwards, 2009).

\subsection{Measuring Precipitation Isotopes}

Three publically available data networks provide $\delta^{18} \mathrm{O}_{\mathrm{ppt}}$ measurements for North American isotopes in precipitation research and applications: (1) the Canadian Network for Isotopes in Precipitation (CNIP) (Birks and Gibson, 2009), (2) the United States Network for Isotopes in Precipitation (USNIP) (Welker, 2000; 2012) and (3) the Global Network for Isotopes in Precipitation (GNIP), coordinated by the International Atomic Energy Agency/World Meteorological Organization (IAEA/WMO) (Aggarwal et al., 2011; IAEA/WMO, 2014). New data from the CNIP network initiated in 1997 consisted of 17 stations distributed across Canada, 


\section{ChAPTER 2}

which added to the existing 19 GNIP stations across the country (Figure 3), resulting in 36 monitoring stations overall. This network marked the first time that stations located in the southern and northern regions had been simultaneously sampled, and included 10 new stations at a longer time-series than previously available. Due to cuts in funding, the CNIP network dissolved in late 2010. For transboundary or Canada-wide applications, the USNIP stations within the upper tier of U.S. states are important for mapping and modelling purposes to extrapolate results across the International Border.

Canadian precipitation samples were collected at a monthly frequency by the CNIP and GNIP networks, while weekly precipitation composites were collected at the USNIP sites. Averaging these weekly observations to monthly for comparison purposes shows that the CNIP/GNIP and USNIP networks have a similar number of observations per station on average (CNIP/GNIP: $\mathrm{n}$ 107; USNIP: $\mathrm{n} \sim 109)$. However, USNIP measurements are more uniformly distributed between stations in comparison to CNIP/GNIP measurements, which overall have more variability in their temporal distribution, ranging from $n=14$ monthly compositions at Inuvik (station 20), to $\mathrm{n}=331$ at Ottawa (station 23) (Figure 3). USNIP observations consistently began in 1989 and concluded in 2004; whereas CNIP and GNIP observations were collected between the years of 1961 to 2010, with minimal consistency in period of record between stations (Figure 4). 


\section{Chapter 2}

Figure 3: CNIP, GNIP (yellow symbols) and USNIP (red symbols) isotopes in precipitation $\left(\delta^{18} \mathrm{O}, \delta^{2} H\right)$ sampling locations. Note that only USNIP stations for the upper tier of U.S. states are displayed.

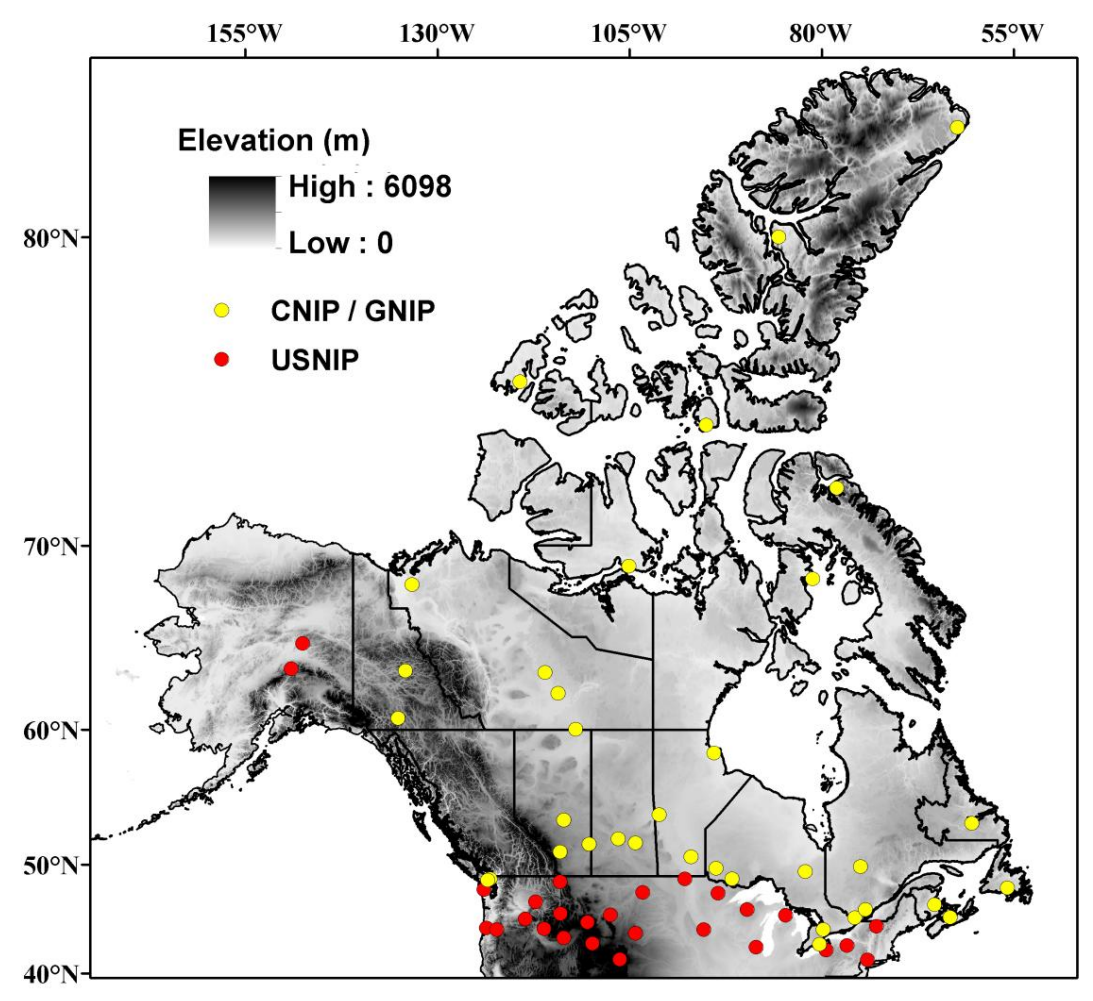

As valuable as CNIP and GNIP observations are, there are challenges with making optimal use of these data due to the sporadic temporal sampling frequencies across the country and the vast distances between stations (on average, station density across Canada is a single station every $275,000 \mathrm{~km}^{2}$ ). Additionally, no new observations have been collected in Canada as part of the CNIP or GNIP programs since 2010, and there is no guarantee that the CNIP network will be reestablished in the future. These challenges highlight the need for other methods to estimate isotopes in precipitation. 


\section{Chapter 2}

Figure 4: Temporal and spatial distribution of CNIP/GNIP and USNIP monthly observations.
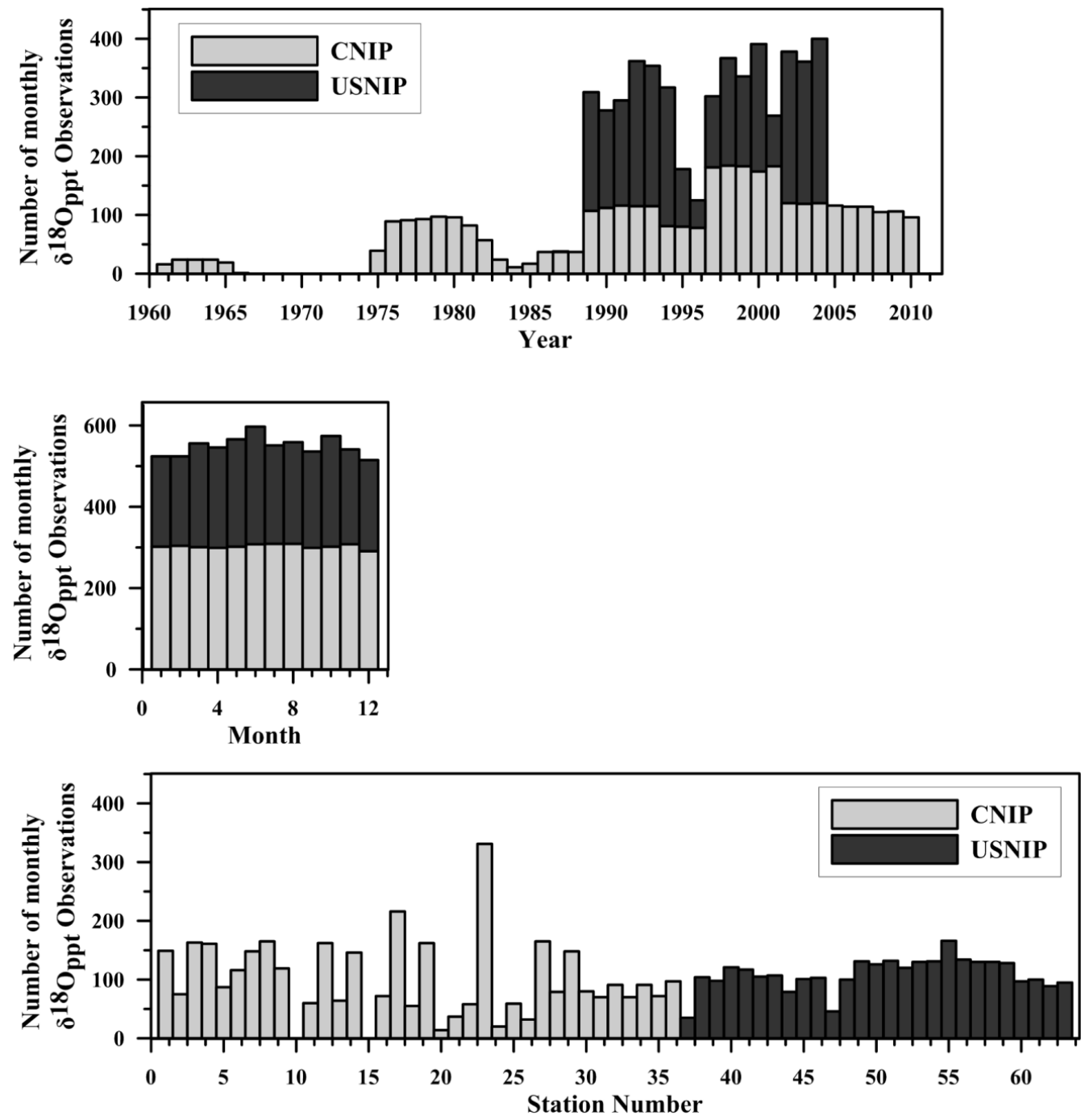

\subsection{Modelling Isotopes in Precipitation}

\subsubsection{Utility of Precipitation Isoscapes}

While precipitation amounts and patterns are relatively well quantified thanks to global and national collection networks, it is only over the last 25 years that we have begun to rigorously explore the spatial patterns of water cycle isotopes ('isoscapes'; Bowen, 2010a; 2010b), thanks to the existence of GNIP and other regional precipitation isotope monitoring programs. 


\section{Chapter 2}

Precipitation isoscapes have helped researchers to understand present-day large-scale water cycle dynamics and hydrologic fluxes (Gibson et al., 2010) in addition to serving as proxies for paleoclimate studies (e.g. Rowley and Garzione, 2007). For example, Jasechko et al. (2013) used precipitation isoscapes generated by Bowen and Revenaugh (2003) to investigate terrestrial water fluxes, concluding that transpiration is by far the most dominant process, accounting for 80 - $90 \%$ of terrestrial evapotranspiration. Precipitation isoscapes are also the backbone for stable water isotope applications in ecology, anthropology, and forensic science. For example, $\delta^{18} \mathrm{O}_{\mathrm{ppt}}$ estimates are required for studies using stable water isotopes to trace the movement or origin of organisms or products, such as the migration of animals (Hobson et al., 2010). A new and interesting application is the use of isoscapes in law enforcement investigations, as the oxygen and hydrogen composition of environmental waters (e.g. tap water) can have a significant influence on the isotopic composition of body tissues (Bowen et al., 2007; Ehleringer et al., 2010). Additionally, isoscapes also serve as inputs for hydrological modelling studies. For example, Fekete et al. (2006) applied stable water isotopes in continental scale hydrological modelling both in the United States and globally, using precipitation isoscapes derived from interpolated maps of GNIP observations (Birks et al., 2002).

The aforementioned studies are just an example of how precipitation isoscapes are useful for various applications across numerous disciplines, spanning from hydrology and climatology to ecology and beyond. Section 2.4.2 will describe the current status of research regarding the estimation of precipitation isoscapes across the world, with particular attention regarding options for Canadian applications. 


\section{ChAPTER 2}

\subsubsection{Empirical Methods}

Past efforts to predict oxygen-18 and deuterium distributions in precipitation have typically focused on creating isoscapes of long-term annual averages utilizing a coupled regression and geostatistical modelling approach. These initial studies placed high importance on geographical parameters (elevation and latitude) as proxies for other more physically-based parameters to approximate Rayleigh distillation. Bowen and Revenaugh (2003) suggest these 'informed' methods are more likely to provide improved spatial estimations of $\delta^{18} \mathrm{O}_{\mathrm{ppt}}$ patterns over a watershed then conventional geostatistical methods, such as inverse distance weighting or statistical kriging, which do not incorporate any geographical or climatological parameters within their interpolation schemes and therefore lack any physical basis. These commonly used geostatistical methods typically fail to capture finer details of the spatial distribution patterns such as orographic effects (Bowen et al., 2010; Bowen, 2010), and typically perform poorly at locations not within close proximity to monitoring sites; which unfortunately for Canada, represents a significant portion of the country (recall Figure 3). Finally, geostatistical interpolation methods are unable to provide performance statistics and therefore quantitative estimates of uncertainty (Bowen et al., 2010). These challenges, in addition to the combination of primary (i.e., Rayleigh distillation) and secondary processes influencing $\delta^{18} \mathrm{O}_{\mathrm{ppt}}$ and $\delta^{2} \mathrm{H}_{\mathrm{ppt}}$ further confounds precipitation isoscape estimation, especially at finer spatial and temporal scales.

As the pioneers of utilizing 'informed interpolation' for $\delta^{18} \mathrm{O}_{\mathrm{ppt}}$ prediction, Farquhar et al. (1993) generated a global map of $\delta^{18} \mathrm{O}_{\mathrm{ppt}}$ utilizing a regression model parameterized with mean annual temperature, annual precipitation and altitude, describing $72 \%$ of the total variance in long term 


\section{Chapter 2}

annual global $\delta^{18} \mathrm{O}_{\mathrm{ppt}}$. Almost ten years later, Bowen and Wilkinson (2002) utilized a two-step regression technique, first separating out the effects of latitude on isotopic composition and then accounting for the effects of elevation. In order to couple the regression model with the autocorrelation abilities of a geostatistical model, they utilized an inverse-distance model to create a gridded global map of the model residuals, and summed the initial $\delta^{18} \mathrm{O}_{\mathrm{ppt}}$ predictions with the interpolated residual map. This technique increased the variance captured by the model from $\sim 76 \%$ to $\sim 92 \%$. In 2003, Bowen and Revenaugh continued refining the 2002 model by applying a search method to fit the regression model and interpolation weighting parameter in a single, combined step. This firstly allowed for automation of the procedure and secondly resulted in a better balance between the regression model and the geostatistical interpolation model. Van der Veer et al. (2009) furthered this work of global long-term $\delta^{18} \mathrm{O}_{\mathrm{ppt}}$ prediction by incorporating various temperature indicators as ancillary variables within the prediction approach.

Long term annual $\delta^{18} \mathrm{O}_{\mathrm{ppt}}$ informed interpolation studies have been conducted on the regional/continental scale for the United States (Dutton et al., 2005), Austria (Liebminger et al., 2006), the Mediterranean (Lykoudis and Argiriou, 2007), and China (Liu et al., 2008), with varying levels of complexity. The empirical or hybrid empirical-geostatistical relationships developed from these regional studies provide better approximations of the spatial and temporal distributions of $\delta^{18} \mathrm{O}_{\mathrm{ppt}}$, likely due to the use of regional isotopic data, the inclusion of climate variables, and the refinement of the scale at which the $\delta^{18} \mathrm{O}_{\mathrm{ppt}}$ relationship is constructed. The poor performance of the Bowen and Wilkinson model over north central Canada (Bowen and Wilkinson, 2002) indicates that a regional model that better represents the controls on isotopic labeling of precipitation is needed for this region. 


\section{Chapter 2}

Several other studies (Bowen et al., 2005; Zhao et al., 2011; Terzer et al., 2013) have moved from mean annual prediction towards mean seasonal, mean monthly or mean growing-season prediction at both the regional and global scales. Zhao et al. (2011) used an empirical model based on temperature and latitude to spatially distribute precipitation oxygen-18 across China. They had success recreating $\delta^{18} \mathrm{O}_{\mathrm{ppt}}$ patterns during the winter months (December, January and February), however were unsuccessful for the remainder of the year due to the complexity of the factors controlling $\delta^{18} \mathrm{O}_{\mathrm{ppt}}$ during those seasons. Terzer et al. (2013) developed numerous $\delta^{18} \mathrm{O}_{\mathrm{ppt}}$ model combinations at the global scale within 36 pre-defined climatic clusters. The best predictive model(s) for each cluster domain were selected based on the combination of climatic and spatial predictors based on the root mean square error and variogram analysis. Results from this study indicated that this approach outperformed other fixed model approaches at the global scale more than $67 \%$ of the time.

Very few studies have been published regarding the prediction of time series (i.e., monthly or event-based) $\delta^{18} \mathrm{O}_{\mathrm{ppt}}$ patterns. Lykoudis et al. (2010) conducted a study for the eastern Mediterranean where they created monthly models for various climate zones to predict timeseries precipitation ${ }^{18} \mathrm{O}$ throughout the study domain. Results showed that models incorporating meteorological data were able to better capture the overall fluctuations of $\delta^{18} \mathrm{O}_{\mathrm{ppt}}$, and separation of the models from a lumped annual model to temporally distributed monthly models helped to improve results. However, given the relative success of the models, the combined uncertainties were significant and the regression models were found to be responsible for this. Fischer and Baldini (2011) developed statistical models between both monthly and daily climate variables, teleconnection indices (NAO), and time series monthly or event-based $\delta^{18} \mathrm{O}_{\mathrm{ppt}}$ for a few defined 


\section{ChAPTER 2}

locations within Ireland. However, this study was conducted with the primary goal of better understanding the links between $\delta^{18} \mathrm{O}_{\mathrm{ppt}}$ predictor relationships at various timescales, not with the objective of increased prediction accuracy and large-scale application. Most recently, Baisden et al. (2016) generated annual and monthly isoscapes of New Zealand, using three years of observations in a regression-based approach with geographic and climate predictors. Their results yielded statistically valid $\delta^{18} \mathrm{O}_{\mathrm{ppt}}$ and $\delta^{2} \mathrm{H}_{\mathrm{ppt}}$ simulations; however the utility of the approach was limited due to incomplete time series of observations and lack of variability in climate during the sampling period.

While these approaches have provided useful depictions of long-term annual and seasonal averages for many regions, most of these estimates are not suitable for predicting precipitation isoscapes at the time-scale necessary for hydrological applications, such as tracer-aided modelling, where a temporal frequency of monthly time-series (or finer) is required for model forcing (Stadnyk et al., 2013). Additionally, those studies that generated times series $\delta^{18} \mathrm{O}_{\mathrm{ppt}} \mathrm{did}$ not develop models for use throughout the Canadian domain, but rather their application is limited to the countries they were developed in. This identifies a need for regional models to develop long-term isoscapes and time-series estimates of $\delta^{18} \mathrm{O}_{\mathrm{ppt}}$ for hydrological, ecological, and forensic applications (among others) throughout the Canadian domain.

\subsubsection{Isotope-enabled Climate Models}

Isotopes in precipitation estimates can also be obtained directly from atmospheric general circulation model output. Due to the complexity of the non-linear processes governing precipitation isotope compositions (i.e., atmospheric circulation patterns, re-evaporation of 


\section{Chapter 2}

moisture, continental water recycling, among others), true process-based models may be the most physically-based method of obtaining spatially and temporally variant estimates of isotopes in precipitation. General circulation models solve the full set of equations, including the conservation of mass, momentum and energy throughout space (three dimensions) and time, as well as account for phase-change fractionation processes. In general, these model outputs have not been rigorously tested against observed data, and have not typically been utilized outside of the climate modelling community (Bowen et al., 2010). This review focuses only on the recent advances (post 2000) in both global and regional isotope-enabled climate models, as the main

focus of this research is to assess the current options available for $\delta^{18} \mathrm{O}_{\mathrm{ppt}}$ hydrological model forcing at the required time scale. Although there are many outputs from, and therefore methods available to validate isotope-enabled general circulation models, the focus of this literature review is on the validation of $\delta^{18} \mathrm{O}_{\mathrm{ppt}}$ output.

\section{Global Climate Models}

The bulk of isotope-enabled climate modelling has been conducted utilizing global climate models (GCMs), and efforts to model isotope hydrology in GCMs have improved substantially since the early 2000s. Table 2 provides the reader with the main isotope-enabled GCMs currently in use across the globe and some general information regarding the model resolution, past version(s) of the model, and main reference(s) for additional information (adapted from $\mathrm{Xi}$, 2014). Many of the models below are part of the SWING/SWING2 project (Stable Water Isotope Intercomparison Group, Phases 1 and 2), and several model output variables can be accessed via the group's website (http://data.giss.nasa.gov/swing2/). 


\section{CHAPTER 2}

Table 2: Selected isotope-enabled GCMs, their resolution, previous versions, and main reference $(s)$.

\begin{tabular}{|c|c|c|c|}
\hline Isotope-enabled GCM & $\begin{array}{c}\text { Resolutions } \\
\text { (Horizontal, } \\
\text { Vertical) }\end{array}$ & Reference(s) & $\begin{array}{c}\text { Previous } \\
\text { Versions } \\
\text { (if applicable) } \\
\end{array}$ \\
\hline $\begin{array}{l}\text { CAM2 } \\
\text { (Community Atmosphere Model) }\end{array}$ & $\begin{array}{c}\sim 2.8^{\circ} \times 2.8^{\circ} \\
26 \text { vertical levels }\end{array}$ & Lee et al. (2007) & CAM3 \\
\hline ECHAM5-wiso & $\begin{array}{c}\sim 3.8^{\circ} \times 3.8^{\circ} \\
19 \text { vertical levels } \\
(\text { adjustable })\end{array}$ & Werner et al. (2011) & $\begin{array}{l}\text { ECHAM3 } \\
\text { ECHAM4 }\end{array}$ \\
\hline $\begin{array}{l}\text { GissE } \\
\text { (Goddard Institute for Space } \\
\text { Studies) } \\
\end{array}$ & $\begin{array}{l}\sim 4^{\circ} \times 5^{\circ} \\
23 \text { vertical levels } \\
(\text { adjustable })\end{array}$ & $\begin{array}{l}\text { Schmidt et al. (2006; } \\
\text { 2007) }\end{array}$ & GISS II \\
\hline $\begin{array}{l}\text { IsoGSM } \\
\text { (Isotope-Incorporated Global } \\
\text { Spectral Model) }\end{array}$ & $\begin{array}{c}\sim 1.85^{\circ} \times 1.85^{\circ} \\
17 \text { vertical levels }\end{array}$ & Yoshimura et al. (2008) & N/A \\
\hline $\begin{array}{l}\text { HadCM3 } \\
\text { (Hadley Centre Coupled Model) }\end{array}$ & $\begin{array}{c}\sim 2.5^{\circ} \times 3.75^{\circ} \\
19 \text { vertical levels }\end{array}$ & Tindall et al. (2009) & N/A \\
\hline $\begin{array}{l}\text { MIROC3.2 } \\
\text { (Model for Interdisciplinary } \\
\text { Research on Climate) }\end{array}$ & $\begin{array}{c}\sim 1.1^{\circ} \times 1.1^{\circ} \\
40 \text { vertical levels }\end{array}$ & Kurita et al. (2011) & N/A \\
\hline $\begin{array}{l}\text { MUGCM } \\
\text { (Melbourne University GCM) }\end{array}$ & $\begin{array}{l}\sim 3.25^{\circ} \times 5.625^{\circ} \\
9 \text { vertical levels }\end{array}$ & $\begin{array}{l}\text { Noone and Simmonds } \\
(2002)\end{array}$ & N/A \\
\hline $\begin{array}{l}\text { LMDZ4 } \\
\text { (Laboratoire de Météorologie } \\
\text { Dynamique) }\end{array}$ & $\begin{array}{c}\sim 2.5^{\circ} \times 3.75^{\circ} \\
19 \text { vertical levels }\end{array}$ & $\begin{array}{l}\text { Hourdin et al. (2006) } \\
\text { Risi (2009) } \\
\text { Risi et al. }(2012)\end{array}$ & LMD \\
\hline $\begin{array}{l}\text { GENESIS GCM } \\
\text { (Global Environmental and } \\
\text { Ecological Simulation of } \\
\text { Interactive Systems) }\end{array}$ & $\begin{array}{c}\sim 3.75^{\circ} \times 3.75^{\circ} \\
18 \text { vertical levels }\end{array}$ & Methieu et al. (2002) & N/A \\
\hline $\begin{array}{l}\text { SPEEDY-IER } \\
\text { (Simplified Parameterizations, } \\
\text { Primitive Equation Dynamics - } \\
\text { Isotope-enabled Reconstructions) }\end{array}$ & $\begin{array}{l}\sim 3.75^{\circ} \times 3.75^{\circ} \\
8 \text { vertical levels }\end{array}$ & Dee et al., (2015) & N/A \\
\hline iLOVECLIM & $\begin{array}{c}\sim 5.6^{\circ} \times 5.6^{\circ} \\
3 \text { vertical levels }\end{array}$ & $\begin{array}{c}\text { Roche (2013) } \\
\text { Roche and Caley (2013) } \\
\text { Caley and Roche (2013) }\end{array}$ & N/A \\
\hline
\end{tabular}

Generally, GCMs have been validated based on a comparison of long term annual or seasonal means between GNIP observations and model simulations. Overall, many of the GCMs have the ability to capture the general global spatial patterns (latitude, altitude, continental and amount effects) and average seasonal fluctuations in precipitation $\delta^{18} \mathrm{O}$ (Noone and Sturm, 2010; Xi, 2014). However, these studies also indicate that GCM long term annual mean $\delta^{18} \mathrm{O}_{\text {ppt }}$ predictions 


\section{Chapter 2}

at northern latitudes (which includes a significant portion of the Canadian domain) display a positive bias in model simulations, with annual mean error ranging from $+1 \%$ up to as high as $+5 \%$ in portions of the Canadian Arctic (Figure 5). These more significant model errors have been tied to regions where deficiencies in model simulation of large scale transport and cloud and isotopic physics exist, as well as poor model representation of surface hydrology (Noone and Sturm, 2010).

There are no published studies available that specifically focus on validating isotope-enabled GCMs over Canada. However, in 2013, Liu et al. compared NCEP-reanalysis nudged isoGSM model simulations with GNIP and USNIP mean amount-weighted winter precipitation $\delta^{18} \mathrm{O}$ and the yearly interannual averages at locations throughout the contiguous United States. Results showed that isoGSM captured the large-scale patterns of mean amount-weighted winter precipitation $\delta^{18} \mathrm{O}$, describing $84 \%$ of the observed spatial variance, however with a positive bias of $\sim 1.7 \%$. This positive bias is most evident in relatively cold regions, such as the northern Rocky Mountains and the Great Lakes regions. A similar positive bias appeared in the interannual prediction of precipitation $\delta^{18} \mathrm{O}$, ranging from $\sim 1.0$ to $2.5 \%$, and was especially prevalent for stations showing high inter-annual variability. At this timescale, the ability of the isoGSM to capture correlation between observed and simulated annual mean precipitation $\delta^{18} \mathrm{O}$ ranged from R-values between 0.54 - 0.90, however correlations at finer timescales (monthly, daily, sub-daily) were not assessed. 


\section{ChAPTER 2}

Figure 5: Simulations of precipitation $\delta^{18}$ O from (a) the GNIP observation-based regression model (Buenning., N., and D. Noone, Role of local and nonlocal processes in the seasonal cycle and interannual variability of the isotopic composition of precipitation deduced through observations and models, submitted to Journal of Geophysical Research, 2008), and three GCMs: (b) MUGCM, (c) ECHAM and (d) GISS, as part of the first phase of the Stable Waterisotope Intercomparison Group (SWING). Colour shading in $(b-d)$ dictates where the models deviate from GNIP observations by more than 1\%o. (red represents positive deviation, blue is negative deviation) with error gradations of 1\%. (From None and Sturm, 2010, (C) Springer International Publishing. Reproduced with permission).
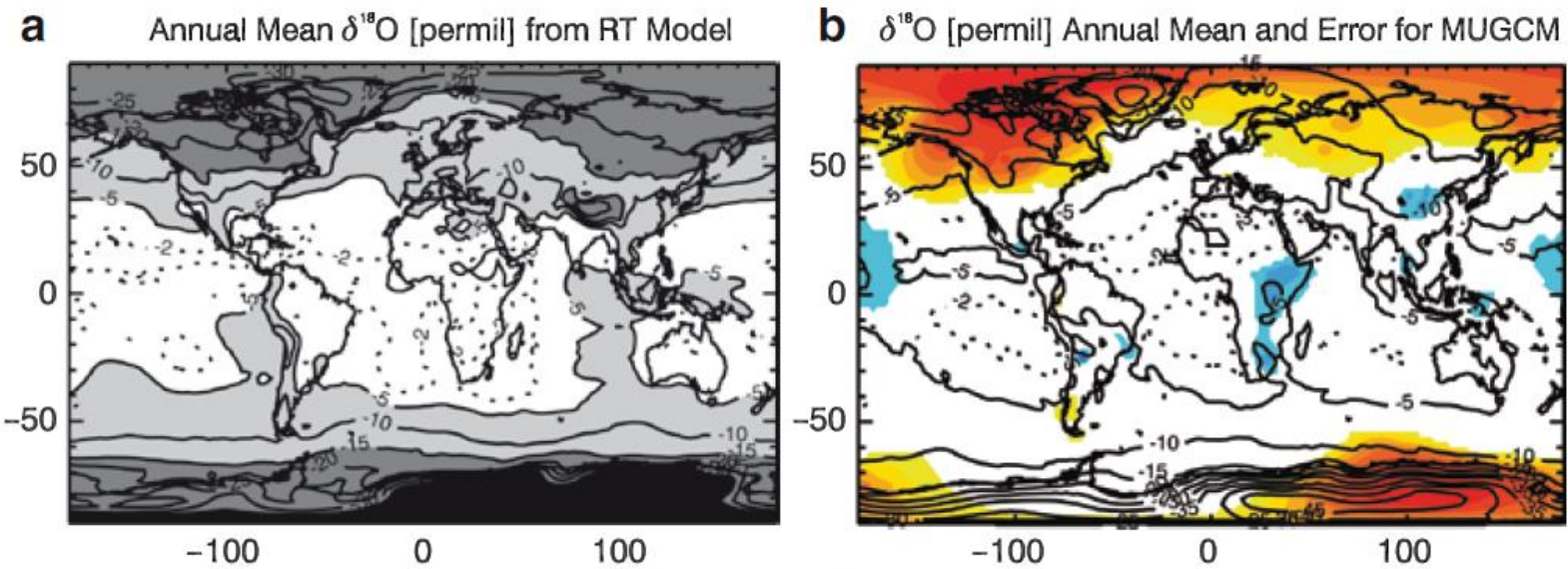

C $\delta^{18} \mathrm{O}$ [permil] Annual Mean and Error for ECHAM
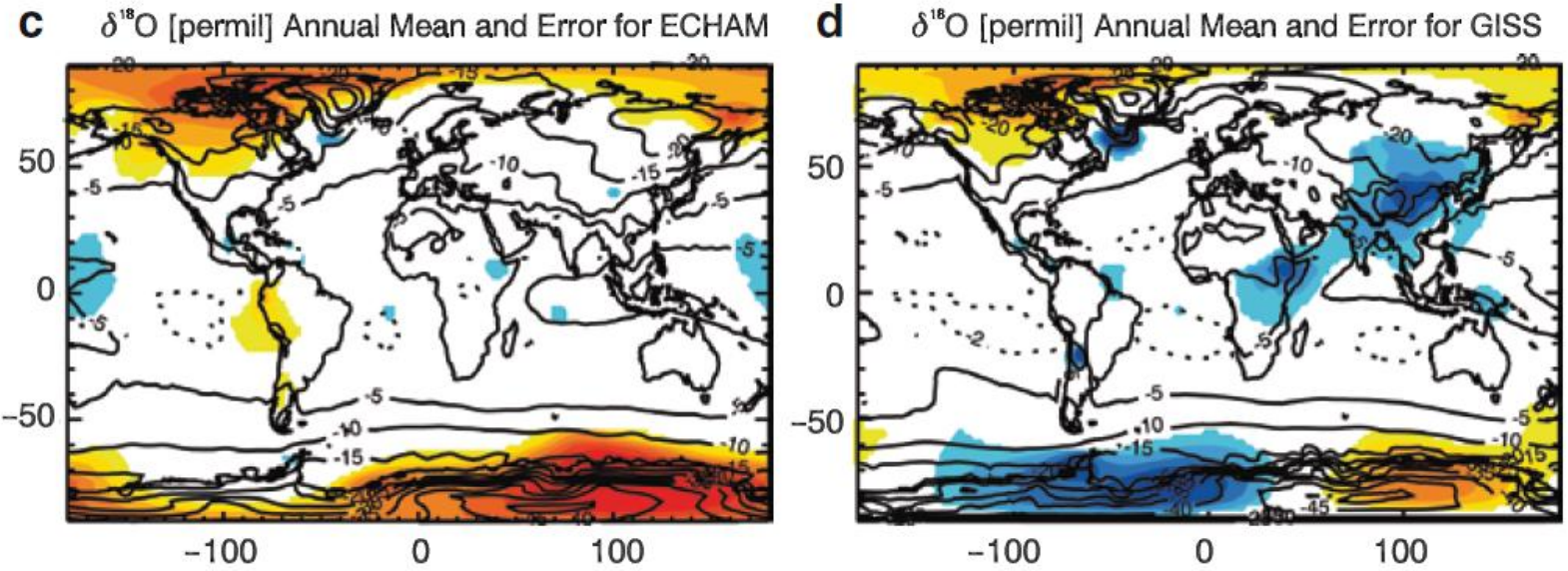

As seen in the above summary, although GCMs have the ability to recreate the general spatial patterns of climatological precipitation $\delta^{18} \mathrm{O}$ distributions, they are not often able to perform at finer spatial and temporal (e.g. monthly, daily, sub-daily) scales, likely due to their coarse resolution. 


\section{Chapter 2}

\section{Regional Climate Models}

Isotope-enabled regional climate models (RCMs) have been developed with increased resolution (by typically one order of magnitude) in an attempt to refine representation of geographic structures (topography, vegetation, coastal features) and cloud physics, among other features; thus improving upon the simulation of isotopes throughout the hydrologic cycle for smaller, defined regions of interest (Noone and Sturm, 2010). The RCM must be nested in an isotopic GCM for the provision of initial and boundary conditions (Sturm et al., 2010). Although not yet as common as isotope-enabled GCMs, there are a handful of isotope-enabled RCMs currently available (Table 3).

Table 3: Isotope-enabled RCMs, their resolution, main reference(s), and if applicable, the GCM they are nested within.

\begin{tabular}{|l|c|c|c|}
\hline Isotope-enabled RCM & $\begin{array}{c}\text { Resolutions } \\
\text { (Horizontal, Vertical) }\end{array}$ & Reference(s) & GCM \\
\hline REMOiso & $\begin{array}{c}10-50 \mathrm{~km} \\
19 \text { vertical levels }\end{array}$ & $\begin{array}{c}\text { Sturm }(2005 \mathrm{a} ; \\
2005 \mathrm{~b})\end{array}$ & ECHAM4 \\
\hline isoRSM & $\begin{array}{c}10-50 \mathrm{~km} \\
28 \text { vertical levels }\end{array}$ & $\begin{array}{c}\text { Yoshimura } \\
(2010)\end{array}$ & isoGSM \\
\hline $\begin{array}{l}\text { COSMOiso } \\
\text { *Limited area model (LAM) }\end{array}$ & $\begin{array}{c}40 \text { vertical levels } \\
\text { (adjustable) }\end{array}$ & $\begin{array}{c}\text { Phahl } \text { et al } . \\
(2012)\end{array}$ & N/A \\
\hline
\end{tabular}

COSMOiso was first applied over the eastern United States to simulate 1986 winter storms (Phahl et al., 2012). The results were promising, whereby the model was able to capture the statistical distribution of the $\delta^{18} \mathrm{O}_{\mathrm{ppt}}$ observations, alongside the large-scale spatial patterns and temporal variability. COSMOiso did have difficulty reproducing the mesoscale structures and local variability, which was attributed to conceptualization of mesoscale atmospheric structures in the model. There are very limited published studies that have investigated the utility of IsoRSM. In 2010, Yoshimura et al. downscaled the IsoRSM model to simulate a 2005 atmospheric river event in northern California. Atmospheric rivers are narrow regions in the 


\section{Chapter 2}

atmosphere that transport large amounts of water vapor. Results indicated that the control run, incorporating all full isotopic processes, was generally able to capture the synoptic-scale temporal variability in precipitation deuterium, reinforcing the model structure of IsoRSM. The authors point out, however, that many uncertainties remain, such as the simple formulation of precipitation re-evaporation (which does not consider cloud physics), which may result in poor simulations in regions where this process dominates.

REMOiso was initially validated over Europe (Sturm et al., 2005; Fischer and Sturm, 2006), but has since been applied over South America (Fischer and Sturm, 2006; Sturm et al., 2007a; 2007b; Insel et al., 2013), the northern Norwegian archipelago of Svalbard, (Divine et al., 2011), and Australia (Fisher and Sturm, 2006). Additionally, some unpublished preliminary work has been completed on ground-truthing REMOiso within Canada using CNIP and GNIP observations (Personal communication with S.J. Birks, 2016). Along the southern Canadian west to east transect (panel a, Figure 6) REMOiso shows a general overestimation of the weighted mean annual $\delta^{18} \mathrm{O}_{\mathrm{ppt}}$ compositions. This overestimation is particularly evident in the western and central regions of the country. At the long-term monthly time scale, REMOiso simulations show a fairly good representation of the seasonality in observed $\delta^{18} \mathrm{O}_{\mathrm{ppt}}$, capturing the smaller seasonal range at the coastal stations (albeit better simulated on the west than east coast) and the enhanced seasonality in the Great Plains region. 


\section{Chapter 2}

Figure 6: REMOiso simulations across a southern Canadian transect (a) compared with CNIP and GNIP $(b)$ long-term average and $(c \& d)$ monthly observations (Reproduced with permission from S. J. Birks)
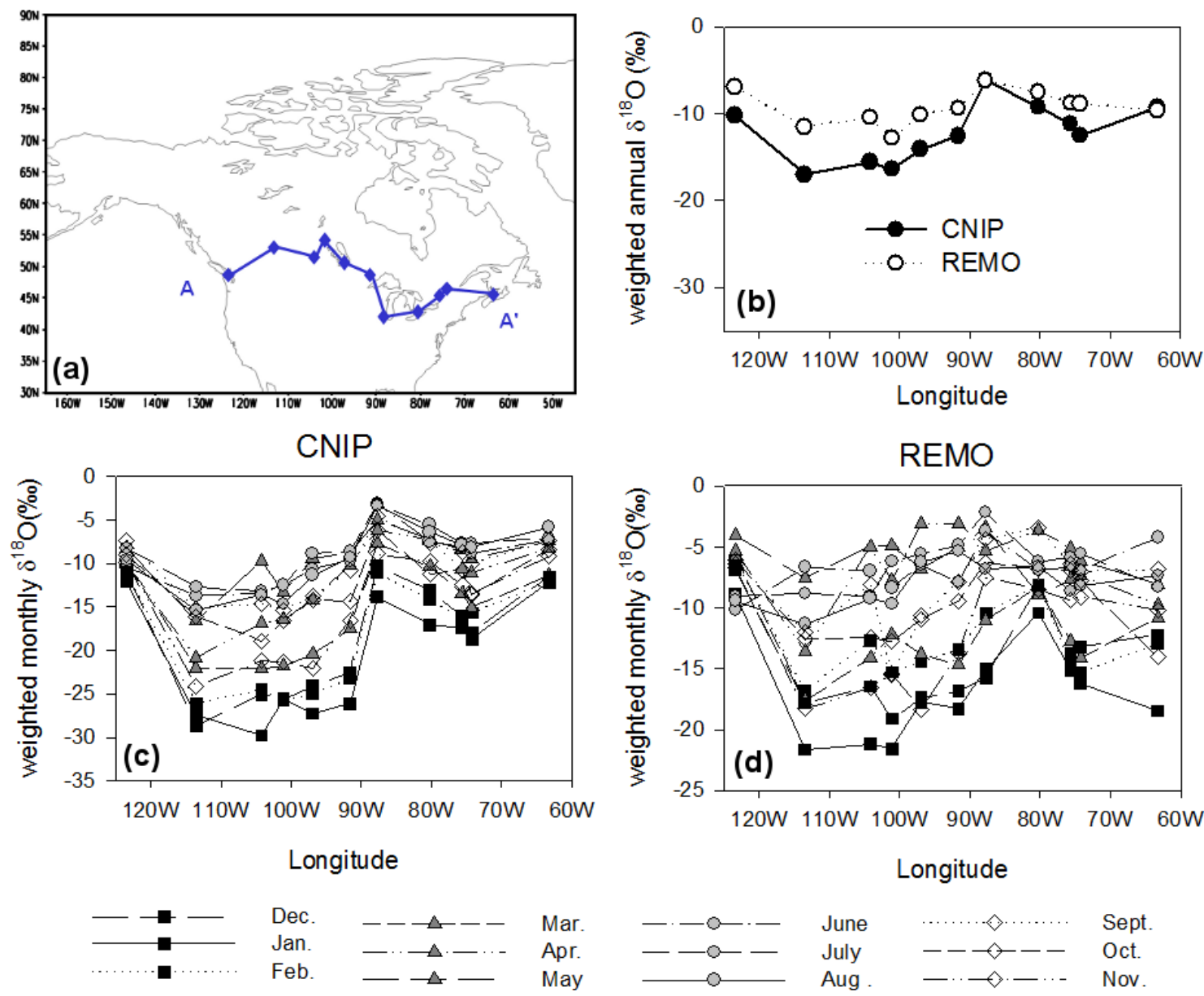

Along the northern Canadian transect (panel a, Figure 7) REMOiso again shows an overestimation of annual and monthly long term $\delta^{18} \mathrm{O}_{\mathrm{ppt}}$. This overestimation is especially apparent at stations within the Arctic Archipelago. The spatial latitude effect of decreasing $\delta^{18} \mathrm{O}_{\mathrm{ppt}}$ with increasing latitude, however, is well captured, and the seasonal range is relatively well modelled. To date, this preliminary validation of REMOiso is the only validation of an isotope-enabled RCM across the Canadian domain. 


\section{Chapter 2}

Figure 7: REMOiso simulations across a northern Canadian transect (a) compared with CNIP and GNIP $(b)$ long-term average and $(c \& d)$ monthly observations (Reproduced with permission from S. J. Birks)
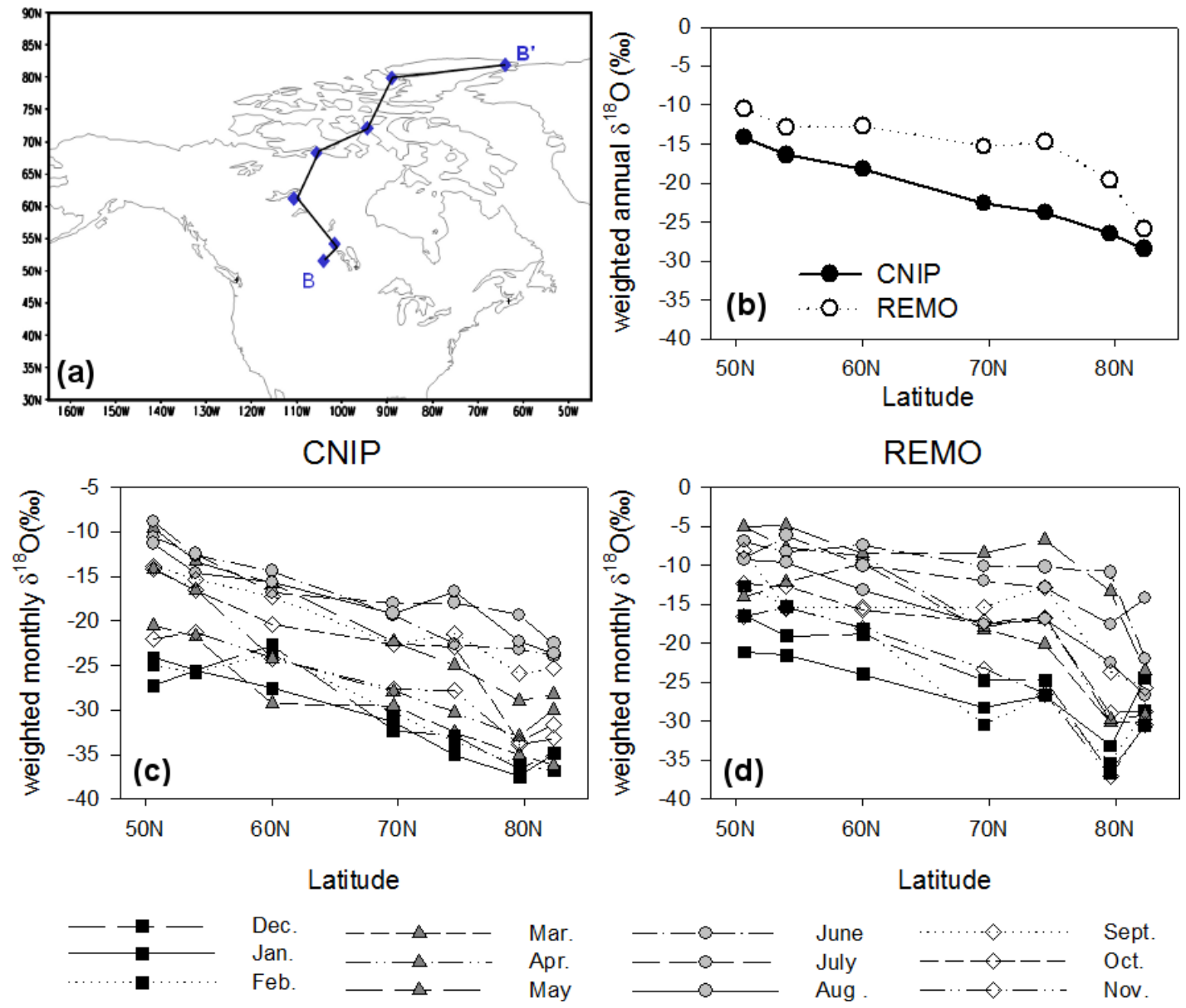

Isotope-enabled climate model output is potentially useful input for regional-scale hydrological modelling applications were measurements of precipitation $\delta^{18} \mathrm{O}$ do not exist, however there are clear model biases that first need to be addressed.

The following sections will explore the question of 'Why use tracers in hydrological models?', and identify the need for estimates of regional $\delta^{18} \mathrm{O}_{\mathrm{ppt}}$ isoscapes throughout Canada for this type of application. 


\section{ChAPTER 2}

\subsection{Uncertainty in Hydrological Models}

A hydrological model is a representation of the processes that move water throughout the hydrologic cycle. Hydrological models are critical tools for the planning, development, design, operation and sustainable management of water resources in Canada (Singh and Frevert, 2006). These models provide insight to applications such as the prediction of floods, droughts and water availability, and the effects of climate and land use changes on water resources. The term 'model structure' or 'representation of internal model processes' refers to the inclusion or exclusion of certain hydrological processes (e.g. overbank flow, sublimation), and the models/equations used to represent these processes (e.g. routing scheme, snowpack algorithm, etc.). These choices are a function of the modelling methodology and philosophy, the complexity of the model, the scale of the model, and the computing resources and data available, among other considerations.

It is common practice that hydrological models must be calibrated and validated (Oreskes et al., 1994; Refsgaard et al., 2004). The multitude of models and equations used to represent the various internal processes contributing to streamflow require parameters during model formulation (e.g. Manning's roughness, hydraulic conductivity, etc.). These parameters can be obtained through several means: (1) direct measurement (if the parameters are physically based and there are sufficient data), (2) regression analysis (also requires a historical record of data), or (3) optimization (Pechlivanidis et al., 2011).

It is this process of fitting model parameters that is referred to as calibration (Oreskes et al., 1994; Refsgaard et al., 2004). Typically watershed modellers, due to a lack of spatially and temporally distributed data for the parameterization process, are required to calibrate 


\section{CHAPTER 2}

hydrological models through optimization methods. Optimization is the process of perturbing model parameters until modelled output and measured data are in agreement, thus minimizing (or maximizing, if appropriate) an objective function (e.g. RMSE, Nash-Sutcliffe statistic, etc.). During optimization of hydrological models, typically the comparison of simulated to observed streamflow is used to calibrate the model; however other data can (and should) be utilized during this process, therefore leading to a multi-objective calibration approach. Calibration can be completed manually, by a trial and error method of selecting and perturbing parameters based on physical constraints, previous experience and engineering judgement, or conversely, the process can be automated. Automated calibration methods are becoming increasingly common due to the availability of computing resources and the increasing complexity of the methods employed to calibrate models and estimate uncertainty (Gupta et al., 1999; Singh and Frevert, 2006).

Validation is the procedure of assessing if the model is capable of reproducing observed data with reasonable accuracy without re-calibration (i.e., further perturbation of parameters). Model validation is typically completed through a split-sample calibration-validation approach, whereby a period of observations is used during model calibration, and one or more separate periods are used to validate the model. However other approaches have also been used such as proxy-basin testing or differential split-sample testing (Klemes, 1986; Refsgaard et al., 2004; Pechlivanidis et al., 2011). Validation can also take the form of confirming the individual internal hydrological processes contributing to the overall modelling goal (i.e., streamflow) by comparing simulated processes to independently measured field data (e.g. ground water levels, saturated areas, etc.) (e.g. Franks, 1998; Kuczera and Mroczkowski, 1998). This additional level of validation helps to 


\section{ChAPTER 2}

demonstrate if the current parameterization and structure of the model achieves reasonable simulations for the right combination of hydrological processes.

As useful as they may be, models are imperfect replications of a system, and are founded on the basis of uncertain data and an incomplete understanding of the processes they are attempting to replicate (Dunn et al., 2008). Numerous difficulties arise in calibrating and validating hydrological model predictions primarily due to: (1) a lack of available data at sufficient resolutions to force, calibrate and validate hydrological models - especially in remote, highlatitude locations (in Canada: Coulibaly et al., 2013); (2) over-parameterization and model structure selection resulting in issues with equifinality; and, (3) the associated uncertainty in model results (Beven and Binley, 1992; Kirchner, 2006; Fenicia et al., 2008; Dunn et al., 2008). Therefore, one of the major avenues of research in the hydrological modelling literature is in finding ways to understand, quantify, and reduce predictive uncertainty (e.g. Beven, 2006; 2008; Liu and Gupta, 2007), while also ensuring that the uncertainty in model simulations is communicated to users and decision makers (Wagener and Gupta, 2005).

Numerous researchers have discussed possible means to accomplish this, namely: (1) improvement of data acquisition techniques and making use of the extensive data networks already available, which includes incorporation of alternative data sources into the modelling methodology; (2) developing model structures that better capture the non-linearity associated with hydrological processes and work well for the right combination of processes; (3) improvement of calibration and model diagnostic approaches to comprehensively test these models; and (4) develop approaches that can methodically quantify and express uncertainty 


\section{Chapter 2}

(Kirchner, 2006; Fenicia et al., 2008). Given the complexity of distributed hydrological models typically required at the regional-scale (Michaud and Sorooshian, 1994; Carpenter and Georgakakos, 2006; Her and Chaubey, 2015), data uncertainty, over-simplification of processes, and over-parameterization are not uncommon. This results in numerous model parameterizations (i.e., different combinations of hydrological processes, or in other words, various ways to apportion water throughout modelled compartments) that give almost identical fits to the calibration data. This concept of multiple solutions to the same problem has been termed nonuniqueness (Oreskes et al., 1994) or 'equifinality' (Beven and Binley, 1992; Beven, 2006; 2008). This realization has led researchers to stop their search for an optimal model structure or parameter set; but rather shift their focus towards providing a more comprehensive estimation of the predictive uncertainty associated with model simulations.

\subsubsection{Estimating Predictive Uncertainty}

The concept of equifinality has led to the development of various methods and 'best practices' to estimate and express uncertainty during the prediction process. Although there is no universal approach to uncertainty estimation agreed upon by the hydrological modelling community (Liu and Gupta, 2007; Beven, 2008), it is now widely accepted that when conducting a modelling study, some form of uncertainty estimation should be incorporated (Wagener and Gupta, 2005; Pappenberger and Beven, 2006; Liu and Gupta, 2007). Due to the wide array of methods available, this review will focus solely on a few specific concepts of uncertainty quantification to prepare the reader for the remainder of this thesis. 


\section{ChAPTER 2}

Two major contributors to predictive uncertainty are model structure and estimation of model parameters (i.e., model parameterization). If we assume for a moment that we are using the 'perfect' model structure or internal process representation, there would still likely be a multitude of parameter sets that would result in 'acceptable' simulations given the limited number and quality of measurements used to force and calibrate the model. This acknowledgement of equifinality results in the need to estimate the predictive uncertainty associated with model parameterization and model structure selection.

The most commonly applied (Mattott et al., 2009) informal uncertainty estimation approach is the sampling based Generalized Likelihood Uncertainty Estimation methodology, GLUE (Beven and Binley, 1992). The GLUE approach includes randomly selecting many different model parameter sets, generating model simulations derived from each parameterization and assessing these simulations against a set of pre-determined evaluation measures (e.g. Nash-Sutcliffe, NS $\geq$ 0.65; volumetric error criteria, $\% \mathrm{Dv} \leq 20 \%$, etc.). Typically, a Monte Carlo (MC) simulation is conducted to independently sample the parameter space and randomly identify various sets of parameters, which are derived from each parameter's respective probability distribution. The GLUE approach then rejects those parameter sets and model structures that do not generate simulations that meet or exceed the evaluation measures, while those that meet the requirements are termed 'behavioural' and are retained in prediction. Specifically within the GLUE framework, the behavioural simulations are weighted by a likelihood measure, whereby the probability distribution of the modelled output can then be determined (Beven and Binley, 1992; Beven and Freer, 2001). Percentiles from these cumulative distribution functions (CDFs), for 


\section{ChAPTER 2}

example the $5^{\text {th }}$ and $95^{\text {th }}$ percentiles, are then used as an estimate of prediction uncertainty (or sometimes are referred to as prediction bounds).

The main disadvantage of GLUE (or other sampling based uncertainty techniques using MC methods) is computational inefficiency. Many simulations are necessary to adequately represent all of the probable results and describe the response surface (Pechlivanidis et al., 2011). The GLUE approach can be computationally feasible for regional-scale distributed hydrological models; however, access to intensive computing resources (such as a parallel computing network) is a requirement due to the large number of parameters (and potentially multiple model structures and objective functions) that need to be included in the uncertainty assessment. Another consideration when employing the GLUE approach is the subjectivity in selecting the evaluation measures (objective function(s) and corresponding threshold value(s)). However, studies show that GLUE can be a robust uncertainty quantification method in comparison to other less subjective approaches if multiple behavioural solution identification strategies are initially compared and evaluated, and the approach best suiting the modeller's needs is selected (Shafii et al., 2015).

There are many other uncertainty analysis frameworks currently used in hydrological modelling, many of which are along the same line of reasoning as GLUE (Liu and Gupta, 2007). The Bayesian Recursive Parameter Estimation (BaRE) technique is a method used to quantify parameter identifiability (Thiemann et al., 2001). BaRE also uses a MC approach and requires specification of parameter ranges and distributions; however, the approach makes explicit assumptions about the errors in the observations by using an exponential power density error 


\section{Chapter 2}

model. The technique then uses a recursive process (prediction and update) to condition parameters based on available observations, thus leading to a constrained region of high probability density in the model-parameter space. Another method to identify suitable parameters is the Dynamic Identifiability Analysis (DYNIA; Wagener et al., 2003). This process uses a MC approach to look at the relationship between parameters and multiple objective functions over time using moving windows. This allows for the identification of both regions of parameter space and periods of time where the parameter is most influential and has higher identifiability. The BAyesian Total Error Analysis (BATEA) framework (Kavetski et al., 2006) systematically accounts for both input and output errors, requiring explicit assumptions (i.e., error models) regarding the likely extent of the accuracy of the data. The authors reported, however, that the error models are poorly understood and require further research before this framework can be used to its full potential.

Other frameworks focus more specifically on quantifying the uncertainty associated with model structure, also known as a Multimodel Analysis (MMA; Matott et al., 2009). Clark et al. (2008) developed a methodology which diagnoses deficiencies in model structure titled the Framework for Understanding Structural Errors (FUSE). This approach used 79 unique model structures by combining components of existing hydrological models. Results suggested that choice of model structure is just as important as the selection of model parameters. Another example of a multimodel framework is the top-down approach of Bai et al. (2009). The top-down approach is one of parsimony, starting with the minimum level of model complexity, and adding additional state variables and parameters as required. The framework evaluates parameter uncertainty (the authors state this could be easily extended to data uncertainty as well) by assessing each model's 


\section{Chapter 2}

ability to simulate streamflow and watershed response, then combining these independent performance measures in a multi-objective fuzzy classification of model performance to achieve consistent decisions on appropriate model complexity.

The aforementioned uncertainty estimation frameworks are an example of current methods employed within the hydrological modelling community. Although quantification of uncertainty is important, the reduction of uncertainty associated with hydrological modelling is also of paramount importance. Section 2.5.2 touches upon the incorporation of alternative data sources into the modelling approach as a means to reduce model uncertainty.

\subsubsection{Incorporation of Alternative Data Sources ('Data Assimilation')}

Model evaluation based on streamflow alone can be misleading and fraught with issues of equifinality (Beven and Binley, 2002). This can result in calibrated models that have the ability to reproduce total streamflow, however fail to apportion streamflow correctly into respective hydrological compartments (e.g. interflow, baseflow, surface runoff, etc.) (Seibert and McDonnell, 2002). There is a large body of research that investigates the need for additional data to evaluate hydrological model performance, with the belief that model results should be "less right, for the right reasons" instead of "right for the wrong reasons" (e.g. Kuczera, 1983; Beven and Binley, 1992; Kuczera and Mroczkowski, 1998; Seibert and McDonnell, 2002; Kirchner, 2003; 2006; Fenicia et al., 2008; Dunn et al., 2008). Different approaches have been used to explore the inclusion of multiple data sources during model calibration. Examples of such data sources include, but are not limited to: dissolved silica (e.g. Uhlenbrook et al., 2004), chloride (e.g. Mroczkowski et al., 1997), gran alkalinity (e.g. Tetzlaff et al., 2008; Birkel et al., 2010a), 


\section{ChAPTER 2}

ground water level data (e.g. Lamb et al., 1998), distribution of saturated areas (e.g. Ambroise et al., 1995; Franks et al., 1998; Gunter et al., 1999), tracer-based hydrograph separation methods (e.g. Stadnyk et al., 2005), isotopically estimated residence times (e.g. Vache and McDonnell, 2006) and environmental tracers sampled on an event basis and continually (e.g. Wissmeier and Uhlenbrook, 2007; Iorgluescu et al., 2007; Birkel et al., 2010b ; Birkel et al., 2011a; 2011b; Birkel et al., 2014; Soulsby et al., 2015).

\section{Tracer-Aided Modelling}

With incorporation of tracers into hydrological models, another dimension of data is added to the analysis; placing an additional constraint on parameter selection and assisting with determination of model structure. The hydrological model is now required to align both streamflow and tracer simulations to observations during the calibration process, thus limiting the number of parameter sets and model structures that result in behavioural (i.e., statistically significant) simulations. For example, if using the GLUE framework, behavioural solutions would have to satisfy the evaluation functions for both streamflow and tracers simultaneously to be retained for prediction (i.e., a multi-objective calibration approach). Efstratiadis and Koutsoyiannis (2010) provide a review of multi-objective calibration approaches, and conclude that particularly for models of complex parameterization, a multi-objective calibration approach is essential for improving parameter identifiability. As conditions shift outside the realm of prior experience (e.g. unprecedented extremes in precipitation, changes in climate, changes in land use), obtaining the right answers for the right reasons during model calibration becomes increasingly important, as past conditions may likely not be representative of future conditions, particularly in northern regions (McClelland et al., 2006; Tetzlaff et al., 2013). Models accurately recreating total 


\section{Chapter 2}

streamflow but failing to correctly simulate flow path contribution to streamflow will likely fail when driven into the future, where predictions become imperative for policy decisions (Beven, 2008).

An increasing number of studies have investigated the utility of tracer-aided modelling approaches to assist with determining both model structure and parameterization, especially over the last 15 years. This brief (and by no means exhaustive) summary will touch upon select more recent 'grey box' conservative tracer-aided modeling approaches that use state variables (i.e., amount of water present in modelled storage compartments, such as soil moisture) to determine tracer concentration through a series of flux equations. However, multiple other approaches exist, such as transit time distributions (e.g. McMillan et al., 2012), data-based transfer function approaches (Iorgluescu et al., 2005), and random particle tracking (e.g. Davies et al., 2011), which are further summarized in Birkel and Soulsby (2015).

After the 1980s and 1990s when the initial development and use of tracer-aided models began, Uhlenbrook et al. (2004) used a semi-distributed hydrological model $\left(\mathrm{TAC}^{\mathrm{D}}-\mathrm{Tracer}^{\mathrm{A}}\right.$ Aided Catchment Model) to model streamflow and dissolved silica in a multi-response validation approach. This study was conducted in the highly instrumented, mountainous Brugga basin (40 $\mathrm{km}^{2}$ ) located in Germany. The distributed nature of the model allowed for improved flow prediction from past lumped modelling attempts, and replicated observed flows well. However, dissolved silica simulations showed much poorer model performance than for streamflow, which was attributed to incorrect process representation due to the temporal resolution silica was modelled at (1 day). In 2007, Wissmeier and Uhlenbrook performed a $\mathrm{TAC}^{\mathrm{D}}$ simulation of 


\section{Chapter 2}

runoff dynamics and distributed transport of oxygen-18 (neglecting kinematic effects) in the hydrologically similar Dreisam Basin $\left(258 \mathrm{~km}^{2}\right)$. Results generally showed good agreement between simulated and measured isotopes, however due to the large uncertainties associated with the input regionalization of precipitation oxygen-18 and the lack of data available for model initialization, validation of the model could not be completed. This was the first attempt to continuously model distributed oxygen-18 signals in a meso-scale catchment at an hourly time step. Also in 2007, Iorgluescu et al. enhanced previous modelling efforts (Iorgulescu et al., 2005) by incorporating simulation of $\delta^{18} \mathrm{O}$ within a tracer-aided model in a small catchment in Switzerland (24 ha). Direct precipitation, acid soil water and deep groundwater were represented through a nested set of hypotheses (i.e., model structures) of increasing complexity. The results from this study justified the increased complexity in model structure as parameter sets (albeit more difficult to identify) were much more meaningful than those derived from the more simplistic model structures.

Also at the catchment scale, Birkel et al. (2010a; 2010b) embedded gran alkalinity into the Saturated Area Model, SAM in the Scottish Girnock Burn catchment $\left(31 \mathrm{~km}^{2}\right)$, and water isotopes (deuterium) into the lumped conceptual Catchment Isotope Model, CIM (in the Scottish Wemyss catchment, $2.3 \mathrm{~km}^{2}$ ). They used multi-criteria, multi-objective approaches for model calibration, and used the additional data to inform model structure selection and parameterization. Although Birkel et al. (2010a) were able to capture the general dynamic of the deuterium response, they had difficulty reproducing daily isotopic variation, which became increasingly evident as the resolution of the input data was increased. However, inclusion of these additional data sources did help to constrain acceptable model structures and parameter 


\section{Chapter 2}

sets, therefore reducing the models' degrees of freedom as well as constraining simulation uncertainty. Birkel et al. continued this work by increasing the CIM model complexity by accounting for lake storage and isotopic fractionation from lakes (2011a) and modelling deuterium within the SAM model while incorporating parameters for passive storage in catchment hill slopes, groundwater mixing in riparian zones and isotopic fractionation (2011b). Overall, both studies showed that although there are challenges inherent to modelling SWIs, the incorporation of SWIs as tracers improved simulations of catchment behaviour and mixing processes and aided model conceptualization, therefore justifying their use as additional data in the calibration process. This model has since been the basis from which to test model conceptualizations of catchment behaviour relating to storage dynamics, connectivity, mixing processes, and stream water age (Birkel et al., 2015; Soulsby et al., 2015). Further developments to the SAM model included integration of oxygen-18, soil isotope data, soil moisture, and groundwater to test model structures, calibration objectives and parameter sensitivity and identifiability (Birkel et al., 2014), highlighting the utility of longer-term tracer datasets on hydrological model development and parameterization.

Currently, within the literature, there are only a handful of tracer-aided modelling applications that have been conducted at regional (operational) scales or continental scales. In 2006, Fekete et al. applied isotope tracers (oxygen-18 and deuterium) in continental scale hydrological modelling with the University of New Hampshire's iWBM/WTM, making use of data collected though GNIP for model forcing, and river data collected by the US Geological Society (Kendall and Coplen, 2001) for validation. The model was successful in reproducing global-scale variations in runoff amounts, suggesting that the primary control on the isotopic composition of 


\section{Chapter 2}

streamflow is the isotopic composition of precipitation, with land surface characteristics and amount of precipitation having less impact. Overall, the additional constraint of incorporating isotopes provided valuable insight during validation and informed future model structure improvements. Cappell et al. (2012) used a semi-distributed approach (i.e., coupled lumped models) to simulate tracers (deuterium and alkalinity) and streamflow, implementing a stepwise model structure development approach for the $749 \mathrm{~km}^{2}$ North Esk watershed in Scotland, specifying different model structures and parameterizations for the uplands and lowlands. The accepted model formulations generally performed quite well however did face challenges in the limitation of the lumped model structure's simplifying assumptions on transport and mixing processes in the subsurface, in addition to the lack of sensitivity of alkalinity as a tracer at the larger scale. Work completed by Stadnyk et al. (2013) in the remote Fort Simpson region of northern Canada used a tracer-aided distributed hydrological model (isoWATFLOOD) to successfully simulate streamflow and oxygen-18 at the regional-scale. Tracer data helped to inform model parameterization, and generated more realistic end member contributions to total streamflow. The isoWATFLOOD model showed great promise for improving predictions in minimally gauged regional-scale basins as it required nominal input and utilized a distributed approach to capture the heterogeneity in meteorological inputs, basin characteristics, and runoff response typical at the larger scale. To date, isoWATFLOOD remains the only fully distributed hydrological model with physically-based routing that possesses the ability to continuously simulate isotopes and streamflow. 


\section{Chapter 2}

\section{Why Use Stable Water Isotopes as Tracers?}

Oxygen-18 and deuterium are well-suited as additional data for hydrological modelling applications because they are naturally occurring and incorporated within the water molecule, they are stable (i.e., non-decaying) and they exhibit systematic and predictable variations throughout space and time as a result of fractionation during phase changes such as evaporation, condensation, and sublimation. Due to this labelling in isotopic composition that occurs during fractionation, stable water isotopes possess the ability to label water sources, pathways and processes throughout the water cycle, and capture the seasonal and annual variability in water sources. SWIs are easy to measure with relatively low analytical error, and are relatively easy to model given they are natural constituents of water. They have been used to achieve a more comprehensive understanding of a wide array of hydrological and climate processes occurring at a variety of scales, ranging from local to global. A common application of SWIs is in hydrograph separation studies, whereby isotopes are used to quantify relative contributions of hydrological flow paths (e.g. surface water, interflow, baseflow, etc.) to streamflow (for a comprehensive overview, see Klaus and McDonnell, 2013). Canadian researchers have become leaders in using water isotopes for regional-scale hydrological studies; diagnosing changes in, and the reasons for long term hydrologic variability (Gibson et al., 2005; Birks and Gibson, 2009).

\subsection{The isoWATFLOOD Model}

The WATFLOOD model is a semi-physically-based, fully distributed hydrological model that uses a grouped response unit (i.e., pixel grouping) approach to simulate streamflow in hydrologically-distinct land cover units (Kouwen et al., 1993; Kouwen, 2014). Using remotely sensed land cover data, each distinct land cover class is assigned a unique parameter set within 


\section{ChAPTER 2}

the model. The WATFLOOD model is considered to be a combination of conceptual and physical as certain processes (e.g. surface runoff and channel routing) are physically-based, while others (e.g. snowmelt and evaporation) are conceptually-based to reduce computational time and data requirements. All WATFLOOD parameters have physical interpretations, and although they cannot be measured in the field, they have physically definable upper and lower thresholds from textbook values and experience (Bingeman et al., 2006; Kouwen, 2014).

isoWATFLOOD is an extension of the WATFLOOD model that simultaneously budgets water and $\delta^{18} \mathrm{O}$ in hydrologic storage and runoff pathways (Stadnyk-Falcone, 2008; Stadnyk et al., 2013). The mass of oxygen-18 is moved from upstream to downstream through the delineated channels and between hydrologic compartments using WATFLOOD-defined fluxes (Figure 8).

Figure 8: Illustration of isoWATFLOOD hydrology (From Stadnyk et al., 2013 @ John Wiley \& Sons, Ltd.. Reproduced with permission).

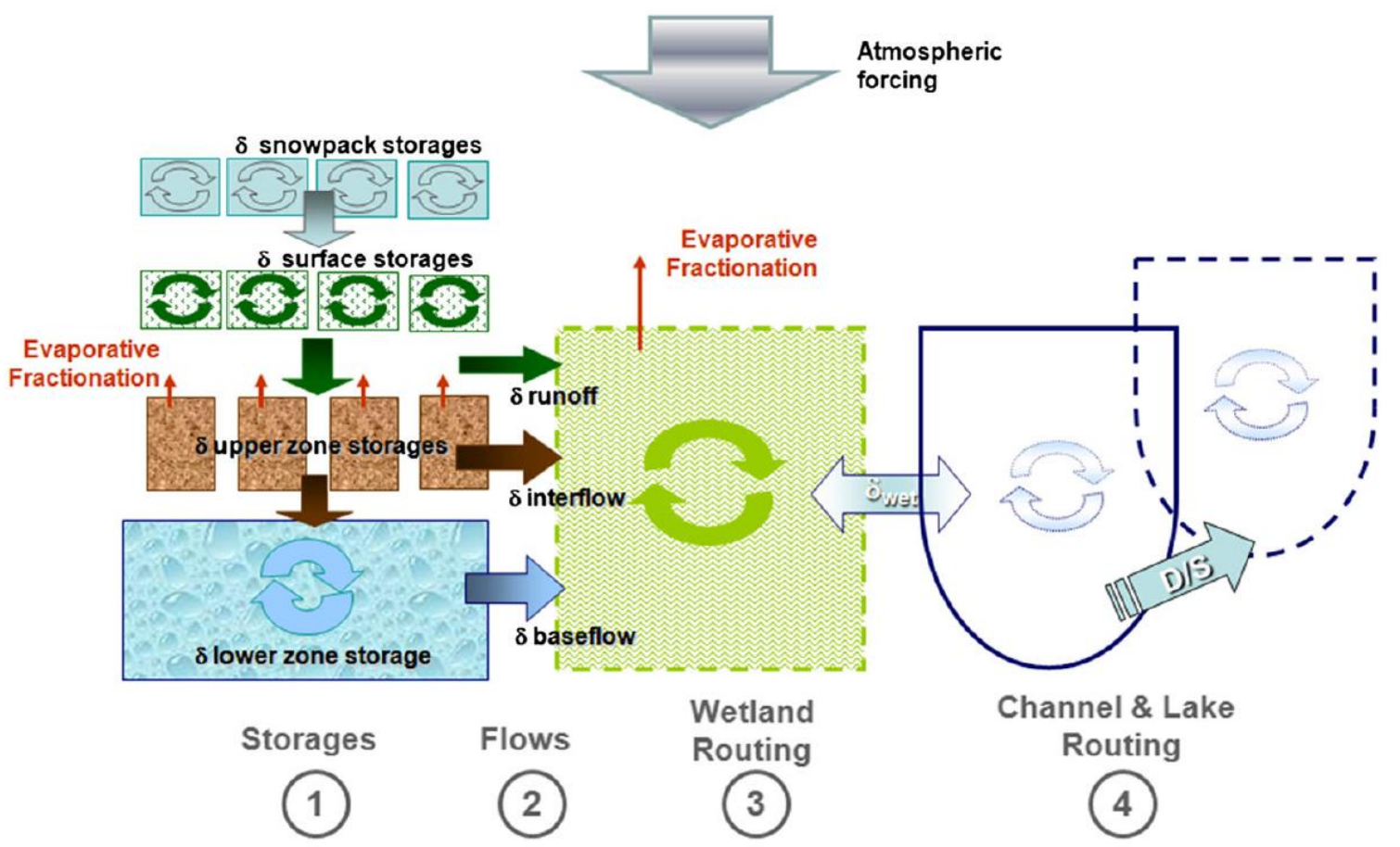




\section{CHAPTER 2}

Isotopic compositions of storages and flow paths are defined for each grid and each land classification, for every time step through a series of mass balance equations (Table 4). Complete mixing is assumed within each compartment for the defined routing time step ( $<1$ hour). Within isoWATFLOOD, the isotope mass-balances for the following storages and fluxes are modelled:

- Surface storage/ponding (and surface runoff) of rain, snow, or glacier melt when infiltration occurs at a slower rate than the intensity of rainfall;

- Upper zone storage (and interflow) and infiltration (vertically descending wetting front) and evaporative enrichment from the top of a shallow soil layer;

- Lower zone storage (and baseflow), assuming no evaporative losses from this compartment;

- Riparian (i.e., fen) wetland processes (if wetlands are present), prolonging water retention and mixing while accounting for mixing and evaporative enrichment;

- Lake storage during open water season, accepting upstream flow contributions, inputs from precipitation, and lateral inflows from adjacent storages, while accounting for mixing and evaporative enrichment, and;

- Isotopic evolution of snowpack, accounting for fractionation due to melting and refreezing of the snowpack.

Evaporative fractionation is represented using a modified Craig and Gordon (1965) linear resistance model (Gonfiantini, 1986; Gibson et al., 2008) to simulate the isotopic composition of the evaporating water $\left(\delta_{\mathrm{E}}\right)$ and the residual liquid $\left(\delta_{\mathrm{L}}\right)$. For storages that undergo significant changes in water volume (i.e., wetlands and upper zone storage), the composition of $\delta_{\mathrm{L}}$ is solved for using a fraction-dependant model, and conversely if there is no significant change in water volume (e.g. large lakes), $\delta_{\mathrm{L}}$ is solved through a time-dependent model (Gibson, 2002). It should 


\section{Chapter 2}

be noted that currently fractionation during sublimation of the snowpack is not incorporated within isoWATFLOOD. Research into defining snow fall, pack and melt offsets (from field studies), and refining isoWATFLOOD's cryospheric dynamics and processes is currently ongoing (Personal Communication with T. Stadnyk, 2016). Other recent improvements include the incorporation of deuterium into the model.

To keep in line with the methodology of the WATFLOOD framework (i.e., maintain the model's applicability to regional-scale domains with poor resolution input and calibration/validation data), isoWATFLOOD does not introduce any additional parameters and requires very little initialization data. Seasonally-averaged $\delta^{18} \mathrm{O}$ initializations for surface water, soil water, baseflow and snowpacks are required, in addition to the user specification of constant annual freeze-thaw fractionations from reported values (Jouzel \& Souchez, 1982; Cooper, 1998). Generally, the information required to produce isotopic signals is provided during model initialization (as previously outlined) or is passed from WATFLOOD forcing or simulations to the isoWATFLOOD module (e.g. distributed temperature and precipitation, simulated evaporation, inflows and outflows, etc.) (Stadnyk-Falcone, 2008; Stadnyk et al., 2013). Sensitivity analyses have shown that within one month of the start of simulations isoWATFLOOD spin-up is complete and past this point initialization values have no bearing on model output (Personal communication with T. Stadnyk, 2016; Holmes, In preparation). 


\section{ChAPTER 2}

Table 4: Summary of isoWATFLOOD isotope-mass balances and assumptions for each hydrological storage compartment (From Stadnyk et al., 2013 @ John Wiley \& Sons, Ltd.. Reproduced with permission).

\begin{tabular}{|c|c|}
\hline \multicolumn{2}{|c|}{ SNOWMELT } \\
\hline \multicolumn{2}{|c|}{$\frac{d i s o S_{S P}}{d t}=C_{I}^{180} I-\left(C_{S P}^{180}+\Delta C_{\text {melt }}^{180}\right) Q_{\text {melt }}+\left(C_{S M}^{180}+\Delta C_{r f}^{180}\right) Q_{r f}-\left(C_{m e l t}^{180}+\Delta C_{\text {melt }}^{180}\right) Q_{m e l t}-\left(C_{S P}^{180}\right) Q_{s u b}$} \\
\hline WATFLOOD Fluxes & isoWATFLOOD fluxes \\
\hline $\begin{array}{l}\mathrm{Q}_{\text {melt }}=\text { rate of melting of the pack } \\
\mathrm{Q}_{\mathrm{rf}}=\text { rate of refreezing of the pack } \\
\mathrm{Q}_{\text {sub }}=\text { rate of sublimation of the pack } \\
\text { Notes: If a pack is ripe and melt occurs }\left(\mathrm{Q}_{\text {melt }}>0\right) \text {, } \\
\text { then the pack does not undergo refreezing and } \mathrm{Q}_{\mathrm{rf}}= \\
0 .\end{array}$ & $\begin{array}{l}\mathrm{C}_{\mathrm{I}}{ }^{180}=\text { mass of }{ }^{18} \mathrm{O} \text { in inflow } \\
\mathrm{C}_{\mathrm{SP}}{ }^{180}=\text { mass of }{ }^{18} \mathrm{O} \text { in the frozen snowpack } \\
\mathrm{C}_{\mathrm{SM}}{ }^{180}=\text { mass of }{ }^{18} \mathrm{O} \text { in the liquid water content in } \\
\text { the snowpack } \\
\mathrm{C}_{\mathrm{melt}}{ }^{180}=\text { mass of }{ }^{18} \mathrm{O} \text { in meltwater leaving the pack } \\
\Delta \mathrm{C}_{\mathrm{rf}}=\text { mass of }{ }^{18} \mathrm{O} \text { adjustment due to refreezing of } \\
\text { the snowpack } \\
\Delta \mathrm{C}_{\text {melt }}=\text { mass of }{ }^{18} \mathrm{O} \text { adjustment due to melting of } \\
\text { the snowpack }\end{array}$ \\
\hline \multicolumn{2}{|c|}{ SURFACE WATER } \\
\hline $\begin{array}{l}\mathrm{P}=\text { rainfall } \\
\mathrm{q}_{\mathrm{df}}=\text { surface water infiltration } \\
\mathrm{q}_{\mathrm{dffs}}=\text { meltwater infiltration } \\
\mathrm{q}_{1}=\text { surface water surface runoff } \\
\mathrm{q}_{1 \mathrm{fs}}=\text { meltwater surface runoff } \\
\text { Notes: It is assumed that there is no evaporation } \\
\text { directly from the surface storage due to turbulent } \\
\text { mixing of inflows and relatively rapid infiltration, or } \\
\text { generation of turbulent surface runoff. }\end{array}$ & $\begin{array}{l}\mathrm{C}_{\mathrm{gmelt}}{ }^{180}=\text { mass of }{ }^{18} \mathrm{O} \text { in glacier melt } \\
\mathrm{C}_{\mathrm{P}}^{180}=\text { mass of }{ }^{18} \mathrm{O} \text { in rainfall } \\
\mathrm{C}_{\mathrm{SW}}{ }^{180}=\text { mass of }{ }^{18} \mathrm{O} \text { in surface water storage }\end{array}$ \\
\hline \multicolumn{2}{|c|}{ INTERFLOW ("upper zone") } \\
\hline $\begin{array}{l}\mathrm{q}_{\mathrm{drng}}=\text { vertical infiltration from UZS into LZS } \\
\mathrm{q}_{\mathrm{drngfs}}=\text { vertical infiltration from UZS into LZS } \\
\text { under snow } \\
\mathrm{q}_{\text {int }}=\text { lateral interflow flux } \\
\mathrm{q}_{\text {intfs }}=\text { lateral interflow flux under snow }\end{array}$ & $\begin{array}{l}\mathrm{C}_{\mathrm{UZ}}{ }^{180}=\text { mass of }{ }^{18} \mathrm{O} \text { in upper zone storage } \\
\mathrm{C}_{\mathrm{E}}{ }^{180}=\text { mass of }{ }^{18} \mathrm{O} \text { in soil moisture vapour }\end{array}$ \\
\hline \multicolumn{2}{|c|}{ BASEFLOW ("lower zone") } \\
\hline $\begin{array}{l}\mathrm{q}_{\mathrm{lz}}=\text { lateral groundwater flux } \\
\text { Notes: Instantaneous and complete mixing of the } \\
\text { inflows into the LZS is assumed, while } \\
\text { hydrodynamic dispersion is considered negligible }\end{array}$ & $\mathrm{C}_{\mathrm{UZ}}{ }^{180}=$ mass of ${ }^{18} \mathrm{O}$ in lower zone storage \\
\hline \multicolumn{2}{|c|}{ WETLANDS } \\
\hline $\mathrm{qo}_{\text {wet }}=$ lateral wetland flux & $\mathrm{C}_{\text {wet }}{ }^{180}=$ mass of ${ }^{18} \mathrm{O}$ in wetland storage \\
\hline
\end{tabular}




\section{ChAPTER 2}

The exception to this sharing of data between WATFLOOD and isoWATFLOOD is the requirement of oxygen-18 in precipitation $\left(\delta^{18} \mathrm{O}_{\mathrm{ppt}}\right)$ compositions and hourly relative humidity data to force the model. Within the current isoWATFLOOD model framework, $\delta^{18} \mathrm{O}_{\mathrm{ppt}}$ is either obtained from the isotope-enabled climate model REMOiso at a 6-hourly temporal frequency (Sturm et al., 2005a; 2005b), or is assumed to equal a constant seasonal composition across the model domain, which the user is required to specify annually in the isotope initialization file. Results from previous isoWATFLOOD applications suggest that utilizing annual, spatially static oxygen-18 in precipitation forcing has the potential to significantly impact simulations and consequently, model parameterization as well (Stadnyk-Falcone, 2008; Stadnyk et al., 2013). The assumption that model forcing is spatially invariant is not preferable, as $\delta^{18} \mathrm{O}_{\mathrm{ppt}}$ can vary drastically over small space and time scales due to changes in moisture sources and transport processes, rainout history and seasonality (e.g. in Canada: Gat et al., 1994; Moran et al., 2007; Birks and Edwards, 2009). This lack of temporal and spatial variability in $\delta^{18} \mathrm{O}_{\mathrm{ppt}}$ input not only impacts the composition of hydrologic storages during rainfall and snowmelt events, but potentially also affects evaporative fractionation as the model makes the assumption that $\delta_{\mathrm{A}}$ is in equilibrium with $\delta_{\mathrm{P}}($ Holmes, In preparation).

The small-scale catchment studies outlined in Section 2.5 .2 rely on continuous records of $\delta^{18} \mathrm{O}_{\mathrm{ppt}}$ observations at high temporal frequencies (typically daily, and less commonly, weekly) for model input. However, at the regional-scale and in poorly gauged, more remote basins, obtaining adequate $\delta^{18} \mathrm{O}_{\mathrm{ppt}}$ observations to force tracer-aided models proves to be a major challenge associated with this type of application (Birkel and Soulsby, 2015). The lack of spatial and 


\section{CHAPTER 2}

temporal density of $\delta^{18} \mathrm{O}_{\mathrm{ppt}}$ observations highlights the need for alternative methods to provide estimates of stable isotopes in precipitation for tracer-aided model forcing.

\subsection{Chapter Summary and Gaps in Existing Research}

Although various global models have been successfully developed to produce long-term annual and seasonal isoscapes, they have not shown satisfactory performance throughout Canada, signaling that regional models, which better represent the controls on isotopic labeling of precipitation, are needed for this region. Additionally, these previous global modelling efforts did not include CNIP observations collected at 17 stations between 1997 and 2010, which have provided significant information and insight to isotope-based climate and hydrology studies across Canada (Gibson et al., 2005; Birks and Gibson, 2009). Although global and regional models generating long-term isoscapes have great utility for many applications, they are not suitable for predicting precipitation isoscapes at the time-scale necessary for many hydrological applications, such as tracer-aided modelling, where a temporal frequency of monthly time-series (or finer) is required for model forcing. Neither long-term average nor time series $\delta^{18} \mathrm{O}_{\mathrm{ppt}}$ models have been developed for use in Canada; but rather their application is limited to the countries they were developed in. Additionally, although global and regional climate models have recently become equipped to simulate isotopic compositions, results have not yet proven accurate enough to provide adequate forcing for hydrological models without some level of bias correction. This identifies several needs: (1) regional empirical models to develop long-term isoscapes and timeseries estimates of $\delta^{18} \mathrm{O}_{\mathrm{ppt}}$ throughout the Canadian domain for hydrological, climatological, ecological, and forensic applications (among others), and (2) a more enhanced understanding of the usefulness of isotope-enabled climate model $\delta^{18} \mathrm{O}_{\mathrm{ppt}}$ output for Canadian applications. 


\section{ChAPTER 2}

In the science of hydrological modelling, although much progress has been made there remain gaps in the research; one of the most significant being the reduction and quantification of uncertainty associated with hydrological models and their predictions. As summarized, many researchers have begun to investigate new and unconventional techniques to reduce this uncertainty, one of the most promising being the incorporation of stable water isotopes within model structures. However, these innovative studies have predominately used lumped conceptual hydrological models set up within small-scale densely instrumented head-water catchments. As valuable as this research is towards understanding the capability of conceptual hydrological models to simulate hydrological response at the catchment scale, there is an unfulfilled need for similar multi-objective calibration/validation studies at the regional scale in remote and/or poorly gauged Canadian basins using distributed tracer-aided hydrological models. It is within these basins where new and innovative modelling techniques are required most (Tetzlaff et al., 2015), as typical measurements (such as precipitation and streamflow) are less available and cannot solely be relied upon to calibrate hydrological models. The paucity of such data are, unfortunately, indicative of most of Canada (Coulibaly et al., 2013) where a lack of access and harsh conditions limit data collection. This is problematic given the prediction of water availability becomes increasingly important in these regions due to the production of hydro-

electric power, the management of current and future water supplies, and the sensitivity of northern basins to climate change, among other factors.

For the isotope tracer modelling approach to be successful in poorly gauged Canadian basins, model input, or forcing, must first be improved (Stadnyk-Falcone, 2008; Stadnyk et al., 2013; 


\section{Chapter 2}

Birkel and Soulsby, 2015). This can either be addressed by the commencement of new data collection programs, or by improving the methods currently available to estimate the necessary input data. In the case of isotopes in precipitation observations, there were 36 collection sites within Canada providing monthly isotopic compositions with varying in-service years operated through the CNIP and GNIP monitoring programs. As helpful (and necessary) as these data are, the density of this network is not alone sufficient for hydrological model forcing, and data collection through CNIP has ceased as of late 2010. This has necessitated the need for predictive methods to generate estimates of $\delta^{18} \mathrm{O}_{\mathrm{ppt}}$ where none exist.

All the tracer-aided modelling studies outlined in this review (with the exception of Stadnyk et $a l ., 2013$ ) have relied on continuous records of $\delta^{18} \mathrm{O}_{\mathrm{ppt}}$ observations at high temporal frequencies (typically daily, and less commonly, weekly) for model input. However, at the regional (operational) scale, these data simply do not exist, as evidenced by the tracer-aided modelling conducted in Stadnyk et al. (2013) where annual average compositions of rainfall and snowfall $\delta^{18} \mathrm{O}$ were used to drive model simulations in a remote Canadian basin. Their results suggest that utilizing annual, spatially static oxygen-18 in precipitation forcing has the potential to significantly impact simulations and model parameterization. The lack of $\delta^{18} \mathrm{O}_{\mathrm{ppt}}$ observations provides an opportunity to make use of other methods of forcing, such as $\delta^{18} \mathrm{O}_{\mathrm{ppt}}$ estimates from empirically-based modelling efforts and isotope-enabled climate model output. However, the impact of estimated $\delta^{18} \mathrm{O}_{\mathrm{ppt}}$ input on tracer-aided model simulations has not yet been investigated, particularly at the regional-scale. Therefore, there is an identified need to explore the usefulness of estimated $\delta^{18} \mathrm{O}_{\mathrm{ppt}}$ inputs for regional tracer-aided modelling within remote and/or poorly gauged Canadian basins, and determine how the various inputs impact model 


\section{ChAPTER 2}

output, parameterization, and uncertainty. Because it is at these larger scales where hydrological models are applied operationally and management decisions are based, there is a critical need to understand the abilities, limitations, and uncertainties associated with distributed tracer-aided modelling at the regional scale.

\subsection{References}

Aggarwal, P. K., K. Froehlich, and R. Gonfiantini (2011), Contributions of the International Atomic Energy Agency to the development and practice of isotope hydrology. Hydrogeol. J., 19(1), 5-8, doi:10.1007/s10040-010-0648-3.

Ambroise B., J. L. Perrin, and D. Reutenauer (1995) Multicriterion validation of a semidistributed conceptual model of the water cycle in the Fecht Catchment (Vosges Massif, France). Water Resour. Res., 31(6), 1467-1481, doi: 10.1029/94WR03293.

Araguás-Araguás, L., K. Froehlich, and K. Rozanski (2000), Deuterium and oxygen-18 isotope composition of precipitation and atmospheric moisture. Hydrol. Process., 14, 1341-1355, doi: 10.1002/1099-1085(20000615)14:8<1341::AID-HYP983>3.0.CO;2-Z.

Bai, Y., T. Wagener, and R. Patrick, (2009), A top-down framework for watershed model evaluation and selection under uncertainty, Environmental Modelling \& Software, 24, 901916, doi:10.1016/j.envsoft.2008.12.012.

Baisden, W. T., E. D. Keller, R. Van Hale, R. D. Frew, and L. I. Wassenaar, (2016), Precipitation isoscapes for New Zealand: enhanced temporal detail using precipitationweighted daily climatology, Isot. Environ. Health Stud., 23, 1-10, doi: 10.1080/10256016.2016.1153472.

Barnes, C. J., and G. B. Allison, (1988), Tracing of water movement in the unsaturated zone using stable isotopes of hydrogen and oxygen, J. Hydrol., 100, 143-176, doi: doi:10.1016/0022-1694(88)90184-9.

Beven, K. (2008), On doing better hydrological science, Hydrol. Process., 22(17), 3549-3553, doi: 10.1002/hyp.7108.

Beven, K. J. (2006), A manifesto for the equifinality thesis, J. Hydrol., 320(1-2), 18-36, doi: 10.1016/j.jhydrol.2005.07.007.

Beven, K. J. and J. E. Freer (2001), Equifinality, data assimilation, and uncertainty estimation in mechanistic modelling of complex environmental systems using the GLUE methodology, J. Hydrol., 249 (1-4), 11-29, doi: 10.1016/S0022-1694(01)00421-8.

Beven, K. And A. Binley (1992), The future of distributed models: Model calibration and uncertainty prediction. Hydrol. Process., 6: 279-298. doi: 10.1002/hyp.3360060305. 


\section{ChAPTER 2}

Bingeman, A. K., N. Kouwen, and E. D. Soulis (2006), Validation of the hydrological processes in a hydrological model, J. Hydrol. Eng., 11(5), 451-463, doi: 10.1061/(ASCE)10840699(2006)11:5(451).

Birkel, C., and C. Soulsby (2015), Advancing tracer-aided rainfall-runoff modelling: a review of progress, problems and unrealised potential. Hydrol. Process., 29: 5227-5240, doi: 10.1002/hyp.10594.

Birkel, C., C. Soulsby, and D. Tetzlaff (2014), Developing a consistent process-based conceptualization of catchment functioning using measurements of internal state variables, Water Resour. Res., 50, 3481-3501, doi:10.1002/2013WR014925.

Birkel, C., D. Tetzlaff, S. M. Dunn, and C. Soulsby (2011a), Using lumped conceptual rainfallrunoff models to simulate daily isotope variability with fractionation in a nested mesoscale catchment, Adv. Water Resour., 34(3), 383-394, doi: 10.1016/j.advwatres.2010.12.006.

Birkel, C., D. Tetzlaff, S. M. Dunn, and C. Soulsby (2011b), Using time domain and geographic source tracers to conceptualize streamflow generation processes in lumped rainfall-runoff models, Water Resour. Res., 47, W02515, doi:10.1029/2010WR009547.

Birkel, C., S. M. Dunn., D. Tetzlaff, and C. Soulsby (2010a), Assessing the value of highresolution isotope tracer data in the stepwise development of a lumped conceptual rainfallrunoff model. Hydrol. Process., 24: 2335-2348, doi: 10.1002/hyp.7763.

Birkel, C., D. Tetzlaff, S. M. Dunn, and C. Soulsby (2010b), Towards a simple dynamic process conceptualization in rainfall-runoff models using multi-criteria calibration and tracers in temperate, upland catchments. Hydrol. Process., 24: 260-275, doi: 10.1002/hyp.7478.

Birks, S. J., and T. W. D. Edwards (2009), Atmospheric circulation controls on precipitation isotope-climate relations in western Canada, Tellus Ser. B, 61B(3), 566-576, doi: 10.1111/j.1600-0889.2009.00423.x.

Birks, S. J., and J. J. Gibson (2009), Isotope hydrology research in Canada, 2003-2007. Cdn. Water Resour. J., 34(2), 163-176, doi: 10.4296/cwrj3402163.

Birks, S. J., J. J. Gibson, L. Gourcy, P. K. Aggarwal, and T. W. D. Edwards (2002), Maps and animations offer new opportunities for studying the global water cycle, Eos Trans. AGU, 83(37), 406, doi: 10.1029/2002EO000298.

Bowen, G.J. (2010a), Isoscapes: Spatial pattern in isotopic biogeochemistry, Annu. Rev. Earth Planet. Sci., 38, 161-187, doi:10.1146/annurev-earth-040809-152429.

Bowen, G. J., (2010b), Statistical and geostatistical mapping of precipitation water isotope ratios, in: Isoscapes: Understanding movement, pattern, and process on Earth through isotope mapping, edited by: West, J. B., G. J. Bowen, T. E. Dawson, and K. P. Tu, Springer, London, 139-178.

Bowen, G. J., J. R. Ehleringer, L. A. Chesson, E. Stange, and T. E. Cerling, (2007), Stable isotope ratios of tap water in the contiguous United States, Water Resour. Res., 43, W03419, doi:10.1029/2006WR005186. 


\section{ChAPTER 2}

Bowen, G. J., L. I. Wassenaar, and K. A. Hobson (2005), Global application of stable hydrogen and oxygen isotopes to wildlife forensics, Oecologia, 143(3),337-348, doi:10.1007/s00442004-1813-y.

Bowen, G. J. and J. Revenaugh (2003), Interpolating the isotopic composition of modern meteoric precipitation, Water Resour. Res., 39(10), 1299-1311, doi: 10.1029/2003WR002086.

Bowen, G. J. and B. H. Wilkinson (2002), Spatial distribution of $\delta 180$ in meteoric precipitation, Geology, 30(4), 315-318, doi: 10.1130/0091-7613(2002)030<0315:SDOOIM>2.0.CO;2.

Caley, T. and D. M. Roche (2013), $\delta^{18} \mathrm{O}$ water isotope in the $i$ LOVECLIM model (version 1.0) Part 3: A palaeo-perspective based on present-day data-model comparison for oxygen stable isotopes in carbonates, Geosci. Model Dev., 6, 1505-1516, doi:10.5194/gmd-6-1505-2013.

Capell, R., D. Tetzlaff, and C. Soulsby (2012), Can time domain and source area tracers reduce uncertainty in rainfall-runoff models in larger heterogeneous catchments?, Water Resour. Res., 48, W09544, doi:10.1029/2011WR011543.

Carpenter, T. M., K. P. Georgakakos (2006), Intercomparison of lumped versus distributed hydrologic model ensemble simulations on operational forecast scales, J. Hydrol., 329(1-2), 174-185, doi: 10.1016/j.jhydrol.2006.02.013.

Clark, M. P., A. G. Slater, D. E. Rupp, R. A. Woods, J. A. Vrugt, H. V. Gupta, T. Wagener, and L. E. Hay, (2008), Framework for Understanding Structural Errors (FUSE): A modular framework to diagnose differences between hydrological models, Water Resour. Res., 44, W00B02, doi:10.1029/2007WR006735.

Cooper, L. W., (1998), Isotopic fractionation in snow cover, in: Isotope tracers in catchment hydrology, edited by: C. Kendall, and J. J. McDonnell, Elsevier, Amsterdam, 119-136.

Coulibaly, P., J. Samuel, A. Pietroniro, and D. Harvey (2013), Evaluation of Canadian National Hydrometric Network density based on WMO 2008 standards, Can. Water Resour. J., 38(2), 159-167, doi: 10.1080/07011784.2013.787181.

Craig, H. (1961), Standard for reporting concentrations of deuterium and oxygen-18 in natural waters, Science, 133, 1833-1834, doi: 10.1126/science.133.3467.1833.

Craig H. and L. I. Gordon (1965), Deuterium and oxygen 18 variations in the ocean and the marine atmosphere, in: Stable Isotopes in Oceanographic Studies and Paleotemperatures, edited by: Tongiori, E., Lab. De Geologica Nucleare: Pisa, 9-130.

Dansgaard, W. (1964). Stable isotopes in precipitation, Tellus, 16(4), 436-468, doi: 10.1111/j.2153-3490.1964.tb00181.x.

Dawson, T. E., \& Ehleringer, J. R. (1998). Plants, isotopes and water use: A catchment-scale perspective, in: Isotope tracers in catchment hydrology, edited by: C. Kendall, and J. J. McDonnell, Elsevier, Amesterdam, 165-202. 


\section{ChAPTER 2}

Davies, J., K. Beven, L. Nyberg, and A. Rodhe, (2011), A discrete particle representation of hillslope hydrology: hypothesis testing reproducing a tracer experiment at Gardsjon, Sweden, Hydrol. Process., 25, 3602-3612, doi: 10.1002/hyp.8085.

Dee, S., D. Noone, N. Buenning, J. Emile-Geay, and Y. Zhou (2015), SPEEDY-IER: A fast atmospheric GCM with water isotope physics, J. Geophys. Res. Atmos., 120, 73-91, doi:10.1002/2014JD022194.

Divine, D. V., J. Sjolte, E. Isaksson, H. A. J. Meijer, R. S. W. van de Wal, T. Martma, V. Pohjola, C. Sturm, and F. Godtliebsen (2011), Modelling the regional climate and isotopic composition of Svalbard precipitation using $\mathrm{REMO}_{\text {iso }}$ : a comparison with available GNIP and ice core data, Hydrol. Process., 25(24), 3748-3759, doi: 10.1002/hyp.8100.

Dunn, S. M., J. Freer, M. Weiler, M. J. Kirkby, J. Seibert, P. F. Quinn, G. Lischeid, D. Tetzlaff, and C. Soulsby (2008), Conceptualization in catchment modelling: simply learning?. Hydrol. Process., 22, 2389-2393, doi: 10.1002/hyp.7070.

Dutton, A. L., B. H. Wilkinson, G. Bowen, J. M. Welker, and K. C. Lohmann (2005), Comparison of river water and precipitation $\delta 180$ across the 48 contiguous United States, Hydrol. Process., 19, 3551-3572, doi: 10.1002/hyp.5876.

Efstratiadis, A. And D. Koutsoyiannis (2010), One decade of multi-objective calibration approaches in hydrological modelling: a review, Hydrol. Sci. J., 55(1), 58-78, doi: $10.1080 / 02626660903526292$.

Ehleringer, J. R., A. H. Thompson, D. W. Podlesak, G. J. Bowen, L. A. Chesson, T. E. Cerling, T. Park, P. Dostle, and H. Schwarcz, (2010), A framework for the incorporation of isotopes and isoscapes in geospatial forensic investigations, in: Isoscapes: Understanding movement, pattern, and process on Earth through isotope mapping, edited by: West, J. B., G. J. Bowen, T. E. Dawson, and K. P. Tu, Springer, London, 357-387.

Farquhar, G. D., J. Lloyd, J. A. Taylor, L. B. Flanagan, J. P. Syvertsen, K. T. Hubick, S. C. Wong, and J. R. Ehleringer (1993), Vegetation effects on the isotope composition of oxygen in atmospheric CO2, Nature, 363, 439-43, doi: doi:10.1038/363439a0.

Fekete, B. M., J. J. Gibson, P. Aggarwal, C .J Vorosmarty (2006), Application of isotope tracers in continental scale hydrological modeling, J. Hydrol., 330(3-4), 444-456, doi: doi:10.1016/j.jhydrol.2006.04.029.

Fenicia, F., J. J. McDonnell, and H. H. G. Savenije (2008), Learning from model improvement: On the contribution of complementary data to process understanding, Water Resour. Res., 44, W06419, doi: 10.1029/2007WR006386.

Fischer M. J., and L. M. Baldini (2011), A climate-isotope regression model with seasonallyvarying and time-integrated relationships, Clim. Dyn., 37(11-12), 2235-2251, doi: 10.1007/s00382-011-1009-1. 


\section{ChAPTER 2}

Fischer M. J. and K. Sturm (2006), REMOiso forcing for the iPILPS Phase 1 experiments and the performance of REMOiso in three domains, Global Planet. Change, 51(1-2), 73-89, doi: 10.1016/j.gloplacha.2005.12.006.

Franks, S. W., P. Gineste, K. J. Beven, and P. Merot (1998), On constraining the predictions of a distributed model: The incorporation of fuzzy estimates of saturated areas into the calibration process, Water Resour. Res., 34(4), 787-797, doi:10.1029/97WR03041.

Froehlich, K., J. J. Gibson, and P. Aggarwal, (2002), Deuterium excess sin precipitation and its climatological significance, Study of Environmental Change Using Isotope Techniques, C\&S Paper Series, International Atomic Energy Agency, Vienna, Austria, ISBN 9200-116402-5.

Gat, J. R., (1996), Oxygen and hydrogen isotopes in the hydrologic cycle, Annu. Rev. Earth Planet. Sci., 24, 225-262, doi: 10.1146/annurev.earth.24.1.25.

Gat, J. R., (1995), Stable isotopes of fresh and saline lakes, in: Physics and Chemistry of Lakes, edited by: Lerman, A., D. Imboden, and J. Gat, Springer-Verlag, New York, 139-166.

Gat, J. R., W. G. Mook and A. J. Meijer (2001), Environmental isotopes in the hydrological cycle- principles and applications, edited by: Mook, W. G., Volume II, Atmospheric Water. By IHP-V (International Hydrological Programme) - Technical Documents in hydrology, No. 39, Vol. II, UNESCO, Paris.

Gat J. R., C. J. Bowser, and C. Kendall (1994), The contribution of evaporation from the Great Lakes to the continental atmosphere: estimate based on stable isotope data, Geophys. Res. Lett., 21, 557-560, doi: 10.1029/94GL00069.

Gibson, J. J. (2002), Short-term evaporation and water budget comparisons in shallow arctic lakes using non-steady isotope mass balance, J. Hydrol., 264(1-4), 242-261, doi: 10.1016/S0022-1694(02)00091-4.

Gibson, J. J, B. M. Fekete, and G. J. Bowen, (2010), Stable isotopes in large scale hydrological applications, in: Isoscapes: Understanding movement, pattern, and process on Earth through isotope mapping, edited by: West, J. B., G. J. Bowen, T. E. Dawson, and K. P. Tu, Springer, London, 389-405.

Gibson, J. J., S. J. Birks, T. W. D. Edwards (2008), Global prediction of $\delta_{\mathrm{A}}$ and $\delta^{2} \mathrm{H}-\delta^{18} \mathrm{O}$ evaporation slopes for lakes and soil water accounting for seasonality, Global Biogeochem. Cycles, 22(2), GB2031, doi:10.1029/2007GB002997.

Gibson, J. J., T. W. D Edwards, S. J. Birks, N. A. St Amour, W. M. Buhay, P. McEachern, B. B. Wolfe, and D. L. Peters (2005), Progress in isotope tracer hydrology in Canada, Hydrological Processes, 19(1), 303-327, doi: 10.1002/hyp.5766.

Gonfiantini R. (1986), Environmental isotopes in lake studies, in: Handbook of environmental isotope geochemistry, the terrestrial environment, vol 2, edited by: Fritz P., and J. Fontes, Elsevier, New York, 113-168. 


\section{ChAPTER 2}

Guntner, A, S. Uhlenbrook, J. Seibert, and C. Leibundgut, (1999), Estimation of saturation excess overland flow areas- comparison of topographic index calculations with field mapping. Proc. Int. Assoc. Hydrol. Sci., 254, 203-210.

Gupta, H., S. Sorooshian, and P. Yapo, (1999). Status of Automatic Calibration for Hydrologic Models: Comparison with Multilevel Expert Calibration, J. Hydrol. Eng., 4(2), 135-143, doi: 10.1061/(ASCE)1084-0699(1999)4:2(135).

Her, Y., and I. Chaubey (2015), Impact of the numbers of observations and calibration parameters on equifinality, model performance, and output and parameter uncertainty. Hydrol. Process., 29, 4220-4237, doi: 10.1002/hyp.10487.

Hobson, K. A., R. Barnett-Johnson, and T. Cerling, (2010), Using isoscapes to track animal migration, in: Isoscapes: Understanding movement, pattern, and process on Earth through isotope mapping, edited by: West, J. B., G. J. Bowen, T. E. Dawson, and K. P. Tu, Springer, London, 273-298.

Holmes, T. L. (In preparation), Assessing the values of stable water isotopes in hydrologic modeling: A dual-isotope approach. M.Sc. Thesis, University of Manitoba, Winnipeg, 198 pp.

Horita J., and D. J. Wesolowski, (1994), Liquid-vapor fractionation of oxygen and hydrogen isotopes of water from the freezing to the critical temperature, Geochimica Et Cosmochimica Acta, 58(16), 3425-3437, doi:10.1016/0016-7037(94)90096-5.

Hourdin, F., I. Musat, S. Bony, P. Braconnot, F. Codron, J. Dufresne, L. Fairhead, M. Filiberti, P. Friedlingstein, J. Grandpeix, G. Krinner, P. LeVan, Z. Li, and F. Lott (2006), The LMDZ4 general circulation model: climate performance and sensitivity to parameterized physics with emphasis on tropical convection, Clim. Dyn., 27(7-8), 787-813, doi: 10.1007/s00382-0060158-0.

Iorgulescu, I., K. J. Beven, and A. Musy, (2007), Flow, mixing, and displacement in using a data-based hydrochemical model to predict conservative tracer data, Water Resour. Res., 43, W03401, doi:10.1029/2005WR004019.

Iorgulescu, I., K. Beven, and A. Musy, (2005), Data-based modelling of runoff and chemical tracer concentrations in the Haute-Mentue research catchment (Switzerland), Hydrol. Processes, 19, 2557 - 2573, doi:10.1002/hyp.5731.

Insel, N., C. J. Poulsen, C. Sturm, and T. A. Ehlers (2013), Climate controls on Andean precipitation $\delta 180$ interannual variability, J. Geophys. Res. Atmos., 118, 9721-9742, doi:10.1002/jgrd.50619.

IAEA/WMO (2014). Global Network of Isotopes in Precipitation. The GNIP Database. Accessible at: http://www.iaea.org/water.

Iorgulescu, I., K. Beven, and A. Musy, (2005), Data-based modelling of runoff and chemical tracer concentrations in the Haute-Mentue research catchment (Switzerland), Hydrol. Processes, 19, 2557 - 2573, doi: 10.1002/hyp.5731. 


\section{ChAPTER 2}

Jasechko, S., Z. D. Sharp, J. J. Gibson, S. J. Birks, Y. Yi, and P. J. Fawcett, (2013), Terrestrial water fluxes dominated by transpiration, Nature, 496(7445), 347-350, doi: doi:10.1038/nature11983.

Jouzel, J. and R. A. Souchez (1982), Melting-freezing at the glacier sole and isotopic composition of the ice, J. Glaciology, 28, 35-42.

Jouzel, J., and L. Merlivat (1984), Deuterium and oxygen 18 in precipitation: Modeling of the isotopic effects during snow formation, J. Geophys. Res., 89(D7), 11749-11757, doi: 10.1029/JD089iD07p11749.

Kavetski, D., G. Kuczera, and S. W. Franks, (2006), Bayesian analysis of input uncertainty in hydrological modeling: 1. Theory, Water Resour. Res., 42, doi:10.1029/2005WR004368.

Kendall, C. And T. B. Coplen, (2001), Distribution of oxygen-18 and deuterium in river waters across the United States, Hydrol. Process., 15, 1363-1393, doi: 10.1002/hyp.217.

Kirchner, J. (2006), Getting the right answers for the right reasons: Linking measurements, analyses, and models to advance the science of hydrology, Water Resour. Res., 42(3), W03S04, doi:10.1029/2005WR004362.

Kirchner, J. W. (2003), A double paradox in catchment hydrology and geochemistry. Hydrol. Process., 17(4), 871-874, doi: 10.1002/hyp.5108.

Klaus, J. and J.J. McDonnell (2013), Hydrograph separation using stable isotopes: Review and evaluation, J. Hydrol., 505, 47-64, doi: 10.1016/j.jhydrol.2013.09.006.

Klemes, V., (1986), Operational testing of hydrological simulation, Hydrol. Sci. J., 31(1), 13-24, doi: 10.1080/02626668609491024.

Kohn, M. J. and J. M. Welker (2005), On the temperature correlation of $\delta^{18} \mathrm{O}$ in modern precipitation, Earth Planet. Sci. Lett., 231(1-2), 87-96, doi: 10.1016/j.epsl.2004.12.004.

Kouwen, N. (2014), WATFLOOD/WATROUTE Hydrological Model Routing and Flood Forecasting System. User's Manual, University of Waterloo, Waterloo, ON. www.watflood.ca.

Kouwen, N., E. D. Soulis, A. Pietroniro, J. Donald, and R. A. Harrington (1993), Grouped response units for distributed hydrological modelling, J. Water Resour. Plann. Manage., 119, 289-305, doi: 10.1061/(ASCE)0733-9496(1993)119:3(289).

Kuczera, G. (1983), Improved parameter inference in catchment models: 2. Combining different kinds of hydrologic data and testing their compatibility, Water Resour. Res., 19(5), 11631172, doi:10.1029/WR019i005p01163.

Kuczera, G. and M. Mroczkowski (1998), Assessment of hydrologic parameter uncertainty and the worth of multiresponse data, Water Resour. Res., 34(6), 1481-1489, doi:10.1029/98WR00496. 


\section{ChAPTER 2}

Kurita, N., D. Noone, C. Risi, G. A. Schmidt, H. Yamada, and K. Yoneyama, (2011), Intraseasonal isotopic variation associated with the Madden-Julian Oscillation, J. Geophys. Res., 116(24), IDD24101, doi: 10.1029/2010JD015209.

Lamb, R., K. J. Beven, and S. Myrabo (1998), Use of spatially distributed water table observations to constrain uncertainty in a rainfall-runoff model, Adv. Water Resour., 22(4), 305-317, doi:10.1016/S0309-1708(98)00020-7.

Lawrence, J. R. and J. W. C. White (1991), The elusive climate signal in the isotopic composition of precipitation, Stable Isotope Geochemistry: A Tribute to Samuel Epstein, 3, $169-185$.

Lee, J-E and I. Fung (2007), “Amount effect" of water isotopes and quantitative analysis of post condensation processes, Hydrol. Process., 22(1), 1-8, doi: 10.1002/hyp.

Lee, J-E, I. Fung, D. J. DePaolo, and C. C. Henning (2007), Analysis of the global distribution of water isotopes using the NCAR atmospheric general circulation model, J. Geophys. Res., 12(16), D16306, doi: 10.1029/2006JD007657.

Liebminger, A., G. Haberhauer, K. Varmuza, W. Papesch, and G. Heiss (2006), Modeling the oxygen 18 concentration in precipitation with ambient climatic and geographic parameters, Geophys. Res. Lett., 33(5), doi:10.1029/2005GL025049.

Liu, Y., and H. V. Gupta, (2007), Uncertainty in hydrologic modeling: Toward an integrated data assimilation framework, Water Resour. Res., 43, W07401, doi:10.1029/2006WR005756.

Liu, Z., T. Lide, X. Chai, and T. Yao (2008), A model-based determination of spatial variation of precipitation $\delta 180$ over China, Chem. Geol., 249, 203-212, doi:10.1016/j.chemgeo.2007.12.011.

Liu, Z., G. Bowen, K. Yoshimura, K., and J. M. Welker (2013), Pacific North American teleconnection controls on precipitation isotopes $(\delta 180)$ across the contiguous USA and adjacent regions, J. Climate, 27, 1046-1061, doi:10.1175/JCLI-D-13-00334.1.

Lykoudis, S. P. and A. A. Argiriou (2007), Gridded data set of the stable isotopic composition of precipitation over the eastern and central Mediterranean, J. Geophys. Res., 112(D18107), doi:10.1029/2007JD008472.

Lykoudis, S. P., A. A. Argiriou, and E. Dotsika (2010), Spatially interpolated time series of $\delta 180$ in Eastern Mediterranean precipitation, Global Planet. Change, 71, 150-159 doi: 10.1016/j.gloplacha.2009.09.004.

Mathieu, R., D. Pollard, J. E. Cole, J. W. C. White, R. S. Webb, and S. L. Thompson (2002), Simulation of stable water isotope variations by the GENESIS GCM for modern conditions, J. Geophys. Res., 107(D4), doi:10.1029/2001JD900255.

Matott, L. S., J. E. Babendreier, and S. T. Purucker, (2009), Evaluating uncertainty in integrated environmental models: A review of concepts and tools, Water Resour. Res., 45, W06421, doi:10.1029/2008WR007301. 


\section{ChAPTER 2}

McClelland, J. W., S. J. Dery, B. J. Peterson, R. M. Holmes, and E. F. Wood, (2006), A panarctic evaluation of changes in river discharge during the latter half of the 20th century, Geophys. Res. Lett., 33, L06715, doi:10.1029/2006GL025753.

McMillan H., D. Tetzlaff, M. Clark, and C. Soulsby (2012), Do time-variable tracers aid the evaluation of hydrological model structure? A multimodel approach, Water Resour. Res., 48,W05501, doi: 10.1029/2011WR011688.

Merlivat, L., (1978), Molecular diffusivities of $\mathrm{H}_{2}{ }^{16} \mathrm{O}, \mathrm{HD}^{16} \mathrm{O}$, and $\mathrm{H}_{2}{ }^{18} \mathrm{O}$ in gases, J. Chem. Phys. 69(2864), doi: 10.1063/1.436884.

Merlivat, L., and J. Jouzel, (1979), Global climatic interpretation of the deuterium-oxygen 18 relationship for precipitation, J. Geophys. Res., 84(C8), 5029-5033, doi: 10.1029/JC084iC08p05029.

Michaud, J. and S. Sorooshian (1994), Comparison of simple versus complex distributed runoff models on a midsized semiarid watershed, Water Resour. Res., 30(3), 593-605, doi:10.1029/93WR03218.

Moran, T. A., S. J. Marshall, E. C. Evans, and K. E. Sinclair (2007), Altitudinal gradients of stable isotopes in lee-slope precipitation in the Canadian Rocky Mountains, Arctic Antarctic Alpine Research, 39(3), 455-467, http://www.jstor.org/stable/20181717.

Mroczkowski, M., P. G. Raper, and G. Kuczera (1997), The quest for more powerful validation of conceptual catchment models, Water Resour. Res., 33(10), 2325-2335, doi:10.1029/97WR01922.

Noone, D. and I. Simmonds (2002), Associations between $\delta 180$ of water and climate parameters in a simulation of atmospheric circulation for 1979-95, J. Clim., 15(22), 3150-3169, doi: 10.1175/1520-0442(2002)015<3150:ABOOWA>2.0.CO;2.

Noone, D., and C. Sturm, (2010), Comprehensive dynamical models of global and regional water isotope distributions, in: Isoscapes: Understanding movement, pattern, and process on Earth through isotope mapping, edited by: West, J. B., G. J. Bowen, T. E. Dawson, and K. P. Tu, Springer, London, 195-219.

Oreskes, N., K. Shrader-Frechette, and K. Belitz, (1994), Verification, validation, and confirmation of numerical models in the earth sciences, Science, 263(5147), 641-646, doi: 10.1126/science.263.5147.641.

Pappenberger, F., and K. J. Beven, (2006), Ignorance is bliss: Or seven reasons not to use uncertainty analysis, Water Resour. Res., 42, W05302, doi:10.1029/2005WR004820.

Pechlivanidis, I.G., B. M. Jackson, N. R. Mcintyre, and H. S. Wheater (2011), Catchment scale hydrological modelling: a review of model types, calibration approaches and uncertainty analysis methods in the context of recent developments in technology and applications, Global NEST J., 13(3), 193-214. 


\section{ChAPTER 2}

Pfahl, S., H. Wernli, and K. Yoshimura (2012), The isotopic composition of precipitation from a winter storm - a case study with the limited-area model COSMOiso, Atmos. Chem. Phys., 12, 1629-1648, doi:10.5194/acp-12-1629-2012.

Refsgaard, J. C., and H. J. Henriksen (2004), Modelling guidelines - terminology and guiding principles, Adv. Water Resour., 27(1), 71-82, doi: 10.1016/j.advwatres.2003.08.006.

Risi, C., D. Noone, J. Worden, C. Frankenberg, G. Stiller, M. Kiefer, B. Funke, K. Walker, P. Bernath, M. Schneider, D. Wunch, V. Sherlock, N. M. Deutscher, D. W. Griffith, P. O. Wennberg, K. Strong, D. Smale, E. Mahieu, S. Barthlott, F. Hase, O. Garcia, J. Notholt, T. Warneke, G. Toon, D. Sayres, S. Bony, J. Lee, D. Brown, R. Uemura, and C. Sturm (2012), Process-evaluation of tropospheric humidity simulated by general circulation models using water vapor isotopologues: 1. comparison between models and observations. J. Geophys. Res., 117 (D5), 1-26.

Roche, D. M. (2013), $\delta^{18} \mathrm{O}$ water isotope in the $i$ LOVECLIM model (version 1.0) - Part 1: Implementation and verification, Geosci. Model Dev., 6, 1481-1491, doi:10.5194/gmd-61481-2013.

Roche, D. M. And T. Caley (2013), $\delta^{18} \mathrm{O}$ water isotope in the $i$ LOVECLIM model (version 1.0) - Part 2: Evaluation of model results against observed $\delta^{18} \mathrm{O}$ in water samples, Geosci. Model Dev., 6, 1493-1504, doi:10.5194/gmd-6-1493-2013.

Rowley, D. B. And C. N. Garzione, (2007), Stable isotope-based paleoaltimetry, Annu. Rev. Earth Planet. Sci., 35, 463-508, doi: 10.1146/annurev.earth.35.031306.140155.

Rozanski, K., L. Araguás-Araguás, and R. Gonfiantini (1993), Isotopic patterns in modem global precipitation, in: Climate Change in Continental Isotopic Records, Geophys. Monogr. Ser., vol. 78, edited by Swart, P. K. et al., pp. 1-36, AGU, Washington, D.C.

Schmidt, G. A., A. N. LeGrande, and G. Hoffmann (2007), Water isotope expressions of intrinsic and forced variability in a coupled ocean-atmosphere model, J. Geophys. Res., 112(10), IDD10103, doi: 10.1029/2006JD007781.

Schmidt, G. A., R. Ruedy, J. E. Hansen et al. (2006), Present-day atmospheric simulations using GISSModelE: comparison to in situ, satellite, and reanalysis data, J. Clim., 19(2), 153-192, doi: 10.1175/JCLI3612.1.

Seibert, J., and J. J. McDonnell (2002), On the dialog between experimentalist and modeler in catchment hydrology: Use of soft data for multicriteria model calibration, Water Resour. Res., 38(11), 1241, doi:10.1029/2001WR000978.

Shafii, M., B. Tolson, and L. S. Matott (2015), Addressing subjective decision-making inherent in GLUE-based multi-criteria rainfall-runoff model calibration, J. Hydrol., 523, 693-705, doi: 10.1016/j.jhydrol.2015.01.051.

Simpkins, W. W. (1995), Isotopic composition of precipitation in central Iowa, Journal of Hydrology, 172, 185-207, doi: 10.1016/0022-1694(95)02694-K.

Singh, V.P., and D. K. Frevert (2006), Watershed models, CRC Taylor \& Francis, Boca Raton. 


\section{ChAPTER 2}

Soulsby, C., C. Birkel, J. Geris, J. Dick, C. Tunaley, and D. Tetzlaff (2015), Stream water age distributions controlled by storage dynamics and nonlinear hydrologic connectivity: Modeling with high-resolution isotope data, Water Resour. Res., 51, 7759-7776, doi:10.1002/2015WR017888.

Stadnyk, T. A., C. Delavau, N. Kouwen, and T. W. D. Edwards (2013), Towards hydrological model calibration and validation: simulation of stable water isotopes using the isoWATFLOOD model. Hydrol. Process., 27, 3791-3810, doi: 10.1002/hyp.9695.

Stadnyk, T., N. A. St Amour, N. Kouwen, T. W. D. Edwards, A. Pietroniro, and J. J. Gibson (2005), A groundwater separation study in boreal wetland terrain: The WATFLOOD hydrological model compared with stable isotope tracers, Isot. Environ. Health Stud., 41(1), 49-60.

Stadnyk-Falcone, T. A. (2008), Mesoscale Hydrological Model Validation and Verification using Stable Water Isotopes: The isoWATFLOOD Model. Ph.D. Thesis, University of Waterloo, Waterloo, 386 pp., http://hdl.handle.net/10012/3970.

Stewart, M.K. (1975) Stable isotope fractionation due to evaporation and isotope exchange of falling water drops: application to atmospheric processes and evaporation of lakes, J. Geophys. Res., 80, 1133-1146, doi: 10.1029/JC080i009p01133.

Sturm, C., Q. Zhang, and D. Noone (2010), An introduction to stable water isotopes in climate models: benefits of forward proxy modelling for paleoclimatology, Clim. Past, 6, 115-129, doi:10.5194/cp-6-115-2010.

Sturm, K., G. Hoffmann, and B. Langmann (2007a), Simulation of the stable water isotopes in precipitation over South America: Comparing regional to global circulation models, J. Clim., 20(15), 3730-3750, doi: 10.1175/JCLI4194.1.

Sturm, C., F. Vimeux, and G. Krinner (2007b), Intraseasonal variability in South America recorded in stable water isotopes, J. Geophys. Res., 112, D20118, doi:10.1029/2006JD008298.

Sturm, K., (2005a), Regional atmospheric modelling of the stable water isotope cycle, Doctorat, Sciences de la Terre et de l'Univers, l’Université Joseph Fourier (Grenoble 1).

Sturm, K., G. Hoffmann, B. Langmann, and W. Stichler (2005b), Simulation of d18O in precipitation by the regional circulation model REMOiso, Hydrol. Process., 19(17), 34253444, doi: 10.1002/hyp.5979.

Terzer, S., L. I. Wassenaar, L. J. Araguás-Araguás, and P. K. Aggarwal (2013), Global isoscapes for $\delta 18 \mathrm{O}$ and $\delta 2 \mathrm{H}$ in precipitation: improved prediction using regionalized climatic regression models, Hydrol. Earth Syst. Sci., 17, 4713-4728, doi:10.5194/hess-17-4713-2013.

Tetzlaff, D., J. Buttle, S. K. Carey, K. McGuire, H. Laudon, and C. Soulsby (2015), Tracer-based assessment of flow paths, storage and runoff generation in northern catchments: a review. Hydrol. Process., 29, 3475-3490, doi: 10.1002/hyp.10412. 


\section{ChAPTER 2}

Tetzlaff, D., C. Soulsby, J. Buttle, R. Capell, S. K. Carey, L. Kruitbos, H. Laudon, J. McDonnell, K. McGuire, S. Seibert, J. Shanley, (2013), Catchments on the cusp? Structural and functional change in northern ecohydrological systems, Hydrol. Process., 27, 766-774, doi: 10.1002/hyp.9700.

Tetzlaff, D., S. Uhlenbrook, S. Eppert, and C. Soulsby (2008), Does the incorporation of process conceptualization and tracer data improve the structure and performance of a simple rainfallrunoff model in a Scottish mesoscale catchment?. Hydrol. Process., 22, 2461-2474, doi: 10.1002/hyp.6841.

Tindall, J.C., P. J. Valdes, and L. C. Sime (2009), Stable water isotopes in HadCM3: isotopic signature of El Niño-Southern oscillation and the tropical amount effect, J. Geophys. Res., 114(4), D04111, doi: 10.1029/2008JD010825.

Thiemann, M., M. Trosset, H. Gupta, and S. Sorooshian, (2001), Bayesian recursive parameter estimation for hydrologic models, Water Resour. Res., 37(10), 2521-2535, doi:10.1029/2000WR900405.

Uhlenbrook S, S. Roser, and N. Tilch (2004), Hydrological process representation at the mesoscale: the potential of a distributed, conceptual catchment model, J. Hydrol., 291(3-4), 278296, doi:10.1016/j.jhydrol.2003.12.038.

Vaché, K. B., and J. J. McDonnell (2006), A process-based rejectionist framework for evaluating catchment runoff model structure, Water Resour. Res., 42, W02409, doi:10.1029/2005WR004247.

Vachon, R. W., J. M. Welker, J. W. C. White, and B.H. Vaughn (2010), Monthly precipitation isoscapes ( $\mathrm{d} 18 \mathrm{O})$ of the United States: Connections with surface temperatures, moisture source conditions, and air mass trajectories, J. Geophys. Res., 115, D21126, doi:10.1029/2010JD014105.

Van der Veer, G., S. Voerkelius, G. Lorentz, G. Heiss, and J. A. Hoogewerff (2009), Spatial interpolation of the deuterium and oxygen-18 composition of global precipitation using temperature as ancillary variable, J. Geochem. Explor., 101, 175-184, doi: 10.1016/j.gexplo.2008.06.008.

Wagener, T., and H. V. Gupta, (2005), Model identification for hydrological forecasting under uncertainty, Stochastic Environ. Res. Risk. Assess., 19, doi:10.1007/s00477-005-0006-5.

Wagener, T., N. McIntyre, M. J. Lees, H. S. Wheater, and H. V. Gupta, (2003), Towards reduced uncertainty in conceptual rainfall-runoff modelling: dynamic identifiability analysis, Hydrol. Process., 17, 455-476, doi: 10.1002/hyp.1135

Welker, J. M. (2000), Isotopic ( $\delta 180)$ characteristics of weekly precipitation collected across the United States: An initial analysis with application to water source studies, Hydrol. Process., 14, 1449-1464, doi: 10.1002/1099-1085(20000615)14:8<1449::AID-HYP993>3.0.CO;2-7. 


\section{ChAPTER 2}

Welker, J. M. (2012), ENSO effects on the isotopic ( $\delta 18 \mathrm{O}, \delta 2 \mathrm{H}$ and d-excess) of precipitation across the US using a long-term network (USNIP), Rapid Comm. in Mass Spec., 17, 16551660, doi:10.1002/rcm.6298.

Werner, M., P. M. Langebroek, T. Carlsen, M. Herold, and G. Lohmann (2011), Stable water isotopes in the ECHAM5 general circulation model: Toward high-resolution isotope modeling on a global scale, J. Geophys. Res., 116, D15109, doi:10.1029/2011JD015681.

Wissmeier, L. and S. Uhlenbrook (2007), Distributed, high-resolution modelling of 180 signals in a meso-scale catchment, J. Hydrol., 332(3-4), 497-510, doi: 10.1016/j.jhydrol.2006.08.003.

Xi, X. (2014), A Review of Water Isotopes in Atmospheric General Circulation Models: Recent Advances and Future Prospects, International Journal of Atmospheric Sciences, 250920, doi:10.1155/2014/250920.

Yoshimura, K., M. Kanamitsu, D. Noone, and T. Oki (2008), Historical isotope simulation using Reanalysis atmospheric data, J. Geophys. Res., 113, D19108, doi:10.1029/2008JD010074.

Yoshimura, K., M. Kanamitsu, and M. Dettinger (2010), Regional downscaling for stable water isotopes: A case study of an atmospheric river event, J. Geophys. Res., 115, D18114, doi:10.1029/2010JD014032.

Yurtsever, Y., (1975), Worldwide survey of stable isotopes in precipitation. Rep. Isotope Hydrology Section. Vienna, IAEA, 40 pp.

Zhao, L., H. Xiao, M. Zhou, G. Cheng, L. Wang, L. Yin, and J. Ren (2011), Factors controlling spatial and seasonal distributions of precipitation d180 in China, Hydrol. Processes, 26, 143152, doi:10.1002/hyp.8118. 


\title{
CHAPTER 3: MODEL BASED SPATIAL DISTRIBUTION OF OXYGEN-18 ISOTOPES IN PRECIPITATION ACROSS CANADA
}

\author{
Carly Delavau $^{1^{*}}$, Tricia Stadnyk ${ }^{2 *}$ and Jean Birks ${ }^{3}$ \\ 1 Department of Civil Engineering, University of Manitoba, Winnipeg, Manitoba \\ 2 Department of Civil Engineering, University of Manitoba, Winnipeg, Manitoba \\ 3 Alberta Innovates Technology Futures, Calgary, Alberta \\ * Member of CWRA
}

Published in 2011 in the Canadian Water Resources Journal (doi: 10.4296/cwrj3604875). Submitted September 2010; accepted October 2011.

This chapter investigates the predictability of long term seasonal averages of oxygen-18 precipitation isotopes across Canada. Long-term average climate data and geographic information are used as predictor variables to generate seasonal maps of $\delta^{18} \mathrm{O}_{\mathrm{ppt}}$. These maps are useful inputs for climatological, ecological, hydrological and hydrogeological studies requiring information on the long-term seasonal and annual labeling of precipitation. 


\section{ChAPTER 3}

\subsection{Abstract}

Stable water isotopic compositions of precipitation $\left(\delta^{18} \mathrm{O}_{\mathrm{ppt}}\right)$ are available from stations sampling at a monthly frequency, however the data are spatially and temporally discontinuous, particularly in northern areas of Canada. This identifies a need for models that can reproduce spatial patterns of $\delta^{18} \mathrm{O}_{\mathrm{ppt}}$ where observations do not exist. Here we use new data from the Canadian Network for Isotopes in Precipitation (CNIP) and existing data from the Global Network for Isotopes in Precipitation (GNIP) to create and evaluate a variety of empirical relationships to develop improved interpolations of the spatial distribution of $\delta^{18} \mathrm{O}_{\mathrm{ppt}}$ across Canada (precipitation 'isoscapes'). Comparison of model results has identified models capable of simulating long-term seasonal $\delta^{18} \mathrm{O}_{\mathrm{ppt}}$ distributions, but also identified time periods and areas where the geographical and climatological parameters included in this analysis were not able to simulate the measured distributions. Spring, summer and fall model results were satisfactory; however, winter model results were more variable, indicating increased complexity in the driving forces of $\delta^{18} \mathrm{O}_{\mathrm{ppt}}$ patterns during this season. Overall, model results improve with the addition of time-variant climate parameters, this finding being especially significant during the winter. The primary goal of this research is to develop $\delta^{18} \mathrm{O}_{\mathrm{ppt}}$ prediction models as a first step towards utilizing precipitation isoscapes in tracer-aided hydrological modelling studies. Improving the precipitation input fields within isotope-equipped hydrological models will provide a valuable tool for water use management within large, remote, and often ungauged Canadian rivers and will facilitate studies of both climate variability and surface hydrology in remote regions. 


\section{Chapter 3}

\subsection{Introduction}

The stable water isotopes of precipitation $\left(\delta^{18} \mathrm{O}_{\mathrm{ppt}}\right.$ and $\left.\delta^{2} \mathrm{H}_{\mathrm{ppt}}\right)$ are natural tracers which provide insight into understanding water cycle processes at a variety of spatial and temporal scales. For regional and continental based studies, station observations of isotopes in precipitation first require distribution across the study domain. Within Canada, these observations can be provided from CNIP or GNIP (Canadian or Global Network for Isotopes in Precipitation; International Atomic Energy Agency/World Meteorological Association, 2006; Birks and Gibson, 2009) $\delta^{18} \mathrm{O}_{\mathrm{ppt}}$ and $\delta^{2} \mathrm{H}_{\mathrm{ppt}}$ records. Estimates of distributed $\delta^{18} \mathrm{O}_{\mathrm{ppt}}$ data where measurements are not available is a requirement for applications such as tracer based hydrological modelling, climatological, ecological and forensic studies (e.g. Gibson et al., 2005; Fekete et al., 2006; Bowen et al., 2007; Stadnyk-Falcone, 2008; Birks and Gibson, 2009).

The abundance of oxygen-18 in precipitation is temporally and spatially variable, especially in seasonal climates similar to those over most of Canada. Changes in the oxygen-isotope signature of an air mass can be complex, and are the result of many different variables. $\delta^{18} \mathrm{O}_{\mathrm{ppt}}$ is controlled by Rayleigh distillation of atmospheric vapour, which is predominantly determined by changes in air-mass temperature due to the strong temperature-dependence of the moisture carrying capacity of air (Dansgaard, 1964; Yurtserver and Gat, 1981; Rozanski et al., 1993). In mid- to high-latitudes, this relationship is described by the depletion of heavy isotopes from water vapour as the air mass moves towards higher altitudes (altitude effect), inland from the coast (continental effect), or the transport of vapour from lower to higher latitude locations (latitude effect). Numerous geographic and climatic parameters are correlated with changes in temperature and hence rain-out, which can include latitude, elevation, distance inland from the 


\section{Chapter 3}

coast and humidity. Changes in moisture sources (e.g. in Canada: Pacific, Arctic, Gulf of Mexico and/or North Atlantic, and potentially large lake systems) and transport processes, rainout history and seasonality (Lawrence and White, 1991; Gat et al., 1994; Simpkins, 1995; Kohn and Welker, 2005; Moran et al., 2007; Birks and Edwards, 2009) will also influence the stable-isotope composition of precipitation, further complicating its prediction. Therefore, interpolation methods with the ability to accurately predict changes in $\delta^{18} \mathrm{O}_{\mathrm{ppt}}$ via correlation with easily obtainable proxy variables are a valuable tool for extending the station based measurements of $\delta^{18} \mathrm{O}_{\mathrm{ppt}}$ across the country.

Bowen and Revenaugh (2003) suggest that these "informed" interpolation methods are more likely to provide an improved spatial estimation of the $\delta^{18} \mathrm{O}_{\mathrm{ppt}}$ pattern over a watershed than currently used conventional methods that do not incorporate any geographical or climatological parameters. Informed interpolation $\delta^{18} \mathrm{O}_{\mathrm{ppt}}$ fields have been conducted on both global (Birks et al., 2002; Bowen and Wilkinson, 2002; Bowen and Revenaugh, 2003; Van der Veer et al., 2009) and regional (Dutton et al., 2005; Liebminger et al., 2006; Liu et al., 2008; Lykoudis et al., 2010; Zhao et al., 2011) scales. The empirical relationships developed from regional studies provided better approximations of the spatial and temporal distributions of $\delta^{18} \mathrm{O}_{\mathrm{ppt}}$, likely due to the use of regional isotopic data, the inclusion of climate variables, and the refinement of the scale at which the $\delta^{18} \mathrm{O}_{\mathrm{ppt}}$ relationship is constructed. The poor performance of the Bowen and Wilkinson model over north central Canada (Bowen and Wilkinson, 2002) indicates that a more regional model that better represents the controls on isotopic labeling of precipitation is needed for this region. 


\section{Chapter 3}

The main objective of this study is to develop empirical relationships to predict average annual and seasonal $\delta^{18} \mathrm{O}_{\mathrm{ppt}}$ patterns spatially across Canada. In evaluating which model parameters provide the best prediction of annual and seasonal isotope compositions of precipitation we will gain insight into the geographical and climatological controls on isotopic labeling of meteoric water. This study builds on the previous global efforts by developing multivariate linear and stepwise regression models from Canadian data and incorporating both geographic and climate variables within the model parameterizations. It represents the first informed interpolation of the spatial distribution of $\delta^{18} \mathrm{O}_{\mathrm{ppt}}$ for Canada. Due to the intended use of the models, publically available data and simplistic parameterizations are utilized to not limit model usage in data-poor regions. The long-term goal of developing this methodology is to work towards implementing the $\delta^{18} \mathrm{O}_{\text {ppt }}$ prediction models within tracer-aided hydrological models to provide spatially variant precipitation isoscapes as forcing where observations do not exist.

\subsection{Data Sources}

The $\delta^{18} \mathrm{O}_{\mathrm{ppt}}$ data utilized in this study is provided from a new CNIP database combined with the existing GNIP database. Together, these databases include monthly compositions for 35 Canadian stations, with the majority of records spanning at least several years, or more than 25 monthly compositions. Previous depictions of precipitation isotope fields across Canada (Bowen and Wilkinson, 2002) were based on the limited number of Canadian stations included in the GNIP database, often composed of data from discontinuous sampling campaigns. New data from the CNIP network initiated in 1997 consists of 17 stations distributed across Canada, collecting weighted monthly precipitation samples (Figure 9). 


\section{Chapter 3}

Figure 9: Spatial Distribution of CNIP/GNIP Stations across Canada. Smaller circles indicate locations where the CNIP station is located at an elevation lower than $200 \mathrm{~m}$ while larger circles indicate stations located at elevations higher than $200 \mathrm{~m}$.

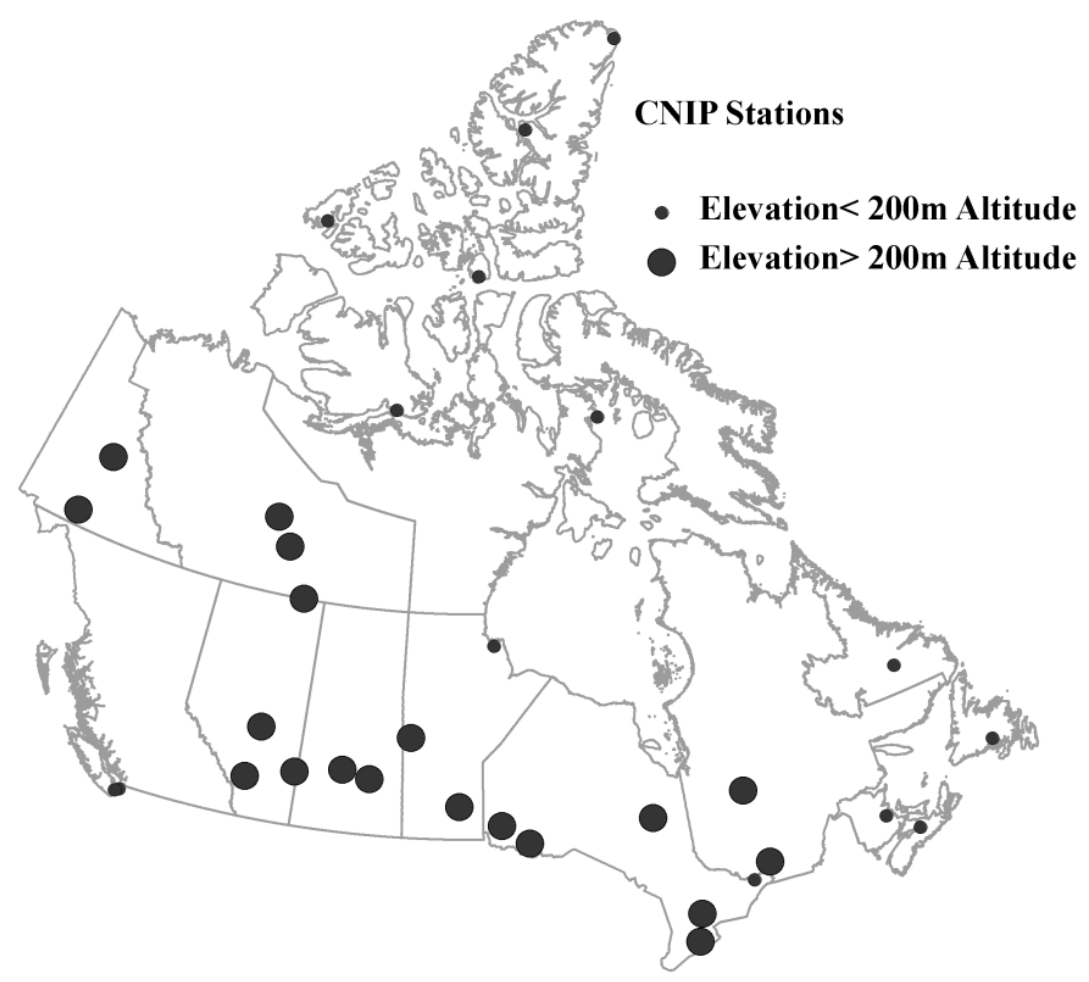

This network marks the first time that stations located in the southern and northern regions of the country have been simultaneously sampled, and includes 10 new stations at a longer time-series than previously available. Data are selected based on record length and completeness so that only stations with at least one complete annual cycle of isotope compositions are used. The final dataset includes 2908 monthly composite samples of $\delta^{18} \mathrm{O}_{\mathrm{ppt}}$ from 33 stations (Table 5). Records with lengths less than five to ten years may introduce bias into the models, by sampling timeperiods not representative of long-term averages for a given location. These biases may include not capturing both phases of the El Nino/La Nina Southern Oscillation (ENSO), the Arctic Oscillation (AO) and climate change, and should be kept in mind during interpretation of the model results. 
Chapter 3

Table 5: $\delta^{18} O_{p p t}$ Period of Record and Sampling Site Geographic Information.

\begin{tabular}{|c|c|c|c|c|c|c|c|}
\hline CNIP Site City & Province & $\begin{array}{l}\text { Latitude } \\
\left({ }^{\circ}\right)\end{array}$ & $\begin{array}{c}\text { Longitude } \\
\left({ }^{\circ}\right)\end{array}$ & $\begin{array}{l}\text { Altitude } \\
\text { (m) }\end{array}$ & $\begin{array}{l}\text { Record } \\
\text { Length }\end{array}$ & $\begin{array}{c}\delta^{18} \mathrm{O}_{\mathrm{PPT}} \\
(\% \%)\end{array}$ & $\mathbf{n}$ \\
\hline Esther & Alberta & 51.67 & -110.2 & 707 & $1997-2003$ & -16.3 & 73 \\
\hline Whitehorse & Yukon Territory & 60.72 & -135.07 & 702 & 1961-1989 & -21.3 & 95 \\
\hline Edmonton & Alberta & 53.57 & -113.52 & 671 & $1961-1966$ & -17.1 & 51 \\
\hline Wynyard & Saskatchewan & 51.77 & -104.2 & 561 & $1965-1982$ & -15.6 & 77 \\
\hline Mayo & Yukon Territory & 63.62 & -134.13 & 504 & $1985-1989$ & -20.8 & 43 \\
\hline Saskatoon & Saskatchewan & 52.1 & -106.43 & 504 & $1997-2001$ & -14.5 & 35 \\
\hline Ste. Agathe & Quebec & 46.05 & -74.28 & 395 & $1975-1982$ & -12.6 & 82 \\
\hline Atikokan & Ontario & 48.75 & -91.62 & 393 & $1975-1982$ & -12.7 & 76 \\
\hline Chapais & Quebec & 49.82 & -74.95 & 382 & $1997-2007$ & -14.1 & 122 \\
\hline Experimental Lakes Area & Ontario & 49.67 & -93.72 & 369 & $1997-2007$ & -12.3 & 123 \\
\hline Bonner Lake & Ontario & 49.38 & -82.12 & 245 & $1997-2007$ & -13.8 & 121 \\
\hline Snare Rapids & Northwest Territories & 63.52 & -116 & 241 & $1997-2007$ & -22.4 & 112 \\
\hline Simcoe & Ontario & 42.85 & -80.27 & 240 & $1975-1982$ & -9.4 & 81 \\
\hline Egbert & Ontario & 44.23 & -79.77 & 224 & $1997-2002$ & -10.4 & 65 \\
\hline Gimli & Manitoba & 50.62 & -96.98 & 223 & $1975-1982$ & -14.2 & 76 \\
\hline Yellowknife & Northwest Territories & 62.28 & -114.27 & 205 & $1989-1993$ & -20.5 & 58 \\
\hline Fort Smith & Northwest Territories & 60.02 & -111.97 & 203 & $1961-1965$ & -18.2 & 40 \\
\hline Bay D'Espoir & Newfoundland & 47.98 & -55.82 & 190 & $1997-2007$ & -9.2 & 121 \\
\hline Saturna Island & British Columbia & 48.78 & -123.13 & 178 & $1997-2007$ & -10.5 & 122 \\
\hline Ottawa & Ontario & 45.32 & -75.67 & 114 & $1979-2007$ & -10.8 & 339 \\
\hline Resolute Bay & Nunavut & 74.72 & -94.98 & 67 & 1989-1993 & -24.1 & 59 \\
\hline Alert & Nunavut & 82.2 & -62.3 & 62 & 1989-1993 & -28.9 & 60 \\
\hline Goose Bay & Newfoundland & 53.32 & -60.42 & 46 & $1997-2007$ & -14.5 & 122 \\
\hline Harcourt & New Brunswick & 46.5 & -65.27 & 40 & $1997-2007$ & -10.4 & 123 \\
\hline Truro & Nova Scotia & 45.37 & -63.27 & 40 & $1975-1983$ & -9.3 & 92 \\
\hline Churchill & Manitoba & 58.45 & -94 & 28 & $1989-1993$ & -17.2 & 56 \\
\hline Cambridge Bay & Nunavut & 69.06 & -105.07 & 23 & 1989-1993 & -23.3 & 55 \\
\hline Victoria & British Columbia & 48.65 & -123.43 & 20 & $1975-1982$ & -10.3 & 72 \\
\hline Mould Bay & Northwest Territories & 76.14 & -119.2 & 15 & 1989-1993 & -24.9 & 58 \\
\hline Eureka & Nunavut & 80 & -85.56 & 10 & 1989-1993 & -26.2 & 55 \\
\hline Hall Beach & Nunavut & 68.47 & -81.15 & 8 & $1989-1993$ & -21.7 & 55 \\
\hline The Pas & Manitoba & 53.97 & -101.10 & 272 & $1975-1982$ & -16.6 & 73 \\
\hline Calgary & Alberta & 51.02 & -114.02 & 1049 & $1992-2001$ & -17.9 & 116 \\
\hline
\end{tabular}

Other similar studies developing spatially distributed $\delta^{18} \mathrm{O}_{\mathrm{ppt}}$ fields have had significantly more measured data available for model construction (e.g. Dutton et al. (2005), 79 stations; Liu et al. (2008), 55 stations). One of the limitations of this analysis is the sparse station $\delta^{18} \mathrm{O}_{\mathrm{ppt}}$ data 


\section{Chapter 3}

available for Canada. Station coverage is denser along the southern portion of Canada than in the north (Figure 9). The vast size, remoteness and harsh climate of northern Canada make the collection of high resolution field measurements a challenge for most meteorological and hydrological monitoring. The lack of station data in the area is a limitation to the accuracy of interpolations of $\delta^{18} \mathrm{O}_{\mathrm{ppt}}$, but also emphasizes the necessity for the development of empirical models to estimate where station based data are not available. As more data are collected in future years, they can be integrated into the proposed models to improve Canadian $\delta^{18} \mathrm{O}_{\mathrm{ppt}}$ interpolations.

Station annual and seasonal $\delta^{18} \mathrm{O}_{\mathrm{ppt}}$ averages are constructed from monthly composite samples over each station's period of record. Four seasons are selected to represent the Canadian annum: winter (December, January, February; or DJF), spring (March, April, May; or MAM), summer (June, July, August; or JJA) and fall (September, October, November; or SON). Monthly precipitation amounts and average temperatures are available for each CNIP/GNIP isotope record and are used to amount weight annual and seasonal average $\delta^{18} \mathrm{O}_{\mathrm{ppt}}$ according to the following equation:

$\left(\delta^{18} O_{P P T}\right)=\sum\left(P_{i} * \delta^{18} O_{P P T}\right) / \sum P_{i}$

(Equation 8)

where $i$ is the month index and $P$ represents precipitation amount. All $\delta^{18} \mathrm{O}_{\mathrm{ppt}}$ values are reported in per mille (\%) and utilize the delta $(\delta)$ notation relative to the VSMOW (Vienna Standard Mean Ocean Water) standard (Craig, 1961). For model regressions, annual and seasonal climate normals for total monthly precipitation amounts and mean monthly temperatures are used and 


\section{Chapter 3}

obtained from Canada's Historical Weather and Climate Data archive (http://climate.weatheroffice.gc.ca/).

\subsection{Methods}

Five model types are evaluated in this study, each representing different regression techniques and parameterizations. The first model type is based on the Bowen and Wilkinson (2002) methodology (herein referred to as the BW model), that makes use of a two-step regression technique incorporating geographic parameters resulting in the following equation:

$\delta^{18} O_{p p t}=A *(L A T)^{2}-B *(L A T)-C *(A L T)+D$

(Equation 9)

where: $L A T$ represents latitude $\left[^{\circ}\right], A L T$ represents altitude [m], and $A$ through $D$ are regression coefficients.

Model types two through four (herein referred to as SIM1, SIM2 and SIM3 models, respectively) are created using simple multivariate regression, each with a slightly differing parameterization, as displayed in the following equations:

$$
\begin{aligned}
& \delta^{18} O_{p p t}=A *(L A T)^{2}+B *(L A T)+C *(A L T)+D \\
& \delta^{18} O_{p p t}=A *(L A T)+B *(A L T)+C *(L O N G)+D \\
& \delta^{18} O_{p p t}=A *(L A T)^{2}+B *(A L T)+C *(L O N G)+\mathrm{D} *(\mathrm{PRECIP})+\mathrm{E} *(\mathrm{TEMP})+\mathrm{F}
\end{aligned}
$$

(Equation 12)

where: $L O N G$ represents longitude $\left[^{\circ}\right]$, and PRECIP and TEMP are the long-term climate normals for total monthly precipitation $[\mathrm{mm}]$, and mean monthly temperature $\left[{ }^{\circ} \mathrm{C}\right]$, respectively. 


\section{ChAPTER 3}

Similarly, $A$ through $F$ are regression coefficients. SIM1 shares the same parameterization as the BW model; however, it is derived utilizing simple multivariate regression rather than the twostep regression technique, therefore yielding slightly different results. Given the dependence of $\delta^{18} \mathrm{O}_{\mathrm{ppt}}$ on continentality, moisture sources, and pathways, longitude is included as a proxy for these effects. Time variant climate parameters are included in two of the model parameterizations (SIM3 and stepwise model approach) to provide physically-based insight into the controls on seasonal variability.

The fifth and final model employs a stepwise regression procedure for model parameter selection. Stepwise regression is carried out on the parameters included in Equation 12 to create a series of stepwise models for the analysis (herein referred to as the SW model). The stepwise regression procedure is included in this study to determine which parameters are statistically significant both annually and seasonally. This method provides an automatic procedure for selecting which variables should be entered into the regression models by conducting a series of t-tests at the $95 \%$ confidence level. For each of the five model types, an annual model and four seasonal models are created, resulting in 25 models for comparison and analysis.

\subsection{Model Results}

Model performance is evaluated statistically through the adjusted coefficient of determination $\left(\operatorname{adj} . \mathrm{R}^{2}\right)$ and the range and variance of the model residuals. Spatial and temporal trends in simulated $\delta^{18} \mathrm{O}_{\mathrm{ppt}}$ and model residuals are examined and discussed to gauge the various strengths and weaknesses of the individual models. For the simple and stepwise multivariate regression models, the underlying assumptions behind the regression framework are tested to ensure that 


\section{ChAPTER 3}

violation of these assumptions does not occur. Two of the main assumptions in using a simple multivariate regression model are the normality of residuals and small amounts of multicollinearity between parameters. Large amounts of multicollinearity result in an uncertain response surface, and consequently the model parameters may no longer be given any meaningful interpretation. The normality of the model residuals are evaluated through a Lilliefors test (Lilliefors, 1967) for normality at the 95\% confidence level. All annual and seasonal models derived using simple multivariate regression passed the Lilliefors test at the 0.05 alpha-level, indicating normality of residuals.

The presence of multicollinearity is determined by the calculation of variance inflation factors (VIF). The VIF is describes how much the variance of an estimated regression coefficient is increased due to the presence of collinearity. VIF's are calculated for each parameter within each model. Table 6 indicates the results of the VIF calculations, denoting a yes (Y) if any of the parameters within a model have a VIF greater than 10. If the VIF is greater than 10, high collinearity is present and action should be taken to reduce the collinearity and caution should be used when placing physical meaning on the regression coefficients. VIF's indicate SIM1 shows high amounts of multicollinearity. This is expected, and is due to the inclusion of both LAT and LAT $^{2}$ within the regression model. Between the annual and seasonal SIM3 and the SW models, four instances of high multicollinearity occur, with VIF's ranging between 15 and 30. These high VIF's are present in the annual, MAM and SON models and in all instances relate to the LAT parameter, indicating that latitude and temperature are highly correlated. No other predictor variables show VIF's greater than 10, indicating no additional instances of multicollinearity. 


\section{ChAPTER 3}

Table 6: Summary of variance inflation factor results for simple linear regression (SIM) and stepwise regression (SW) models. A VIF greater than 10 is indicated with a $(Y)$ while a VIF less than 10 is indicated by a $(N)$.

\begin{tabular}{|lllll|}
\hline & \multicolumn{4}{c|}{ Models with VIF Exceeding 10 } \\
\cline { 2 - 5 } Season & SIM1 & SIM2 & SIM3 & SW \\
\hline Annual & Y & N & Y & N \\
DJF & Y & N & N & N \\
MAM & Y & N & Y & N \\
JJA & Y & N & N & N \\
SON & Y & N & Y & Y \\
\hline
\end{tabular}

Table 7 and Table 8 summarize the model parameterizations and performance for the annual and seasonal models, respectively. Stepwise regression results are indicated with an $(\mathrm{R})$, denoting the parameters retained within each model type. Model results are analyzed and interpreted within the Discussion Section.

Table 7: Annual model parameterization and summary statistics. Bowen and Wilkinson and simple regression parameterizations indicated by an $(X)$. Stepwise regression retained parameters indicated by an $(R)$.

\begin{tabular}{|c|c|c|c|c|c|c|c|c|c|c|}
\hline \multirow[b]{2}{*}{ Season } & \multirow[b]{2}{*}{$\begin{array}{c}\text { Model } \\
\text { Type }\end{array}$} & \multicolumn{6}{|c|}{ Parameterization } & \multirow[b]{2}{*}{$\begin{array}{c}\text { Residual } \\
\text { Range }(\%)\end{array}$} & \multirow[b]{2}{*}{$\begin{array}{c}\text { Adjusted } \\
\qquad \mathrm{R}^{2}\end{array}$} & \multirow[b]{2}{*}{$\begin{array}{c}\text { Residua } \\
\text { Variance } \\
(\%)\end{array}$} \\
\hline & & LAT & $\mathrm{LAT}^{2}$ & ALT & LONG & PRECIP & TEMP & & & \\
\hline \multirow[t]{5}{*}{ Annual } & BW & $\mathrm{X}$ & $\mathrm{X}$ & $\mathrm{X}$ & & & & -1.8 to 2.5 & 0.97 & 0.9 \\
\hline & SIM1 & $\mathrm{X}$ & $\mathrm{X}$ & $\mathrm{X}$ & & & & -1.8 to 2.5 & 0.97 & 1.0 \\
\hline & SIM2 & $\mathrm{X}$ & & $\mathrm{X}$ & $\mathrm{X}$ & & & -2.2 to 2.5 & 0.97 & 1.1 \\
\hline & SIM3 & $\mathrm{X}$ & & $\mathrm{X}$ & $\mathrm{X}$ & $\mathrm{X}$ & $\mathrm{X}$ & -2.3 to 1.6 & 0.97 & 0.9 \\
\hline & SW & $\mathrm{R}$ & & $\mathrm{R}$ & & $\mathrm{R}$ & & -2.2 to 1.8 & 0.97 & 0.9 \\
\hline
\end{tabular}




\section{Chapter 3}

Table 8: Seasonal model parameterization and summary statistics. Parameters included in each of the models are indicated with an $(X)$. Stepwise regression retained parameters indicated by an $(R)$.

\begin{tabular}{|c|c|c|c|c|c|c|c|c|c|c|}
\hline \multirow[b]{2}{*}{ Season } & \multirow[b]{2}{*}{$\begin{array}{c}\text { Model } \\
\text { Type }\end{array}$} & \multicolumn{6}{|c|}{ Parameterization } & \multirow[b]{2}{*}{$\begin{array}{l}\text { Residual } \\
\text { Range }(\%)\end{array}$} & \multirow[b]{2}{*}{$\begin{array}{c}\text { Adjusted } \\
\mathrm{R}^{2}\end{array}$} & \multirow[b]{2}{*}{$\begin{array}{c}\text { Residual } \\
\text { Variance } \\
(\%)\end{array}$} \\
\hline & & LAT & $\mathrm{LAT}^{2}$ & ALT & LONG & PRECIP & TEMP & & & \\
\hline \multirow[t]{5}{*}{ DJF } & BW & $\mathrm{X}$ & $\mathrm{X}$ & $\mathrm{X}$ & & & & -6.5 to 9.0 & 0.70 & 16.4 \\
\hline & SIM1 & $\mathrm{X}$ & $\mathrm{X}$ & $\mathrm{X}$ & & & & -6.0 to 6.6 & 0.78 & 12.5 \\
\hline & SIM2 & $\mathrm{X}$ & & $\mathrm{X}$ & $\mathrm{X}$ & & & -6.5 to 7.2 & 0.78 & 12.2 \\
\hline & SIM3 & $\mathrm{X}$ & & $\mathrm{X}$ & $\mathrm{X}$ & $\mathrm{X}$ & $\mathrm{X}$ & -3.1 to 5.2 & 0.91 & 4.8 \\
\hline & SW & $\mathrm{R}$ & & & $\mathrm{R}$ & $\mathrm{R}$ & & -3.5 to 5.1 & 0.91 & 4.8 \\
\hline \multirow[t]{5}{*}{ MAM } & BW & $\mathrm{X}$ & $\mathrm{X}$ & $\mathrm{X}$ & & & & -2.8 to 2.9 & 0.95 & 2.2 \\
\hline & SIM1 & $\mathrm{X}$ & $\mathrm{X}$ & $\mathrm{X}$ & & & & -3.0 to 2.8 & 0.95 & 2.2 \\
\hline & SIM2 & $\mathrm{X}$ & & $\mathrm{X}$ & $\mathrm{X}$ & & & -3.4 to 3.0 & 0.95 & 2.3 \\
\hline & SIM3 & $\mathrm{X}$ & & $\mathrm{X}$ & $\mathrm{X}$ & $\mathrm{x}$ & $\mathrm{X}$ & -3.3 to 2.8 & 0.97 & 1.7 \\
\hline & SW & $\mathrm{R}$ & & $\mathrm{R}$ & $\mathrm{R}$ & $\mathrm{R}$ & & -3.0 to 2.6 & 0.96 & 1.7 \\
\hline \multirow[t]{5}{*}{ JJA } & BW & $\mathrm{X}$ & $\mathrm{X}$ & $\mathrm{X}$ & & & & -4.3 to 2.7 & 0.95 & 1.4 \\
\hline & SIM1 & $\mathrm{X}$ & $\mathrm{X}$ & $\mathrm{X}$ & & & & -3.8 to 2.3 & 0.95 & 1.2 \\
\hline & SIM2 & $\mathrm{X}$ & & $\mathrm{X}$ & $\mathrm{X}$ & & & -4.2 to 2.0 & 0.94 & 1.5 \\
\hline & SIM3 & $\mathrm{X}$ & & $\mathrm{X}$ & $\mathrm{X}$ & $\mathrm{X}$ & $\mathrm{X}$ & -3.5 to 1.9 & 0.95 & 1.4 \\
\hline & SW & $\mathrm{R}$ & & $\mathrm{R}$ & & & $\mathrm{R}$ & -3.5 to 2.2 & 0.95 & 1.4 \\
\hline \multirow[t]{5}{*}{ SON } & BW & $\mathrm{X}$ & $\mathrm{X}$ & $\mathrm{X}$ & & & & -3.2 to 3.0 & 0.94 & 2.5 \\
\hline & SIM1 & $\mathrm{X}$ & $\mathrm{X}$ & $\mathrm{X}$ & & & & -2.8 to 3.5 & 0.95 & 2.4 \\
\hline & SIM2 & $\mathrm{X}$ & & $\mathrm{X}$ & $\mathrm{X}$ & & & -2.9 to 3.4 & 0.95 & 2.5 \\
\hline & SIM3 & $\mathrm{X}$ & & $\mathrm{X}$ & $\mathrm{X}$ & $\mathrm{X}$ & $\mathrm{X}$ & -2.5 to 2.7 & 0.97 & 1.6 \\
\hline & SW & $\mathrm{R}$ & & $\mathrm{R}$ & & $\mathrm{R}$ & $\mathrm{R}$ & -2.5 to 2.7 & 0.97 & 1.5 \\
\hline
\end{tabular}

\subsection{Discussion}

For the annual stepwise regression, latitude, altitude and precipitation were retained while longitude and temperature were eliminated. The retained parameters in the seasonal SW models also indicate the importance of latitude, altitude and precipitation as predictor variables. Latitude survived the stepwise regression for all four seasonal SW models, while altitude and precipitation were both retained in three out of four seasonal models. Precipitation did not survive the stepwise regression for the JJA model, indicating that the amount of precipitation is 


\section{Chapter 3}

not highly correlated to changes in $\delta^{18} \mathrm{O}_{\mathrm{ppt}}$ during the summer months. Temperature and longitude remained in only half of the seasonal stepwise regression models (JJA \& SON and JFM \& MAM, respectively). Longitude is more prevalent in the winter and spring model results, likely due to the enhanced role of continentality controlling the isotopic labeling of precipitation during colder seasons. The temperature difference between the vapour source (i.e., the ocean) and the condensation site is largest during the winter and spring seasons. The reduced role of temperature and continentality in the summer months is also consistent with the dominance of convective, localized precipitation in the continental interior of Canada during this season (Koster et al., 1993).

Regression coefficients from models not showing multicollinearity are analyzed to determine if they are consistent with the expected controls on the isotopic labeling of precipitation. For all annual and seasonal model parameterizations, latitude and altitude show the expected negative relationship with $\delta^{18} \mathrm{O}_{\mathrm{ppt}}$. Longitude, precipitation and temperature consistently show positive correlation with $\delta^{18} \mathrm{O}_{\mathrm{ppt}}$ for the annual models, however, the magnitude and direction of correlation changes seasonally. Temperature is positively correlated with $\delta^{18} \mathrm{O}_{\mathrm{ppt}}$ for the SON, DJF and MAM seasons, but becomes negative during the JJA season. Longitude shows a similar but opposing trend to temperature, where negative correlations are present in the SON, DJF and MAM seasons and positive correlations are found in the summer. Precipitation regression coefficients always remain positive.

Evaluation of model performance statistics indicates that annual models perform comparably and overall, satisfactorily (Table 7). On average the models have an adjusted $\mathrm{R}^{2}$ value of 0.97 and a 


\section{Chapter 3}

residual variance of approximately $0.96 \%$. The addition of climate parameters (PRECIP and TEMP) did not result in a noticeable improvement due to the annual averaging involved with this analysis. Comparison of seasonal model type performance (Table 8) show that models with time variant climate parameters (SIM3 and SW models) consistently outperformed models composed solely of geographic parameters (BW, SIM1, and SIM2 models); typically showing higher adjusted $\mathrm{R}^{2}$ and lower residual variance.

Figure 10 displays seasonal variations in simulated $\delta^{18} \mathrm{O}_{\mathrm{ppt}}$ for six strategically picked CNIP stations from various climate regions (Environment Canada, 2010) across Canada. Two stations from coastal locations are selected: Bay D’Espoir, NL in Atlantic Canada, and Saturna Island, BC located on the Pacific coast. Calgary, AB and Chapais, QC are chosen as east and west continental stations, representing prairies and northeastern forest climate regions, respectively. Snare Rapids, NWT is located within the Mackenzie District, and is therefore considered to represent continental stations above $55^{\circ}$ latitude. Finally, Resolute Bay, NU represents the Arctic tundra CNIP stations. 


\section{Chapter 3}

Figure 10: Seasonal variations in simulated $\delta^{18} O_{\text {ppt }}$ from six select CNIP stations. Measured $\delta^{18} O_{p p t}$ is indicated by the solid black lines.
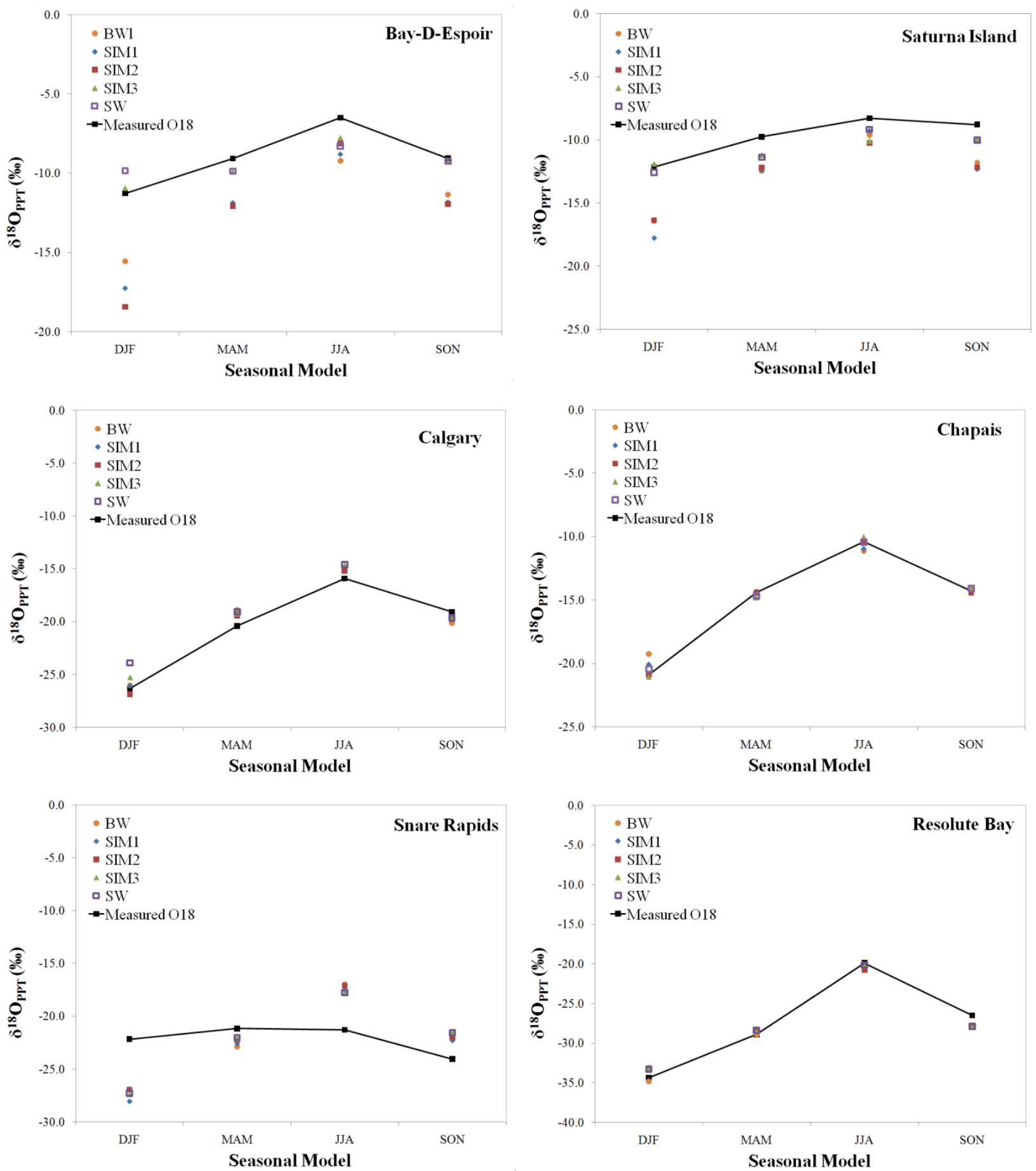

Analyzing the model results temporally, the MAM, JJA and SON seasonal models all perform satisfactorily; however the DJF models show surprisingly low $\mathrm{R}^{2}$ values (0.70 to 0.91$)$, high 


\section{Chapter 3}

error variance ( 4.8 to $16.4 \%$ ), and large residual magnitudes in relation to models for the other seasons; indicating increased complexity in the driving forces of $\delta^{18} \mathrm{O}_{\mathrm{ppt}}$ patterns during the winter season (e.g., enhanced kinetic effects during phase changes at sub-zero temperatures, pronounced continentality) resulting in weaker relationships between $\delta^{18} \mathrm{O}_{\mathrm{ppt}}$ and the predictor variables. Another significant finding is the large difference in performance between DJF model parameterizations solely comprised of geographic parameters and parameterizations including both geographic and climate parameters. The addition of climate parameters to the DJF models significantly improved results and increased $\mathrm{R}^{2}$ values from 0.78 (SIM1, SIM2) to 0.91 (SIM3, $\mathrm{SW}$ ), while decreasing the residual variance substantially (12.5\% compared to $4.8 \%$ ). This improvement in performance is not as apparent in the remaining seasons, where all model types perform comparably, with typical $\mathrm{R}^{2}$ values ranging from 0.94 to 0.97 and residual variances range from $1.2 \%$ to $2.5 \%$, suggesting strong relationships between $\delta^{18} \mathrm{O}_{\mathrm{ppt}}$ and the parameter sets. The probable cause of the poor DJF model performance is due to the weaker relationship between $\delta^{18} \mathrm{O}_{\mathrm{ppt}}$ and latitude during the winter, when interannual variations in isotope labelling are largest. Linear regression of $\delta^{18} \mathrm{O}_{\mathrm{ppt}}$ versus latitude for the winter season shows an $\mathrm{R}^{2}$ of 0.71 , in comparison to $\mathrm{R}^{2}$ values ranging from 0.85 to 0.91 for identical regressions completed for the remaining seasons. To better understand model performance, spatial trends in the DJF model residuals are assessed (Figure 11). 


\section{Chapter 3}

Figure 11: Regression model residuals for the DJF model series. Negative residuals (measured $<$ modelled) are shown in black and positive residuals (measured > modelled) are shown in light gray. Residuals are calculated by subtracting modelled $\delta^{18} O_{p p t}$ from measured $\delta^{18} O_{p p t}$. The size of the circles represents the relative magnitude of the residuals.
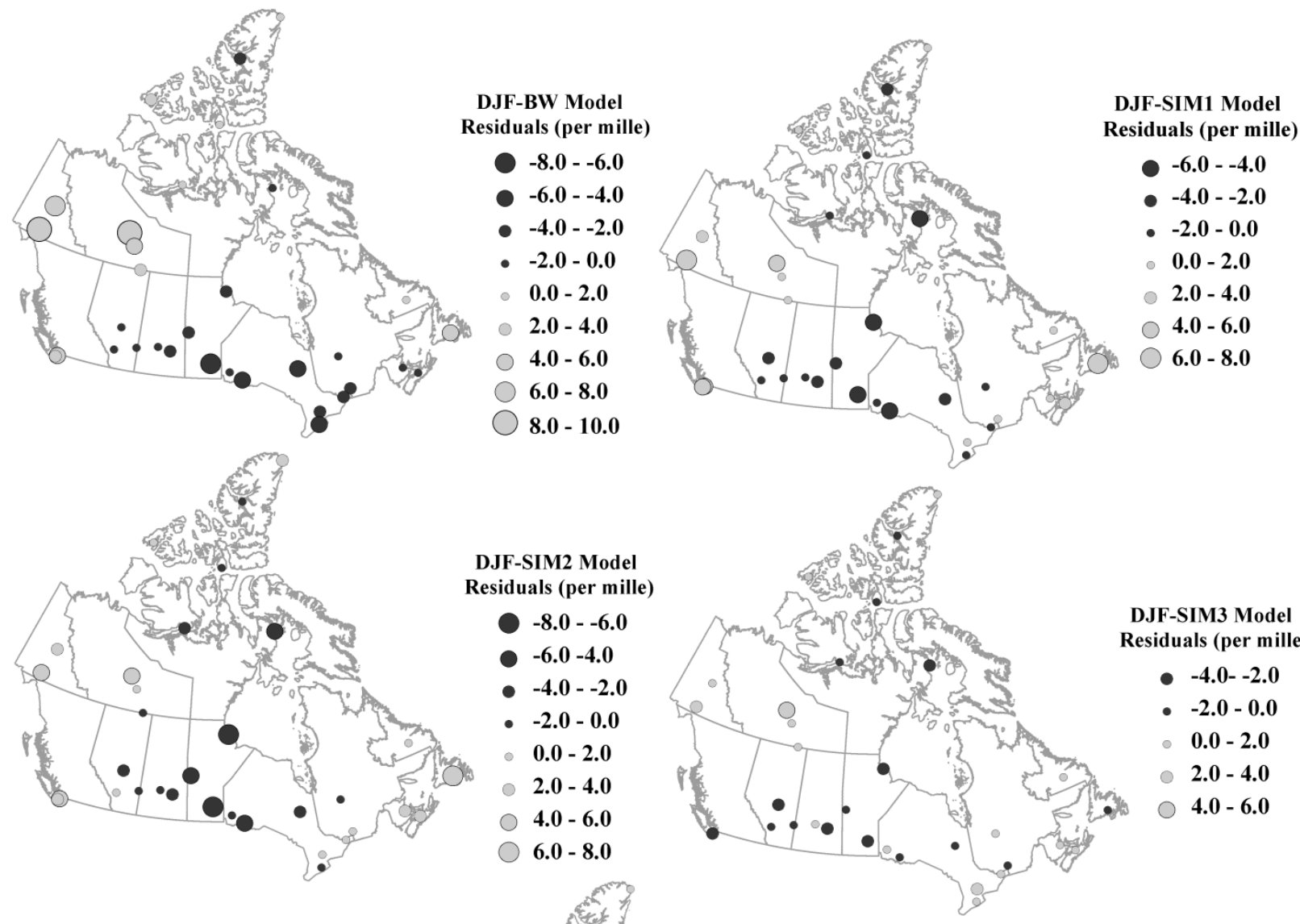

DJF-SIM3 Model Residuals (per mille)

- $-4.0-\mathbf{- 2 . 0}$

- $-2.0-0.0$

$0.0-2.0$

$2.0-4.0$

4.0 - 6.0

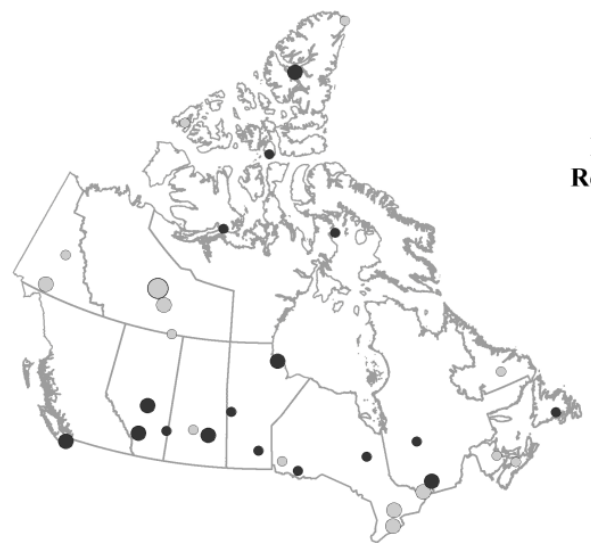

DJF-SW Model

Residuals (per mille)

- $-4.0--2.0$

- $-2.0-0.0$

$0.0-2.0$

$2.0-4.0$

4.0 - 6.0

There are two types of patterns evident in the residual maps for the DJF seasonal models (Figure

11). Despite the slight differences between the geographically based models and the combined geographical and climatological models, generally all DJF models typically show similar large- 


\section{Chapter 3}

scale trends in the sign of the residuals, but large differences in the magnitude of the residuals. One consistent pattern in the DJF residual maps is the presence of high-magnitude negative residuals within the south-central continental CNIP stations, indicating the models predict more positive $\delta^{18} \mathrm{O}_{\mathrm{ppt}}$ values than measured. Birks and Edwards (2009) found that circulationdependent factors play a significant role in the isotopic signature over central Canada, which is where a large portion of the negative residuals (i.e., model over-prediction) are occurring. The sets of parameters used in the winter models may not adequately capture the depletion of heavy isotopes from the longitudinal transport of air masses from the Atlantic or Pacific oceans inland or the influence of depleted Arctic air masses over central Canada. Additionally, in this region measured $\delta^{18} \mathrm{O}_{\mathrm{ppt}}$ data can show anomalously negative or positive values when associated with more zonal or meridional flow, respectively (Birks and Edwards, 2009). Based on the winter model results, it is apparent that longitude does not make a significant enough model contribution to progressively deplete $\delta^{18} \mathrm{O}_{\mathrm{ppt}}$ signatures inland from the coast and cannot account for the different isotopic labeling occurring at a single geographic location under different circulation patterns or multiple moisture sources. A possible solution to this problem is the introduction of separate models for various climate regions in future model iterations.

Another trend visible in Figure 11 is the extremely positive residuals at a group of western CNIP stations between $55^{\circ}$ and $70^{\circ} \mathrm{N}$ latitude (Snare Rapids, Yellowknife, Whitehorse, Fort Smith, Mayo), indicating that the model simulations predict more negative $\delta^{18} \mathrm{O}_{\mathrm{ppt}}$ than measured. The isotope time series from Fort Smith and Mayo are both less than five years in length and there is no overlap between the time periods for these stations (1985-1989 and 1961-1965, respectively). Therefore, the large positive residuals at this location could be related to biases in the data used 


\section{Chapter 3}

to develop the models. As with the south central anomaly, the positive residuals could indicate a circulation dependant control on the isotopic composition of precipitation in this location, similar to the anomalously positive $\delta^{18} \mathrm{O}_{\mathrm{ppt}}$ values that occur when meridional transport of moisture across the Rockies results in less rainout.

The anticipated trend towards increasingly negative $\delta^{18} \mathrm{O}_{\mathrm{ppt}}$ values moving from the coast towards the interior stations is captured by all of the winter models; however, the models based solely on geographical parameters largely under predict at coastal locations. The models that incorporate climate parameters have small to medium residuals at these locations indicating that the addition of climate parameters to seasonal models may help to capture some of the physical processes behind the seasonality in isotope patterns, especially at coastal locations where isotope patterns are influenced by high amounts of precipitation and moderate temperatures, and less so by seasonality. Spatial maps similar to those shown in Figure 11 created for the remaining MAM, JJA and SON models also show similar findings; all models predict similar large-scale patterns and the addition of climate parameters to regression models improved the evaluation statistics and decreased the magnitude of residuals. This is further highlighted in a series of plots detailing the seasonal variations in model residuals (Figure 12) for all 35 CNIP stations.

Figure 12 establishes that generally each model type provides similar spatial residual patterns for each respective season. Therefore, the remainder of the discussion will focus on the analysis from the SIM3 model because it consistently out-performs the other model types (Table 7, Table 8). A time-series of residual maps based on the seasonal models from the SIM3 regression is 


\section{Chapter 3}

created to spatially assess the changes in residuals annually and from season to season (Figure 13).

Figure 12: Residuals from seasonal regression models plotted against longitude for each of the five model types.
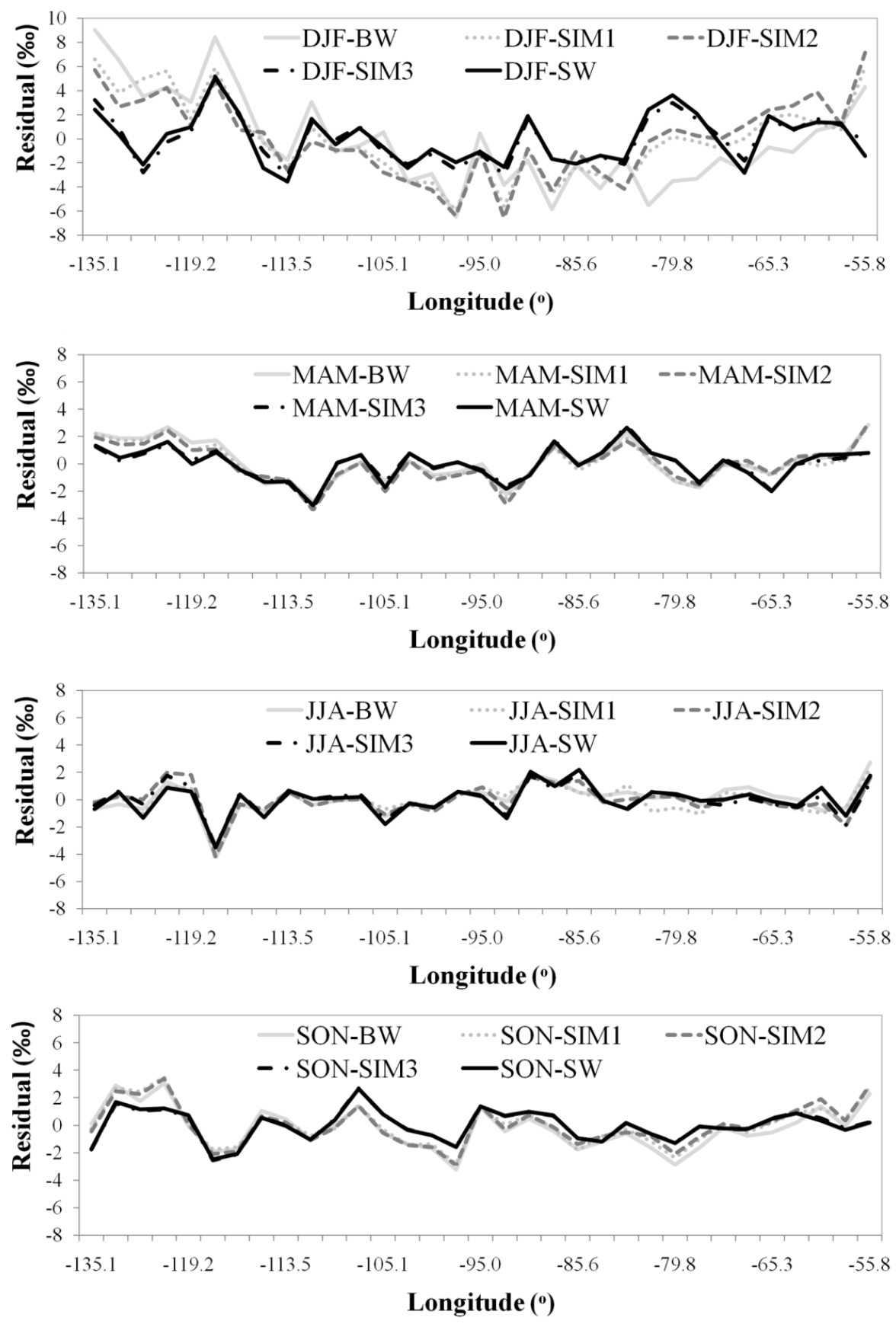


\section{Chapter 3}

Figure 13: Regression model residuals for the annual, DJF, MAM, JJA and SON SIM3 models.

Negative residuals (measured <modelled) are shown in black and positive residuals

(measured >modelled) are shown in light gray. Residuals are arrived at by subtracting modelled

$\delta^{18} O_{p p t}$ from measured $\delta^{18} O_{p p t}$
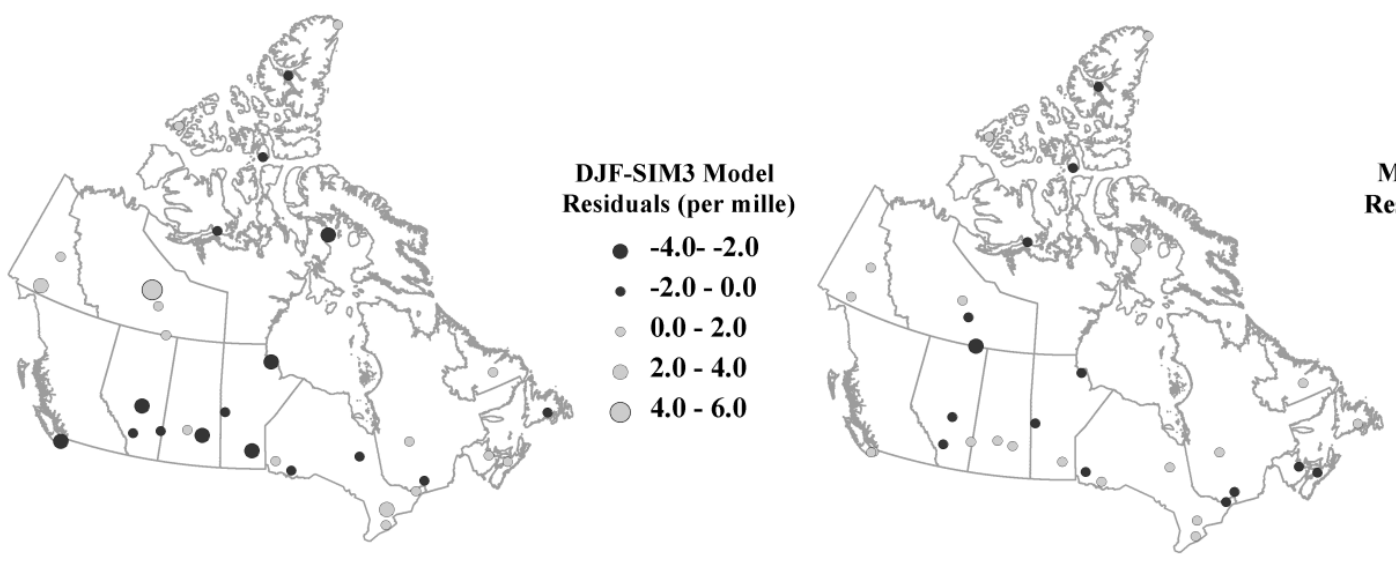

MAM-SIM3 Model Residuals (per mille)

- $-4.0--2.0$

- $-2.0-0.0$

0.0 - 2.0

$\mathbf{2 . 0}-\mathbf{4 . 0}$
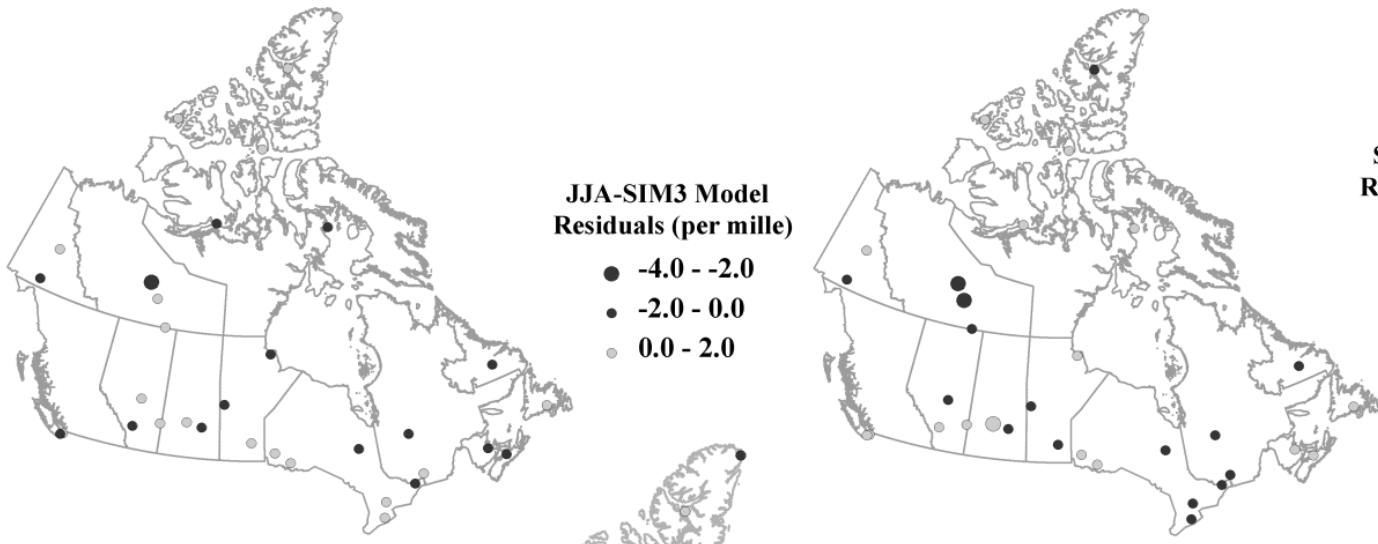

SON-SIM3 Model

Residuals (per mille)

$-4.0--2.0$

- $-2.0-0.0$

$0.0-2.0$

$-4.0--2.0$

- $-2.0-0.0$

$0.0-2.0$

$2.0-4.0$

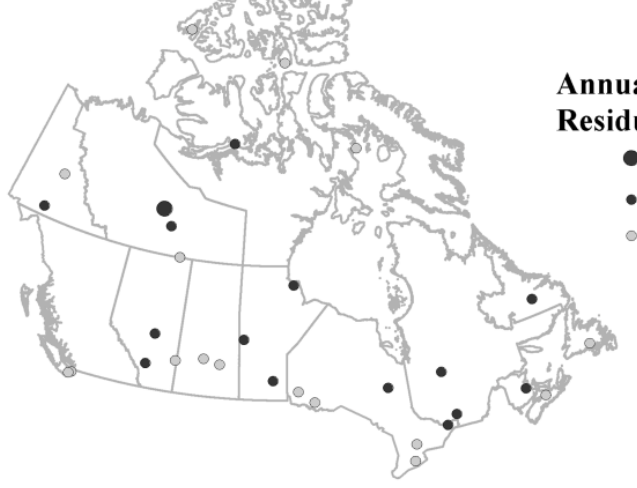

Annual-SIM3 Model

Residuals (per mille)

$-\mathbf{- 4 . 0}-\mathbf{- 2 . 0}$

- $-2.0-0.0$

- $0.0-2.0$

The distributions of residuals for annual, MAM, JJA, and SON show different trends than those introduced for the DJF model. Across central Canada a shift from negative residuals in the winter to a mix of negative and positive residuals in the remaining months occurs, indicating no major model bias exists at this location for these months. The SIM3 model underestimates the $\delta^{18} \mathrm{O}_{\mathrm{ppt}}$ 


\section{Chapter 3}

for stations located near the Great Lakes for most of the year, until fall when there is a reversal in the sign of the residuals indicating the model overestimates $\delta^{18} \mathrm{O}_{\mathrm{ppt}}$ for this season, a trend similar to the annual models. Fall is a time of high evaporation in the vicinity of the Great Lakes and the switch in the sign of the residuals may reflect increased contributions of recycled moisture (Van der Ent et al., 2010) or the moderating effect of the lakes on local temperature. Isotopic evidence for this recycling has been noted in the higher d-excess of precipitation and river runoff in the vicinity of the North American Great Lakes (Gat et al., 1994). Generally, high Arctic residuals tend towards negative residuals in the winter and spring seasons and positive residuals in the summer and fall seasons, indicating the model is not capturing the full seasonality inherent to this area.

\subsection{Spatial Distribution of Annual and Seasonal $\delta^{18} \mathbf{O}_{\text {ppt }}$ over Canada}

Annual and seasonal contour maps from SIM3 model simulations are created for the Canadian domain through use of Canada3D, a digital elevation model (DEM) with a horizontal grid spacing of 30 arc-seconds. Elevation at latitude and longitude pairs is obtained by sampling the $\mathrm{DEM}$ at a $0.25^{\circ} \times 0.25^{\circ}$ resolution. Annual and seasonal long-term averages for gridded temperature and precipitation are extracted from the National Centers for Environmental Prediction (NCEP) North American Regional Reanalysis (NARR) dataset. NCEP reanalysis data are provided by the NOAA/OAR/ESRL PSD, Boulder, Colorado, USA, from their Website at http://www.esrl.noaa.gov/psd/. NARR is a long term high-resolution climate dataset for the North American domain at a grid resolution of approximately $32 \mathrm{~km}$. Annual and seasonal climatologies are derived from monthly mean climatologies, and subsequently used as input into the SIM3 model. The SIM3 model simulation of $\delta^{18} \mathrm{O}_{\mathrm{ppt}}$ across Canada annually and seasonally 


\section{Chapter 3}

is presented on Figure 14. The $\delta^{18} \mathrm{O}_{\mathrm{ppt}}$ bands visible in the figure are due to the dependence of oxygen-18 on latitude, and deviations from the banding effect are due to altitude or climate effects. The $\delta^{18} \mathrm{O}_{\mathrm{ppt}}$ pattern becomes more depleted in heavy isotopes as it travels poleward, which is expected due to the removal of moisture from air masses (Yurtsever and Gat, 1981). The Maritimes indicate more enriched $\delta^{18} \mathrm{O}_{\text {ppt }}$ patterns, which is predominantly due to their close proximity to the ocean and lower latitude locations.

The final maps of the distribution of isotopes in precipitation generated in similar studies (Bowen and Wilkinson, 2002; Dutton et al., 2005; Liu et al., 2008), are based on correcting an estimated $\delta^{18} \mathrm{O}_{\mathrm{ppt}}$ map by applying a contoured residual field. The emphasis in this study is to develop improved empirical relationships to approximate the isotopic labeling of precipitation across Canada thereby decreasing the residuals and the need for correction. For this reason we have presented our estimated $\delta^{18} \mathrm{O}_{\mathrm{ppt}}$ maps (Figure 14) and the residuals (Figure 15) separately. Interpolated maps of the annual and seasonal residuals are created as companions to Figure 14, to give an estimate of the uncertainty of the SIM3 model results across Canada. However, it should be noted that additional uncertainty exists when interpolating within areas where there are very little data, therefore application of the residual map contours to the $\delta^{18} \mathrm{O}_{\text {ppt }}$ estimates to arrive at a final isotope signature should be carried out with caution. 
Figure 14: SIM3 annual and seasonal $\delta^{18} O_{p p t}$ patterns across Canada.

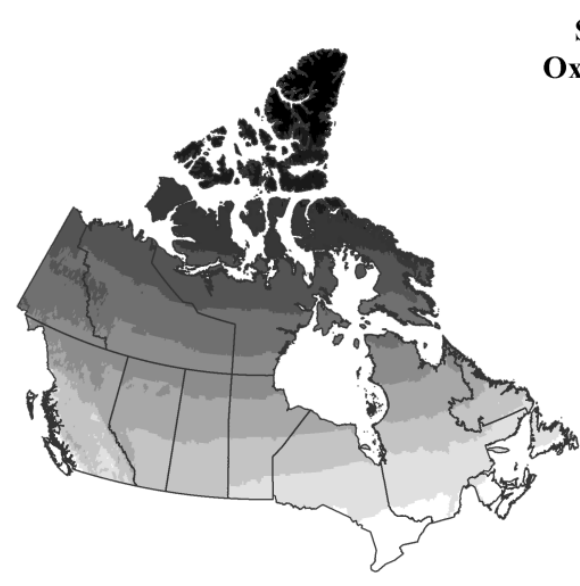

SIM3 ANNUAL

Oxygen-18 Contours (per mille)

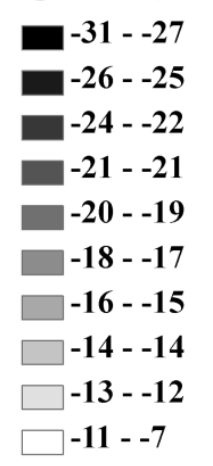

SIM3 MAM

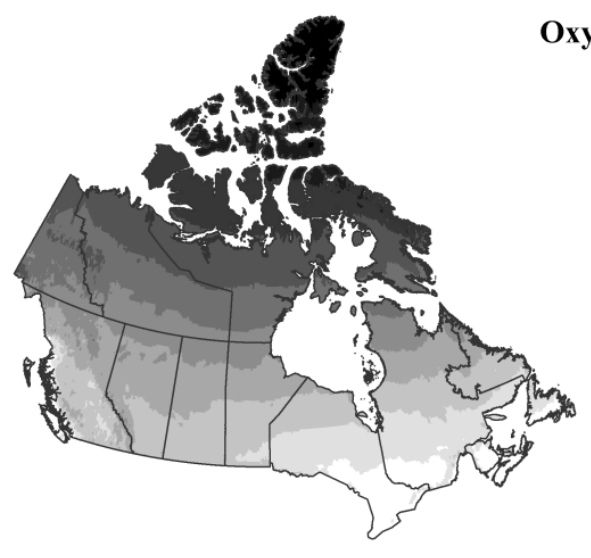

Oxygen-18 Contours (per mille)

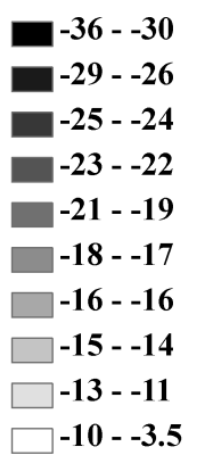

\author{
$\mathbf{s}$
}
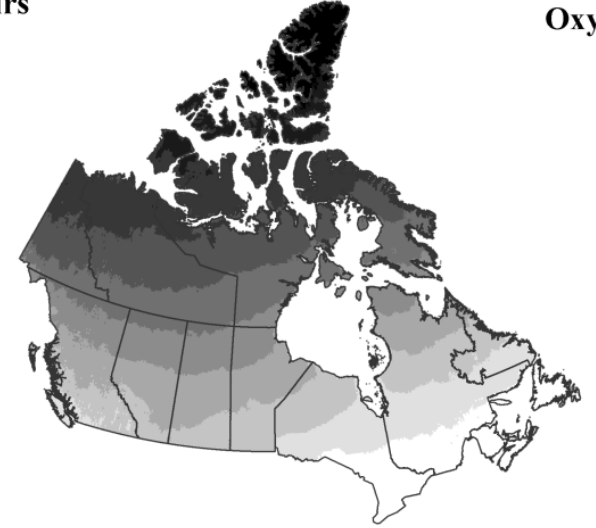

SIM3 JJA

Oxygen-18 Contours (per mille)

$-25--22$

$-21--20$

$-19--18$

$-17--17$

$-16--15$

$-14--13$

$\square-12--12$

$-11--10$

$-9--8.7$

$-8.6--5.3$

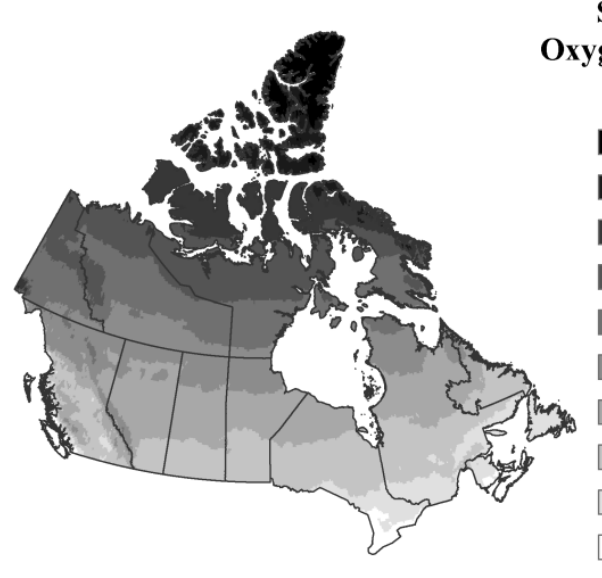

SIM3 SON

Oxygen-18 Contours (per mille)

$-36--31$

$-30--28$

$-27--26$

$-25--23$

$-22--21$

$-20--18$

$\square-17--16$

$-15--14$

$\square-13--11$

$-10--4.5$ 
Figure 15: SIM3 annual and seasonal residual contours.

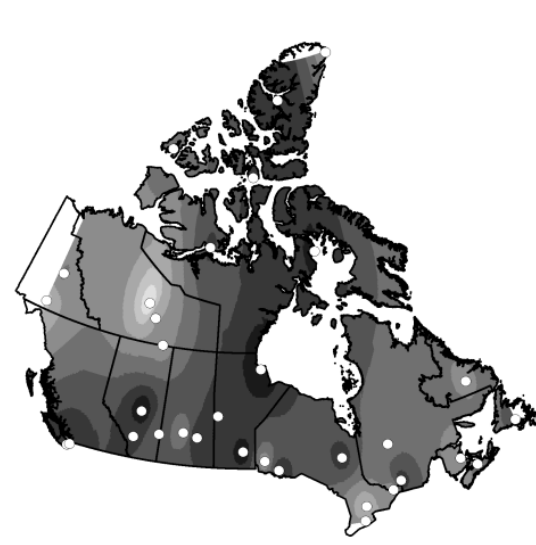

SIM3 DJF
Residual Contours (per mille)

CNIP Station

$-3.5--3.0$

$-3.0--2.0$

$-2.0--1.0$

-1.0 - 0

0 - 1.0

$1.0-2.0$

2.0 - 3.0

$\square .0-4.0$

$\square 4.0$ - 5.0

$\square 5.0$ - 6.0

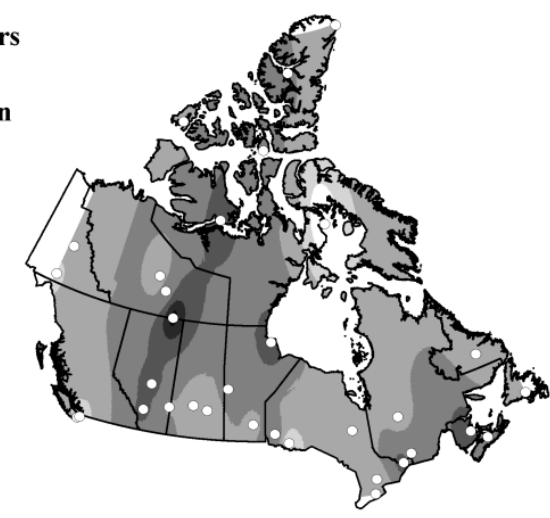

SIM3 MAM

Residual Contours

(per mille)

CNIP Station

$-4.0--3.0$

$-3.0--2.0$

$-2.0--1.0$

$-1.0-0$

$\square$ - 1.0

$\square 1.0-2.0$

$\square 2.0$ - 3.0

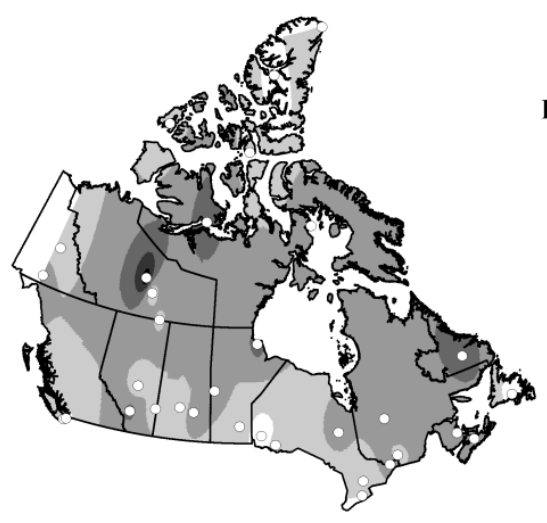

SIM3 JJA

Residual Contours (per mille)

CNIP Station

$-3.5--3.0$

$-3.0--2.0$

$-2.0--1.0$

$-1.0-0$

$\square 0$ - 1.0

$\square 1.0$ - 2.0

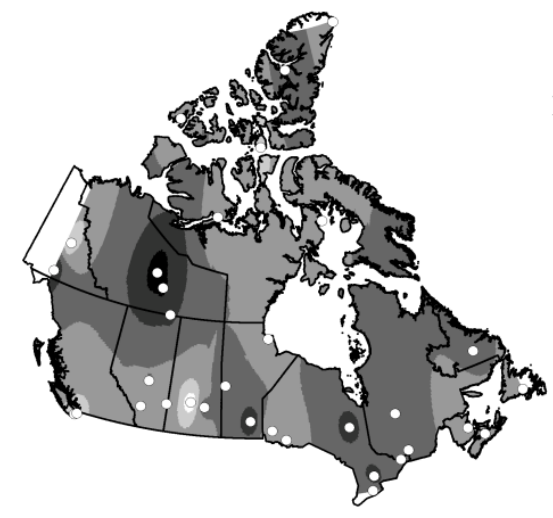

SIM3 SON

Residual Contours (per mille)

- CNIP Station

$-2.5-\mathbf{2 . 0}$

$-2.0--1.0$

$-1.0-0$

0 - 1.0

$\square 1.0$ - 2.0

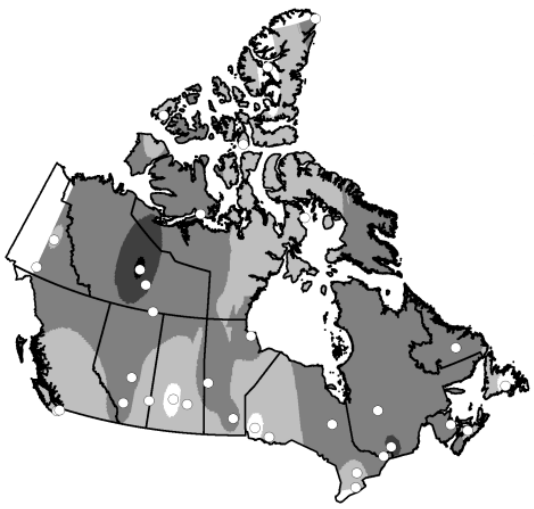

SIM3 Annual

Residual Contours

(per mille)

CNIP Station

$-2.5--2.0$

$-2.0--1.0$

$-1.0-0$

0 - 1.0

$\square 1.0$ - 2.0

\subsection{Conclusions and Next Steps}

This research develops and evaluates five predictive $\delta^{18} \mathrm{O}_{\mathrm{ppt}}$ models that provide estimates of the average annual and seasonal compositions of Canadian $\delta^{18} \mathrm{O}_{\mathrm{ppt}}$ using a combination of geographical and climatological parameters. The statistics describing the model-data comparisons show satisfactory model results for annual, spring, summer and fall models. Winter 


\section{Chapter 3}

$\delta^{18} \mathrm{O}_{\mathrm{ppt}}$ predictions, however, show significantly lower adjusted $\mathrm{R}^{2}$ and higher residual variances than the other seasonal models. Seasonal model results improve with the addition of climate parameters (temperature and precipitation), this finding being especially significant in the winter season. There are still aspects of model development and performance that could benefit from improvement before application in tracer-aided modelling studies. Results suggest that inclusion of additional parameters, selected to capture the influence of circulation patterns on the isotopic labeling of Canadian precipitation, may be useful for developing improved predictive $\delta^{18} \mathrm{O}_{\mathrm{ppt}}$ models suitable for finer spatial and temporal scales. Additional parameterization needs to be carefully scrutinized so as not to limit the practicality of the model in data-sparse regions.

For future studies, the Canadian domain should be separated into climate zones, and several $\delta^{18} \mathrm{O}_{\text {ppt }}$ models created; each reflecting the conditions of their respective climate zone. This methodology may strengthen the relationships between $\delta^{18} \mathrm{O}_{\mathrm{ppt}}$ and the model parameters. Additionally, the temporal resolution of $\delta^{18} \mathrm{O}_{\mathrm{ppt}}$ predictions should be refined to monthly time series compositions, if adequate correlation between $\delta^{18} \mathrm{O}_{\mathrm{ppt}}$ and predictor variables exists. Prediction of time series $\delta^{18} \mathrm{O}_{\mathrm{ppt}}$ at this temporal scale will help to capture both the intra-annual and inter-annual variability in $\delta^{18} \mathrm{O}_{\mathrm{ppt}}$ compositions that is important for hydrological modelling applications. Upon completion, the intent is to embed such models within the tracer-aided hydrological model isoWATFLOOD to enable simulations of $\delta^{18} \mathrm{O}_{\mathrm{ppt}}$ at the regional-scale, where tracer-aided modelling approaches cannot typically be used due to a lack of $\delta^{18} \mathrm{O}_{\mathrm{ppt}}$ observations for model forcing. Tracer-aided hydrological models have demonstrated effectiveness in reducing model uncertainty, producing more realistic, less uncertain, regional simulations of water fluxes and their isotopic compositions throughout the hydrologic cycle. 


\section{Chapter 3}

This study shows great promise in determining relationships to accurately predict $\delta^{18} \mathrm{O}_{\mathrm{ppt}}$ isoscapes across Canada. These new annual and seasonal maps of the distribution of $\delta^{18} \mathrm{O}_{\mathrm{ppt}}$ in Canadian precipitation provide an improved basemap for climatological, ecological, hydrological and hydrogeological studies requiring information on the long-term seasonal and annual labeling of precipitation.

\subsection{Acknowledgments}

The authors would like to thank all of the reviewers who provided their comments and insight, helping to improve this paper. This research has benefited from discussions with Dr. John Gibson, Dr. Yi Yi, and Dr. Tom Edwards. This research was funded by a University of Manitoba Graduate Scholarship, a Natural Sciences and Engineering Research Council of Canada (NSERC) Canada Graduate Scholarship, and Alberta Innovates-Technology Futures. Additional gratitude is expressed to the Canadian Network for Isotopes in Precipitation for providing the updated isotopes in precipitation data necessary to conduct this research.

\subsection{References}

Birks, S. J., and T. W. D. Edwards (2009), Atmospheric circulation controls on precipitation isotope-climate relations in western Canada, Tellus Ser. B, 61B(3), 566-576, doi: 10.1111/j.1600-0889.2009.00423.x.

Birks, S. J., and J. J. Gibson (2009), Isotope hydrology research in Canada, 2003-2007. Cdn. Water Resour. J., 34(2), 163-176, doi: 10.4296/cwrj3402163.

Birks, S. J., J. J. Gibson, L. Gourcy, P. K. Aggarwal, and T. W. D. Edwards (2002), Maps and animations offer new opportunities for studying the global water cycle, Eos Trans. AGU, 83(37), 406, doi: 10.1029/2002EO000298.

Bowen, G. J., J. R. Ehleringer, L. A. Chesson, E. Stange, and T. E. Cerling, (2007), Stable isotope ratios of tap water in the contiguous United States, Water Resour. Res., 43, W03419, doi:10.1029/2006WR005186. 


\section{Chapter 3}

Bowen, G. J., and J. Revenaugh (2003), Interpolating the isotopic composition of modern meteoric precipitation, Water Resour. Res., 39(10), 1299-1311, doi: 10.1029/2003WR002086.

Bowen, G. J., and B. H. Wilkinson (2002), Spatial distribution of $\delta 180$ in meteoric precipitation, Geology, 30(4), 315-318, doi: 10.1130/0091-7613(2002)030<0315:SDOOIM>2.0.CO;2.

Craig, H. (1961), Standard for reporting concentrations of deuterium and oxygen-18 in natural waters, Science, 133, 1833-1834, doi: 10.1126/science.133.3467.1833.

Creutin, J.D. and C. Obled (1982), Objective analysis and mapping techniques for rainfall fields: an objective comparison, Water Resour. Res., 18(2), 251-256, doi: 10.1029/WR018i002p00413.

Dansgaard, W. (1964), Stable isotopes in precipitation, Tellus, 16(4), 436-468, doi: 10.1111/j.2153-3490.1964.tb00181.x.

Dingman, S. L., (1994), Physical Hydrology, Waveland Press Inc., Long Grove.

Dutton, A. L., B. H. Wilkinson, G. Bowen, J. M. Welker, and K. C. Lohmann (2005), Comparison of river water and precipitation $\delta 180$ across the 48 contiguous United States, Hydrol. Process., 19, 3551-3572, doi: 10.1002/hyp.5876.

Environment Canada, Atmospheric Environment Service, Climate Research Branch (1998), Climate Trends and Variations Bulletin for Canada, Ottawa.

Fekete, B. M., J. J. Gibson, P. Aggarwal, C .J Vorosmarty (2006), Application of isotope tracers in continental scale hydrological modeling, J. Hydrol., 330(3-4), 444-456, doi: doi:10.1016/j.jhydrol.2006.04.029.

Gat J. R., C. J. Bowser, and C. Kendall (1994), The contribution of evaporation from the Great Lakes to the continental atmosphere: estimate based on stable isotope data, Geophys. Res. Lett., 21, 557-560, doi: 10.1029/94GL00069.

Gibson, J. J., T. W. D Edwards, S. J. Birks, N. A. St.Amour, W. M. Buhay, P. McEachern, B. B. Wolfe, and D. L. Peters (2005), Progress in isotope tracer hydrology in Canada, Hydrological Processes, 19(1), 303-327, doi: 10.1002/hyp.5766.

IAEA/WMO (2006), Global Network of Isotopes in Precipitation. The GNIP Database. Available at: http://isohis.iaea.org.

Kohn, M. J. and J. M. Welker (2005), On the temperature correlation of $\delta^{18} \mathrm{O}$ in modern precipitation, Earth and Planetary Science Letters, 231, 87-96, doi: 10.1016/j.epsl.2004.12.004.

Koster, R. D., Perry de Valpine, D., and Jouzel, J (1993), Continential water recycling and $\mathrm{H}_{2}{ }^{18} \mathrm{O}$ concentrations, Geophysical Research Letters, 20(20), 2215-2218, doi: 10.1029/93GL01781.

Lawrence, J. R. and J. W. C. White (1991), The elusive climate signal in the isotopic composition of precipitation, Stable Isotope Geochemistry: A Tribute to Samuel Epstein, 3, 169-185. 


\section{Chapter 3}

Liebminger, A., G. Haberhauer, K. Varmuza, W. Papesch, and G. Heiss (2006), Modeling the oxygen 18 concentration in precipitation with ambient climatic and geographic parameters, Geophys. Res. Lett., 33(5), doi:10.1029/2005GL025049.

Liu, Z., T. Lide, X. Chai, and T. Yao (2008), A model-based determination of spatial variation of precipitation $\delta 180$ over China, Chem. Geol., 249, 203-212, doi:10.1016/j.chemgeo.2007.12.011.

Lykoudis, S. P., A. A. Argiriou, and E. Dotsika (2010), Spatially interpolated time series of $\delta 180$ in Eastern Mediterranean precipitation, Global Planet. Change, 71, 150-159 doi: 10.1016/j.gloplacha.2009.09.004.

Machavaran M. W. And R. V. Krishnamurthy (1995), Earth surface evaporative processes: a case study from the Great Lakes region of the United States based on deuterium excess in precipitation, Geochimica et Cosmochimica Acta, 59, 4279-4283, doi: 10.1016/00167037(95)00256-Y.

Moran, T. A., S. J. Marshall, E. C. Evans, and K. E. Sinclair (2007), Altitudinal gradients of stable isotopes in lee-slope precipitation in the Canadian Rocky Mountains, Arctic Antarctic Alpine Research, 39(3), 455-467, http://www.jstor.org/stable/20181717.

Rozanski, K., L. Araguás-Araguás, and R. Gonfiantini (1993), Isotopic patterns in modem global precipitation, in: Climate Change in Continental Isotopic Records, Geophys. Monogr. Ser., vol. 78, edited by Swart, P. K. et al., pp. 1-36, AGU, Washington, D.C.

Schotterer, U., F. Oldfield, and K. Frohlich, 1996), GNIP: Global Network for Isotopes in Precipitation., Druckerei Laderach AG, Bern.

Simpkins, W. W. (1995), Isotopic composition of precipitation in central Iowa, Journal of Hydrology, 172, 185-207, doi: 10.1016/0022-1694(95)02694-K.

Stadnyk-Falcone, T. A. (2008), Mesoscale Hydrological Model Validation and Verification using Stable Water Isotopes: The isoWATFLOOD Model. Ph.D. Thesis, University of Waterloo, Waterloo, 386 pp., http://hdl.handle.net/10012/3970.

St. George, S. (2006), Hydrological dynamics in the Winnipeg River basin, Manitoba; Report of Activities 2006, Manitoba Science, Technology, Energy and Mines, Manitoba Geological Survey: 226-230.

Tabios, G. Q. and J. D. Salas (1985), A comparative analysis of techniques for spatial interpolation of precipitation, Journal of the American Water Resources Association, 21(3), 365-380, doi: 10.1111/j.1752-1688.1985.tb00147.x.

Van der Ent, R. J., H. H. G. Savenije, and B. Schaefli (2010), Origin and fate of atmospheric moisture over continents, Water Resources Research, doi:10.1029/2010WR009127.

Van der Veer, G., S. Voerkelius, G. Lorentz, G. Heiss, and J. A. Hoogewerff (2009), Spatial interpolation of the deuterium and oxygen-18 composition of global precipitation using temperature as ancillary variable, Journal of Geochemical Exploration, 101, 175-184, doi: 10.1016/j.gexplo.2008.06.008. 


\section{Chapter 3}

Yurtsever, Y. and J. R. Gat (1981), Atmospheric waters. In: Gat, J.R., Gonfiantini, R. (Eds.), Stable Isotope Hydrology: Deuterium and Oxygen-18 in the Water Cycle, International Atomic Energy Association, Vienna: 103-139.

Zhao, L., H. Xiao, M. Zhou, G. Cheng, L Wang, L. Yin, and J. Ren (2011), Factors controlling spatial and seasonal distributions of precipitation $\delta^{18} \mathrm{O}$ in China, Hydrological Processes, doi: 10.1002/hyp.8118. 


\title{
CHAPTER 4: NORTH AMERICAN PRECIPITATION ISOTOPE $\left(\delta^{18} \mathrm{O}\right)$
} ZONES REVEALED IN TIME-SERIES MODELLING ACROSS CANADA

\author{
AND NORTHERN UNITED STATES \\ ${ }^{1}$ Delavau, C., ${ }^{2}$ Chun, K.P., ${ }^{1}$ Stadnyk, T., ${ }^{3}$ Birks, S.J., and ${ }^{4}$ Welker, J.M. \\ ${ }^{1}$ University of Manitoba, Department of Civil Engineering (Water Resources), Winnipeg, MB, Canada. \\ ${ }^{2}$ Global Institute for Water Security, University of Saskatchewan, Saskatoon, SK, Canada. \\ ${ }^{3}$ Alberta Innovates- Technology Futures, Calgary, AB, Canada. \\ ${ }^{4}$ University of Alaska Anchorage, Anchorage, AK, United States of America.
}

Published in 2015 in Water Resources Research (doi: 10.1002/2014WR015687).

Received April 8, 2014; accepted January 22, 2015; published online January 28, 2015.

This chapter investigates the predictability of monthly time series $\delta^{18} \mathrm{O}_{\mathrm{ppt}}$ by creating a suite of multivariate regression models using re-analysis climate data, geographic information and teleconnection indices. The effect of regionalization on model performance and model structure uncertainty is explored. Both time series monthly $\delta^{18} \mathrm{O}_{\mathrm{ppt}}$ simulations (and uncertainty bounds) at select locations and long-term annual average maps of $\delta^{18} \mathrm{O}_{\mathrm{ppt}}$ for the study domain are developed and analyzed. 


\section{Chapter 4}

\subsection{Abstract}

Delineating spatial patterns of precipitation isotopes ("isoscapes") is becoming increasingly important to understand the processes governing the modern water isotope cycle and their application to migration forensics, climate proxy interpretation, and hydrology of terrestrial systems. However, the extent to which these patterns can be empirically predicted across Canada and the United States of America (USA) has not been fully articulated, in part due to a lack of time-series precipitation isotope data for major regions of North America. In this study, we use multiple linear regressions of CNIP, GNIP and USNIP observations alongside climatological variables, teleconnection indices, and geographic indicators to create empirical models that predict the $\delta^{18} \mathrm{O}$ of monthly precipitation $\left(\delta^{18} \mathrm{O}_{\mathrm{ppt}}\right)$ across Canada and the northern USA. Five regionalization approaches are used to separate the study domain into isotope zones to explore the effect of spatial grouping on model performance. Stepwise regression-derived parameterizations quantified by permutation testing indicate the significance of precipitable water content and latitude as predictor variables. Within the Canadian Arctic and eastern portion of the study domain, models from all regionalizations capture the inter- and intra-annual variability of $\delta^{18} \mathrm{O}_{\mathrm{ppt}}$. The Pacific coast and northwestern portions of the study domain show less agreement between models and poorer model performance, resulting in higher uncertainty in simulations throughout these regions. Long-term annual average $\delta^{18} \mathrm{O}_{\mathrm{ppt}}$ isoscapes are generated, highlighting the uncertainty in regionalization as it compounds over time. Additionally, monthly time-series simulations are presented at various locations, and model structure uncertainty and $90 \%$ bootstrapped prediction bounds are detailed for these predictions. 


\section{Chapter 4}

\subsection{Introduction}

Precipitation isotopes $\left(\delta^{18} \mathrm{O}\right.$ and $\left.\delta^{2} \mathrm{H}\right)$ are natural tracers providing diverse attributes for understanding processes characterizing the water cycle at local, regional and continental scales. This understanding is of paramount importance today as water resources provide the basis of rural and urban community sustainability, commercial industries, and the delivery of essential ecosystem services. While precipitation amounts and patterns are relatively well quantified, it is only over the last 25 years that we have begun to rigorously explore the spatial patterns of water cycle isotopes at the continental and global scales (Rozanski et al., 1993; Welker, 2000; 2012; Dutton et al., 2005; Birks and Edwards, 2009; Vachon et al., 2010a; Liu et al., 2013). Woven into these spatial pattern analyses- termed 'isoscapes'- is now the ability to resolve processes and mechanisms that may be controlling the temporal variability in water cycle isotopes such as moisture source and climate conditions along the rainout trajectory (Rozanski et al., 1992; Birks and Edwards, 2009; Liu et al., 2010; Vachon et al., 2010b; Welker, 2012).

Past efforts to predict oxygen-18 and deuterium distributions in precipitation $\left(\delta^{18} \mathrm{O}_{\mathrm{ppt}} / \delta^{2} \mathrm{H}_{\mathrm{ppt}}\right)$ have typically focused on creating isoscapes of long-term annual or seasonal averages at both the global scale (Birks et al., 2002; Bowen and Wilkinson, 2002; Bowen and Revenaugh, 2003) and regional/continental scale for the United States (Dutton et al., 2005; Welker, 2012) and China (Liu et al., 2008) utilizing a coupled regression and geostatistical modelling approach. These initial studies placed high importance on geographical parameters (elevation and latitude) as proxies for more physically-based parameters to approximate Rayleigh distillation (i.e., the amount of temperature-dependent rainout that occurs as an air mass is transported to locations of higher latitude and/or elevation without any secondary processes) (Dansgaard, 1964). More 


\section{CHAPTER 4}

recent studies have begun incorporating climate parameters within the prediction models at the regional scale for Austria (Liebminger et al., 2006), the eastern Mediterranean (Lykoudis and Argiriou, 2007; Lykoudis et al., 2010), China (Zhao et al., 2011), Ireland (Fischer and Baldini, 2011), and Canada (Delavau et al., 2011); and at the global scale (van der Veer et al., 2009; Terzer et al., 2013). While these approaches have provided useful depictions of long-term annual and seasonal averages for many regions, most of these estimates are not suitable for predicting precipitation isotope compositions on the time-scale necessary for many hydrological applications, such as tracer-aided hydrological modelling, where a temporal frequency of monthly time-series (or finer) compositions are required for model forcing (Stadnyk et al., 2013).

This study focuses on the creation of time-series $\delta^{18} \mathrm{O}_{\mathrm{ppt}}$ predictions at a monthly temporal frequency across Canada and the northern United States of America (USA). The objectives of this study are to: (1) quantify the degree to which empirical models utilizing climate and geographic parameters capture the variability in monthly time-series $\delta^{18} \mathrm{O}_{\mathrm{ppt}}$ observations across the study domain and, (2) provide an estimate of uncertainty associated with the empirical simulations that reflects the boundaries of expected seasonal variation. Establishing this knowledge is essential for future applications in coupled tracer-aided modelling, where isoscapes provide the basis for modelling applications (specifically in ungauged or sparsely gauged locations, such as most of northern Canada) and input uncertainty is propagated into hydrological model output. 


\section{Chapter 4}

\subsection{Data and Methods}

\subsubsection{Observations and Gridded Products}

Oxygen-18 in precipitation is used as the dependent variable for model development in this study. Three data networks provide $\delta^{18} \mathrm{O}_{\mathrm{ppt}}$ measurements for this research: the Canadian Network for Isotopes in Precipitation (CNIP) (Birks and Gibson, 2009), the United States Network for Isotopes in Precipitation (USNIP) (Welker, 2000; 2012) and the Global Network for Isotopes in Precipitation (GNIP), coordinated by the International Atomic Energy Agency/World Meteorological Organization (IAEA/WMO) (Aggarwal et al., 2011; IAEA/WMO, 2014). Canadian precipitation samples are collected at a monthly frequency by the CNIP and GNIP networks, with the exception of the supplementary Calgary record which is taken from Peng et al. (2004). Calgary $\delta^{18} \mathrm{O}_{\mathrm{ppt}}$ observations are obtained from short-term sampling (0.5-3 days) and are amount-weighted to monthly compositions for direct comparison to CNIP and GNIP measurements utilizing the following formula:

$\delta^{18} O_{\text {ppt monthly }}=\sum P_{i} *\left(\delta^{18} O_{p p t}\right)_{i} / \sum P_{i}$

(Equation 13)

$P_{i}$ is the amount of each individual precipitation sample. Weekly precipitation composites are collected throughout the northern tier of the USA at the 27 USNIP sites included in this study (Welker, 2000; 2012; Dutton et al., 2005; Vachon et al., 2007). Utilizing the precipitation amount-weighting approach outlined in Equation 13, weekly USNIP $\delta^{18} \mathrm{O}_{\mathrm{ppt}}$ compositions are amount-weighted to monthly composites utilizing precipitation data obtained from the NTN (National Trends Network) Branch of the NADP (North America Deposition Program) (nadp.sws.uiuc.edu). Figure 16 depicts the temporal distribution of the CNIP/GNIP (stations 1 to 36) and USNIP (stations 37 to 63) observations at each station. Figure $17 \mathrm{~d}$ displays the stations 


\section{Chapter 4}

spatially across the study domain. The supplementary material for this study (Appendix A) summarizes the station name, location, years, and number of monthly measurements at each station.

Figure 16: Distribution of CNIP/GNIP and USNIP monthly $\delta^{18} O_{p p t}$ compositions at each station. Number of monthly observations within each decade is specified.

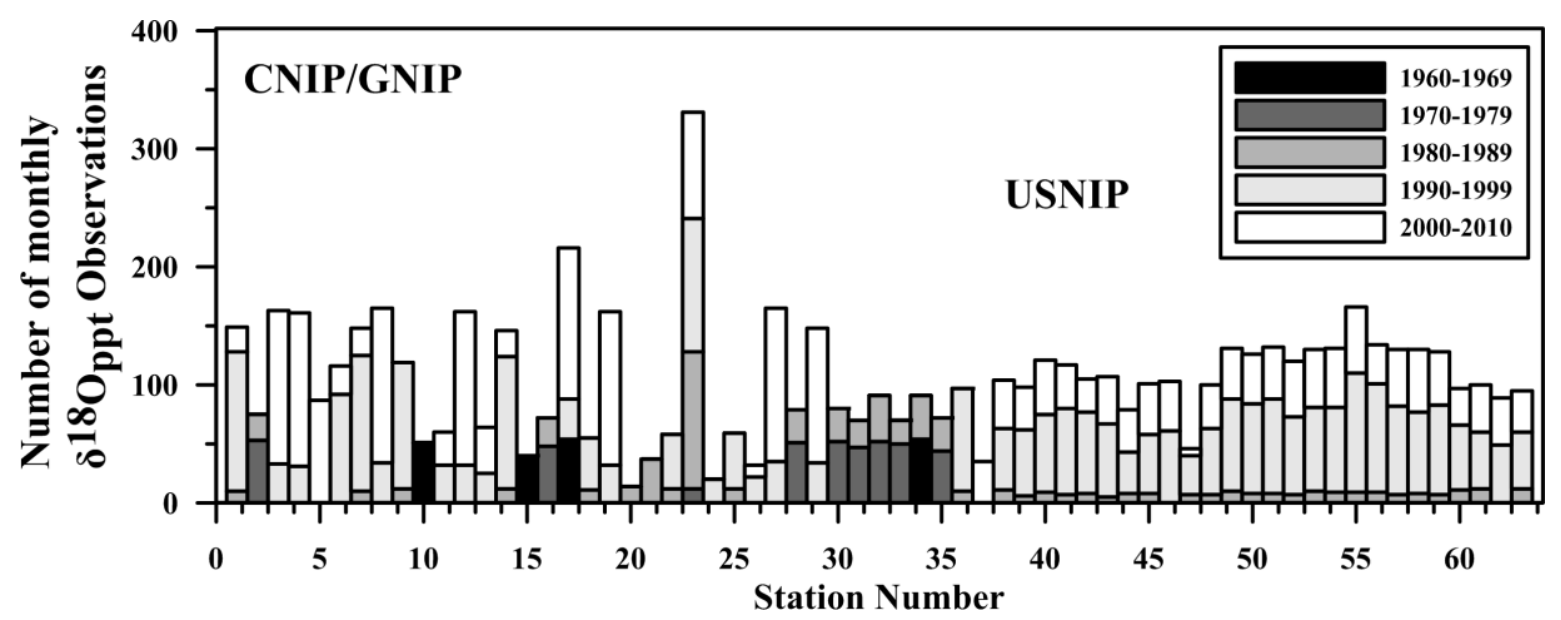

On average, the CNIP/GNIP and USNIP networks have a similar number of monthly observations per station (CNIP/GNIP: n 107; USNIP: $\mathrm{n} \sim 109$ ). However, USNIP measurements are more uniformly distributed between stations in comparison to CNIP/GNIP measurements, which overall have more variability in their temporal distribution, ranging from $n=14$ monthly compositions at Inuvik (station 20), to $\mathrm{n}=331$ at Ottawa (station 23) (Figure 16). USNIP observations used in this study consistently begin in 1989 and conclude in 2004; whereas CNIP and GNIP observations are collected between the years of 1961 to 2010, with minimal consistency in the period of record between stations. These temporal and spatial discontinuities in $\delta^{18} \mathrm{O}_{\mathrm{ppt}}$ records may negatively affect model development, potentially biasing model parameters in data-sparse regions, such as northern Canada and Alaska. Pre-1979 observations are excluded due to the lack of North American Regional Reanalysis (NARR) climate data for this time period, resulting in over $6000 \delta^{18} \mathrm{O}_{\mathrm{ppt}}$ observations for use in this modelling study. 


\section{Chapter 4}

\subsubsection{Climate and Geographic Data}

To approximate $\delta^{18} \mathrm{O}_{\mathrm{ppt}}$ time-series for a region as large and climatically diverse as Canada and the northern USA, parameters with the ability to capture the multitude of factors contributing to $\delta^{18} \mathrm{O}_{\mathrm{ppt}}$ variability across the study domain need to be incorporated into the modelling framework. The variables included in this approach (Table 9) are selected based on this goal.

The climate data in this study are from the National Centers for Environmental Prediction (NCEP) NARR dataset. NARR is a long-term atmospheric and land surface hydrology reanalysis dataset spanning the North American domain (Mesigner et al., 2006). NARR utilizes lateral boundary conditions from the NCEP-DOE (Department of Energy) Global Reanalysis and makes use of the data assimilation system from the NCEP Eta Model. This dataset is available from 1979 to 2003, and is continued post-2003 as the Regional Climate Data Assimilation system (RCDAS). NARR has a spatial resolution of $32 \mathrm{~km}$, and utilizes 45 layers in the vertical. For this study, monthly time series of selected climate variables (Table 9) are extracted from the NARR grid cell closest to each CNIP/GNIP or USNIP measurement location. Total precipitation, convective precipitation, total evaporation and precipitable water variables are converted to monthly totals from monthly averages.

In addition to the 14 NARR climate variables, three geographic indicators and six teleconnection indices are incorporated as potential predictors within the models (Table 9). Teleconnection indices are obtained from the National Oceanic and Atmospheric Administration (NOAA) and University of Washington's Joint Institute for the Study of the Atmosphere and Ocean (JISAO). Finally, sine and cosine curves with one complete cycle per year are used as a smoothing 


\section{Chapter 4}

function of time (i.e., "dummy variables") to account for seasonal effects that may not be captured by the aforementioned predictors (Peng and Dominici, 2008; Chun, 2010).

Table 9: Variables included in regression model development.

\begin{tabular}{|c|c|c|c|}
\hline Variable ID & Description & Frequency & Source \\
\hline \multicolumn{4}{|c|}{ Climate Variables } \\
\hline apcp & Accumulated total precipitation & Monthly total & NARR \\
\hline cape & Convective available potential energy & Monthly average & NARR \\
\hline cdcon & Mean of convective cloud cover & Monthly average & NARR \\
\hline cdlyr & Mean of nonconvective cloud cover & Monthly average & NARR \\
\hline evap & Accumulated total evaporation & Monthly total & NARR \\
\hline hodc & High cloud area fraction & Monthly average & NARR \\
\hline hpbl & Planetary boundary layer height & Monthly average & NARR \\
\hline mcdc & Mean cloud area fraction & Monthly average & NARR \\
\hline prwtr & Precipitable water for entire atmosphere & Monthly total & NARR \\
\hline rhum $2 \mathrm{~m}$ & Relative humidity at $2 \mathrm{~m}$ & Monthly average & NARR \\
\hline uwnd $10 \mathrm{~m}$ & U-wind at $10 \mathrm{~m}$ (zonal) & Monthly average & NARR \\
\hline vwnd $10 \mathrm{~m}$ & V-wind at $10 \mathrm{~m}$ (meridional) & Monthly average & NARR \\
\hline wcconv & Water condensate flux convergence & Monthly average & NARR \\
\hline wcvflx & Water condensate meridional flux convergence & Monthly average & NARR \\
\hline \multicolumn{4}{|c|}{ Teleconnection Indices } \\
\hline AMO & Atlantic Multidecadal oscillation & Monthly & NOAA \\
\hline $\mathrm{AO}$ & Arctic oscillation & Monthly & NOAA \\
\hline NAO & North Atlantic oscillation & Monthly & NOAA \\
\hline PDO & Pacific decadal oscillation & Monthly & JISAO \\
\hline PNA & Pacific North American pattern & Monthly & NOAA \\
\hline sol & El Nino/La Nina (Southern oscillation index) & Monthly & NOAA \\
\hline \multicolumn{4}{|c|}{ Geographic Variables } \\
\hline LAT & Latitude & N/A & CNIP/GNIP/USNIP \\
\hline LONG & Longitude & N/A & CNIP/GNIP/USNIP \\
\hline ALT & Altitude (elevation) & N/A & CNIP/GNIP/USNIP \\
\hline \multicolumn{4}{|c|}{ Dummy Variables } \\
\hline SIN & Sine function & Monthly & $\mathrm{N} / \mathrm{A}$ \\
\hline $\cos$ & Cosine function & Monthly & $\mathrm{N} / \mathrm{A}$ \\
\hline
\end{tabular}

\subsection{Model Regionalization}

Pooling information from nearby locations within a region can be useful due to the similarity of processes and mechanisms controlling the variability in $\delta^{18} \mathrm{O}_{\mathrm{ppt}}$. Given the large geographic area and diverse climate conditions and moisture sources (e.g. Pacific Ocean, Gulf of Mexico, Arctic, recycled continental moisture) present across northern North America, a single empirical relationship may not be universally applicable throughout the entire study domain. Our hypothesis is that empirical models for predicting monthly time-series of precipitation $\delta^{18} \mathrm{O}$ may 


\section{Chapter 4}

be improved if they are developed specifically for individual "isotope zones". By identifying isotope zones based on well-established meteorological and climatological zones where moisture sources and hydroclimate parameters are likely more similar, we hope to improve our ability to understand the physical parameters controlling isotopic labelling in different regions as well as improve predictions of $\delta^{18} \mathrm{O}$ time-series. For these reasons, five different regionalization approaches (three of which are based on established classification schemes) are used to separate the study domain into isotope zones to explore the effect of regionalization on model performance and to investigate the outcome of regionalization on model structure uncertainty (i.e., selection of predictor variables). Isotope zones are displayed on Figure 17, whereby $\delta^{18} \mathrm{O}_{\mathrm{ppt}}$ observations from stations within the boundaries of each zone are used to create a set of seasonal empirical models for that specific zone.

The Synoptic Scale Classification (SSC) (Kalkstein et al., 1996; Sheridan, 2002) (S. Sheridan, available at http://sheridan.geog.kent.edu/ssc.html) system is a hybrid system, and therefore uses both manual and automated methods to classify daily weather conditions into one of six different weather types, or a transition between weather types, at a station by station basis across the North American continent. Classification is solely based on surface observations at individual stations (including temperature, dew point, wind, pressure and cloud cover). Since the SSC does not incorporate any upper-level conditions or air mass source, the SSC is primarily a weather type classification system and not an air mass classification system. SSC climate zones are created based on principal component analysis (PCA) decomposition of seasonal normals and a k-means cluster analysis. Canada is separated into five zones, Arctic (SSC4), Boreal Coast (SSC6), 


\section{Chapter 4}

Marine (SSC8), Laurentian (SSC3a- herein referred to as SSC31), and Northern Rockies (SSC3b- herein referred to as SSC32) (Figure 17a).

Figure 17: Study domain regionalization into isotope zones: (a) SSC, (b) Kpn, (c) RCWIP, and (d) 2-Zone. The CNIP, GNIP and USNIP stations included in each zone are indicated, alongside the number of years of data at each station, represented by the magnitude of the symbol.
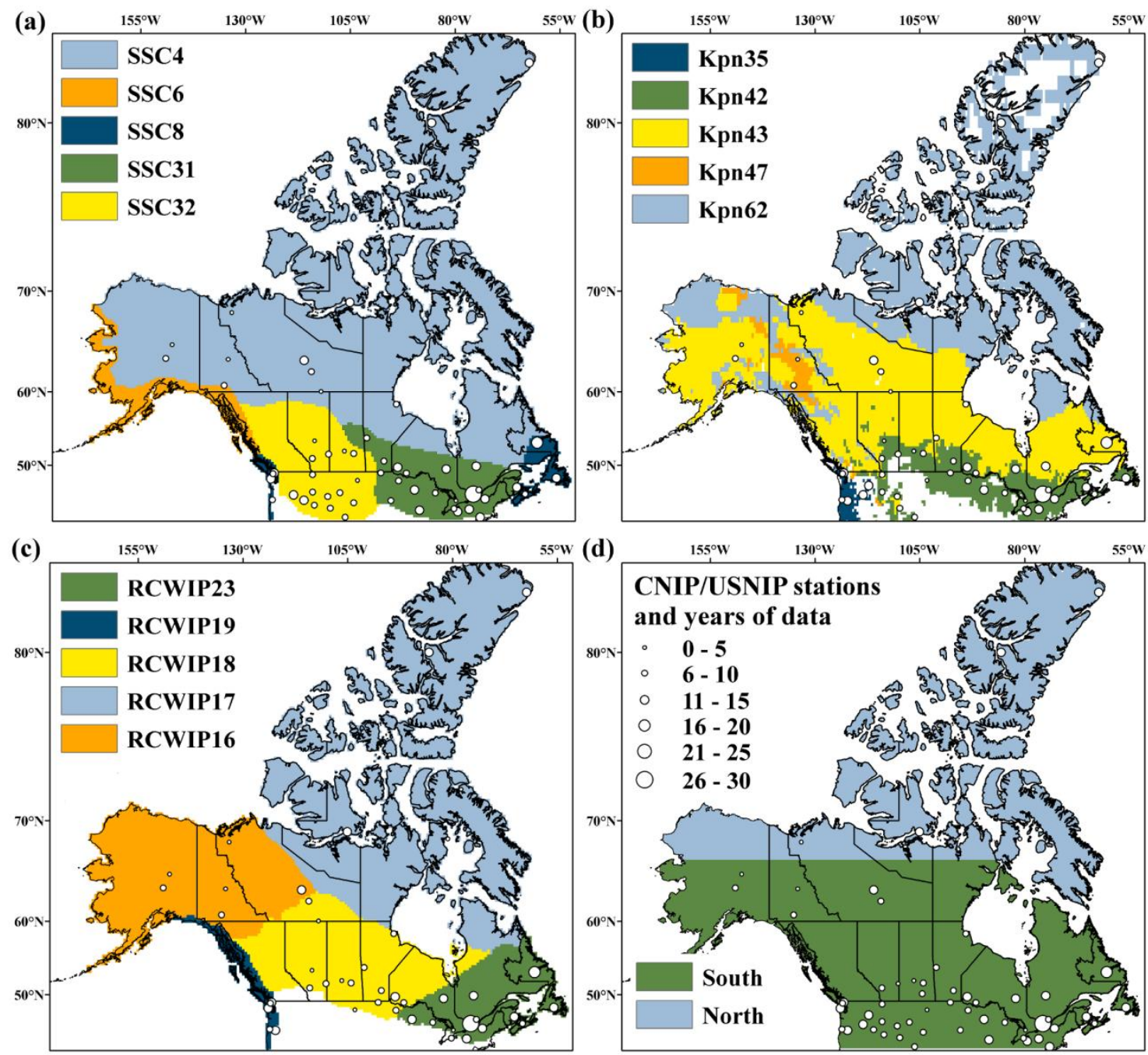

The Köppen-Geiger (Kpn) climate classification system is the most commonly used global climate classification. The historical world map of Köppen-Geiger climate classes was recently updated utilizing global data sets of monthly temperature and precipitation observations covering the 50-year period of 1951 to 2000 (Kottek et al., 2006). The Köppen-Geiger classification labels zones across the globe by a three letter name, indicating the main climate, precipitation type, and 


\section{Chapter 4}

air temperature, respectively. Ten Köppen-Geiger climate zones exist within Canada, whereby CNIP stations are situated within five of these zones representing approximately $97 \%$ of the Canadian land mass (Figure 17b): Kpn35 (Csb- warm temperate, steppe precipitation, warm summer), Kpn42 (Dfb- snow, fully humid precipitation, warm summer), Kpn43 (Dfc- snow, fully humid precipitation, cool summer), Kpn47 (Dsc- snow, steppe precipitation, cool summer), and Kpn62 (ET- polar tundra).

The third classification system is the Regionalized Climatic Water Isotope Prediction (RCWIP) approach (Terzer et al., 2013). RCWIP utilizes weighted fuzzy clustering techniques (including fuzzy c-means) to build climate clusters from Global Historical Climate Network (GHCN) records, incorporating normalized climatic variables of monthly mean temperature and precipitation and spatial variables (latitude and longitude), resulting in 36 climatic clusters across the globe. Six of the 36 clusters encompass the Canadian domain, with $\delta^{18} \mathrm{O}_{\mathrm{ppt}}$ collection stations located within five of the six: RCWIP16 (Dfc), RCWIP17 (ET), RCWIP18 (Dfb), RCWIP19 (Cfb - warm temperate, fully humid precipitation, warm summer) and RCWIP23 (Dfb) (Figure 17c). This approach utilizes the CNIP, GNIP and USNIP measurements within the aforementioned five climate clusters, resulting in an enhanced data set used for the current regionalization relative to the RCWIP study.

The final two classification systems represent more simplified regionalization approaches. The 2Zone classification scheme separates the study domain into north and south zones, with the border between zones located at the Arctic Circle (Figure 17d). The 1-Zone regionalization (not 


\section{Chapter 4}

shown) is the most simplistic approach, whereby no regionalization occurs, and all available $\delta^{18} \mathrm{O}_{\mathrm{ppt}}$ data are utilized in model development, excluding those set aside for validation purposes.

\subsection{Regression Model Development}

The general approach to developing regression models capable of predicting time-series of $\delta^{18} \mathrm{O}_{\mathrm{ppt}}$ for each of the regionalization schemes includes a statistical evaluation of which parameters to include, an examination of the regression diagnostics to assess model deficiencies (e.g. collinearity, autocorrelation, etc.) and quantification of the model uncertainty.

A multiple linear regression approach is utilized to create the empirical models in this study. The general expression of the ordinary least-squares (OLS) regression model of precipitation oxygen18 compositions is:

$\delta^{18} O_{p p t}=X \beta+\varepsilon$

(Equation 14)

$X$ is a matrix of regression variables which can be NARR climate variables, geographical variables, or teleconnection indices, $\beta$ is the regression coefficient array, and $\varepsilon$ represents the regression residuals. Prior to model creation, the relationship between potential predictors (Table 9) and $\delta^{18} \mathrm{O}_{\mathrm{ppt}}$ is assessed through OLS regression, and variables are natural-log transformed if necessary to linearize relationships. Additionally, data are standardized to assist with numerical stability. Seasonal models are created for each zone within the five regionalizations. A season is defined as: winter, December-January-February (DJF); spring, March-April-May (MAM); summer, June-July-August (JJA); and fall, September-October-November (SON). The SSC6 and Kpn47 isotope zones only include 34 and 69 observations for model calibration, respectively. For this reason annual models are utilized within these zones to ensure adequate data for model 


\section{Chapter 4}

development. This methodology results in a total of 66 empirical models for evaluation. A split sample calibration and validation modelling approach is utilized, whereby a portion of the $\delta^{18} \mathrm{O}_{\mathrm{ppt}}$ observations are removed from the dataset to serve as a separate validation dataset. Based on spatial and temporal data availability, the years 1982, 1985, and 2000 are selected to serve as a portion of the validation subset. Using three random discrete years instead of three consecutive years can help to alleviate the autocorrelation problem due to low frequency oscillations (e.g. PDO) which cause decadal dry or wet periods. Using a consecutive period (either dry or wet) for validation or calibration will introduce bias into the parameters. The remainder of the validation dataset comprises four additional USNIP stations from the various isotope zones (station numbers $37,47,52$ and 55), resulting in approximately $14.3 \%$ of the $\delta^{18} \mathrm{O}_{\mathrm{ppt}}$ observations for validation and $85.7 \%$ for calibration, on average. The regression models utilize all $\delta^{18} \mathrm{O}_{\mathrm{ppt}}$ observations within a specified zone as either calibration or validation data for model development. The amount of measurements for calibration and validation within each model is provided in the supplementary material (Appendix A).

\subsubsection{Parameter Selection}

Selection of the climate variables, teleconnection indices and geographical parameters to include in each of the models is made using a stepwise regression approach in Matlab software (The Mathworks Inc., 2013). This approach utilizes forward and backward stepwise regression to add or remove predictor variables from the regression models. The advantage of this method is it allows flexibility in selecting the criterion and threshold to add or remove terms from the model. The Akaike Information Criteria (AIC) (Akaike, 1974) is used for this application, and is defined as: 


\section{Chapter 4}

$A I C_{i}=-2 \log \left(L_{i}\right)+2\left(V_{i}\right)$

(Equation 15)

$L_{i}$ is the $\log$ likelihood for model $i$, with $V_{i}$ free parameters. Smaller values of the AIC indicate a better model fit. Addition of parameters to the model is an iterative procedure by changing the AIC threshold, and assessing if the retained parameters are statistically significant and free of multicollinearity issues. Statistical significance is assessed by permutation tests (Good, 2005) conducted in the R-software lmPerm package (Wheeler, 2010), the results of which are used as a guide to remove insignificant parameters. Permutation tests are selected as they are nonparametric and therefore make no assumptions of the underlying distribution of the model residuals. It should be noted that quadratic terms and interaction between terms are considered within the models included in this study.

\subsubsection{Regression Diagnostics}

Regression diagnostics are used to evaluate whether the assumptions regarding the dependent and independent variables and modelled residuals are valid, and to diagnose model deficiencies. The presence of multicollinearity is assessed through calculation of Variance Inflation Factors (VIFs). VIFs greater than five suggest that multicollinearity is present and are further investigated. Normally distributed model residuals are required to satisfy model assumptions, specifically with respect to hypothesis testing and calculation of confidence intervals for slope coefficients or prediction intervals for individual $\delta^{18} \mathrm{O}_{\mathrm{ppt}}$. Although we have taken steps to utilize non-parametric approaches, normality is still assessed qualitatively through box plots or quantilequantile (QQ) plots of the residuals, alongside utilization of the Lilliefors test for normality (Lilliefors, 1967). Homoskedasticity is graphically evaluated through plots of residuals versus predicted $\delta^{18} \mathrm{O}_{\mathrm{ppt}}$. 


\section{Chapter 4}

Another assumption of OLS regression is independence of the residuals. Provided that we are working with spatio-temporal data, this assumption is thoroughly examined. To investigate if the models display serial correlation, the autocorrelation function (ACF) is calculated for lag values from 0 to 20 and tested against standard-error bands for white noise at each sampling station. Additionally, plots of model residuals versus time are examined at each measurement location, and the Durbin-Watson statistic (Durbin and Watson, 1951) is calculated and compared with published Durbin-Watson significance tables as a check. The second aspect of independence involves assessing the existence of spatial correlation. Semivariograms of model residuals (not shown) are plotted to identify the critical distance that is influenced by spatial correlations. Overall, we do not see significant spatial or temporal correlation in model residuals. The distances between stations are generally larger than the de-correlation distance.

\subsubsection{Uncertainty Quantification}

For time-series simulations, a bootstrapping approach (Davison and Hinkley, 1997) is utilized to quantify uncertainty of model predictions. Ninety percent prediction intervals are created by estimating the distribution of the prediction error:

$\delta^{*}=x_{+}^{T} \hat{\beta}^{*}-\left(x_{+}^{T} \hat{\beta}+\varepsilon_{+}^{T}\right)$

(Equation 16)

$x_{+}^{T}$ is the explanatory variable matrix, $\hat{\beta}^{*}$ is the simulated vector of parameter estimates from the model based resampling algorithm, $\hat{\beta}$ is the ordinary least squares estimates of the parameter vector, and $\varepsilon_{+}^{T}$ is the vector of prediction errors from the resampled model, which are sampled from $\hat{G}$, the empirical distribution function of the centered modified residuals, $r_{i}-\bar{r}$. Modified residuals are calculated as follows: 


\section{ChAPTER 4}

$r_{i}=e^{e_{i}} /\left(1-h_{i}\right)^{1 / 2}$

(Equation 17)

$e_{i}$ are the raw residuals form the regression model and $h_{i}$ are the respective leverages. The exact quantiles are estimated by sampling the empirical quantiles of ranked $\delta^{*} s$. This estimated distribution is generated from 1000 iterations of the resampling algorithm for each point in time and space where a prediction is required. This approach is applied to each of the five regionalization schemes, and the uncertainty due to model structure (i.e., method of regionalization) is also quantified.

\subsection{Results and Discussion}

\subsubsection{Model Performance, Parameterization, and Diagnostics}

Results are summarized for the 66 models created within this study and are outlined in the following section. Figure 18 shows the average number of parameters retained within each zone, and provides a seasonal analysis of significant parameters for the prediction of $\delta^{18} \mathrm{O}_{\mathrm{ppt}}$. "Combined" box and whisker plots of the model residuals (Figure 19) display model performance within each zone. Additionally, due to the differing number of observations incorporated within each model, performance for each regionalization scheme is evaluated station by station through the mean squared error (MSE), residual excess kurtosis, and residual inter quartile range (IQR) (Figure 20) to more directly compare model results. The combined box and whisker plots on Figure 19 display the calibration (Figure 19a) and validation (Figure 19b) residuals from all seasons for each zone within a regionalization. Residuals greater than $1.5 * \mathrm{IQR}$ are classified as possible outliers (hollow diamond symbols), and residuals greater than 3.0*IQR 


\section{Chapter 4}

are classified as outliers (red filled diamond symbols). The IQR for each regionalization is indicated to the direct right of each box.

Figure 18: (a) Average number of parameters retained within each model, and (b) overall seasonal parameter retention frequency for all models.
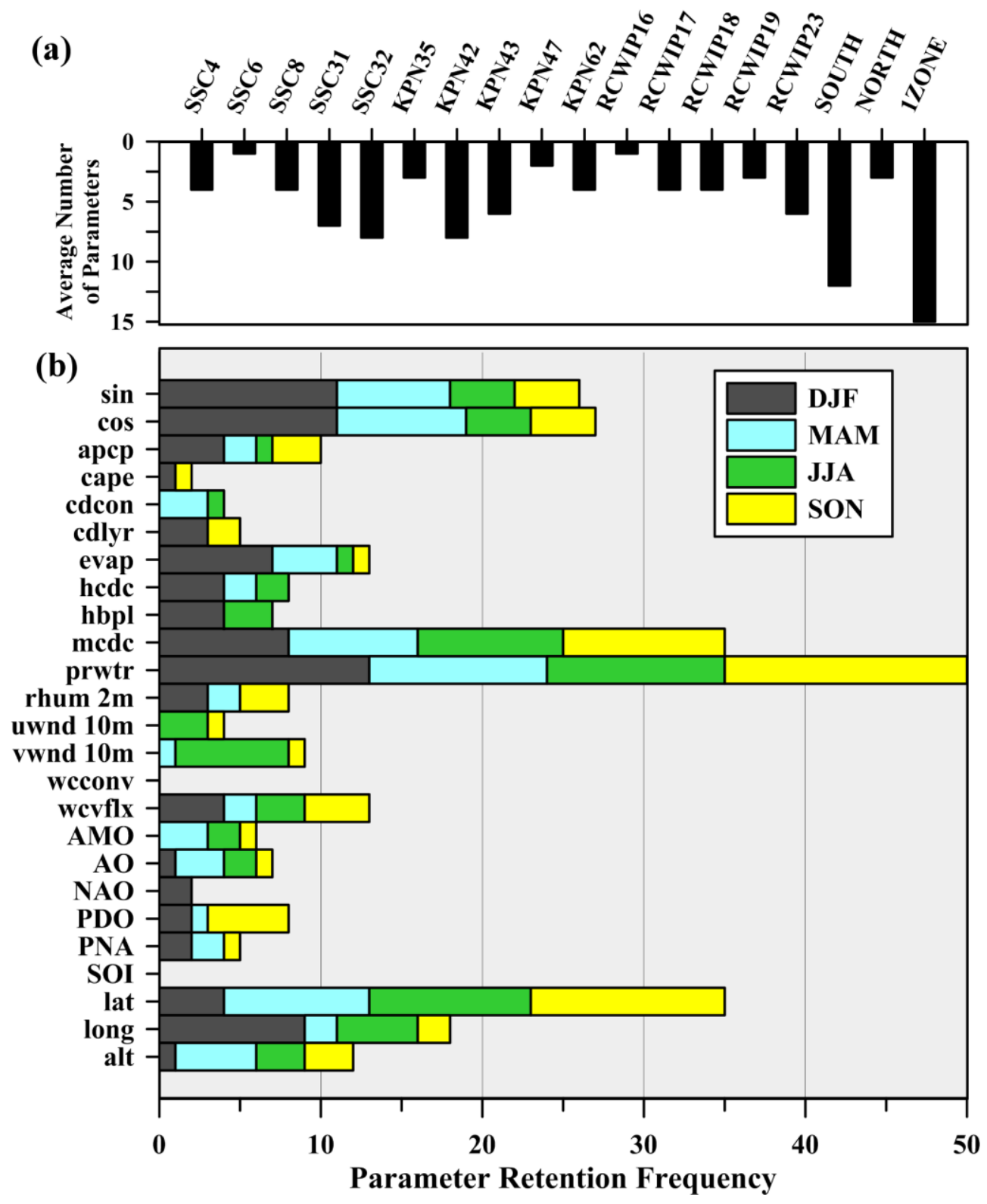


\section{Chapter 4}

Figure 19: Residual box and whisker plots for the (a) calibration and (b) validation subsets of each regionalization.

(a)

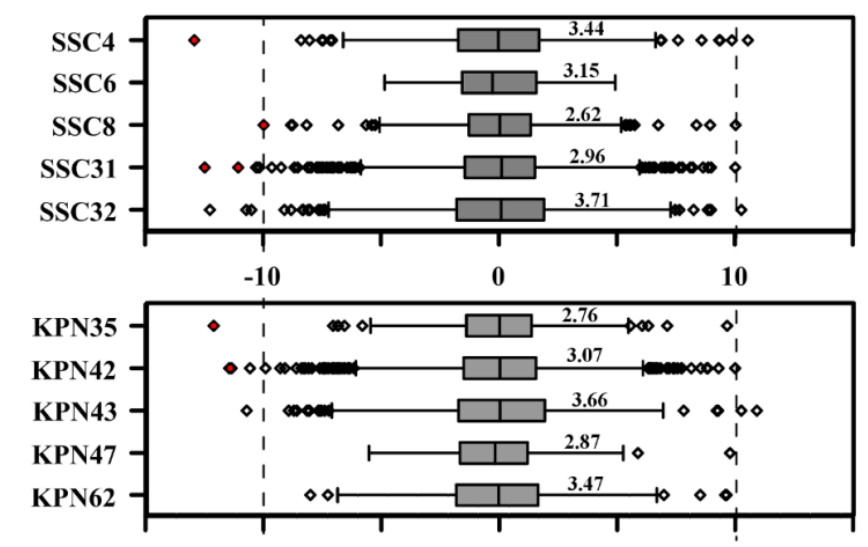

$\begin{array}{lll}-10 & 0 & 10\end{array}$

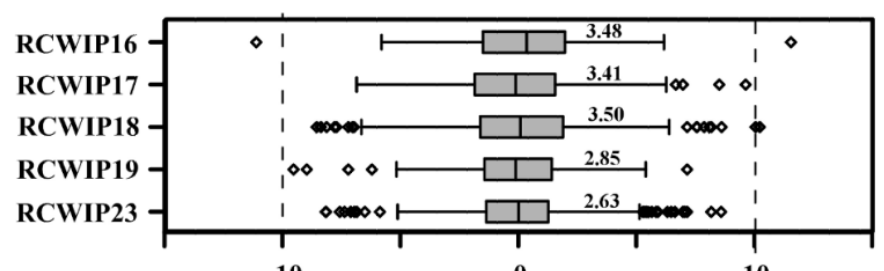

$-10$

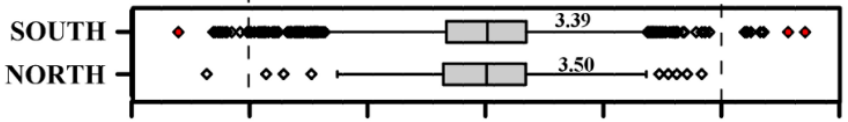

$-10$

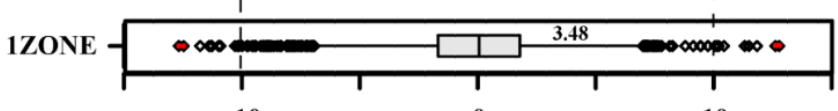

$-10$
10

Calibration Residuals (\%) (b)

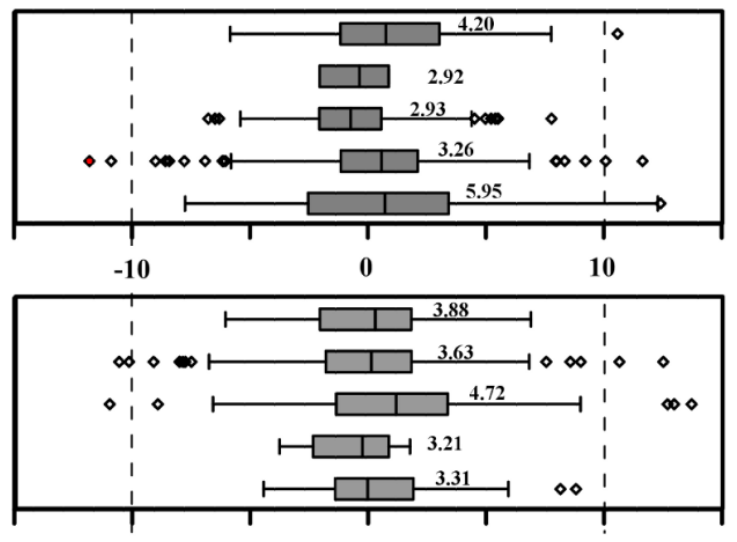

$\begin{array}{lll}-10 & 0 & 10\end{array}$

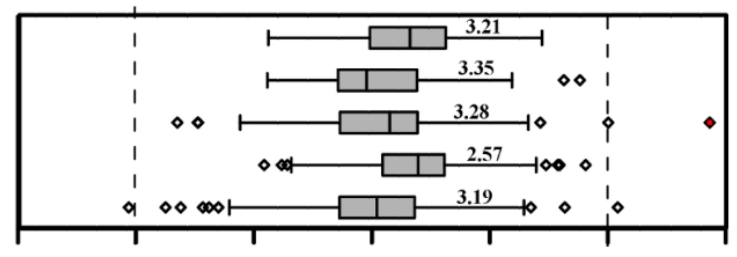

$\begin{array}{rrr}-10 & 0 & 10\end{array}$

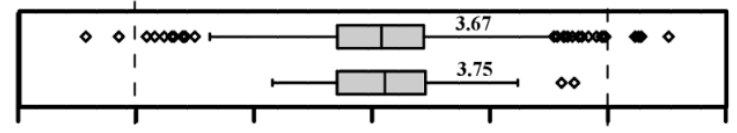

$-10$

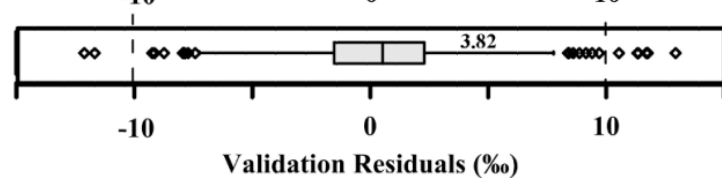

Stepwise regression derived parameterizations (Figure 18) indicate the importance of several variables that repeatedly survive the selection procedure. The most frequently retained climate predictor variable is precipitable water content, followed by mean cloud area fraction, evaporation, and water condensate meridional flux convergence. Although not temporally variant, geographic parameters explain enough variance in monthly time-series $\delta^{18} \mathrm{O}_{\mathrm{ppt}}$ to be retained in a large portion of the empirical models, specifically the latitude and longitude predictors. Latitude and precipitable water account for the largest components of the variance in simulated $\delta^{18} \mathrm{O}_{\mathrm{ppt}}$, which is not surprising, since many of the "effects" described by Dansgaard, (1964) (e.g. temperature effect, altitude effect, continental effect) are derived from the amount of 


\section{Chapter 4}

precipitable water present in an air mass. Other studies have also found strong linkages between $\delta^{18} \mathrm{O}_{\mathrm{ppt}}$ and precipitable water content (e.g. Araguás-Araguás et al., 2000) and atmospheric moisture residence time (Aggarwal et al., 2012). This relationship between precipitable water content and $\delta^{18} \mathrm{O}_{\mathrm{ppt}}$ appears to strengthen in high latitude regions (i.e., SSC4, KPN62, RCWIP17, and NORTH models) as this variable is retained in 100 percent of northern models (16/16), while the number of other parameters remains relatively low (on average, less than three additional parameters per model in this region).

The prediction of $\delta^{18} \mathrm{O}_{\mathrm{ppt}}$ becomes increasingly complex within lower latitude continental zones, where the correlation with precipitable water is still prominent, however is confounded by additional effects, such as recycling of water from evaporating Great Lakes (Gat et al., 1994), and transpiration of meteoric water from soils into the atmosphere (Yakir and Sternberg, 2000), resulting in an increased variety and number of parameters retained in the models within these central Canadian/USA regions (SSC31/32, KPN42/43, RCWIP23 and SOUTH models). Although model parameterizations become increasingly complex in these regions, overall model performance within the southeastern region (SSC31, Kpn42, and RCWIP23) is consistently strong, with relatively low IQR compared to other zones (ranging from 2.63 to 3.07). Southcentral and western regions (SSC32, Kpn43, RCWIP18) also display a high parameter retention rate (on average, six parameters retained per model), however, show relatively poorer simulation statistics (IQR's range from 3.50 to 3.71 ), potentially indicating more complex isotope-climate relations within these regions. Both low-latitude coastal zones (SSC8, Kpn35, RCWIP19) and northwestern regional models (SSC6, KPN47, RCWIP16) typically show poor correlation between $\delta^{18} \mathrm{O}_{\mathrm{ppt}}$ and predictor variables, resulting in very low parameter retention rates (on 


\section{Chapter 4}

average, less than three parameters retained per model). This lack of correlation is likely associated with the low seasonality of precipitation isotopes in coastal regions in general (Welker, 2000; Vachon et al., 2007) and changes in oceanic source (Fisher, 2004). The isotopic labelling of precipitation in paleorecords from the northwestern region has been attributed to changes in oceanic source rather than local climate parameters (Fisher, 2004), therefore the poor correlation between $\delta^{18} \mathrm{O}_{\mathrm{ppt}}$ and local climate parameters is not surprising. Although IQR's are low in this region (ranging from 2.62 to 2.85) and outliers are less prevalent than other models, this is likely due to subdued seasonality in these locations rather than superior model performance.

Overall, the 1-Zone and 2-Zone models show relatively comparable yet slightly higher IQR's (ranging from 3.39 to 3.50). Models from these more simplistic regionalizations are more outlierprone, resulting in an increased occurrence of high-magnitude outliers in comparison to the rest of the models. It should also be noted that reducing the number of zones within a regionalization results in an increased parameter retention rate and therefore more complex, less parsimonious models overall.

Teleconnection indices are retained in 35 percent of all models, therefore demonstrating moderate correlation with monthly time-series $\delta^{18} \mathrm{O}_{\mathrm{ppt}}$ for this type of modelling application. PDO and PNA are most typically retained during the fall and winter seasons in the west and central zone models (e.g. SSC31/32, Kpn 42/43, RCWIP18/19, etc.), while NAO is included in two central region models (SSC32 and Kpn43) during the winter season. The majority of the models incorporating the AO index are for northern regions (SSC4, Kpn62, RCWIP16/17, etc.), 


\section{Chapter 4}

typically during MAM; however retention of AO throughout all seasons is present. The aforementioned indices have been established to have significant relationships with cold season precipitation, primarily for the west and central (PDO), and within the province of Alberta (PNA), and northeastern regions of Canada (NAO/AO) (Bonsal et al., 2001; Bonsal and Shabbar, 2011). Strong correlations have been found between the PNA index and the $\delta^{18} \mathrm{O}$ of precipitation in the Canadian prairies (Birks and Edwards, 2009). The AMO index is retained during warmer seasons (MAM, JJA and SON) throughout the south-central models (SSC31/32, Kpn43, etc.). Bonsal and Lawford (1999) indicate that the positive phase of AMO is related to dry summer conditions over the central and northern regions of the Canadian Prairies and the lower Great Lakes and St. Lawrence Valley. This agreement between the timing and location of retained teleconnection indices and the aforementioned studies suggests the teleconnection predictors make physical sense.

To further diagnose spatial and temporal bias or deficiencies in the models, residuals from the five regionalization schemes are grouped by station, and the MSE is examined on a seasonal basis (Figure 20). To assist with spatial analyses, stations are classified as either north or south of $55^{\circ}$ latitude. Southerly stations are ordered by longitude and displayed from west to east, and northern stations are sorted by latitude, with the northernmost stations (station numbers 18 to 1 ) located coastally on the Arctic Archipelago. In an attempt to differentiate model performance spatially, residual IQR and excess kurtosis between observed and simulated $\delta^{18} \mathrm{O}_{\mathrm{ppt}}$ for each regionalization are plotted alongside MSE. 


\section{Chapter 4}

Figure 20: Seasonal MSE (bar chart), for all model residuals at each station, and excess kurtosis and IQR's for individual regionalizations (scatter plots) at each station. Stations are grouped into two subsets: (a) stations located south of $55^{\circ}$ latitude, ordered from west to east; $(b)$ stations

located north of $55^{\circ}$ latitude, ordered some south to north. Variance in observed $\delta^{18} O_{p p t}$ is indicated by the black line. Star symbols indicate stations displayed in further detail below on

Figure 21.

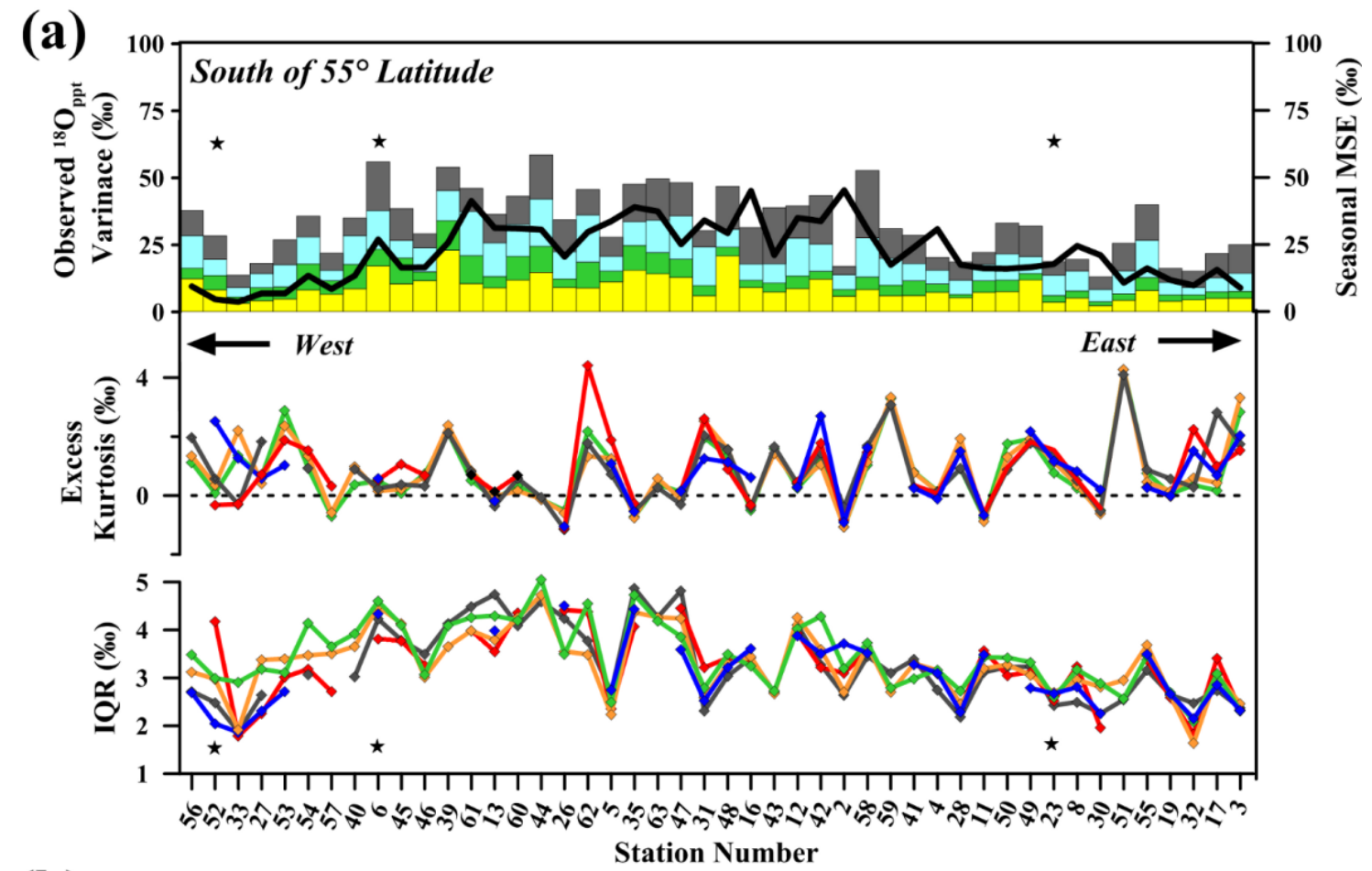

(b)
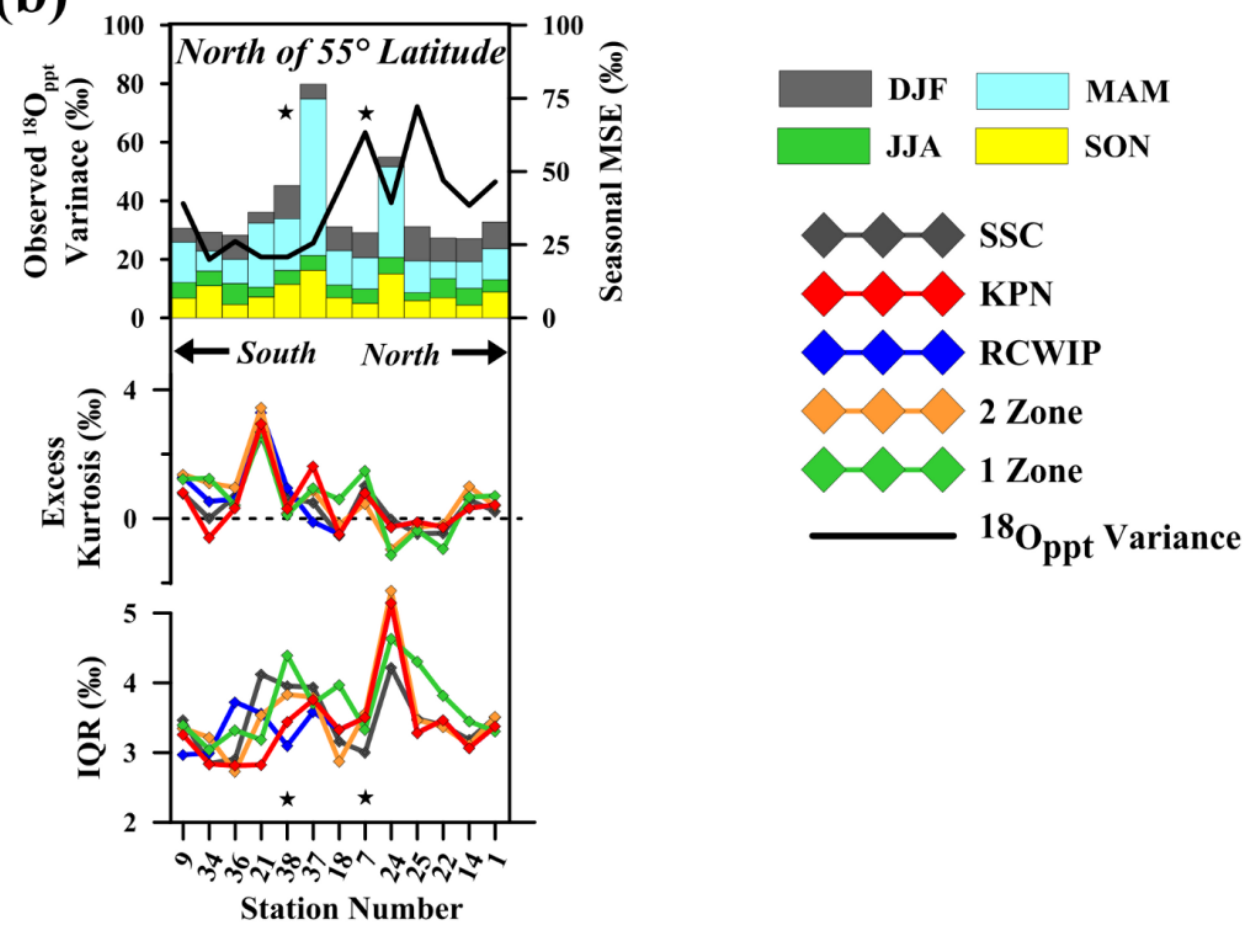


\section{Chapter 4}

The first item of mention from Figure 20 is that overall, the 1-Zone and 2-Zone simulations show higher IQRs and higher magnitude kurtosis effects than the SSC, Kpn and RCWIP simulations, supporting findings from the box and whisker plots (Figure 19). Spatially, the smallest residual IQRs (and lowest MSE) generally occur at southerly located coastal stations (both Pacific and Atlantic) and stations throughout southeast Canada and USA (Figure 20a). These are typically locations where the variability in $\delta^{18} \mathrm{O}_{\mathrm{ppt}}$ observations is considered average or below average. Vachon et al. (2007) noted that although $\delta^{18} \mathrm{O}_{\mathrm{ppt}}$ variability is moderate within the Great Lakes, Ohio River Valley, and Northeast regions, very little inter-annual variability in seasonal precipitation is observed. This consistency from year to year may lead to strong model performance at these locations. Regions of larger residual IQR's (and higher MSE) are located in both the south (below $55^{\circ}$ latitude) and north (above $55^{\circ}$ latitude) continental Canada and USA, particularly the west and central regions. In many instances these are at locations of higher altitude and display above average variance in observed $\delta^{18} \mathrm{O}_{\mathrm{ppt}}$. These attributes may, in part, be driven by the stronger intra-annual variance in $\delta^{18} \mathrm{O}_{\mathrm{ppt}}$ values for colder continental regions, such as the high-altitude sites of the Alps and the Rocky Mountains and the deep interior of the USA in Nebraska and Wisconsin (Rozanski et al., 1992; Harvey and Welker, 2000; Welker, 2000; Vachon et al., 2007). Correlation coefficients ( $r$ ) between residual IQR and observed $\delta^{18} \mathrm{O}_{\mathrm{ppt}}$ variance, and IQR and altitude are 0.50 and 0.45 , respectively (significantly different than zero at the 0.05 level), validating the presence of such trends.

Focusing on high-latitude stations (Figure 20b; latitude $\geq 55^{\circ}$ ), there is a larger range in model performance in the more southerly continental stations (stations 9 to 37), while coastal stations situated within the Arctic Archipelago (stations 18 to 1) show consistently low error variance 


\section{Chapter 4}

despite the large variability in observed $\delta^{18} \mathrm{O}_{\mathrm{ppt}}$, with the exception of station 24, Pond Inlet. This is primarily attributed to the small number of observations at this station $(n=20)$, whereby the few larger magnitude residuals occurring in MAM and SON skew the MSE. The northern models seem to be able to capture the annual cycle in observed $\delta^{18} \mathrm{O}_{\mathrm{ppt}}$, further reinforcing a strong correlation with precipitable water and potentially fewer complicating factors influencing Rayleigh distillation in this region.

Temporally, the least amount of error occurs during the summer (JJA) season (this is consistently the case for almost all stations throughout the study domain). In many instances, the largest errors occur during the cold season in winter (DJF) and spring (MAM), which echoes the findings from long-term seasonal model performance from Delavau et al. (2011). However, this trend is less consistent and varies spatially across the domain. For instance, southwest continental stations (e.g. station numbers 54, 57, 40, 45, 46, 39, etc.) show increased warm season (JJA and SON) contributions to error variance. These temporal trends in the distribution of error may be related to the increased contributions of recycled moisture during the warmer months, potentially acting to dampen the portion of variability in $\delta^{18} \mathrm{O}_{\mathrm{ppt}}$ related to air mass circulation and trajectory. The parameters utilized in the models cannot diagnose changes in moisture trajectory or source, therefore resulting in increased error at locations and times of year when these effects are most prominent on the composition of $\delta^{18} \mathrm{O}_{\mathrm{ppt}}$.

\subsection{Time-series Ensemble Simulations}

Five stations from different physiographic zones across the study domain are selected to further investigate seasonal error patterns and to visually quantify the uncertainty in model simulations 


\section{Chapter 4}

over time. Bootstrap-generated prediction intervals for each regionalization are produced, and the minimum and maximum prediction bounds alongside model simulations and observed $\delta^{18} \mathrm{O}_{\mathrm{ppt}}$ are displayed below on Figure 21. To adequately visualize model performance, a 10-year subset of the 34-year (1979 - 2012) simulation is plotted.

Generally the models are able to capture the timing and magnitude of the intra-annual (seasonal) $\delta^{18} \mathrm{O}_{\mathrm{ppt}}$ cycle, whereby simulations show moderate inter-annual variation when climate parameters are included within the models. However, the time-series plots reveal that although many of the models do quite well predicting monthly $\delta^{18} \mathrm{O}_{\mathrm{ppt}}$ compositions, showing small to moderate departures from the long-term monthly mean of a given location, they often fail to capture the anomalies in observed $\delta^{18} \mathrm{O}_{\mathrm{ppt}}-$ both enriched and depleted. This suggests that the climatic and geographic variables used in this study, or the modelling methodology itself, are not able to fully describe the complex physical processes driving the extreme shifts in $\delta^{18} \mathrm{O}_{\mathrm{ppt}}$, whether that be a change in moisture source, mixing of air masses, water recycling, secondary effects (such as below-cloud evaporation), or a combination thereof. An example of this is at Station 6 (Calgary, Canada), where $\delta^{18} \mathrm{O}_{\mathrm{ppt}}$ derived from warm weather small rainfall events $(<4 \mathrm{~mm})$ is known to be affected by partial evaporation of raindrops beneath the cloud base (i.e., secondary evaporation), causing an enrichment in $\delta^{18} \mathrm{O}_{\mathrm{ppt}}$ under these circumstances (Peng et al., 2004; 2007). There are multiple instances where the models are likely not able to capture this effect and large positive residuals occur during the warmer months. 


\section{Chapter 4}

Figure 21: Ten year monthly time-series simulations for five stations throughout the study domain. Ensemble means are indicated by the solid lines. $\delta^{18} O_{p p t}$ observations are denoted as black diamonds. The gray shaded region represents the envelope of bootstrapped $90 \%$ prediction intervals for all regionalizations.
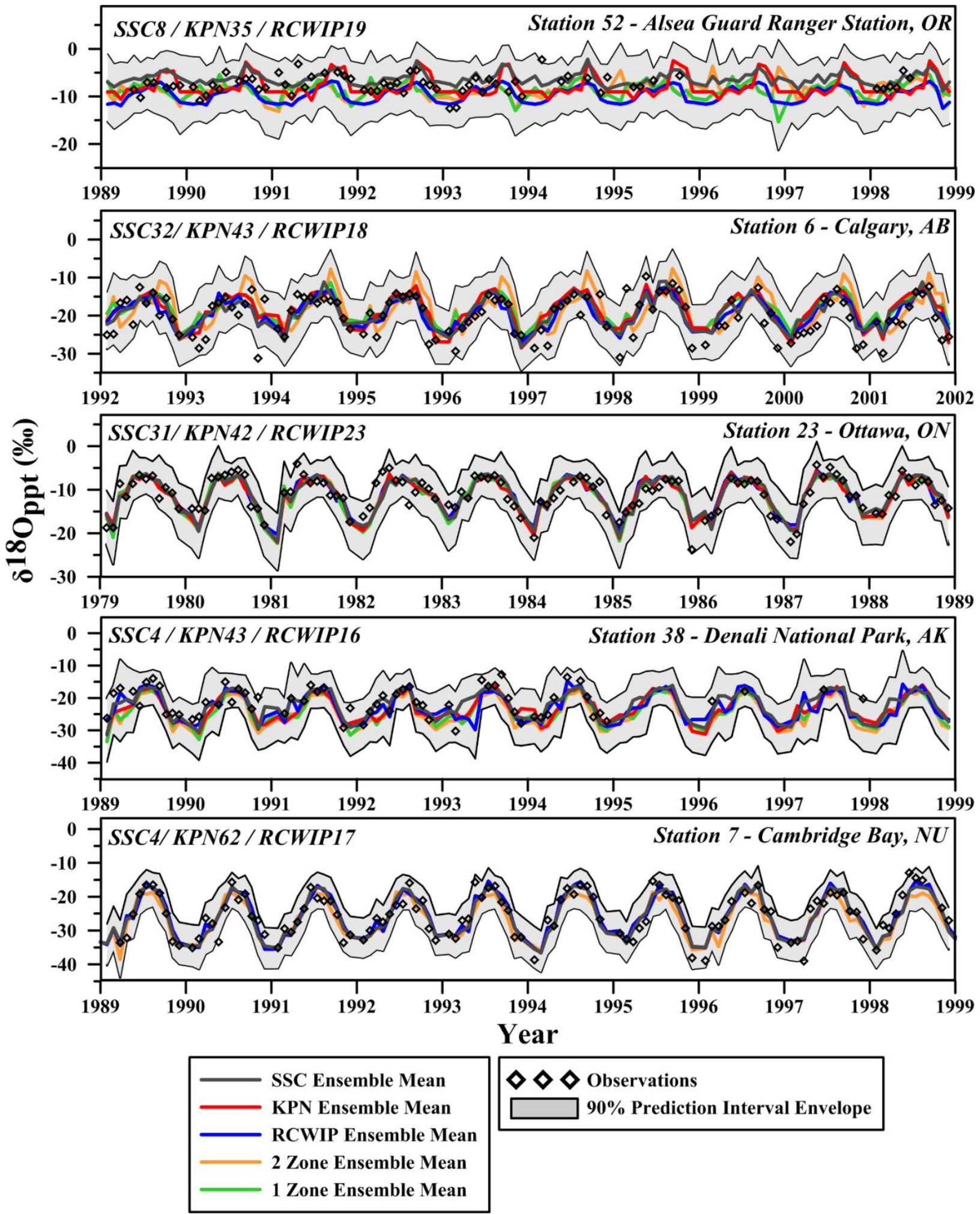

$\diamond \diamond \diamond$ Observations

90\% Prediction Interval Envelope 


\section{Chapter 4}

Many of the results described earlier are also reinforced within the time-series plots on Figure 21. For example, Station 52 (Alsea Guard Ranger Station) located within the Coast Range Mountains in Oregon, USA, is a validation station that shows considerable differences between model simulations. As previously mentioned, there is a lack of seasonality in this region and poor correlation between $\delta^{18} \mathrm{O}_{\mathrm{ppt}}$ and the predictor variables, resulting in a lack of physical basis, poor performance outside the region of calibration, and wider prediction bounds. Simulations in the southeast region of the study domain are quite strong, which can be seen in the time-series plot of Station 23 (Ottawa, Canada). All ensemble members show very similar results throughout this region, resulting in narrow prediction bounds and tightly constrained mean ensemble members. The Arctic Archipelago station models perform comparably well, represented by the time-series plot at Station 7 (Cambridge Bay, Canada).

\subsection{Long-Term Spatial Mapping}

Long-term annual average maps of $\delta^{18} \mathrm{O}_{\mathrm{ppt}}$ across Canada and the northern portion of the USA are created for each regionalization, generated from the mean of monthly time-series ensembles over the period of 1981-2010. Time-series simulations are generated at the grid scale at a resolution of 17 arc minutes and are precipitation amount-weighted to create the long-term annual average compositions displayed on Figure 22. The gridded range between the five longterm simulations is displayed to provide an estimate of the model structure uncertainty as it compounds over the aforementioned thirty year period (Figure 22f). 


\section{Chapter 4}

Figure 22: Long-term precipitation amount weighted annual average $\delta^{18} O_{\text {ppt }}$ simulations (units of \%o) for: (a) SSC, (b) Kpn, (c) RCWIP, (d) 2-Zone, and (e) 1-Zone regionalizations. The gridded range in long-term simulations is displayed on Figure $22 f$.

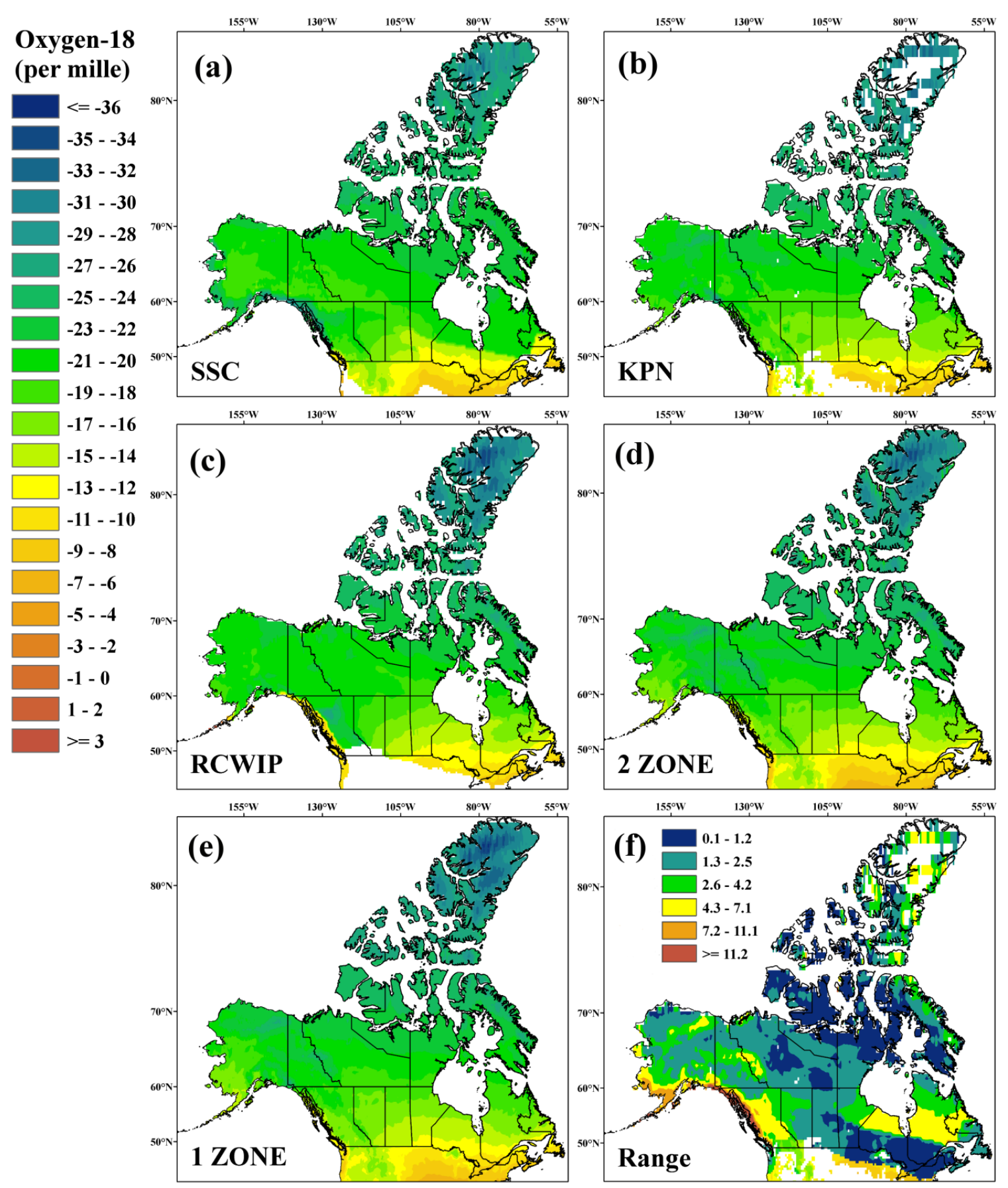

Generally the different models are able to produce long-term annual average $\delta^{18} \mathrm{O}_{\mathrm{ppt}}$ contours of reasonable magnitude while capturing the main trends in the variability in $\delta^{18} \mathrm{O}_{\mathrm{ppt}}$, such as 


\section{Chapter 4}

depletion from: south to north (latitude effect), coast to interior (continentality), and in areas of high elevation (altitude effect) (Dansgaard, 1964). However, as evident on Figure 22, the SSC and RCWIP regionalizations produce unrealistic border effects at several of the isotope zone boundaries, manifesting in an unrealistic enrichment along west coast of British Columbia and into Alaska (RCWIP) and an extremely sharp transition from relatively depleted to enriched in heavy isotopes within the northern Ontario, Quebec, and Newfoundland and Labrador region (SSC). The Kpn, 2-Zone and 1-Zone regionalizations appear to have much less apparent border effects due to the nature of the isotope zone locations, or lack of regionalization in the case of the 1-Zone models.

Figure 22f provides an estimate of the long-term uncertainty between the regionalizations. The largest range in model simulations occurs along the Pacific coastal regions of British Columbia and Alaska, while more moderate discrepancies are within the Cordilleran region in British Columbia and Alberta, the western portion of the Mackenzie District in the Northwest Territories and the Yukon Territory, and into Quebec, Newfoundland and Labrador. Regions of model disagreement are caused by either one of two phenomenon: (1) significant differences in model structure (i.e., parameterization) and therefore discrepancies in model simulations (e.g. southern Pacific Coast models), or (2) similarity in model simulations at locations of model development, but unrealistically placed isotope border locations (e.g. SSC31, SSC6).

Throughout the mid-Arctic, central, and southeastern portions of the study domain, all regionalizations are relatively comparable, resulting in a smaller range in long-term simulations and less uncertainty associated with model structure. The SSC models produce relatively 


\section{Chapter 4}

enriched predictions in the Arctic Archipelago in comparison to the remaining four regionalizations, and are the cause of the larger range in model simulations within this region.

\subsection{Conclusions and Next Steps}

This study investigates the use of physically-based hydroclimate parameters alongside geographic variables and teleconnection indices within an empirical modelling framework to capture the time-series monthly variability in observed $\delta^{18} \mathrm{O}_{\mathrm{ppt}}$, and development of regional isoscapes for Canada. Additionally, the uncertainty due to regionalization is assessed for both time-series and long-term average predictions.

Precipitable water content and latitude are found to be the most significant parameters for the time-series prediction of $\delta^{18} \mathrm{O}_{\mathrm{ppt}}$, typically explaining the largest portions of variance in observed $\delta^{18} \mathrm{O}_{\mathrm{ppt}}$. Within the mid- to high-Arctic and eastern portion of the study domain, all five regionalizations generate models with the ability to capture the inter- and intra-annual variability of $\delta^{18} \mathrm{O}_{\mathrm{ppt}}$. Other areas, however, such as the Pacific coast and northwestern portion of the study domain show less agreement between regionalizations and poorer model performance, resulting in higher uncertainty in simulations throughout these regions. Overall, the current study is an improvement from the regional simulations reported by Delavau et al. (2011) and previous global simulations due to the refined temporal scale of prediction (i.e., time-series versus longterm averages), enhancement of the suite of physically-based predictor variables, and the incorporation of isotope zones for regionalization during model development. 


\section{Chapter 4}

Results indicate that with long-term predictions, model structure uncertainty can be substantial in certain locations. At the monthly time-series scale, however, 90\% bootstrapped prediction intervals show that uncertainty of an individual estimate is much greater than that attributed to model structure. Based on these findings, it is recommended that future studies continue to incorporate the corresponding method of uncertainty quantification depending upon the temporal

scale of predictions required. Uncertainty can be further reduced by continued $\delta^{18} \mathrm{O}_{\mathrm{ppt}}$ monitoring and through enhancement of existing monitoring networks, particularity in data-sparse regions with high model uncertainty.

In an attempt to reduce border effects, more simplistic regionalizations (2-Zone and 1-Zone) are investigated within the current study. Although border effects are eliminated, these more simplistic regionalizations result in poorer model performance, including higher IQRs and more frequent outliers. SSC, Kpn and RCWIP simulations perform comparably at most locations of model development. However, it is the extrapolation of the models across the study domain that, in many instances, causes major discrepancies between regionalizations. As previously outlined, both the SSC and RCWIP regionalizations produce long term average maps with unrealistic $\delta^{18} \mathrm{O}_{\mathrm{ppt}}$ contours. For these reasons, the Kpn regionalization is suggested as the preferred regionalization scheme for future iso-hydrologic modelling and other applications.

The next step in this research is to generate $\delta^{18} \mathrm{O}_{\mathrm{ppt}}$ monthly time-series estimations to force the tracer-aided hydrological model, isoWATFLOOD, and create predictions of oxygen-18 in streamflow $\left(\delta^{18} \mathrm{O}_{\mathrm{SF}}\right)$ within the Fort Simpson Basin (FSB), NWT, Canada. Results will be compared to other simulations in the FSB that are derived from annual average $\delta^{18} \mathrm{O}_{\mathrm{ppt}}$ model 


\section{Chapter 4}

forcing (Stadnyk et al., 2013) and isotope-enabled climate output. This enables a regional assessment of the uncertainty resulting from choice of model forcing or input data (i.e., choice of simulated $\delta^{18} \mathrm{O}_{\mathrm{ppt}}$ time-series), and the propagation of that uncertainty on simulations and model parameterization. Improving $\delta^{18} \mathrm{O}_{\mathrm{ppt}}$ input and assessing the uncertainty attributable to $\delta^{18} \mathrm{O}_{\mathrm{ppt}}$ forcing is an important step towards the end goal of quantifying and reducing uncertainty in isoWATFLOOD streamflow simulations; which becomes extremely important when models are used operationally and drive policy decisions on management of water resources now and into the future.

\subsection{Acknowledgements}

CNIP is made possible through the help of the Canadian Air and Precipitation Monitoring Network (CAPMoN) for sample collection—Kaz Higuchi and Dave MacTavish in particular, the Environmental Isotope Laboratory at the University of Waterloo for sample analysis, and Tom Edwards for initiating and maintaining the network. USNIP is supported in part by NSF awards (ESH-0080952, DBI- 0923571) to J.M. Welker and is a collaboration with the U.S. National Atmospheric Deposition Network. We would like to thank the IAEA/WMO for the collection, organization, and provision of the GNIP observations utilized in this study. GNIP data are publically available and can be accessed through the WISER database at: http://wwwnaweb.iaea.org/napc/ih/IHS_resources_gnip.html. Finally, we would like to acknowledge the contributions of our reviewers whose valuable input has improved this manuscript significantly. This research was partially funded by Natural Sciences and Engineering Research Council (NSERC) Alexander Graham Bell Canada Graduate Scholarship (CGS-D). 


\section{Chapter 4}

\subsection{References}

Aggarwal, P. K., K. Froehlich, and R. Gonfiantini (2011), Contributions of the International Atomic Energy Agency to the development and practice of isotope hydrology. Hydrogeol. J., 19(1), 5-8, doi:10.1007/s10040-010-0648-3.

Aggarwal, P. K., O. A. Alduchov, K. O. Froehlich, L. J. Araguas-Araguas, N. C. Sturchio, and N. Kurita (2012), Stable isotopes in global precipitation: A unified interpretation based on atmospheric moisture residence time, Geophys. Res. Lett., 39(L11705), doi:10.1029/2012GL051937.

Akaike, H. (1974), A new look at the statistical model identification, IEEE Trans. Autom. Control, 19 (6), 716-723.

Araguás-Araguás, L., K. Froehlich, and K. Rozanski (2000), Deuterium and oxygen-18 isotope composition of precipitation and atmospheric moisture. Hydrol. Process., 14, 1341-1355, doi: 10.1002/1099-1085(20000615)14:8<1341::AID-HYP983>3.0.CO;2-Z.

Birks, S. J., and T. W. D. Edwards (2009), Atmospheric circulation controls on precipitation isotope-climate relations in western Canada, Tellus Ser. B, 61B(3), 566-576, doi: 10.1111/j.1600-0889.2009.00423.x.

Birks, S. J., and J. J. Gibson (2009), Isotope hydrology research in Canada, 2003-2007. Cdn. Water Resour. J., 34(2), 163-176, doi: 10.4296/cwrj3402163.

Birks, S. J., J. J. Gibson, L. Gourcy, P. K. Aggarwal, and T. W. D. Edwards (2002), Maps and animations offer new opportunities for studying the global water cycle, Eos Trans. AGU, 83(37), 406, doi: 10.1029/2002EO000298.

Bonsal, B. R., and R. G. Lawford (1999), Teleconnections between El Niño and La Niña events and summer extended dry spells on the Canadian Prairies. Int. J. Climatol., 19, 1445-1458, doi: 10.1002/(SICI)1097-0088(19991115)19:13<1445::AID-JOC431>3.0.CO;2-7.

Bonsal B. R., and A. Shabbar (2011), Large-scale climate oscillations influencing Canada, 19002008, Canadian Biodiversity: Ecosystem Status and Trends 2010, Technical Thematic Report No. 4, Canadian Councils of Resource Ministers, Ottawa, ON.

Bonsal, B. R., A. Shabbarr, and K. Higuchi (2001), Impacts of low frequency variability modes on Canadian winter temperature, Int. J. Climatol., 21, 95-108, doi: 10.1002/joc.590.

Bowen, G. J., and J. Revenaugh (2003), Interpolating the isotopic composition of modern meteoric precipitation, Water Resour. Res., 39(10), 1299-1311, doi: 10.1029/2003WR002086.

Bowen, G. J., and B. H. Wilkinson (2002), Spatial distribution of $\delta 180$ in meteoric precipitation, Geology, 30(4), 315-318, doi: 10.1130/0091-7613(2002)030<0315:SDOOIM>2.0.CO;2.

Chun, K. P. (2010), Statistical downscaling of climate model outputs for hydrological extremes, $\mathrm{Ph} . \mathrm{D}$ thesis, Department of Civil and Environmental Engineering, Imperial College London, London, UK. 


\section{Chapter 4}

Dansgaard, W. (1964). Stable isotopes in precipitation, Tellus, 16(4), 436-468, doi: 10.1111/j.2153-3490.1964.tb00181.x.

Davison, A., and D. Hinkley. (1997), Bootstrap Methods and Their Application, Cambridge University Press, Cambridge, UK.

Delavau, C., T. A. Stadnyk, and S. J. Birks (2011), Model based distribution of oxygen-18 isotopes in precipitation across Canada, Cdn. Water Resour. J., 36(4), 313-330, doi: 10.4296/cwrj3604875.

Durbin, J., and G. S. Watson (1951), Testing for serial correlation in least squares regression. 2., Biometrika, 38, 159-178.

Dutton, A. L., B. H. Wilkinson, G. Bowen, J. M. Welker, and K. C. Lohmann (2005), Comparison of river water and precipitation $\delta 18 \mathrm{O}$ across the 48 contiguous United States, Hydrol. Process., 19, 3551-3572, doi: 10.1002/hyp.5876.

Fisher, D. A., C. Wake, K. Kreutz, K. Yalcin, E. Steig, P. Mayewski, L. Anderson, J. Zheng, S. Rupper, C. Zdanowicz, M. Demuth, M. Waszkiewicz, D. Dahl-Jensen, K. Goto-Azuma, J. B. Bourgeois, R. M. Koerner, J. Sekerka, E. Osterberg, M. B. Abbott, B. P. Finney, and S. J. Burns (2004), Stable isotope records from Mount Logan and Eclipse ice cores and nearby Jellybean Lake; water cycle of the North Pacific over 2000 years and over 5 vertical kilometres; sudden shifts and tropical connections. Géographie physique et Quaternaire, 58, 337-52. doi: 10.7202/013147ar.

Fischer M. J., and L. M. Baldini (2011), A climate-isotope regression model with seasonallyvarying and time-integrated relationships, Clim. Dyn., 37(11-12), 2235-2251, doi: 10.1007/s00382-011-1009-1.

Gat J. R., C. J. Bowser, and C. Kendall (1994), The contribution of evaporation from the Great Lakes to the continental atmosphere: estimate based on stable isotope data, Geophys. Res. Lett., 21, 557-560, doi: 10.1029/94GL00069.

Good, P. (2005), Permutation, Parametric and Bootstrap Tests of Hypotheses, 3rd ed. Springer, New York, NY.

Harvey, F. E., and J. M. Welker (2000), Stable isotopic composition of precipitation in the semiarid north-central portion of the US Great Plains, J. Hydrol., 238, 90-109, doi:.1016/S00221694(00)00316-4.

IAEA/WMO (2014). Global Network of Isotopes in Precipitation. The GNIP Database. Accessible at: http://www.iaea.org/water.

Kalkstein, L. S., M. C. Nichols, C .D. Barthel, and J. S. Greene (1996), A new spatial synoptic classification: application to air-mass analysis. Int. J. Climatol., 16, 983-1004. doi: 10.1002/(SICI)1097-0088(199609)16:9<983::AID-JOC61>3.0.CO;2-N

Kottek, M., J. Grieser, C. Beck, B. Rudolf, and F. Rubel (2006), World Map of the KöppenGeiger climate classification updated, Meteorol. Z., 15(3), 259-263, doi: 10.1127/09412948/2006/0130. 


\section{Chapter 4}

Liebminger, A., G. Haberhauer, K. Varmuza, W. Papesch, and G. Heiss (2006), Modeling the oxygen 18 concentration in precipitation with ambient climatic and geographic parameters, Geophys. Res. Lett., 33(5), doi:10.1029/2005GL025049.

Lilliefors, H. W. (1967), On the Kolmogorov-Smirnov test for normality with mean and variance unknown, J. Am. Stat. Assoc., 62, 399-402, doi: 10.2307/2283970.

Liu, Z., T. Lide, X. Chai, and T. Yao (2008), A model-based determination of spatial variation of precipitation $\delta 180$ over China, Chem. Geol., 249, 203-212, doi:10.1016/j.chemgeo.2007.12.011.

Liu, Z., G. Bowen, and J. M. Welker (2010), Atmospheric circulation is reflected in precipitation isotope gradients over the conterminous United States, J. Geophys. Res., 115(D22120), doi:10.1029/2010JD014175.

Liu, Z., G. Bowen, K. Yoshimura, K., and J. M. Welker (2013), Pacific North American teleconnection controls on precipitation isotopes $(\delta 180)$ across the contiguous USA and adjacent regions, J. Climate, 27, 1046-1061, doi:10.1175/JCLI-D-13-00334.1.

Lykoudis, S. P., and A. A. Argiriou (2007), Gridded data set of the stable isotopic composition of precipitation over the eastern and central Mediterranean, J. Geophys. Res., 112(D18107), doi:10.1029/2007JD008472.

Lykoudis, S. P., A. A. Argiriou, and E. Dotsika (2010), Spatially interpolated time series of $\delta 180$ in Eastern Mediterranean precipitation, Global Planet. Change, 71, 150-159 doi: 10.1016/j.gloplacha.2009.09.004.

MATLAB and Statistics Toolbox Release 2013a (2013), The MathWorks, Inc., Natick, Massachusetts, United States.

Mesinger, F., et al. (2006), North American regional reanalysis, Bull. Am. Meteorol. Soc, 87, 343-360, doi: 10.1175/BAMS-87-3-343.

Peng, H., B. Mayer, S. Harris, and H. R. Krouse (2004), A 10-yr record of stable isotope ratios of hydrogen and oxygen in precipitation at Calgary, Alberta, Canada, Tellus Ser. B, 56B, 147159, doi: 10.1111/j.1600-0889.2004.00094.x.

Peng, H., B. Mayer, S. Harris, and H. R. Krouse (2007), The influence of below-cloud secondary effects on the stable isotope composition of hydrogen and oxygen in precipitation at Calgary, Alberta, Canada. Tellus Ser. B, 59, 698-704, doi: 10.1111/j.1600-0889.2007.00291.x

Peng, R. D., and F. Dominici (2008), Statistical Methods for Environmental Epidemiology with R: A Case Study in Air Pollution and Health Series, Springer-Verlag, New York, NY.

Rozanski, K., L. Araguás-Araguás, and R. Gonfiantini (1992), Relation between long-term trends of oxygen-18 isotope composition of precipitation and climate, Science, 258, 981-985, doi: $10.1126 /$ science.258.5084.981. 


\section{Chapter 4}

Rozanski, K., L. Araguás-Araguás, and R. Gonfiantini (1993), Isotopic patterns in modem global precipitation, in: Climate Change in Continental Isotopic Records, Geophys. Monogr. Ser., vol. 78, edited by Swart, P. K. et al., pp. 1-36, AGU, Washington, D.C.

Sheridan, S. C. (2002), The redevelopment of a weather-type classification scheme for North America. Int. J. Climatol., 22, 51-68, doi: 10.1002/joc.709.

Stadnyk, T. A., C. Delavau, N. Kouwen, and T. W. D. Edwards (2013), Towards hydrological model calibration and validation: simulation of stable water isotopes using the isoWATFLOOD model. Hydrol. Process., 27, 3791-3810, doi: 10.1002/hyp.9695.

Terzer, S., L. I. Wassenaar, L. J. Araguás-Araguás, and P. K. Aggarwal (2013), Global isoscapes for $\delta 18 \mathrm{O}$ and $\delta 2 \mathrm{H}$ in precipitation: improved prediction using regionalized climatic regression models, Hydrol. Earth Syst. Sci., 17, 4713-4728, doi:10.5194/hess-17-4713-2013.

Welker, J. M. (2000), Isotopic ( $\delta 180$ ) characteristics of weekly precipitation collected across the United States: An initial analysis with application to water source studies, Hydrol. Process., 14, 1449-1464, doi: 10.1002/1099-1085(20000615)14:8<1449::AID-HYP993>3.0.CO;2-7.

Welker, J. M. (2012), ENSO effects on the isotopic ( $\delta 18 \mathrm{O}, \delta 2 \mathrm{H}$ and d-excess) of precipitation across the US using a long-term network (USNIP), Rapid Comm. in Mass Spec., 17, 16551660, doi:10.1002/rcm.6298.

Wheeler, B. (2010), lmPerm: Permutation tests for linear models. R package version 1.1-2. http://CRAN.R-project.org/package=lmPerm.

Vachon, R. W., J. W. C. White, E. Gutmann, and J. M. Welker (2007), Amount-weighted annual isotopic (d180) values are affected by the seasonality of precipitation: A sensitivity study, Geophys. Res. Lett., 34, L21707, doi:10.1029/2007GL030547.

Vachon, R. W., J. M. Welker, J. W. C. White, and B.H. Vaughn (2010a), Monthly precipitation isoscapes (d18O) of the United States: Connections with surface temperatures, moisture source conditions, and air mass trajectories, J. Geophys. Res., 115, D21126, doi:10.1029/2010JD014105.

Vachon, R. W., J. M. Welker, J. W. C. White, and B.H. Vaughn (2010b), Moisture source temperatures and precipitation d180-temperature relationships across the US, Water Resour. Res., 46, W07523, doi:10.1029/2009WR008558.

Van der Veer, G., S. Voerkelius, G. Lorentz, G. Heiss, and J. A. Hoogewerff (2009), Spatial interpolation of the deuterium and oxygen-18 composition of global precipitation using temperature as ancillary variable, J. Geochem. Explor., 101, 175-184, doi:10.1016/j.gexplo.2008.06.008.

Yakir, D., and L. Sternberg (2000), The use of stable isotopes to study ecosystem gas exchange, Oecologia, 123, 297-311, doi:10.1007/s004420051016.

Zhao, L., H. Xiao, M. Zhou, G. Cheng, L. Wang, L. Yin, and J. Ren (2011), Factors controlling spatial and seasonal distributions of precipitation d180 in China, Hydrol. Processes, 26, 143152, doi:10.1002/hyp.8118. 


\title{
CHAPTER 5: EXAMINING THE IMPACTS OF ESTIMATED
}

PRECIPITATION ISOTOPE $\left(\delta^{18}\right.$ O) INPUTS ON DISTRIBUTED TRACER-

\author{
AIDED HYDROLOGICAL MODELLING \\ ${ }^{1}$ Delavau, C., ${ }^{1}$ Stadnyk, T., and ${ }^{1}$ Holmes, T. \\ ${ }^{1}$ University of Manitoba, Department of Civil Engineering (Water Resources), Winnipeg, MB, Canada.
}

Submitted to Hydrology and Earth System Sciences in October, 2016.

Manuscript Number: hess-2016-539.

This chapter selects three types of $\delta^{18} \mathrm{O}_{\mathrm{ppt}}$ estimates as input for the tracer-aided isoWATFLOOD model and investigates how selection of $\delta^{18} \mathrm{O}_{\mathrm{ppt}}$ input affects simulations, the internal apportionment of water, and the resulting model parameterizations. A multi-criteria, multiobjective multi- approach is used, and parameter uncertainty is accounted for using a GLUEbased methodology. 


\section{Chapter 5}

\subsection{Abstract}

Tracer-aided hydrological models are becoming increasingly popular tools as they have documented utility in constraining model parameter space during calibration, reducing model uncertainty, and assisting with selection of appropriate model structures. However, the issue of data availability, particularly input data, proves to be a major challenge associated with this type of application. Tracer-aided hydrological modelling typically requires a time series of isotopes in precipitation $\left(\delta^{18} \mathrm{O}_{\mathrm{ppt}}\right)$ to drive model simulations, but unfortunately, throughout much of the world, and particularly in sparsely populated high-latitude regions, these data are not widely available. This study uses the isoWATFLOOD tracer-aided hydrological model to investigate the usefulness of three types of estimated $\delta^{18} \mathrm{O}_{\mathrm{ppt}}$ for model input, and the impact that these data have on model simulations and parameterization in the remote Fort Simpson Basin, NWT, Canada. This study showed that although total simulated streamflow was not significantly impacted by choice of $\delta^{18} \mathrm{O}_{\mathrm{ppt}}$ input, isotopes in streamflow $\left(\delta^{18} \mathrm{O}_{\mathrm{SF}}\right)$ simulations and the internal apportionment of water (and therefore, model parameterizations) were impacted, particularly during large precipitation and snowmelt events. This finding highlighted the importance of estimated $\delta^{18} \mathrm{O}_{\mathrm{ppt}}$ to capture both the variability and seasonality in precipitation isotopes as critical for tracer-aided hydrological modelling, especially when precipitation events displayed distinctly different isotopic compositions than that of streamflow. This study achieves an understanding of how isoWATFLOOD can be used in regions with a limited number of $\delta^{18} \mathrm{O}_{\mathrm{ppt}}$ observations, and that the model can be of value in such regions. This study reinforces that a tracer-aided modelling approach assists with resolving hydrograph component contributions, and works towards diagnosing the issue of model equifinality. 


\section{Chapter 5}

\subsection{Introduction}

Hydrological models are critical tools for the planning, development, design, operation and sustainable management of water resources in Canada (Singh and Frevert, 2006). These models provide insight into applications such as the prediction of floods, droughts and water availability, and the effects of climate and land use change on water resources. Problems arise in calibrating and validating hydrological model predictions, primarily due to: (1) a lack of available data at sufficient resolutions to force and validate model simulations - especially in remote, high-latitude locations (in Canada: Coulibaly et al., 2013); (2) model parameterization and issues with equifinality; and (3) the associated uncertainty in model results (Beven and Binley, 1992; Kirchner, 2006; Fenicia et al., 2008; Dunn et al., 2008).

It is now widely accepted that calibration and validation of hydrological models based solely on streamflow is not a sufficient evaluation measure (Kuczera, 1983; Beven and Binley, 1992; Kuczera and Mroczkowski, 1998; Seibert and McDonnell, 2002; Kirchner, 2006; Fenicia et al., 2008; Dunn et al., 2008). Modellers are focusing on a model's ability to correctly partition, store and release water from hydrologic compartments, in addition to adequately simulating total streamflow response. Conservative tracer data provides insights into the dominant hydrological processes and integrated runoff response (in northern catchments: Birks and Gibson, 2009; Tezlaff et al., 2015), and such data assist with constraining model parameter space during calibration, reducing model uncertainty, and assisting with selection of appropriate model structures (e.g. Tetzlaff et al., 2008; Birkel et al., 2010a; McMillian et al., 2012; Birkel et al., 2014; Smith et al., 2016). An increasing number of studies have investigated the utility of tracer- 


\section{Chapter 5}

aided modelling approaches, especially over the past decade (for a comprehensive overview, see Birkel and Soulsby, 2015).

Although greatly informative, previous tracer-aided modelling studies have generally been conducted using lumped conceptual rainfall-runoff models in highly instrumented small-scale experimental catchments $\left(<10^{2} \mathrm{~km}^{2}\right)$. This has resulted in distributed studies at the regional-scale $\left(>10^{3} \mathrm{~km}^{2}\right)$ left largely unexplored, with the exception of a few, select applications (Stadnyk et al., 2013). Modelling at the regional-scale typically requires a distributed approach to capture the heterogeneity in meteorological inputs, basin characteristics, and runoff response, resulting in more complex, highly parameterized models (e.g. Michaud and Sorooshian, 1994; Carpenter and Georgakakos, 2006; Her and Chaubey, 2015). Because it is at these larger scales where models are applied operationally and management decisions are based, there is a critical need to understand the abilities, limitations, and uncertainties associated with distributed tracer-aided modelling at the regional scale.

Although there is an identified need, the issue of data availability, particularly input data, proves to be a major challenge associated with this type of application (Birkel and Soulsby, 2015). Tracer-aided hydrological modelling typically requires a time series of isotopes in precipitation $\left(\delta^{18} \mathrm{O}_{\mathrm{ppt}}\right)$ to drive model simulations. Unfortunately, throughout much of the world, and particularly in sparsely populated high-latitude regions (such as the vast majority of Canada), these data are not widely available. Although automatic samplers are becoming increasingly common, watersheds in which snow accumulation is substantial will continue to be fraught with difficulties surrounding the collection and characterization of precipitation isotopes, particularly 


\section{Chapter 5}

during the winter months (Dietermann and Weiler, 2013; Penna et al., 2014). The lack of spatial and temporal density of $\delta^{18} \mathrm{O}_{\mathrm{ppt}}$ observations highlights the need for alternative methods to provide estimates of stable isotopes in precipitation for tracer-aided model forcing. Options include empirically-based models generating gridded time series estimates of precipitation isotopes (e.g. Lykoudis et al., 2010; Delavau et al., 2015), in addition to isotope-enabled climate model output (for a comprehensive overview, see: Noone and Sturm, 2010; Xi et al., 2014).

Small-scale catchment studies rely on continuous records of $\delta^{18} \mathrm{O}_{\mathrm{ppt}}$ observations at high temporal frequencies (typically daily, and less commonly, weekly) for model input. At the larger scale, tracer-aided modelling completed by Stadnyk et al. (2013) in the remote Fort Simpson region of northern Canada used annual average compositions of rainfall and snowfall $\delta^{18} \mathrm{O}$ to drive model simulations. Their results suggested that utilizing annual, spatially static oxygen-18 in precipitation forcing has the potential to significantly impact simulations and consequently, model parameterization as well. The assumption that model forcing is spatially invariant is not preferable, as $\delta^{18} \mathrm{O}_{\mathrm{ppt}}$ can vary drastically over small space and time scales due to changes in moisture sources and transport processes, rainout history and seasonality (e.g. in Canada: Gat $e t$ al., 1994; Moran et al., 2007; Birks and Edwards, 2009).

Utilizing estimates of $\delta^{18} \mathrm{O}_{\mathrm{ppt}}$ to drive tracer-aided model simulations has not yet been investigated, particularly at the regional-scale where the lack of observed data have identified a need for estimates of $\delta^{18} \mathrm{O}_{\mathrm{ppt}}$. Therefore, this study aims to explore how estimated $\delta^{18} \mathrm{O}_{\mathrm{ppt}}$ inputs of differing spatial and temporal variability impact regional tracer-aided modelling within two 


\section{Chapter 5}

remote Canadian basins, where limited $\delta^{18} \mathrm{O}_{\mathrm{ppt}}$ observations exist. Our specific research objectives are to:
a) force a regional tracer-aided hydrological model (isoWATFLOOD) with three types of estimated $\delta^{18} \mathrm{O}_{\mathrm{ppt}}$ input of varying temporal and spatial resolution;
b) examine how choice of $\delta^{18} \mathrm{O}_{\mathrm{ppt}}$ input affects the simulation of total streamflow and isotopes in streamflow $\left(\delta^{18} \mathrm{O}_{\mathrm{SF}}\right)$, while accounting for parameter uncertainty, and;
c) explore if choice of $\delta^{18} \mathrm{O}_{\mathrm{ppt}}$ input affects the internal apportionment of water, namely the seasonality of hydrograph components.

\subsection{Study Area and Data}

\subsubsection{The Fort Simpson Basin}

The Fort Simpson Basin (FSB) is located within the Lower Liard River valley close to the town of Fort Simpson, Northwest Territories, Canada $\left(61^{\circ} 45 \mathrm{~N} ; 121^{\circ} 14 \mathrm{~W}\right.$; Figure 23$)$. This region has been the focus of several tracer-aided hydrological studies (e.g. St Amour et al., 2005; Stadnyk et al., 2005; 2013; Stadnyk-Falcone, 2008). The FSB is selected for this study to build upon previous modelling work conducted within the region, and follow up on recommendations from Stadnyk et al. (2013) suggesting further analysis and improvement of isoWATFLOOD $\delta^{18} \mathrm{O}_{\mathrm{ppt}}$ input. The study period of 1997-1999 is selected based data availability.

This study considers two sub-basins of the greater Fort Simpson basin: the Jean-Marie and Blackstone River sub-basins (Figure 23). Differences in wetland distribution and function, basin physiography and land cover make-up between the two watersheds (Table 10) are the primary reasons in selecting these sub-basins for this study. These marked differences ensure that 


\section{ChAPTER 5}

watersheds of varying dominant hydrological processes are represented in the modelling, and therefore the impacts of $\delta^{18} \mathrm{O}_{\mathrm{ppt}}$ input selection on these processes can be examined.

Figure 23: Fort Simpson River Basin (all other tributaries of the Liard and Mackenzie Rivers have been removed for ease of viewing).

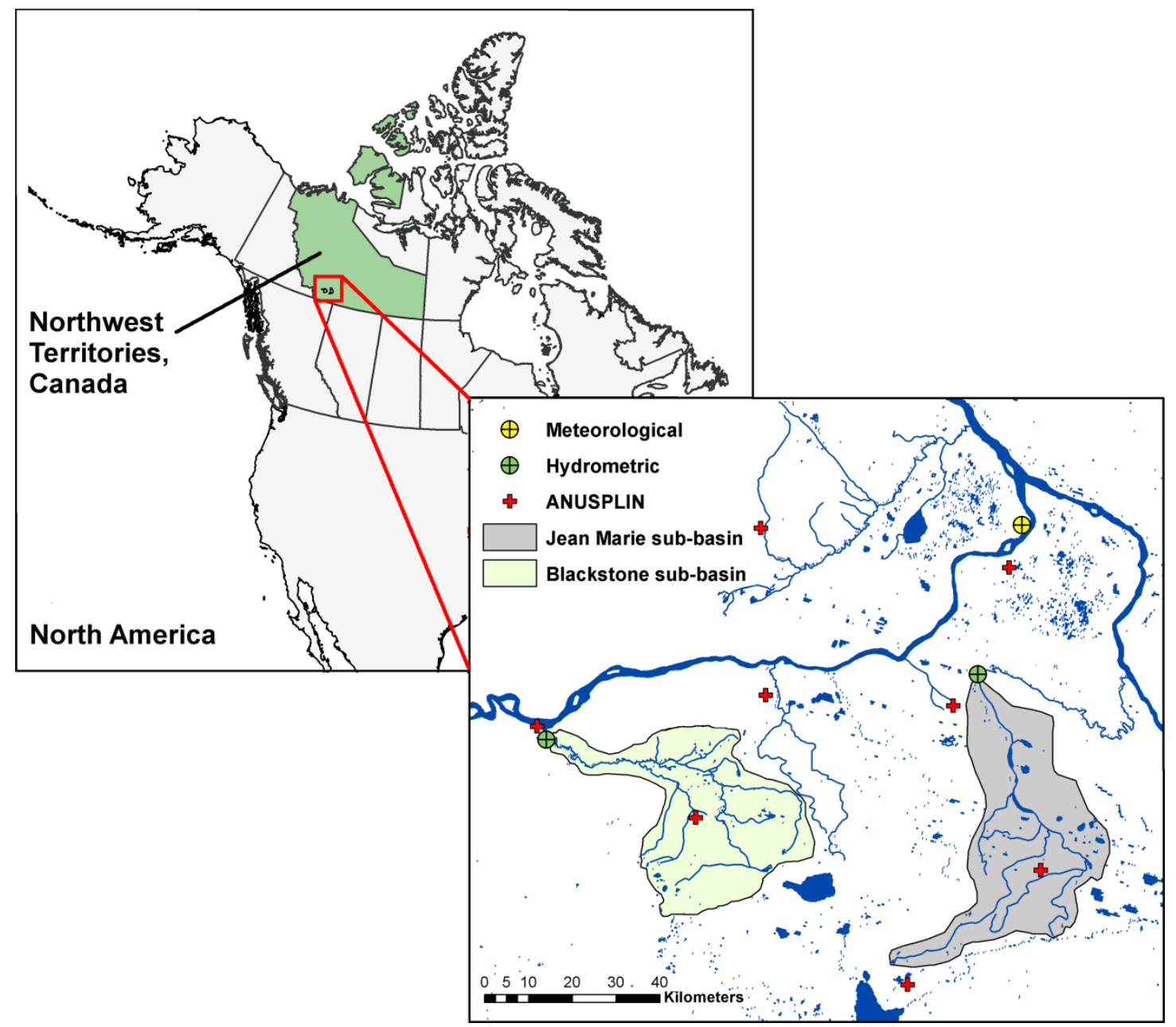

The land cover classification breakdown (Table 10) shows the primary land cover type within the sub-basins as transitional, consisting of shrubs, deciduous varieties and early generation spruce. The region has a high proportion of wetlands, with the total wetland percentage in Table 10 representing both bogs (disconnected drainage) and fens (connected drainage); although the amount of each type within each respective sub-basin varies. Aylsworth and Kettles (2000) state 


\section{Chapter 5}

that Jean-Marie is predominately fen peatlands, while Blackstone is bog-dominated peatlands, with very few or no fen peatlands present.

Table 10: Basin characteristics, including land cover classification, area, and average basin slope (recreated from data provided in St Amour et al., 2005)

\begin{tabular}{|c|c|c|c|c|c|c|c|c|}
\hline \multirow{2}{*}{ Sub-basin } & \multicolumn{6}{|c|}{ Land Cover Classification (\%) } & \multirow{2}{*}{$\begin{array}{l}\text { Area } \\
\left(\mathbf{k m}^{2}\right)\end{array}$} & \multirow{2}{*}{$\begin{array}{c}\text { Basin } \\
\text { Slope (\%) }\end{array}$} \\
\hline & Deciduous & Mixed & Coniferous & Transitional & Wetland & Water & & \\
\hline Jean- Mar & 5 & 22 & 23 & 31 & 14 & 1.3 & 1310 & 0.3 \\
\hline Blackstone $\mathbf{F}$ & 7 & 17 & 14 & 39 & 21 & 0.7 & 1390 & 0.63 \\
\hline
\end{tabular}

The Ecoregions Working Group (1989) classifies the FSB as a sub-humid mid- to high-boreal ecoclimatic region (Hbs), classified by cool summers approximately five months in length, with moderate $(300-500 \mathrm{~mm})$ annual precipitation. Winters are very cold with persistent snow cover. The hydrological response is dominated by snowmelt during late April to early May, while summer and fall runoff events are due to major rainfall, with a return to baseflow occurring during dry summer periods or towards the beginning of the ice-on season in October.

\subsubsection{Meteorological and Hydrometric Data}

Daily total precipitation, mean daily temperature, and hourly relative humidity data are obtained from Environment Canada's Fort Simpson Airport weather station. Observed precipitation is supplemented with ANUSPLIN-derived daily precipitation extracted at eight locations throughout the Fort Simpson region (Figure 23). ANUSPLIN is a multidimensional nonparametric surface fitting method that has been found well suited to the interpolation of various climate variables, particularity in data-sparse, high-elevation regions as the method accounts for spatially varying dependencies on elevation (McKenney et al., 2011). An inverse-distance weighting approach is used spatially distribute the daily ANUSPLIN and observed precipitation time series across the model domain (Kouwen, 2014). Rainfall that occurred over the study 


\section{Chapter 5}

period, particularly in 1997, was significantly higher than normal. Additionally, 1998 was above average in temperature, which is especially prevalent in the first portion of the year. Other researchers have attributed the increased rainfall and warmer temperatures to a strong El Niño influence from mid-1997 to mid-1998 (Petrone et al., 2000; St Amour et al., 2005).

Hydrometric records are obtained from Water Survey of Canada. Jean Marie was gauged at Highway No.1 in 1972 with a period of record of 44 years, whereas Blackstone was gauged at Highway No.7 in 1991 having a record length of 25 years. Neither sub-basin is regulated, therefore all flows are considered to be natural. During the study period, mean annual discharge was above normal in both sub-basins in 1997, normal in Jean Marie and slightly below normal in Blackstone in 1998, and below normal in both sub-basins in 1999. A statistical summary of observations used in this study is provided in Table 11.

Table 11: Data summary for the study period (SP) and period of record (PoR). The coefficient of variation $(C V)$ is calculated as the ratio of the standard deviation to the mean.

\begin{tabular}{|c|c|c|c|c|c|}
\hline Variable (gauge ID) & Unit & $\begin{array}{c}\text { Number of } \\
\text { Measurements }\end{array}$ & $\begin{array}{c}\text { Mean } \\
(\text { SP,PoR }) \\
\end{array}$ & $\begin{array}{c}\text { CV } \\
\text { (SP, PoR) }\end{array}$ & $\begin{array}{l}\text { SP Range } \\
(\text { min, max })\end{array}$ \\
\hline \multicolumn{6}{|c|}{ Hydrometric/Meteorological Data } \\
\hline $\begin{array}{c}\text { Daily Average Streamflow } \\
\text { Jean Marie (10FB005) }\end{array}$ & $\mathrm{m}^{3} / \mathrm{s}$ & 1095 & $4.66,5.25$ & $1.24,2.06$ & $0.19,34.9$ \\
\hline $\begin{array}{c}\text { Daily Average Streamflow } \\
\text { Blackstone (10ED007) }\end{array}$ & $\mathrm{m}^{3} / \mathrm{s}$ & 1095 & $8.96,10.76$ & $1.65,2.17$ & $0.04,109$ \\
\hline $\begin{array}{l}\text { Mean Daily Air Temperature } \\
\text { Fort Simpson (2202101) }\end{array}$ & ${ }^{\circ} \mathrm{C}$ & 1093 & $-1.5,-3.02$ & N/A & $-40.8,25.3$ \\
\hline $\begin{array}{l}\text { Daily Precipitation } \\
\text { Fort Simpson (2202101) }\end{array}$ & $\mathrm{mm}$ & 1088 & $1.12,1.01$ & $3.04,3.19$ & $0.0,43.0$ \\
\hline $\begin{array}{l}\text { Hourly Relative Humidity* } \\
\text { Fort Simpson (2202101) } \\
\end{array}$ & $\%$ & 26280 & 73.9 & 0.24 & 14,100 \\
\hline \multicolumn{6}{|c|}{ Isotopic Measurements* } \\
\hline Streamflow $\delta^{18} \mathrm{O}-$ Jean Marie & $\%$ & 71 & -19.70 & 0.03 & $-21.34,-18.72$ \\
\hline Streamflow $\delta^{18} \mathrm{O}$ - Blackstone & $\%$ & 69 & -20.17 & 0.06 & $-24.01,-17.92$ \\
\hline $\begin{array}{l}\text { Rainfall } \delta^{18} \mathrm{O} \\
\text { Jean Marie and Blackstone }\end{array}$ & $\%$ & 27 & -17.55 & 0.23 & $-26.70,-11.12$ \\
\hline \multicolumn{6}{|c|}{ Precipitation $\delta^{18}$ O Forcing* } \\
\hline $\mathrm{KPN} 43 \delta^{18} \mathrm{O}_{\mathrm{ppt}}$ input & $\%$ & $\begin{array}{l}1800 \text { (36 values at } \\
50 \text { grid points) }\end{array}$ & -20.48 & 0.19 & $-28.86,-13.91$ \\
\hline
\end{tabular}




\section{Chapter 5}

\begin{tabular}{|l|c|c|c|c|c|}
\hline REMOiso $\delta^{18} \mathrm{O}_{\mathrm{ppt}}$ input & $\%$ & $\begin{array}{c}54750(1095 \text { values } \\
\text { at } 50 \text { grid points })\end{array}$ & -21.78 & 0.25 & $-42.82,-10.68$ \\
\hline Static $\delta^{18} \mathrm{O}_{\text {ppt }}$ input & $\%$ & $\begin{array}{c}300(6 \text { values at } 50 \\
\text { grid points })\end{array}$ & -22.82 & 0.20 & $-29.35,-16.52$ \\
\hline
\end{tabular}

* Provided only for the study period, 1997 - 1999.

\subsubsection{Isotope Data}

During 1997 to 1999, intensive sampling took place in the Fort Simpson Basin as part of the Mackenzie Study of the Global Energy and Water Experiment (GEWEX; Stewart et al., 1998). The campaign sampled $\delta^{18} \mathrm{O}$ and $\delta^{2} \mathrm{H}$ of streamflow, rainfall, snowpack, and surface waters (wetlands and lakes) during the open water season (May to October). During ice-on conditions, the isotope stratigraphy of river ice extracted during late March in 1998 and 1999 was used to reconstruct the isotopic composition of winter streamflow (Gibson and Prowse, 1999; Prowse et al., 2002; St Amour et al., 2005). This study uses measured $\delta^{18} \mathrm{O}$ compositions in streamflow $\left(\delta^{18} \mathrm{O}_{\mathrm{SF}}\right)$ in the Jean-Marie $(\mathrm{n}=71)$ and Blackstone $(\mathrm{n}=69)$ sub-basins for model calibration. Although $\delta^{18} \mathrm{O}_{\mathrm{ppt}}$ compositions $(\mathrm{n}=27)$ were collected as part of the GEWEX sampling campaign, their spatial and temporal resolutions are not adequate for model forcing. These data are incorporated into the study as a means to validate simulated $\delta^{18} \mathrm{O}_{\mathrm{ppt}}$ forcing input, when available. The number of measurements and their statistical properties are summarized in Table 11. Isotopic compositions of $\delta^{18} \mathrm{O}$ are expressed in delta $(\delta)$ notation as a deviation from VSMOW (Vienna Mean Standard Mean Ocean Water) in units of per mille (\%o), such that such that $\delta_{\text {water }}=\left(\mathrm{R}_{\text {water }} / \mathrm{R}_{\text {VSMOw }}-1\right) \times 1000 \%$, where $\mathrm{R}$ is ${ }^{18} \mathrm{O} /{ }^{16} \mathrm{O}$ in the sample and standard, respectively. Isotope samples were analyzed at the Environmental Isotope Laboratory at the University of Waterloo, and St Amour et al. (2005) indicated maximum analytical uncertainties of $\pm 0.1 \%$ for $\delta^{18} \mathrm{O}$. 


\section{Chapter 5}

\subsubsection{Precipitation Oxygen-18 Input}

The default method for $\delta^{18} \mathrm{O}_{\mathrm{ppt}}$ input in isoWATFLOOD is compositions of rainfall and snowfall $\delta^{18} \mathrm{O}$ for each year of the simulation. Values for the FSB are obtained through averaged measurements of $\delta^{18} \mathrm{O}$ in rainfall and snowpack from the GEWEX study (Table 12; Table 11). $\delta^{18} \mathrm{O}_{\mathrm{ppt}}$ compositions are assumed constant throughout the watershed domain. Due to the averaged values and lack of spatial variability, this input type is referred to as 'static' throughout the remainder of the manuscript.

Table 12: Static $\delta^{18} O_{\text {ppt }}$ input compositions of annual rainfall and snowfall oxygen-18 for isoWATFLOOD.

\begin{tabular}{|c|c|c|}
\hline Year & $\begin{array}{c}\delta^{18} \text { O rainfall } \\
\text { (\%) }\end{array}$ & $\begin{array}{c}\delta^{18} \text { O snowfall } \\
\text { (\%o) }\end{array}$ \\
\hline 1996 & -17.00 & -29.35 \\
\hline 1997 & -19.10 & -29.35 \\
\hline 1998 & -20.10 & -25.03 \\
\hline 1999 & -16.52 & -26.79 \\
\hline
\end{tabular}

Times series simulations obtained from the KPN43 model created by Delavau et al. (2015) are used as a secondary $\delta^{18} \mathrm{O}_{\mathrm{ppt}}$ input. The KP43 model uses North American Regional Reanalysis (NARR; Mesinger et al., 2006) climate variables, teleconnection indices, and geographic information to produce gridded time series of oxygen-18 in precipitation at a monthly time step. This input is generated at a $10 \mathrm{~km}$ resolution (to mirror model set-up), and varies spatially throughout the study area due to the variation in the climatic predictors and geographic information required to produce simulations.

The third $\delta^{18} \mathrm{O}_{\mathrm{ppt}}$ input assessed in this study is regional climate model output from the isotopeenabled climate model, REMOiso (Sturm et al., 2005; Sturm et al., 2007). Raw REMOiso $\delta^{18} \mathrm{O}_{\mathrm{ppt}}$ output is available at a $55 \mathrm{~km}$ spatial resolution and a 6-hour time step. However, 


\section{Chapter 5}

REMOiso output is averaged to a daily time-step, as the range and variability of sub-daily $\delta^{18} \mathrm{O}_{\mathrm{ppt}}$ are erroneously large, and the resolution of streamflow oxygen-18 calibration data do not warrant a temporal frequency of input finer than daily.

\subsubsection{REMOiso Bias Correction}

Due to a lack of published studies evaluating REMOiso performance within Canada, a comparison between REMOiso output and Canadian Network for Isotopes in Precipitation observations (CNIP; Birks and Gibson, 2009) is completed to determine if REMOiso simulations require a regional bias correction. CNIP data are now part of the Global Network for Isotopes in Precipitation (GNIP) database and can be accessed at: http://www.iaea.org/water (IAEA, 2014). This analysis is completed at Snare Rapids, NWT, the closest CNIP station to the FSB, for the years of 2000 and 2001. Snare Rapids is located approximately $330 \mathrm{~km}$ northeast of Fort Simpson and has monthly $\delta^{18} \mathrm{O}_{\mathrm{ppt}}$ observations spanning the years of $1997-2010$. A longer time frame of comparison between CNIP and REMOiso is not possible due to the short overlapping period of REMOiso simulations and CNIP observations. Daily REMOiso simulations are averaged to monthly compositions for direct comparison to CNIP data using a precipitation amount-weighting approach:

$\delta^{18} O_{p p t \text { monthly }}=\sum P_{i} *\left(\delta^{18} O_{p p t}\right)_{i} / \sum P_{i}$

(Equation 18)

$P_{i}$ is the amount of daily precipitation [mm] obtained from the Snare Rapids Canadian Air and Precipitation Monitoring Network (CAPMoN) station operated by Environment Canada, where isotopic compositions are also sampled. 


\section{Chapter 5}

Uncorrected REMOiso simulations exhibit a positive bias in this region (Figure 24), which is expected based on the ECHAM4 mean annual $\delta^{18} \mathrm{O}_{\mathrm{ppt}}$ output (Noone and Sturm, 2010) and personal communications with S. J. Birks and K. Sturm (2016). Therefore, a seasonal bias correction is applied to daily REMOiso simulations. The bias correction is calculated as the average seasonal difference between the monthly amount-weighted REMOiso output and the CNIP observations (Table 13). Corrected monthly and daily REMOiso output at Snare Rapids are displayed on Figure 24 as the dashed red and solid orange lines, respectively.

Table 13: Seasonal REMOiso bias correction.

\begin{tabular}{|l|c|}
\hline Season & Correction (\%) \\
\hline November - December - January - February & -4.5 \\
\hline March - April - May & -8.9 \\
\hline June - July - August & -7.3 \\
\hline Septemer - October & -8.5 \\
\hline Average Correction Applied: & $\mathbf{- 7 . 0}$ \\
\hline
\end{tabular}

Figure 24: Comparison of raw and corrected REMOiso $\delta^{18}{ }_{\text {ppt }}$ output with CNIP monthly compositions at Snare Rapids, NWT.

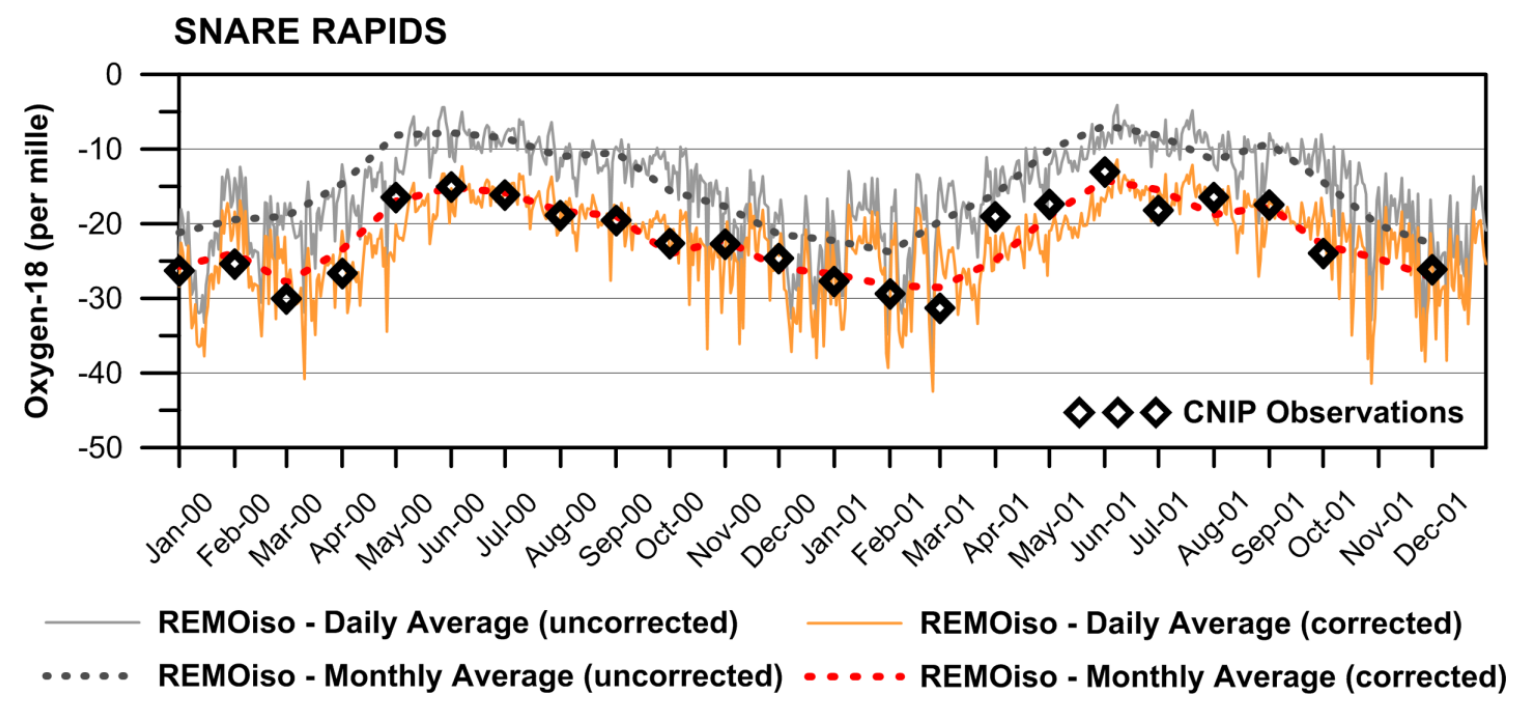

For the current study, daily REMOiso output for the Fort Simpson region is bias corrected with the seasonal values in Table 13. The statistical properties of the corrected daily REMOiso 


\section{Chapter 5}

simulations, alongside the KPN43 monthly simulations and the static seasonal averages are summarized in Table 11.

\subsection{Methods}

\subsubsection{Background and Set-up}

The tracer-aided hydrological model used in this study is isoWATFLOOD (Stadnyk-Falcone, 2008; Stadnyk et al., 2013). isoWATFLOOD is an extension of the WATFLOOD hydrological model, whereby water and oxygen-18 are simultaneously budgeted throughout the modelled hydrologic cycle. WATFLOOD is a distributed model that uses grouped response units (GRU's) to simulate streamflow in hydrologically-distinct land cover units (Kouwen et al., 1993; Kouwen, 2014). Process representation within WATFLOOD is considered to be a combination of both conceptual and physical, as certain algorithms are conceptually-based (e.g. evaporation and snowmelt), while others are more based in physics (e.g. channel routing). Due to the coupling of isotopes to each hydrological processes simulated in WATFLOOD, simulation of isotopic composition does not introduce any additional parameters. A more comprehensive description of isoWATFLOOD's model structure and governing equations can be found in Stadnyk et al. (2013) and select descriptions are provided in Table 15.

isoWATFLOOD requires $\delta^{18} \mathrm{O}$ of rainfall and snowfall and hourly distributed relative humidity

to force the model. Additionally, $\delta^{18} \mathrm{O}$ compositions for hydrologic storages of river/fen water, soil water, baseflow, and snowpack are needed for model initialization, which can be obtained from field data or estimated. Here, regional isotopic initializations are derived from measured data (St Amour et al., 2005), and are summarized in Table 14. Sensitivity analyses have shown 


\section{Chapter 5}

that within one month of simulation isoWATFLOOD spin-up is complete and, past this point, initialization values have no bearing on model output. All other data required by isoWATFLOOD (e.g. distributed precipitation, temperature, evaporation, inflows, etc.) are passed from WATFLOOD forcings or computations.

Table 14: Initialization values for FSB isoWATFLOOD simulations.

\begin{tabular}{|c|l|c|}
\hline Variable & Description & Value (\%o) \\
\hline$\delta^{18} \mathrm{O}_{\mathrm{sf}}$ & Background delta for river water initialization & -13.52 \\
\hline$\delta^{18} \mathrm{O}_{\mathrm{IF}}$ & Background delta for soil water initialization & -14.60 \\
\hline$\delta^{18} \mathrm{O}_{\mathrm{GW}}$ & Background delta for groundwater initialization & -20.00 \\
\hline$\delta^{18} \mathrm{O}_{\mathrm{SNW}}$ & Background delta for snow initialization & -22.00 \\
\hline
\end{tabular}

The watershed model set-up in this study is based off the version used by Stadnyk et al. (2013), with several changes and improvements. Based on findings from Aylsworth and Kettles (2000), we implemented a $90 \%$ bog and $10 \%$ fen split in Blackstone and a $30 \%$ bog and $70 \%$ fen split in Jean-Marie. The entirety of the FSB is modelled at a $10-\mathrm{km}$ spatial resolution, and the model is run continuously from January 1996 to December 1999; whereby 1996 is utilized as spin-up to set initial hydrologic and isotopic storage conditions.

\subsubsection{Calibration and Parameter Uncertainty}

Being a distributed model, WATFLOOD has a large number of parameters requiring calibration. For this reason, a sensitivity analysis is first conducted to identify which parameters have the largest influence on both streamflow and $\delta^{18} \mathrm{O}_{\text {SF. }}$ A subset of parameters are identified for inclusion in the calibration based on this sensitivity analysis, including nine hydrological parameters from each of the five most prominent land classes (mixed/deciduous, coniferous, transit, bogs and fens), and four routing parameters from each of the two modelled sub-basins. This results in 53 parameters that are incorporated in the parameter uncertainty assessment 


\section{Chapter 5}

(Table 15; Table 17). Allowable ranges for each parameter are determined based on published values alongside personal communications with N. Kouwen (Kouwen, 2014) (Table 17).

Table 15: Parameters included in the Monte Carlo calibration, alongside a description of what the parameter represents and the algorithm it is used within.

\begin{tabular}{|c|c|c|}
\hline Name & Description & Algorithm \\
\hline \multicolumn{3}{|c|}{ Routing Parameters } \\
\hline$p w r$ & $\begin{array}{l}\text { Lower zone drainage function } \\
\text { Lower zone drainage function } \\
\text { exponent }\end{array}$ & $\begin{array}{c}\text { An exponential ground water depletion function that gradually } \\
\text { diminishes the base flow. Ground water is replenished by } \\
\text { drainage of the UZS: } \\
\text { QLZ }=\mathbf{L Z F} *(\mathbf{L Z S}) \text { PWR } \\
\text { Where: } \text { LZS is lower zone storage } \\
\text { QLZ is the baseflow flux }\end{array}$ \\
\hline $\begin{array}{l}\text { theta } \\
\text { kcond }\end{array}$ & $\begin{array}{c}\text { Wetland porosity } \\
\text { Conductivity parameter }\end{array}$ & $\begin{array}{l}\text { Physically-based wetland routing algorithm } \\
\text { (McKillop et al., 1999) }\end{array}$ \\
\hline \multicolumn{3}{|c|}{ Hydrologic Parameters } \\
\hline$f$-ratio & Interception capacity multiplier & $\begin{array}{c}\text { Conceptual evaporation algorithm based on Hargreaves and } \\
\text { Samani (1982). } f \text {-ratio is a multiplier for the interception } \\
\text { capacity for each land class. }\end{array}$ \\
\hline$a k$ & $\begin{array}{l}\text { Surface permeability (bare ground) } \\
\text { Surface permeability }\end{array}$ & $\begin{array}{c}\text { Conceptual infiltration algorithm (similar to Green and Ampt, } \\
\text { 1911); but based on Richard's equation which is physically- } \\
\text { based (Philip, 1954) }\end{array}$ \\
\hline retn & $\begin{array}{l}\text { Interflow coefficient } \\
\text { Upper zone retention }[\mathrm{mm}]\end{array}$ & $\begin{array}{c}\text { Interflow is represented by a simple storage-discharge } \\
\text { relation: } \\
\text { DUZ }=\mathbf{R E C} *(\mathbf{U Z S}-\mathbf{R E T N}) * \mathbf{S i} \\
\text { Where: } \mathrm{UZS}=\text { upper zone storage } \\
\text { DUZ = depth of upper zone storage released as interflow } \\
\mathrm{Si}=\text { internal land surface slope }\end{array}$ \\
\hline$a k 2$ & Recharge coefficient (bare ground) & $\begin{array}{c}\text { Upper zone to lower zone drainage is represented by a simple } \\
\text { storage-discharge relation: } \\
\text { DRNG = AK } 2 * \text { (UZS - RETN) } \\
\text { Where: DRNG is the drainage from UZS to LZS }\end{array}$ \\
\hline $\begin{array}{c}m f \\
\text { base }\end{array}$ & $\begin{array}{l}\text { Melt factor }\left[\mathrm{mm} /{ }^{\circ} \mathrm{C} / \mathrm{hr}\right] \\
\text { Base Temperature }\left[{ }^{\circ} \mathrm{C}\right]\end{array}$ & $\begin{array}{c}\mathbf{M}=\mathbf{M F}\left(\mathbf{T}_{\mathbf{a}}-\mathbf{b a s e}\right) \\
\text { Anderson }(1976)\end{array}$ \\
\hline$s u b$ & Sublimation factor & $\begin{array}{c}\text { Sublimation is modelled by a static sublimation factor. } \\
\text { Amount of sublimation is a fraction of the observed snowfall. } \\
\text { For new model setups, the sublimation factor has been } \\
\text { replaced by a static sublimation rate. }\end{array}$ \\
\hline
\end{tabular}

This study uses a multi-criteria, multi-objective approach to model calibration, with the procedure summarized as follows: 


\section{Chapter 5}

i. A Monte Carlo random sampling approach, assuming uniform parameter distributions, is used to individually select each parameter from its allowable range (Table 17). Random parameter sampling is completed 30,000 times, generating 30,000 unique parameter sets for isoWATFLOOD model evaluation.

ii. For each of the three $\delta^{18} \mathrm{O}_{\mathrm{ppt}}$ inputs (KPN43, REMOiso and static), streamflow and $\delta^{18} \mathrm{O}_{\mathrm{SF}}$ are simulated from 1996 to 1999 for all 30,000 parameter sets (as defined in (i)).

iii. $\quad$ Modelled streamflow and $\delta^{18} \mathrm{O}_{\mathrm{SF}}$ are assessed statistically over the period of study (1997 - 1999, excluding the 1996 spin-up year), and regionally across the Jean Marie and Blackstone sub-basins. Simulations are classified as behavioural or non-behavioural based on the following set of efficiency criteria thresholds for streamflow and $\delta^{18} \mathrm{O}_{\mathrm{SF}}$ :

a. Streamflow:

$$
\begin{aligned}
& \text { NSE }>=0.5 ; \\
& |\% \mathrm{Dv}|<=20 \% \text {, and; } \\
& |\log (\% \mathrm{Dv})|<=20 \% .
\end{aligned}
$$

b. $\delta^{18} \mathrm{O}_{\mathrm{SF}}$ :

$$
\begin{aligned}
& \text { RMSE }<=2.5 \% \text {, and; } \\
& \text { KGE }>=0.3 .
\end{aligned}
$$

iv. All reported results, such as simulation means, percentiles and parameter values, are derived from behavioural simulations corresponding to each $\delta^{18} \mathrm{O}_{\mathrm{ppt}}$ input. The presented uncertainty bounds are the $5^{\text {th }}$ and $95^{\text {th }}$ percentiles of simulated streamflow, $\delta^{18} \mathrm{O}_{\mathrm{SF}}$, and snowpack $\delta^{18} \mathrm{O}$, drawn from the behavioural simulations at each time step for each $\delta^{18} \mathrm{O}_{\mathrm{ppt}}$ input.

The behavioural thresholds used in this study are subjectively defined, however, are arrived at through a review of methods employed in similar studies (e.g. Moriasi et al., 2007; Birkel et al., 


\section{Chapter 5}

2010a; 2010b; 2011; Smith et al., 2016), measurement error, and an iterative process exploring the sensitivity between the set thresholds and resulting behavioural simulations for each input type. Based on this analysis, the Nash-Sutcliffe efficiency (NSE; Nash and Sutcliffe, 1970), volumetric error criteria (\%Dv), root mean square error (RMSE), and the Kling-Gupta efficiency criterion (KGE; Gupta et al., 2009; Kling et al., 2012) are selected. A multi-criteria model evaluation approach is used as each criterion places emphasis on different statistical properties of a simulation. For example, NSE has a documented bias towards peak flow, and conversely, log (\%Dv) is more appropriate evaluation measure for periods of low flow. The NSE, \%Dv, and $\log (\% \mathrm{Dv})$ efficiency are not considered suitable metrics for $\delta^{18} \mathrm{O}_{\mathrm{SF}}$ assessment due to the temporal discontinuity of the isotope observations, therefore RMSE and KGE are used as isotopic simulation statistics. It should also be noted that $\delta^{18} \mathrm{O}_{\mathrm{SF}}$ observations are not equally distributed through time, whereby the highest concentration of observations occurs during snowmelt in the month of May ( $25 \%)$, and the fewest observations during the six month ice-on period from November to April ( 23\%). The sporadic distribution of observations may result in the calibrations more highly weighted to certain periods of the year and the dominate processes occurring at that time; therefore having the potential to impact model parameterization.

\subsection{Results and discussion}

Results of the three calibrations indicate that $\delta^{18} \mathrm{O}_{\mathrm{ppt}}$ input influences the number simulations that meet the behavioural criteria thresholds. The KPN43 input results in an increased number of behavioural simulations $(\mathrm{n}=321)$ in comparison to the REMOiso $(\mathrm{n}=268)$ or static $(\mathrm{n}=216)$ input types (Table 16). This suggests that the choice of $\delta^{18} \mathrm{O}_{\mathrm{ppt}}$ input may potentially impact internal apportionment of water (i.e., the modelled proportion of water entering, stored, and 


\section{Chapter 5}

released from the ground surface, upper and lower zones) through model parameterization. A summary of behavioural parameter set characteristics is provided in Table 17. Land cover parameters are reported as weighted averages for the modelled region.

Table 16: Average simulation statistics from $n$ behavioural simulations for streamflow and $\delta^{18} O_{S F}$ for the three model calibrations (using KPN43, REMOiso, and static inputs).

\begin{tabular}{|c|c|c|c|}
\hline $\begin{array}{c}\text { Average statistics } \\
\text { from } \boldsymbol{n} \text { behavioural } \\
\text { simulations }\end{array}$ & KPN43 & REMOiso & Static \\
\hline $\boldsymbol{n}$ & $321 / 30000$ & $268 / 30000$ & $216 / 30000$ \\
\hline Streamflow $(1095$ observations for performance evaluation) \\
\hline $\mathbf{N S E}$ & 0.68 & 0.68 & 0.69 \\
\hline $\boldsymbol{\%} \mathbf{D v} \mid$ & 13.9 & 13.4 & 14.2 \\
\hline $\mathbf{L o g}(\boldsymbol{\%} \mathbf{D v}) \mid$ & 11.5 & 8.9 & 11.6 \\
\hline$\delta^{18} \mathrm{O}_{\mathrm{SF}}(140$ observations for performance evaluation) \\
\hline RMSE & 1.39 & 1.32 & 2.09 \\
\hline KGE & 0.36 & 0.33 & 0.35 \\
\hline
\end{tabular}

Among input types there are potentially significant differences in several parameters, which will be explored further throughout the remainder of the manuscript. In almost all instances, the range of the parameters was not significantly constrained from the allowable parameter range. Due to the wide range of behavioural parameter values (Table 17), we are confident that the approach used is sufficient to characterize parameter uncertainty. However, and not unexpectedly, this finding also indicates that 30,000 model evaluations are not sufficient to quantify parameter identifiability for isoWATFLOOD.

\subsubsection{Precipitation Oxygen-18 Input}

Time series of $\delta^{18} \mathrm{O}_{\mathrm{ppt}}$ inputs for Jean Marie and Blackstone are displayed on panel (a) of Figure 25 and Figure 26, respectively. On average, KPN43 input is the most enriched (-20.48\%o), followed by REMOiso (-21.78\%), with static being the most depleted (-22.82\%o). KPN43 and static inputs have similar variation about their mean values, with CV's equal to 0.19 and 0.20 , 


\section{Chapter 5}

respectively. Conversely, REMOiso has a higher CV (0.25) and much larger range, which is, in part, due to the finer daily time step of this input. Spatial variability between Jean Marie and Blackstone sub-basins is zero for the static input; however some variation among sub-basins is seen for KPN43 and REMOiso. Interestingly, both the KPN43 and REMOiso inputs show, on average, more depleted $\delta^{18} \mathrm{O}_{\mathrm{ppt}}$ values within Blackstone (-20.79\% and -22.01\%, respectively) in comparison to Jean Marie (-20.17\%o and $-21.54 \%$, respectively), in addition to increased variability. This is likely caused by the higher elevations present in the headwaters of the Blackstone relative to the Jean Marie (a maximum difference of $\sim 215$ meters).

Although there are only 19 rainfall $\delta^{18} \mathrm{O}$ observations collected over the study period for Jean Marie, and eight within Blackstone (hollow black diamonds on Figure 25 and Figure 26), these limited data provide some information regarding accuracy of the estimated $\delta^{18} \mathrm{O}_{\mathrm{ppt}}$ inputs. By visual inspection, each of the three inputs produces reasonable estimates of $\delta^{18} \mathrm{O}_{\mathrm{ppt}}$. This is expected for the static input as the seasonal compositions are derived from observations; however, this comparison provides some level of validation for KPN43 and REMOiso. REMOiso is the only input that can somewhat replicate the event-scale variability in $\delta^{18} \mathrm{O}_{\mathrm{ppt}}$ due to its daily time step. Both KPN43 and static inputs appear to generally capture the average magnitude of summer rainfall events and overall seasonal variability; however there are insufficient observations to statistically support this statement within the Fort Simpson basin. 


\section{Chapter 5}

Table 17: Allowable parameter ranges and resulting averaged parameter characteristics for behavioural simulations retained from the three model calibrations (KPN43, REMOiso, and static inputs). Parameters are summarized as: median (minimum, maximum).

\begin{tabular}{|c|c|c|c|c|}
\hline Parameter & $\begin{array}{c}\text { Allowable } \\
\text { Range }\end{array}$ & KPN43 & REMOiso & static \\
\hline \multicolumn{5}{|c|}{ Jean Marie Sub-basin } \\
\hline$l z f$ & {$\left[1 \times 10^{-7}, 1 \times 10^{-4}\right]$} & $8.60 \times 10^{-6}\left(1.49 \times 10^{-7}, 9.32 \times 10^{-5}\right)$ & $8.60 \times 10^{-6}\left(2.03 \times 10^{-7}, 9.86 \times 10^{-5}\right)$ & $8.60 \times 10^{-6}\left(2.03 \times 10^{-7}, 9.86 \times 10^{-5}\right)$ \\
\hline$p w r$ & {$[1,4]$} & $3.05(1.33,4.00)$ & $3.38(1.12,4.00)$ & $3.39(1.12,3.96)$ \\
\hline theta & {$[0.1,1.0]$} & $0.60(0.13,0.96)$ & $0.61(0.13,1.0)$ & $0.60(0.13,0.98)$ \\
\hline kcond & {$[0.1,1.5]$} & $0.79(0.17,1.46)$ & $0.68(0.17,1.46)$ & $0.86(0.17,1.46)$ \\
\hline \multicolumn{5}{|c|}{ Blackstone Sub-basin } \\
\hline$l z f$ & {$\left[1 \times 10^{-7}, 1 \times 10^{-4}\right]$} & $2.30 \times 10^{-5}\left(4.19 \times 10^{-7}, 9.41 \times 10^{-5}\right)$ & $4.91 \times 10^{-5}\left(5.36 \times 10^{-7}, 9.95 \times 10^{-5}\right)$ & $1.67 \times 10^{-5}\left(3.02 \times 10^{-7}, 9.86 \times 10^{-5}\right)$ \\
\hline$p w r$ & {$[1,4]$} & $3.34(1.82,3.96)$ & $3.21(1.35,3.96)$ & $3.57(2.28,3.91)$ \\
\hline theta & {$[0.1,1.0]$} & $0.55(0.11,1.0)$ & $0.60(0.13,1.0)$ & $0.52(0.24,1.0)$ \\
\hline kcond & {$[0.1,1.5]$} & $0.69(0.11,1.41)$ & $0.80(0.21,1.48)$ & $0.69(0.17,1.49)$ \\
\hline \multicolumn{5}{|c|}{ Land Cover Weighted-Average Parameter results: median (minimum, maximum) } \\
\hline fratio & {$[0.1,2.5]$} & $0.70(0.12,2.22)$ & $0.70(0.15,2.16)$ & $0.80(0.12,2.23)$ \\
\hline$a k$ & {$[1,50]$} & $21.6(2.1,47.6)$ & $25.8(2.4,47.5)$ & $23.6(1.2,46.9)$ \\
\hline$a k f s$ & {$[0.005,2]$} & $0.212(.006,1.878)$ & $0.059(0.006,1.724)$ & $0.203(0.006,1.850)$ \\
\hline rec & {$[0.05,1]$} & $0.47(0.08,0.90)$ & $0.46(0.08,0.88)$ & $0.43(0.09,0.90)$ \\
\hline retn & {$[10,200]$} & $122(18,189)$ & $119(23,181)$ & $114(20,186)$ \\
\hline$a k 2$ & {$[.001,0.2]$} & $0.013(0.001,0.188)$ & $0.008(0.001,0.172)$ & $0.021(0.001,0.184)$ \\
\hline$m f$ & {$[0.075,0.2]$} & $0.117(0.076,0.189)$ & $0.119(0.078,0.190)$ & $0.112(0.076,0.189)$ \\
\hline base & {$[-3.5,3.5]$} & $-0.20(-3.28,3.14)$ & $0.34(-2.81,3.13)$ & $-0.35(-3.11,2.85)$ \\
\hline sub & {$[0.1,1.1]$} & $0.53(0.11,1.05)$ & $0.43(0.13,1.05)$ & $0.50(0.11,1.05)$ \\
\hline
\end{tabular}




\section{ChAPTER 5}

\subsubsection{Modelling Streamflow}

All calibrations adequately capture variations in total streamflow in both sub-basins, as emphasised by the regional calibration statistics (Table 16). On average, behavioural streamflow simulations have a NSE of 0.68 , and $\% \mathrm{Dv}$ of $13.8 \%$. Mean daily streamflow and uncertainty bounds for the KPN43, REMOiso and static model calibrations are displayed on panel (b) of Figure 25 and Figure 26. Differences in hydrograph characteristics between Jean Marie and Blackstone are due to variations in basin physiography, storage mechanisms and land cover composition, specifically large differences in average basin slope and wetland dynamics (St Amour et al., 2005).

Within the Jean Marie sub-basin, both the timing and volume of peak flows derived from snow melt and early summer rains are well captured in 1998, however, volume is under predicted in 1997 and 1999 for the average streamflow simulation. The model also has difficultly capturing the volume of the recession limb, which may be attributed to the parameterization of baseflow and fen response in this sub-basin. In the Blackstone, the recession limb of the hydrograph and low flow volume are well modelled, however peak flows (with the exception of the 1997 snow melt) are under estimated. Within both sub-basins, flows from 1997 fall rain events are well captured, except for an October 1998 rainfall event that generated a limited streamflow response in both sub-basins. This may point to inadequate precipitation forcing due to the climate station proximity and high spatial variability of rainfall, or possibly inadequate soil moisture parameterization. 


\section{Chapter 5}

Figure 25: Input and behavioural simulations for Jean Marie, including: (a) KPN43, REMOiso and static $\delta^{18} O_{\text {ppt }}$ input time series and daily precipitation; and simulated $(b)$ mean daily streamflow and uncertainty bounds and (c) mean daily $\delta^{18} O_{S F}$ and uncertainty bounds, for KPN43, REMOiso and static driven model calibrations. $\delta^{18} O_{\text {ppt }}$ input-specific uncertainty bounds are represented as the shaded regions, with shading colour corresponding to $\delta^{18} O_{\text {ppt }}$ type.
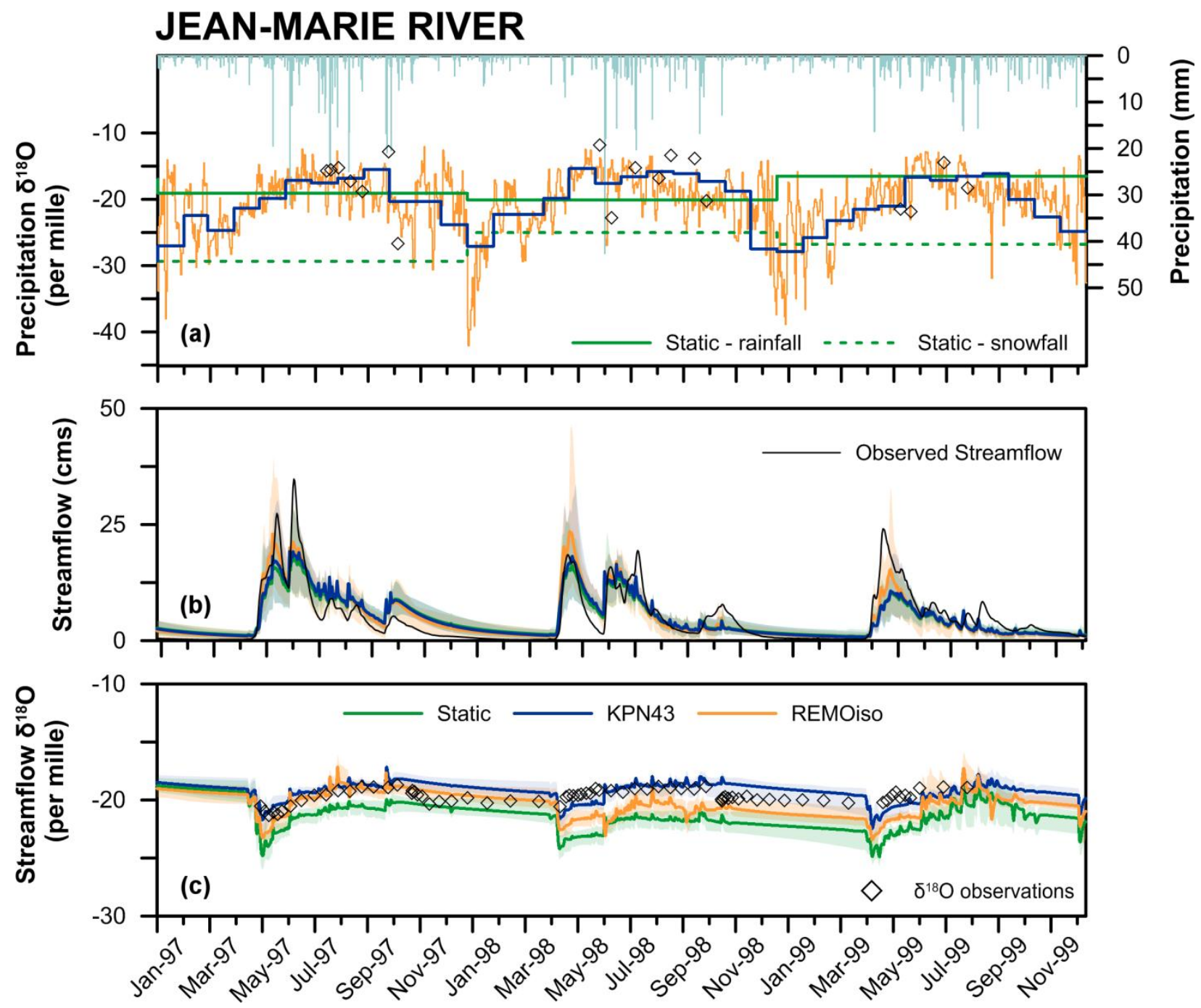


\section{Chapter 5}

Figure 26: Input and behavioural simulations for Blackstone, including: (a) KPN43, REMOiso and static $\delta^{18} O_{\text {ppt }}$ input time series and daily precipitation; and simulated $(b)$ mean daily streamflow and uncertainty bounds and (c) mean daily $\delta^{18} O_{S F}$ and uncertainty bounds, for KPN43, REMOiso and static driven model calibrations. $\delta^{18} O_{\text {ppt }}$ input-specific uncertainty bounds are represented as the shaded regions, with shading colour corresponding to $\delta^{18} O_{p p t}$ type.

\section{BLACKSTONE RIVER}
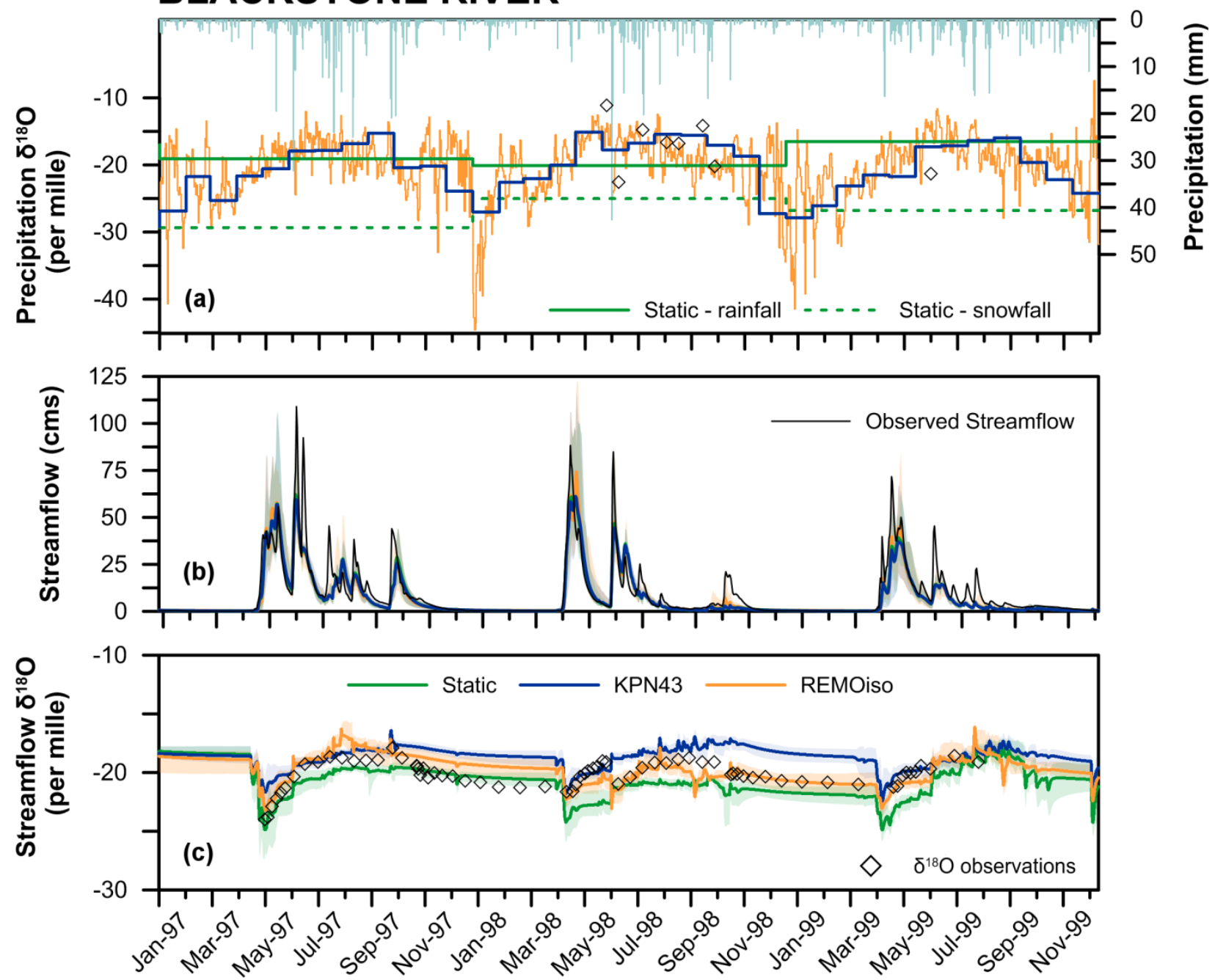

An interesting finding is the similarity of mean streamflow simulation despite contrasting $\delta^{18} \mathrm{O}_{\mathrm{ppt}}$ inputs. Kendall's tau coefficient $(\tau)$ is used to determine the level of correlation between streamflow simulations generated by the three $\delta^{18} \mathrm{O}_{\mathrm{ppt}}$ input methods (and associated model parameterizations). In Jean Marie, $\tau$ ranges between 0.92 (REMOiso versus static) to 0.97 (KPN43 versus static). In Blackstone $\tau$ is more tightly constrained, ranging from 0.96 (REMOiso 


\section{Chapter 5}

versus static) to 0.98 (KPN43 versus static). All $\tau$ values are statistically significant. It should be noted that small deviations between mean streamflow simulations occur during spring melt, where REMOiso driven streamflow consistently shows higher peaks than KPN43 and static driven simulations. However, these differences in mean streamflow fall within overlapping uncertainty bounds and therefore are not deemed significant outside of parameter uncertainty.

\subsubsection{Modelling $\delta^{18} \mathrm{O}$}

Mean daily $\delta^{18} \mathrm{O}_{\mathrm{SF}}$ simulations and uncertainty bounds for KPN43, REMOiso and static model calibrations are displayed on panel (c) of Figure 25 and Figure 26. Each calibration produces mean simulations that capture many of the trends (but not particularly the magnitudes) present in the observed $\delta^{18} \mathrm{O}_{\mathrm{SF}}$ record. Observed $\delta^{18} \mathrm{O}_{\mathrm{SF}}$ show a depletion in $\delta^{18} \mathrm{O}$ due to large influxes of snowmelt during the spring freshets, with $\delta^{18} \mathrm{O}_{\mathrm{SF}}$ gradually enriching over the summer months due to the influence of evaporative enrichment of surface and soil waters, occasionally punctuated by rainfall events that may enrich or deplete $\delta^{18} \mathrm{O}_{\mathrm{SF}}$. During late fall and throughout the winter, $\delta^{18} \mathrm{O}_{\mathrm{SF}}$ tends toward a more depleted, stable groundwater composition (St Amour et al., 2005).

Though each of the calibrations demonstrate many of the same trends as the observed $\delta^{18} \mathrm{O}_{\mathrm{SF}}$ record, there are notable differences. As simulated $\delta^{18} \mathrm{O}_{\mathrm{SF}}$ uncertainly envelopes associated with each input type are, at times, non-overlapping, differences in $\delta^{18} \mathrm{O}_{\mathrm{SF}}$ simulations can be attributed to $\delta^{18} \mathrm{O}_{\mathrm{ppt}}$ input and are therefore are not just an artefact of parameter uncertainty. The dissimilarities between $\delta^{18} \mathrm{O}_{\mathrm{SF}}$ simulations are also reflected in the RMSE statistic (Table 16). The RMSE is larger for static-derived $\delta^{18} \mathrm{O}_{\mathrm{SF}}$ simulations due to increased emphasis on periods 


\section{Chapter 5}

with observed data (i.e., spring freshet), where larger offsets between simulated and observed $\delta^{18} \mathrm{O}_{\mathrm{SF}}$ exist. The KGE statistic does not mirror RMSE, as it shows only minor differences between $\delta^{18} \mathrm{O}_{\mathrm{SF}}$ simulations. The nature of the KGE statistic is to put less emphasis on error offsets derived from peak flows (i.e., spring freshet) by providing a more balanced approach where error is summed first and squared at the end, preserving the sign of the error and enabling a trade-off of error throughout the simulation (Gupta et al., 2009). Therefore, this statistic better reflects the fit of the overall simulation throughout the study period, however, further research is required to better understand the impacts of sporadic sampling resolution (of $\delta^{18} \mathrm{O}_{\mathrm{SF}}$ observations) on efficiency criteria, and consequently the objective functions(s).

Differences in $\delta^{18} \mathrm{O}_{\mathrm{SF}}$ simulations within each sub-basin are due to a combination of: (1) the markedly different $\delta^{18} \mathrm{O}_{\mathrm{ppt}}$ compositions between inputs entering the system during large precipitation events, and (2) the way in which new water flushes through the system via the various hydrological compartments. For this study area, large precipitation events can be further separated into: (1) major rainfall events occurring in post-freshet (summer and fall) months, and (2) the accumulation of winter snowfall and corresponding spring freshet.

Post-freshet $\delta^{18} \mathrm{O}_{\mathrm{SF}}$ simulations are impacted by rainfall amount and composition, as well as the offset between simulated $\delta^{18} \mathrm{O}_{\mathrm{SF}}$ and $\delta^{18} \mathrm{O}_{\mathrm{ppt}}$ input at the time of rainfall. As rainfall amount and/or the offset increases, the resulting impact on simulated $\delta^{18} \mathrm{O}_{\mathrm{SF}}$ also increases. This highlights the importance of capturing the variability in the $\delta^{18} \mathrm{O}_{\mathrm{ppt}}$ input, particularly for large and isotopically distinct (from streamflow) rainfall events. The threshold defining a large rainfall event will vary depending on factors such as basin physiography, land cover, storage capacity 


\section{Chapter 5}

and antecedent conditions. St Amour et al. (2005) estimate this threshold to be $\geq 40 \mathrm{~mm}$ within the Fort Simpson region. An example of a large, yet isotopically distinct, rainfall event is June 11-12, 1998 when approximately $70 \mathrm{~mm}$ fell over two days with an observed $\delta^{18} \mathrm{O}_{\mathrm{ppt}}$ composition of $-22.7 \%$. Both REMOiso and static inputs reasonably captured the event (-20.9\%o and $-20.1 \%$, respectively), however, the KPN43 input predicted a composition of $-17.6 \%$. This single event resulted in a significant offset between KPN43 $\delta^{18} \mathrm{O}_{\mathrm{SF}}$ compared with REMOiso and static $\delta^{18} \mathrm{O}_{\mathrm{SF}}$ which was maintained throughout the remainder of 1998, until the 1999 freshet.

Throughout much of Canada and other regions experiencing a high-latitude climate, a substantial portion of annual streamflow (and typically the peak flow) is generated during the spring freshet when the accumulation of solid precipitation from the winter season melts over the period of a few weeks. Therefore, it is important to understand how differences in $\delta^{18} \mathrm{O}_{\mathrm{ppt}}$ input impact snowpack and snowmelt isotopic compositions in isoWATFLOOD. Figure 27 shows the

evolution of precipitation-weighted snowpack oxygen-18 $\left(\delta^{18} \mathrm{O}_{\mathrm{SNW}}\right)$ throughout each winter season of the study period. 


\section{Chapter 5}

Figure 27: Precipitation-weighted $\delta^{18} O$ of snowpack $\left(\delta^{18} O_{S N W}\right)$ for KPN43, REMOiso and static inputs from January to the end of melt for each year of the study period. Snow water equivalent

(SWE), snowfall (gray line) and rainfall (blue line) are also shown. $\delta^{18} O_{p p t}$ input-specific uncertainty bounds are represented as the shaded regions.

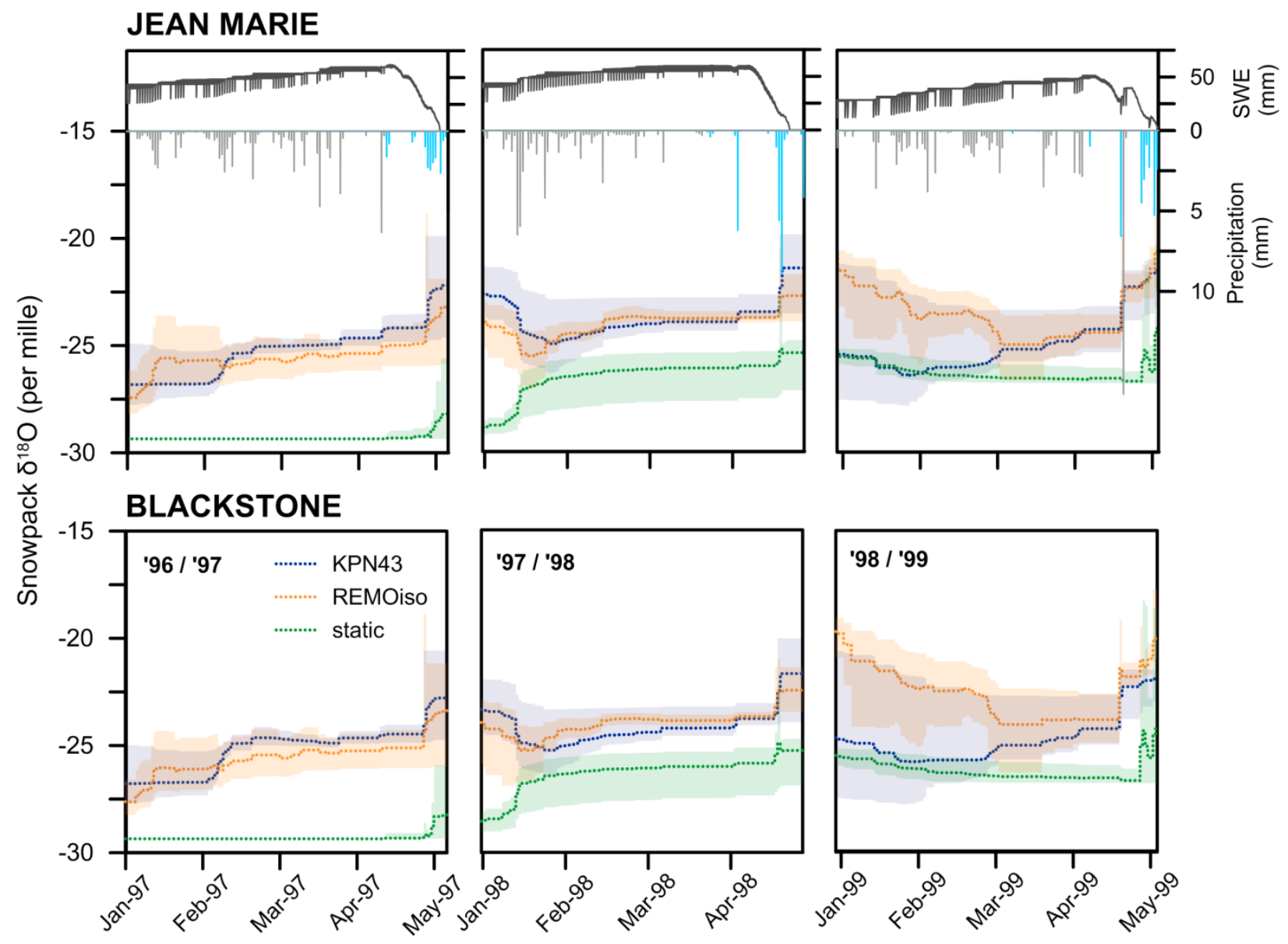

Comparison of like-forcing pairs between Jean Marie and Blackstone reveals subtle spatial differences in simulated $\delta^{18} \mathrm{O}_{\mathrm{SNW}}$. There are, however, significant differences between KPN43, REMOiso and static snowpack compositions within each sub-basin. Interestingly, REMOiso and KPN43 simulations of snowpack show similar end of winter precipitation-weighted $\delta^{18} \mathrm{O}_{\mathrm{SNW}}$, differing by less than 0.5\% in 97/98 and 98/99. REMOiso and KPN43 inputs also consistently generate significantly more enriched snowpack compositions throughout the study period in comparison to static $\delta^{18} \mathrm{O}_{\mathrm{SNW}}$ input. On average, KPN43 is 3.3\%o more enriched, and REMOiso is $3.1 \%$ more enriched than end of season static $\delta^{18} \mathrm{O}_{\mathrm{SNW}}$. These differences may also stem from 


\section{Chapter 5}

insufficiencies in modelled snowpack due to fractionation during sublimation, melting and refreezing of the snowpack that is unaccounted for in the current isoWATFLOOD model. The static input may inadvertently account for some of these processes, as the specified compositions are from snow pack sampling conducted towards the end of winter (in late March). Research into defining snow fall, pack and melt offsets (from field studies), and refining isoWATFLOOD's cryospheric dynamics and processes is currently ongoing.

These significant differences in simulated snowpack composition are one of the primary causes for the offsets between KPN43, REMOiso and static $\delta^{18} \mathrm{O}_{\mathrm{SF}}$ simulations (Figure 25 and Figure 26). Once a $\delta^{18} \mathrm{O}_{\mathrm{SF}}$ simulation has been offset, it is not possible to 'reset' the isotopic composition in late fall when streamflow decreases to near-zero since there is still mass remaining in the system. This can result in compounding isotopic error over a continuous simulation period, thus highlighting the sensitivity of this tracer as a calibration tool. This compounding error is also observed for rainfall events, but generally to a lesser extent due to the relatively smaller durations and magnitudes (volume contributions) of most rainfall events in high-latitude regions.

Provided that both $\delta^{18} \mathrm{O}_{\mathrm{SF}}$ and $\delta^{18} \mathrm{O}_{\mathrm{SNW}}$ are significantly different among $\delta^{18} \mathrm{O}_{\mathrm{ppt}}$ inputs, internal water apportionment (determined by model parameterization) may also be influenced by $\delta^{18} \mathrm{O}_{\mathrm{ppt}}$ input type. Therefore, hydrograph component contributions are further explored to determine the effect that the differences in $\delta^{18} \mathrm{O}_{\mathrm{ppt}}$ input has on these contributions. 


\section{Chapter 5}

\subsubsection{Hydrograph Component Analysis and Parameter Distributions}

Percent of volume contributing to total streamflow from surface runoff, interflow and baseflow storage for each season (DJF: December-January-February; MAM: March-April-May; JJA: June-July-August; and, SON: September-October-November) and each of the three $\delta^{18} \mathrm{O}_{\mathrm{ppt}}$ inputs are shown on Figure 28.

Jean Marie and Blackstone sub-basins generally display similar trends in internal water apportionment throughout the year, indicating generally similar model parameterizations. Some seasonal differences are visible, which can be linked to variations in basin physiography, land cover, and storage characteristics reflected by differences in the baseflow (lzf and $p w r)$ and wetland parameters ( $k$ cond and theta) between basins (Table 17). Overall, the freshet and postfreshet percent volume contributions to total streamflow in this study are in general agreement with those reported in previous studies. For example, St Amour et al. (2005) also found groundwater contributions to be significant throughout the year, and estimated post-freshet contributions to total streamflow at $71 \%( \pm 9 \%)$ and $64 \%( \pm 10 \%)$ within Jean Marie and Blackstone, respectively. Snowmelt contributions were estimated to be $21 \%( \pm 2 \%)$ and $40 \%( \pm$ $4 \%$ ) of total streamflow volume for Jean Marie and Blackstone. Additionally, Jasechko et al. (2016) estimate that annually 80 - 90\% of the Mackenzie River streamflow is "old" water (i.e., water that has not entered the stream within the last $2.3 \pm 0.8$ months). Their findings also suggest that the annual percentage of old streamflow can be higher in mountainous watersheds with steeper slopes, such as the FSB, than lower-gradient watersheds. 


\section{Chapter 5}

Figure 28: Percent seasonal volume contributing to total streamflow from surface runoff, interflow and baseflow storages for each season. Cross symbols represent the $5^{\text {th }}$ and $95^{\text {th }}$ percentiles for each forcing method, and circle symbols signify the mean values. The combined uncertainty bounds representing the $5^{\text {th }}$ and $95^{\text {th }}$ simulations from all three $\delta^{18} O_{p p t}$ input types are shaded in gray.
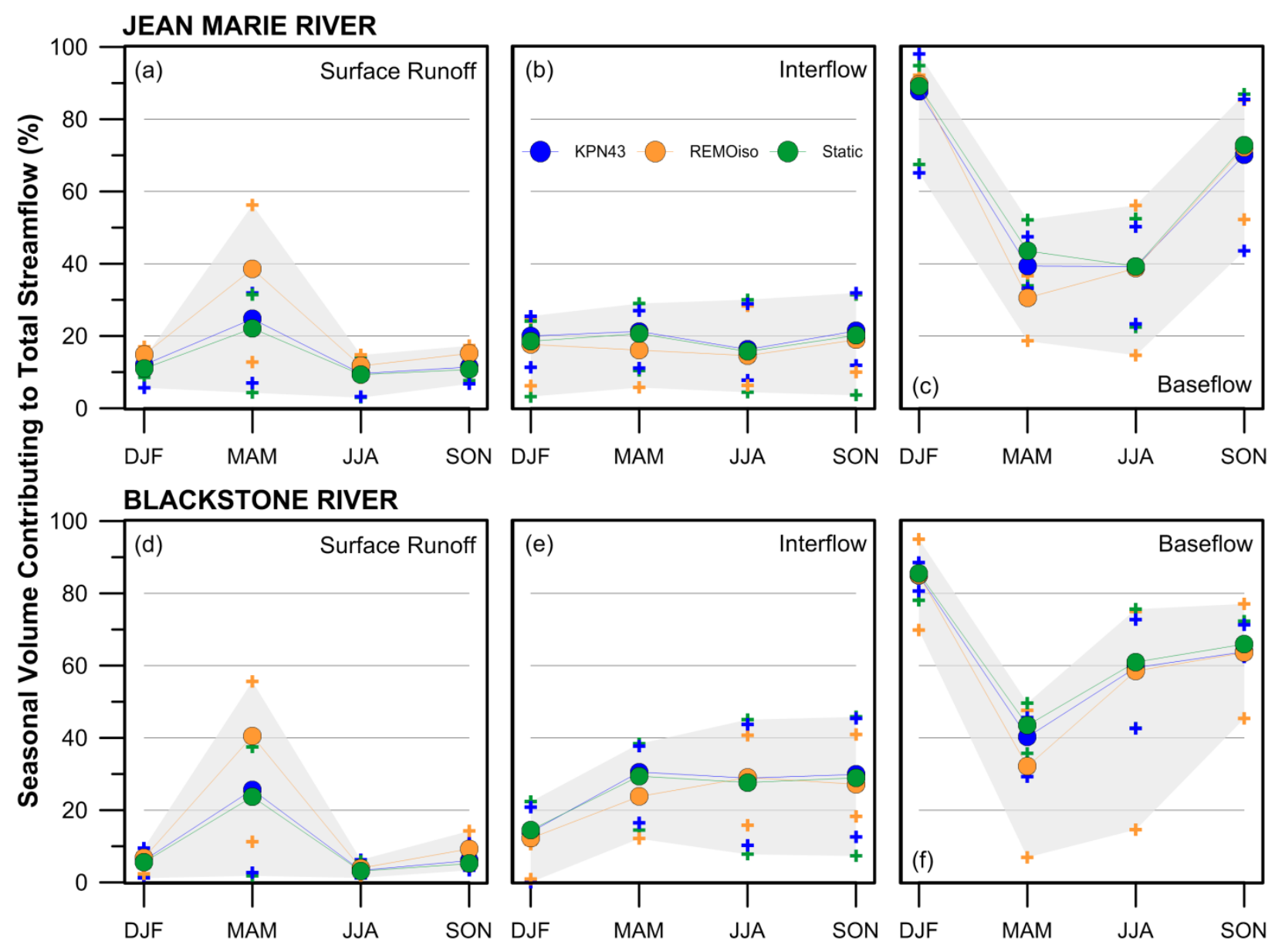

Comparison of seasonal volume contributions derived from each $\delta^{18} \mathrm{O}_{\mathrm{ppt}}$ input reveal that during spring (MAM), REMOiso-driven simulations show significantly more surface flow contribution to total streamflow, with the mean volume lying above the $95^{\text {th }}$ percentile for both the KPN43 and static input simulations (Figure 28). On average, REMOiso simulations contribute almost twice as much surface runoff to total streamflow as KPN43 and static simulations during MAM (39\% versus $25 \%$ and $22 \%$, respectively, for Jean Marie; and similar, yet slightly larger, percent contributions for Blackstone). 


\section{Chapter 5}

Based on the averaged seasonal analysis, no other significant differences in component contributions outside of parameter uncertainty can be attributed to $\delta^{18} \mathrm{O}_{\mathrm{ppt}}$ input. It is important to note, however, that each $\delta^{18} \mathrm{O}_{\mathrm{ppt}}$ input results in differing amounts of parameter uncertainty, both seasonally and overall, as represented by differing widths of uncertainty bounds (cross symbols) on Figure 28. The variation in uncertainty bounds between $\delta^{18} \mathrm{O}_{\mathrm{ppt}}$ inputs is also visible on Figure 25 through Figure 27. The REMOiso input yields the largest amount of uncertainty in total streamflow, also reflected in the relatively larger amounts of uncertainty in surface water and baseflow component contributions (Figure 28). Conversely, KPN43 and static inputs generate similar or slightly larger uncertainty in interflow (soil water) contributions relative to REMOiso and lower uncertainty surrounding surface and baseflow contributions, and overall total streamflow. These differences in uncertainty are attributed to the number, and characteristics of the behavioural parameters retained for each $\delta^{18} \mathrm{O}_{\mathrm{ppt}}$ input, which originate due to distinctions in magnitude and variability (both spatial and temporal) among $\delta^{18} \mathrm{O}_{\mathrm{ppt}}$ inputs.

Further demonstrated by parameter probability distributions (Figure 29), the three calibrations resulted in noteworthy differences in behavioural parameters. We do not display these distributions to comment definitively on parameter identifiability because, as previously noted, the number of evaluations was insufficient for that purpose. But rather, we introduce this analysis for select parameters to reinforce and explain the findings from Figure 25 through Figure 27, and to highlight that within this study, model parameterization is impacted by $\delta^{18} \mathrm{O}_{\mathrm{ppt}}$ input. 


\section{Chapter 5}

Figure 29: Probability distributions for select parameters, as indicated in the bottom right corner of each panel. Parameters are from behavioural simulations, and (a), $(b),(e)$ and $(f)$ have been weighted to the land cover distribution within Jean Marie and Blackstone, as outlined in Table 10. Panels $(c)$ and $(d)$ and river class parameters within Jean Marie, and panels $(g)$ and (h) contain river class parameters for Blackstone.

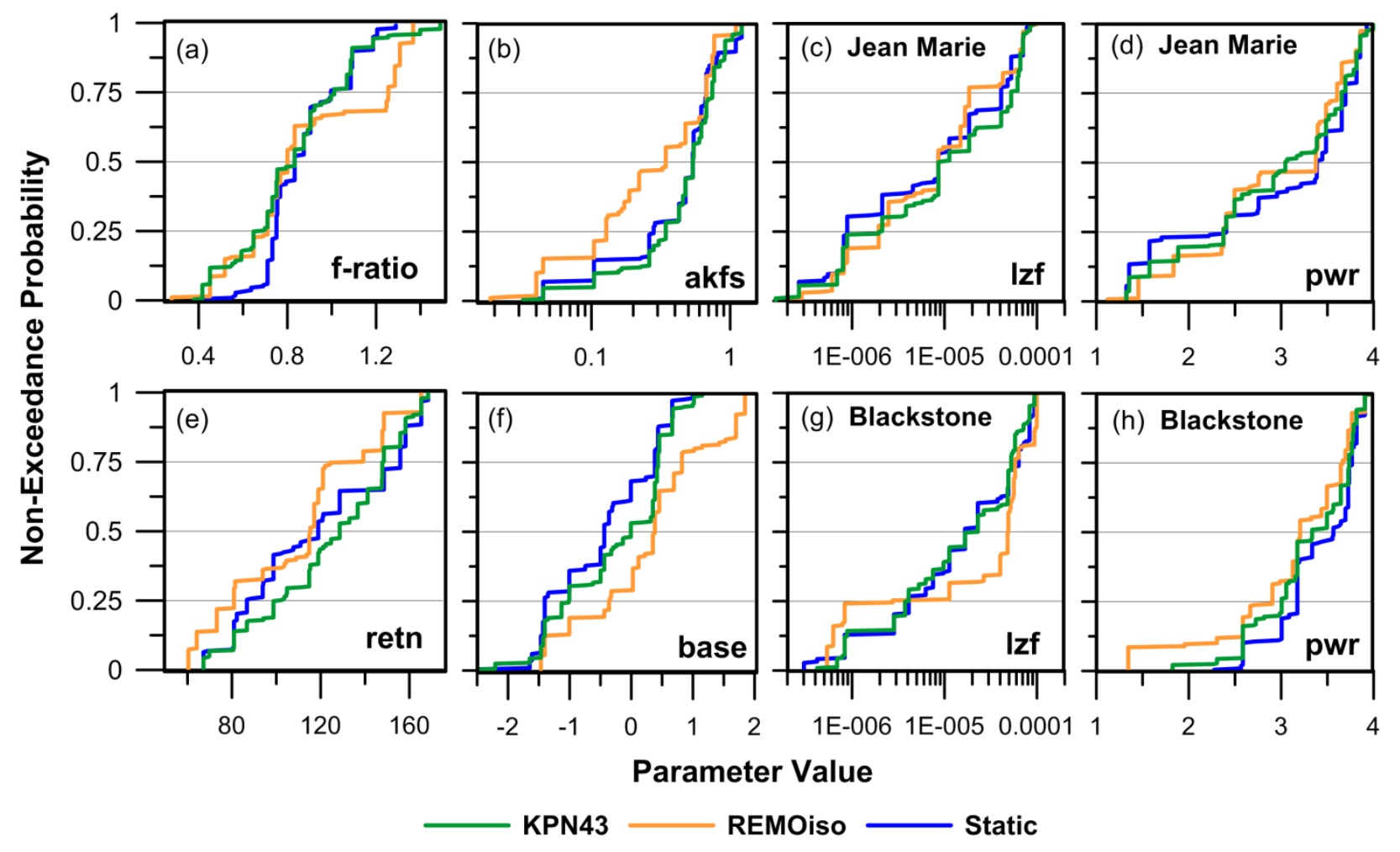

The selected parameters influence evaporation (retn, f-ratio), surface runoff during snowmelt (akfs, base), upper and lower zone storage (retn), interflow (retn), and baseflow (lzf, pwr). Results show that more often than not, REMOiso parameter distributions are different than KPN43 or static parameter distributions. Although there are dissimilarities between KPN43 and static parameter distributions, however these are typically not as prevalent. This echoes the findings from Figure 28 that KPN and static derived contributions to total streamflow are more similar than contributions arising from REMOiso; which may very well be an artifact of the increased temporal and spatial variability in the REMOiso $\delta^{18} \mathrm{O}_{\mathrm{ppt}}$ input relative to that of the KPN43 and static inputs. 


\section{Chapter 5}

Differences in surface water contribution during snowmelt between REMOiso, KPN43 and static inputs are likely be explained by differences in the akfs and base parameters. Parameter distributions derived from REMOiso are significantly different (as verified through Kolmogorov-Smirnov testing of distributions) than those from the KPN43 and static inputs for these parameters (Figure 29, panels (b) and (f)). Lower akfs values represent decreased infiltration and increased surface runoff during snowmelt, which corresponds to REMOiso's increased surface water contributions to total streamflow during spring (MAM). Differences in baseflow contribution and uncertainty between $\delta^{18} \mathrm{O}_{\mathrm{ppt}}$ inputs are attributed, in part, to differences in the $l z f$ and $p w r$ parameters (Figure 29, panels (c-d) and (g-h)), which have a large impact on the quantity of baseflow and the slope of the recession limb of the hydrograph. Wider uncertainty bounds for REMOiso relative to KPN43 and static within Blackstone (Figure 28, panel (f)), and for all $\delta^{18} \mathrm{O}_{\mathrm{ppt}}$ inputs during fall and winter within Jean Marie (Figure 28, panel (c)), are likely due to the wider range of behavioural values for the $p w r$ parameter, specifically the inclusion of lower values which results in longer, more drawn out recession limbs.

Although more work is required towards assessing and understanding parameter identifiability for WATFLOOD, the above analysis shows that selection of $\delta^{18} \mathrm{O}_{\mathrm{ppt}}$ input has direct implications on model parameterization, and this source of uncertainty should be considered in future studies.

\subsection{Conclusion and Recommendations}

This study uses three types of estimated $\delta^{18} \mathrm{O}_{\mathrm{ppt}}$ input to force a tracer-aided hydrological model, isoWATFLOOD, and investigates the impact that $\delta^{18} \mathrm{O}_{\mathrm{ppt}}$ inputs of differing spatial and temporal variability have on total streamflow, isotopic composition of streamflow, and the seasonality of 


\section{Chapter 5}

individual hydrograph components. This work informs the over-arching goal of quantifying and reducing uncertainty (and equifinality) in isoWATFLOOD streamflow simulations.

This study demonstrated that although total simulated streamflow is not significantly affected by choice of $\delta^{18} \mathrm{O}_{\mathrm{ppt}}$ input, $\delta^{18} \mathrm{O}_{\mathrm{SF}}$ simulations and the internal apportionment of water (surface flow, interflow, and baseflow contributions) in WATFLOOD can be significantly impacted, especially during large precipitation and snowmelt events. The ability of estimated $\delta^{18} \mathrm{O}_{\mathrm{ppt}}$ to capture both the variability and seasonality in precipitation isotopes, especially when precipitation events display distinctly different isotopic compositions than that of streamflow, is critical for traceraided model forcing. Differences in $\delta^{18} \mathrm{O}_{\mathrm{SF}}$ and water partitioning between compartments are driven by differences in model parameterization, as witnessed by variations in the amount of uncertainty and parameter distributions between $\delta^{18} \mathrm{O}_{\mathrm{ppt}}$ input types. This suggests that choice of $\delta^{18} \mathrm{O}_{\mathrm{ppt}}$ input impacts parameterization of WATFLOOD, and for this reason, if estimates of $\delta^{18} \mathrm{O}_{\mathrm{ppt}}$ are used in modelling, modellers should account for this input uncertainty in overall uncertainty assessments. Findings also show that simulations of total streamflow did not show significant differences between the three $\delta^{18} \mathrm{O}_{\mathrm{ppt}}$ inputs and corresponding parameterizations, despite $\delta^{18} \mathrm{O}_{\mathrm{SF}}$ simulations displaying significant differences. This reinforces to the utility of tracer-aided models to diagnose issues with equifinality in model simulations.

As WATFLOOD is a complex model with a large amount of parameters, it is important to work towards conducting a comprehensive study focusing on $\delta^{18} \mathrm{O}_{\mathrm{ppt}}$ input uncertainty and parameter identifiability. Ideally, further studies should be conducted in a watershed that is adequately instrumented to characterize observed $\delta^{18} \mathrm{O}_{\mathrm{ppt}}$ input both spatially, but more importantly, 


\section{Chapter 5}

temporally (i.e., daily or weekly sampling resolution). This will facilitate a 'baseline' model calibration (using observed $\delta^{18} \mathrm{O}_{\mathrm{ppt}}$ ) from which deviations in parameter distributions due to estimated $\delta^{18} \mathrm{O}_{\mathrm{ppt}}$ input can be more intensely explored. This type of study would allow further investigation of several key questions: first, if these pseudo-forcings are adequate alternatives in place of $\delta^{18} \mathrm{O}_{\mathrm{ppt}}$ observations; second, if there is a specific subset of model parameters that are more sensitive to estimated $\delta^{18} \mathrm{O}_{\mathrm{ppt}}$ input, and how (if at all) these parameters compensate for compounding error stemming from estimated $\delta^{18} \mathrm{O}_{\mathrm{ppt}}$ input. Unfortunately, at least within Canada, a well instrumented watershed at the regional scale does not yet exist. This again points to the importance of implementing additional (or enhancing current) hydro-meteorological monitoring networks. If observation networks allow, this type of study should also be conducted in watersheds of differing dominant hydrological processes (e.g. rainfall-dominated versus snowmelt-dominated) to better understand $\delta^{18} \mathrm{O}_{\mathrm{ppt}}$ input uncertainty on parameterization across the range of modelled hydrologic processes.

As expected, REMOiso exhibits some bias and will continue to need correction before application within Canadian watersheds. More studies are needed to examine the differences between $\delta^{18} \mathrm{O}_{\mathrm{ppt}}$ observations and REMOiso simulations throughout Canada to better understand the nature of this bias, and the most appropriate bias correction methods; which can be done using observations from the CNIP database. This feedback regarding REMOiso performance across Canada is also beneficial to model developers. Additionally, the suitability and performance of other isotope-enabled RCM's for use in Canada should be explored. Regarding the usefulness of the inputs within regions of limited $\delta^{18} \mathrm{O}_{\mathrm{ppt}}$ observations, both the static and REMOiso inputs require existing $\delta^{18} \mathrm{O}_{\mathrm{ppt}}$ observations (i.e., from CNIP) to either define or bias 


\section{Chapter 5}

correct the input, which may limit their use for certain applications. If these data are not available, the KPN43 input provides reasonable results without the need for any additional observations. For all inputs, the existence of CNIP (and other isotopes in precipitation networks) observations is crucial to the development, validation, and bias correction of estimated $\delta^{18} \mathrm{O}_{\mathrm{ppt}}$ inputs.

Understanding how estimated $\delta^{18} \mathrm{O}_{\mathrm{ppt}}$ input affects model parameterization and subsequently internal distribution of water is important to understanding overall uncertainty of the model and the model's abilities and limitations without access to observed $\delta^{18} \mathrm{O}_{\mathrm{ppt}}$ times series data. Canada, alongside many other countries, continues to have significant regions with sparse hydrometeorological observations (Coulibaly et al., 2013). This study achieves an understanding of

how isoWATFLOOD can be used in regions with a limited number of $\delta^{18} \mathrm{O}_{\mathrm{ppt}}$ observations, and that the model can be of value in such regions. This study reinforces that a tracer-aided modelling approach assists with resolving hydrograph component contributions, and works towards diagnosing the issue of model equifinality and knowledge that modellers are achieving the 'right answers for the right reasons' (Kirchner, 2006). Attaining this understanding of $\delta^{18} \mathrm{O}_{\mathrm{ppt}}$ input uncertainty on simulated model output is especially important when calibrated models are used as tools to assess how changes in climate or land-use effect future predictions of streamflow.

\subsection{Acknowledgements}

The authors would like to acknowledge Dr. K. Sturm for provision of the REMOiso data utilized in this study. Additional thanks go to Dr. N. Kouwen for direction and input on WATFLOOD 


\section{Chapter 5}

modelling. CNIP is made possible through the help of the Canadian Air and Precipitation

Monitoring Network (CAPMoN) for sample collection-Kaz Higuchi and Dave MacTavish in particular, the Environmental Isotope Laboratory at the University of Waterloo for sample analysis, and Tom Edwards for initiating and maintaining the network. We would also like to acknowledge Dan McKinney for provision of the ANUSPLIN data used in this study. Finally, we would like to acknowledge the contributions of our reviewers whose valuable input has improved this manuscript significantly. This research was partially funded by Natural Sciences and Engineering Research Council (NSERC) Alexander Graham Bell Canada Graduate Scholarship (CGS-D).

\subsection{References}

Aylsworth, J. M., I. M. Kettles (2000), Distribution of peatlands, in: The Physical Environment of the Mackenzie Valley, Northwest Territories: A Base Line for the Assessment of Environmental Change, edited by: Dyke, L. D., and G. R. Brooks, Geological Survey of Canada Bulletin 547, Geological Survey of Canada, Ottawa, 49-55.

Beven, K. And A. Binley (1992), The future of distributed models: Model calibration and uncertainty prediction. Hydrol. Process., 6: 279-298. doi: 10.1002/hyp.3360060305.

Birkel, C., and C. Soulsby (2015), Advancing tracer-aided rainfall-runoff modelling: a review of progress, problems and unrealised potential. Hydrol. Process., 29: 5227-5240, doi: 10.1002/hyp.10594.

Birkel, C., C. Soulsby, and D. Tetzlaff (2014), Developing a consistent process-based conceptualization of catchment functioning using measurements of internal state variables, Water Resour. Res., 50, 3481-3501, doi:10.1002/2013WR014925.

Birkel, C., D. Tetzlaff, S. M. Dunn, and C. Soulsby (2011), Using time domain and geographic source tracers to conceptualize streamflow generation processes in lumped rainfall-runoff models, Water Resour. Res., 47, W02515, doi:10.1029/2010WR009547.

Birkel, C., S. M. Dunn., D. Tetzlaff, and C. Soulsby (2010a), Assessing the value of highresolution isotope tracer data in the stepwise development of a lumped conceptual rainfallrunoff model. Hydrol. Process., 24: 2335-2348, doi: 10.1002/hyp.7763. 


\section{Chapter 5}

Birkel, C., D. Tetzlaff, S. M. Dunn, and C. Soulsby (2010b), Towards a simple dynamic process conceptualization in rainfall-runoff models using multi-criteria calibration and tracers in temperate, upland catchments. Hydrol. Process., 24: 260-275, doi: 10.1002/hyp.7478.

Birks, S. J., and J. J. Gibson (2009), Isotope hydrology research in Canada, 2003-2007, Can. Water Resour. J., 34(2), 163-176, doi:10.4296/cwrj3402163.

Birks, S. J., and T. W. D. Edwards (2009), Atmospheric circulation controls on precipitation isotope-climate relations in western Canada, Tellus Ser. B, 61B(3), 566-576, doi: 10.1111/j.1600-0889.2009.00423.x.

Carpenter, T. M., K. P. Georgakakos (2006), Intercomparison of lumped versus distributed hydrologic model ensemble simulations on operational forecast scales, J. Hydrol., 329(1-2), 174-185, doi: 10.1016/j.jhydrol.2006.02.013.

Coulibaly, P., J. Samuel, A. Pietroniro, and D. Harvey (2013), Evaluation of Canadian National Hydrometric Network density based on WMO 2008 standards, Can. Water Resour. J., 38(2), 159-167, doi: 10.1080/07011784.2013.787181.

Delavau, C., K. P. Chun, T. Stadnyk, S. J. Birks, and J. M. Welker (2015), North American precipitation isotope $(\mathrm{d} 180)$ zones revealed in time series modeling across Canada and northern United States, Water Resour. Res., 51, doi:10.1002/2014WR015687.

Dietermann, N. and M. Weiler (2013), Spatial distribution of stable water isotopes in alpine snow cover, Hydrol. Earth Syst. Sci., 17, 2657-2668, doi:10.5194/hess-17-2657-2013.

Dunn, S. M., J. Freer, M. Weiler, M. J. Kirkby, J. Seibert, P. F. Quinn, G. Lischeid, D. Tetzlaff and C. Soulsby (2008), Conceptualization in catchment modelling: simply learning?. Hydrol. Process., 22: 2389-2393, doi: 10.1002/hyp.7070.

Ecoregions Working Group (1989), Ecoclimatic regions of Canada, first approximation. In Ecoregions Working Group of the Canada Committee on ecological land classification, Ecological Land Classification Series 23. Sustainable Development Branch, Canadian Wildlife Service, Environment Canada: Ottawa, Ontario.

Fenicia, F., J. J. McDonnell, and H. H. G. Savenije (2008), Learning from model improvement: On the contribution of complementary data to process understanding, Water Resour. Res., 44, W06419, doi: 10.1029/2007WR006386.

Gat, J. R., C. J. Bowser, and C. Kendall (1994), The contribution of evaporation from the Great Lakes to the continental atmosphere: estimate based on stable isotope data, Geophys. Res. Lett., 21, 557-560, doi: 10.1029/94GL00069.

Gibson J. J., T. D. Prowse (1999), Isotopic characteristics of ice cover in a large northern river basin, Hydrol. Process., 13, 2537-2548, doi: 10.1002/(SICI)10991085(199911)13:16<2537::AID-HYP940>3.0.CO;2-A.

Gupta, H. V., H. Kling, K. K. Yilmaz, and G. F. Martinez (2009), Decomposition of the mean squared error and NSE performance criteria: Implications for improving hydrological modelling, J. Hydrol., 377(1-2), doi: 10.1016/j.jhydrol.2009.08.003. 


\section{Chapter 5}

Hargraeves, G. H., and Z. A. Samani (1982), Estimating potential evapotranspiration, ASCE, J. Irrig. and Drain, 108(3), 225-230.

Her, Y., and I. Chaubey (2015), Impact of the numbers of observations and calibration parameters on equifinality, model performance, and output and parameter uncertainty. Hydrol. Process., 29, 4220-4237, doi: 10.1002/hyp.10487.

IAEA/WMO (2014). Global Network of Isotopes in Precipitation. The GNIP Database. Accessible at: http://www.iaea.org/water.

Jasechko, S., J. W. Kirchner, J. M. Welker, and J. J. McDonnell (2016), Substantial proportion of global streamflow less than three months old, Nat. Geosci., 9, 126-129, doi: $10.1038 /$ ngeo 2636 .

Kirchner, J. (2006), Getting the right answers for the right reasons: Linking measurements, analyses, and models to advance the science of hydrology, Water Resour. Res., 42(3), W03S04, doi:10.1029/2005WR004362.

Kling, H., M. Fuchs, and M. Paulin (2012), Runoff conditions in the upper Danube basin under an ensemble of climate change scenarios, J. Hydrol., 424-425, 264-277, doi: 10.1016/j.jhydrol.2012.01.011.

Kouwen, N. (2014), WATFLOOD/WATROUTE Hydrological Model Routing and Flood Forecasting System. User's Manual, University of Waterloo, Waterloo, ON. www.watflood.ca.

Kouwen, N., E. D. Soulis, A. Pietroniro, J. Donald, R. A. Harrington (1993), Grouped response units for distributed hydrological modelling, J. Water Resour. Plann. Manage., 119, 289-305, doi: 10.1061/(ASCE)0733-9496(1993)119:3(289).

Kuczera, G. (1983), Improved parameter inference in catchment models: 2. Combining different kinds of hydrologic data and testing their compatibility, Water Resour. Res., 19(5), 11631172, doi:10.1029/WR019i005p01163.

Kuczera, G., and M. Mroczkowski (1998), Assessment of hydrologic parameter uncertainty and the worth of multiresponse data, Water Resour. Res., 34(6), 1481-1489, doi:10.1029/98WR00496.

Lykoudis, S. P., A. A. Argiriou, and E. Dotsika (2010), Spatially interpolated time series of d180 in Eastern Mediterranean precipitation, Global Planet. Change, 71, 150-159 doi: 10.1016/j.gloplacha.2009.09.004.

Noone, D., and C. Sturm, (2010), Comprehensive dynamical models of global and regional water isotope distributions, in: Isoscapes: Understanding movement, pattern, and process on Earth through isotope mapping, edited by: West, J. B., G. J. Bowen, T. E. Dawson, and K. P. Tu, Springer, London, 195-219.

McKenney, D. W., M. F. Hutchinson, P. Papadopol, K. Lawrence, J. Pedlar, K. Campbell, and T. Owen (2011), Customized Spatial Climate Models for North America, Bull. Am. Meteorol. Soc., 92(12), 1611-1622, doi:10.1175/2011BAMS3132.1. 


\section{Chapter 5}

McMillan, H., D. Tetzlaff, M. Clark, and C. Soulsby (2012), Do time-variable tracers aid the evaluation of hydrological model structure? A multimodel approach, Water Resour. Res., 48, W05501, doi:10.1029/2011WR011688.

Mesinger, F., et al. (2006), North American regional reanalysis, Bull. Am. Meteorol. Soc, 87, 343-360, doi: 10.1175/BAMS-87-3-343.

Michaud, J., and S. Sorooshian (1994), Comparison of simple versus complex distributed runoff models on a midsized semiarid watershed, Water Resour. Res., 30(3), 593-605, doi:10.1029/93WR03218.

Moran, T. A., S. J. Marshall, E. C. Evans, and K. E. Sinclair (2007), Altitudinal gradients of stable isotopes in lee-slope precipitation in the Canadian Rocky Mountains, Arctic Antarctic Alpine Research, 39(3), 455-467, http://www.jstor.org/stable/20181717.

Moriasi, D. N., J. G. Arnold, M. W. Van Liew, R. L. Bingner, R. D. Harmel, and T. L. Veith (2007), Model evaluation guidelines for systematic quantification of accuracy in watershed simulations, Trans. ASABE, 50(3), 885-900.

Nash, J. E., and J. V. Sutcliffe (1970), River flow forecasting through conceptual models part IA discussion of principles, J. Hydrol., 10(3), 282-290, doi:16/0022-1694(70)90255-6.

Penna, D., M. Ahmad, S. J. Birks, L. Bouchaou, M. Brenčič, S. Butt, L. Holko,G. Jeelani, D. E. Martínez, G. Melikadze, J. B. Shanley, S. A. Sokratov, T. Stadnyk, A. Sugimoto, and P. Vreča (2014), A new method of snowmelt sampling for water stable isotopes, Hydrol. Process., 28, pages 5367-5644, doi: 10.1002/hyp.10273.

Petrone, R. M., T. J. Griffis, W. R. Rouse (2000), Synoptic and surface climatology interactions in the central Canadian subarctic: normal and El Niño seasons, Phys. Geog., 21, 368-383, doi: 10.1080/02723646.2000.10642715.

Pietroniro, A., T. D. Prowse, L. Hamlin, N. Kouwen, R. Soulis (1996), Application of a grouped response unit hydrological model to a northern wetland region, Hydrol. Process., 10(10), 1245-1261, doi: 10.1002/(SICI)1099-1085(199610)10:10<1245::AID-HYP457>3.0.CO;2-0.

Philip, J. R.. (1954), An infiltration equation with physical significance, J. Soil Sci., 77(2), 153157.

Prowse, T. D., F. M. Conly, M. Church, and M. C. English (2002), A review of hydroecological results of the Northern River Basins study, Canada. Part 1. Peace and Slave Rivers, River Res. Appl., 18(5), 429-446, doi: 10.1002/rra.681.

Seibert, J., and J. J. McDonnell (2002), On the dialog between experimentalist and modeler in catchment hydrology: Use of soft data for multicriteria model calibration, Water Resour. Res., 38(11), 1241, doi:10.1029/2001WR000978.

Singh, V.P. and D. K. Frevert, (2006), Watershed models, CRC Taylor \& Francis, Boca Raton.

Smith A., C. Welch, and T. Stadnyk (2016). Assessment of a lumped coupled flow-isotope model in data scarce Boreal catchments, Hydrol. Process., doi: 10.1002/hyp.10835. 


\section{Chapter 5}

Stadnyk, T. A., C. Delavau, N. Kouwen, and T. W. D. Edwards (2013), Towards hydrological model calibration and validation: Simulation of stable water isotopes using the isoWATFLOOD model, Hydrol. Process., 27, 3791-3810, doi:10.1002/hyp.9695.

Stadnyk-Falcone, T. A., (2008), Mesoscale Hydrological Model Validation and Verification using Stable Water Isotopes: The isoWATFLOOD Model. Ph.D. Thesis, University of Waterloo, Waterloo, 386 pp., http://hdl.handle.net/10012/3970.

Stadnyk, T., N. A. St Amour, N. Kouwen, T. W. D. Edwards, A. Pietroniro, and J. J. Gibson (2005), A groundwater separation study in boreal wetland terrain: The WATFLOOD hydrological model compared with stable isotope tracers, Isot. Environ. Health Stud., 41(1), 49-60.

St Amour, N. A., J. J. Gibson, T. W. D. Edwards, T. D. Prowse, and A. Pietroniro (2005), Isotopic time-series partitioning of streamflow components in wetland dominated catchments, lower Liard river basin, Northwest Territories, Canada, Hydrol. Process., 19(17), 3357-3381, doi: 10.1002/hyp.5975.

Stewart, R. E., H. G. Leighton, P. Marsh, G. W. K. Moore, H. Ritchie, W. R. Rouse, E. D Soulis, G. S. Strong, R. W. Crawford, and B. Kochtubajda (1998), The Mackenzie GEWEX Study: the water and energy cycles of a major North American river basin, Bull. Am. Meteorol. Soc., 79, 2665-2684, doi: 10.1175/1520-0477(1998)079<2665:TMGSTW>2.0.CO;2.

Sturm, K., G. Hoffmann, and B. Langmann (2007), Simulation of the stable water isotopes in precipitation over South America: Comparing regional to global circulation models, J. Clim., 20(15), 3730-3750, doi: 10.1175/JCLI4194.1.

Sturm, K., G. Hoffmann, B. Langmann, and W. Stichler (2005), Simulation of d18O in precipitation by the regional circulation model REMOiso, Hydrol. Process., 19(17), 34253444, doi: 10.1002/hyp.5979.

Tetzlaff, D., J. Buttle, S. K. Carey, K. McGuire, H. Laudon, and C. Soulsby (2015), Tracer-based assessment of flow paths, storage and runoff generation in northern catchments: a review. Hydrol. Process., 29, 3475-3490, doi: 10.1002/hyp.10412.

Tetzlaff, D., S. Uhlenbrook, S. Eppert, and C. Soulsby (2008), Does the incorporation of process conceptualization and tracer data improve the structure and performance of a simple rainfallrunoff model in a Scottish mesoscale catchment?. Hydrol. Process., 22, 2461-2474, doi: 10.1002/hyp.6841.

Töyra J., (1997), Generation of a digital elevation model and establishment of a database for the Fort Simpson study area, No. KW504-7-0074. National Hydrology Research Institute, Saskatoon, Saskatchewan.

Xi, X. (2014), A Review of Water Isotopes in Atmospheric General Circulation Models: Recent Advances and Future Prospects, International Journal of Atmospheric Sciences, 250920, doi:10.1155/2014/250920. 


\section{Chapter 6}

\section{CHAPTER 6: SUMMARY AND CONCLUSIONS}

\subsection{Summary and Major Findings}

\subsubsection{Chapter 3}

In Chapter $3, \delta^{18} \mathrm{O}_{\mathrm{ppt}}$ observations from the CNIP and GNIP networks are used to develop and apply empirical models to predict the first ever long-term annual and seasonal precipitation isoscapes specifically for the Canadian domain (Delavau et al., 2011), addressing a portion of thesis Objective 1. Various model structures are explored from simplistic geographic-based models (i.e., BW, SIM1, SIM2) to more complex models that incorporate both geographic and climate parameters (i.e., SIM3 and SW) in an effort to determine which method(s) capture the spatial and temporal (seasonal) variability in observed $\delta^{18} \mathrm{O}_{\mathrm{ppt}}$

Model results indicate that annual $\delta^{18} \mathrm{O}_{\mathrm{ppt}}$ compositions are more 'predictable' than seasonal compositions (generating higher adjusted $\mathrm{R}^{2}$ and lower error variance), and the addition of climate parameters (PRECIP and TEMP) to the annual models does not result in a noticeable improvement due to the annual averaging involved with this analysis. Comparison of long-term seasonal models show that models with time variant climate parameters (SIM3 and SW models) consistently outperform models composed solely of geographic parameters (BW, SIM1, and SIM2 models); typically showing higher adjusted $\mathrm{R}^{2}$ and lower residual variance. The improvement due to incorporating climate parameters is especially significant in the winter season. Overall, the SIM3 model (LAT ${ }^{2}$, ALT, LONG, PRECIP, TEMP) consistently out- 


\section{Chapter 6}

performs (or performs equally as well as) the other models, and is therefore identified as the 'best' model and is used to generate all remaining simulations and isoscape mapping.

Seasonally, winter $\delta^{18} \mathrm{O}_{\mathrm{ppt}}$ predictions show poorer model performance than during other seasons, indicating increased complexity in the driving forces of $\delta^{18} \mathrm{O}_{\mathrm{ppt}}$ patterns during this season (e.g., enhanced kinetic effects, pronounced continentality) resulting in weaker correlations between $\delta^{18} \mathrm{O}_{\mathrm{ppt}}$ and predictor variables. Additionally, it is discovered that longitude is not an adequate proxy for the progressive depletion of $\delta^{18} \mathrm{O}_{\mathrm{ppt}}$ signatures inland from the coast. None of the geographic or climate variables included in this analysis are able to account for the more complex causes for isotopic labeling due to changing seasonal circulation patterns or multiple moisture sources, which are diagnosed as several possible reasons for larger model residuals at various locations throughout the year.

The SIM3 annual and seasonal models are used to generate isoscapes for Canada utilizing NARR data and the Canada3D DEM. An assessment of uncertainty is provided for each isoscape. The models are able to capture the general spatial and seasonal trends in $\delta^{18} \mathrm{O}_{\mathrm{ppt}}$ compositions, such as the latitude, altitude, continental effects, and changes in $\delta^{18} \mathrm{O}_{\mathrm{ppt}}$ due to seasonality, and show improved results from previous global studies (Bowen and Wilkinson, 2002; Bowen and Revenaugh, 2003). An interesting finding that occurred after the publication of Delavau et al. (2011) is the detection of an error in the ordering of CNIP $\delta^{18} \mathrm{O}_{\mathrm{ppt}}$ observations at Snare Rapids, NWT (Personal communication with T. W. D. Edwards, 2014). This mistake in data management was diagnosed by the consistent errors present at Snare Rapids in the residual mapping completed for this study (recall: Figure 15). 


\section{Chapter 6}

Results of this study suggest that inclusion of additional parameters to capture the influence of circulation patterns on the isotopic labeling of Canadian precipitation may be useful for developing improved predictive $\delta^{18} \mathrm{O}_{\mathrm{ppt}}$ isoscape models suitable for finer spatial and temporal scales. Additionally, another method to possibly improve model predictions is to separate Canada into zones and create $\delta^{18} \mathrm{O}_{\mathrm{ppt}}$ models based on data within each zone to strengthen the correlation between $\delta^{18} \mathrm{O}_{\mathrm{ppt}}$ and model parameters. Although this study was successful in generating long-term annual and seasonal Canadian precipitation isoscapes, there is still an unfulfilled need to refine the prediction time frame to monthly time series $\delta^{18} \mathrm{O}_{\mathrm{ppt}}$ estimates for certain applications, such as tracer-aided hydrological modelling, where both inter- and intraannual variability in $\delta^{18} \mathrm{O}_{\mathrm{ppt}}$ inputs are required.

\subsubsection{Chapter 4}

Chapter 4 builds upon the suggestions and knowledge obtained from Chapter 3, further refining the temporal scale of $\delta^{18} \mathrm{O}_{\mathrm{ppt}}$ estimation for Canada while also including additional data from the northern USA. Delavau et al. (2015) use multiple linear regressions of CNIP, GNIP and USNIP observations alongside climatological variables, teleconnection indices, and geographic indicators to create empirical models and generate the first-ever predictions of $\delta^{18} \mathrm{O}$ in monthly precipitation $\left(\delta^{18} \mathrm{O}_{\mathrm{ppt}}\right)$ across Canada and the northern tier of the United States, specifically addressing the remainder of thesis Objective 1. Five regionalization approaches (SSC, Kpn, RCWIP, 2-Zone and 1-Zone) are used to separate the study domain into isotope zones and the effect of this regionalization (and therefore, the uncertainty attributable to model structure) on model performance is assessed. 


\section{Chapter 6}

Stepwise regression-derived parameterizations reveal the importance of precipitable water content and latitude as predictor variables, as they are most often retained in the models and account for the largest amounts of variance in simulated $\delta^{18} \mathrm{O}_{\mathrm{ppt}}$. The correlation between precipitable water content and $\delta^{18} \mathrm{O}_{\mathrm{ppt}}$ is strongest in high latitude regions, resulting in strong model performance at such locations. Additionally, the parameter retention rate remained relatively low, possibly suggesting fewer complicating factors influencing Rayleigh distillation in this part of Canada. Within lower latitude regions, the prediction of $\delta^{18} \mathrm{O}_{\mathrm{ppt}}$ became increasingly complex due to the presence of additional effects, such as recycling of water and secondary kinetic effects, resulting in a larger variety and number of parameters retained in the models within these central regions. Model performance within the southeastern region is consistently strong, however the south-central and western regions show relatively poorer simulation statistics, potentially indicating more complex isotope-climate relations within these areas. Finally, low-latitude coastal zones and northwestern regional models typically show poor correlation between $\delta^{18} \mathrm{O}_{\mathrm{ppt}}$ and predictor variables. In coastal regions, this is likely due to the low seasonality of precipitation isotopes in coastal regions in general. This lack of correlation between $\delta^{18} \mathrm{O}_{\mathrm{ppt}}$ and predictors results in very low parameter retention rates and high amounts of model uncertainty in these areas.

Time series simulations show that the models are able of capturing the timing and magnitude of the intra-annual (seasonal) $\delta^{18} \mathrm{O}_{\mathrm{ppt}}$ cycle across the study domain, in addition to simulating moderate inter-annual variation when climate parameters are retained in the models. However, the models often failed to capture the anomalies in observed $\delta^{18} \mathrm{O}_{\mathrm{ppt}}-$ both enriched and depleted. The long-term average isoscapes generated for each regionalization demonstrate that 


\section{Chapter 6}

the models are able to produce long-term annual average $\delta^{18} \mathrm{O}_{\mathrm{ppt}}$ contours of reasonable magnitude, while capturing the main trends in the variability in observed $\delta^{18} \mathrm{O}_{\mathrm{ppt}}$. However, the range in modelled $\delta^{18} \mathrm{O}_{\text {ppt }}$ predictions show large amounts of uncertainty in various regions, which are attributed to either significant differences in model structure (i.e., parameterization) or unrealistically placed isotope border locations. Both the SSC and RCWIP regionalizations produce long term average isoscapes with unrealistic $\delta^{18} \mathrm{O}_{\mathrm{ppt}}$ contours due to the placement of isotope zone boundaries. Additionally, although they do not demonstrate any border effects, the 1-Zone and 2-Zone models show higher IQRs and are more outlier prone in addition to being less parsimonious. For these reasons, the Kpn regionalization is suggested as the preferred regionalization scheme for future tracer-aided hydrological modelling and other isoscape applications.

Although not detailed in Chapter 3, a pre-processing module (isoP) is developed for isoWATFLOOD to automate the process of generating monthly time series isoscapes for model forcing, specifically addressing thesis Objective 2. Details regarding the development of the module are available in Appendix B. Although developed specifically for isoWATFLOOD, the module can be easily adapted to output $\delta^{18} \mathrm{O}_{\mathrm{ppt}}$ isoscapes in the format required for other applications. For example, in addition to the application outlined in Chapter 5, results from this work have already been applied in a tracer-aided hydrological modelling study in the Lower Nelson River Basin (Personal communication T. Holmes, 2016), and in an Alberta Innovates Technology Futures wetland study at over 1500 sites (Personal communication with J.J. Gibson and S.J. Birks, 2015). 


\section{Chapter 6}

\subsubsection{Chapter 5}

The work summarized in Chapter 5 is an application of the time series $\delta^{18} \mathrm{O}_{\mathrm{ppt}}$ models developed in Chapter 4 (Delavau et al., 2015) within a tracer-aided hydrological model, isoWATFLOOD, in the remote Fort Simpson Basin, NWT, Canada. In addition to utilizing KPN43 model simulations as $\delta^{18} \mathrm{O}_{\mathrm{ppt}}$ input, seasonal $\delta^{18} \mathrm{O}_{\mathrm{ppt}}$ compositions ('static'), and daily $\delta^{18} \mathrm{O}_{\mathrm{ppt}}$ estimates from an isotope-enabled climate model (REMOiso) are also used as model forcing to investigate the impacts of input forcing on model output and parameterizations, specifically addressing thesis Objective 3.

A comparison between CNIP observations at Snare Rapids and REMOiso output revealed that REMOiso simulations exhibit a positive bias, and therefore require bias correction before they are used as model input. After implementing a seasonal bias correction to REMOiso, a comparison of $\delta^{18} \mathrm{O}_{\mathrm{ppt}}$ inputs reveal that on average, KPN43 is the most enriched of all three $\delta^{18} \mathrm{O}_{\text {ppt }}$ inputs, followed by REMOiso, with the static input being the most depleted. KPN43 and static inputs show similar coefficients of variance (CV) whereby REMOiso has a higher CV and much larger range in $\delta^{18} \mathrm{O}_{\mathrm{ppt}}$, which in part is due to its daily time step. Spatially, KPN43 and REMOiso inputs show more depleted $\delta^{18} \mathrm{O}_{\mathrm{ppt}}$ values within Blackstone in comparison to Jean Marie, in addition to increased variability due to higher elevations within this sub-basin; highlighting both of these methods can simulate spatial variability in $\delta^{18} \mathrm{O}_{\mathrm{ppt}}$. Of all the $\delta^{18} \mathrm{O}_{\mathrm{ppt}}$ inputs, REMOiso is the only forcing with the ability to somewhat replicate the event-scale variability in $\delta^{18} \mathrm{O}_{\mathrm{ppt}}$ due to its daily time step. 


\section{Chapter 6}

Overall, the isoWATFLOOD model is able to adequately capture variations in total streamflow in both sub-basins for each of the three calibrations (KPN43, static and REMOiso). Each calibration shows statistically similar simulations of total streamflow (also within the limits of parameter uncertainty), despite contrasting $\delta^{18} \mathrm{O}_{\mathrm{ppt}}$ inputs. Conversely, the calibrations produced mean $\delta^{18} \mathrm{O}_{\mathrm{SF}}$ simulations which capture many of the trends, but not particularly the magnitudes present in the observed $\delta^{18} \mathrm{O}_{\mathrm{SF}}$ record. Simulated $\delta^{18} \mathrm{O}_{\mathrm{SF}}$ uncertainly envelopes associated with each input type are non-overlapping at various points, and therefore differences in $\delta^{18} \mathrm{O}_{\mathrm{SF}}$ simulations are attributed to $\delta^{18} \mathrm{O}_{\mathrm{ppt}}$ input and not just due to parameter uncertainty. These differences in $\delta^{18} \mathrm{O}_{\mathrm{SF}}$ simulations are due to unique $\delta^{18} \mathrm{O}_{\mathrm{ppt}}$ compositions during large precipitation events between $\delta^{18} \mathrm{O}_{\mathrm{ppt}}$ inputs (both rainfall and snowmelt), and the way in which new water then traverses through the system via various hydrological compartments (surface runoff, interflow, baseflow, etc.), particularly during periods of snowmelt. Results show that REMOiso hydrograph separations and parameter distributions are different than those generated by the KPN43 and static calibrations, which is postulated to be caused by the increased temporal variability in the REMOiso $\delta^{18} \mathrm{O}_{\mathrm{ppt}}$ input.

This study shows that although total simulated streamflow is not significantly impacted by choice of $\delta^{18} \mathrm{O}_{\mathrm{ppt}}$ input, $\delta^{18} \mathrm{O}_{\mathrm{SF}}$ simulations and the internal apportionment of water (and therefore model parameterizations) are impacted, particularly during large precipitation and snowmelt events. This finding highlights the importance of estimated regional $\delta^{18} \mathrm{O}_{\mathrm{ppt}}$ isoscapes to capture both the variability and seasonality in precipitation isotopes for tracer-aided hydrological modelling applications, especially when precipitation events display distinctly different isotopic compositions than that of streamflow. Results also show that simulations of total streamflow do 


\section{Chapter 6}

not show significant differences between the three $\delta^{18} \mathrm{O}_{\mathrm{ppt}}$ inputs and corresponding parameterizations despite $\delta^{18} \mathrm{O}_{\mathrm{SF}}$ simulations displaying significant differences, reinforcing the utility of tracer-aided models to diagnose issues with equifinality.

\subsection{Limitations and Future Work}

Although the work completed for this thesis makes significant and unique contributions towards developing and applying $\delta^{18} \mathrm{O}_{\mathrm{ppt}}$ isoscapes throughout Canada alongside understanding the impact of $\delta^{18} \mathrm{O}_{\mathrm{ppt}}$ estimates on a tracer-aided hydrological models, there are still some limitations of this research that should be discussed, alongside recommendations of future work which stem from these contributions.

One of the main limitations of this work remains the sporadic temporal and spatial resolutions of the CNIP/GNIP observations used to calibrate and validate the empirical $\delta^{18} \mathrm{O}_{\mathrm{ppt}}$ models. There is a lack of consistency in the timing of data collection and the period of records, and there are large distances between stations given the vast size and remoteness of the Canadian domain. This sporadic nature of the data likely impacts model parameterization in some regions and results in larger amounts of uncertainty in predictions. However, the modelling completed in Chapters 3 and 4 has diagnosed both regions of higher uncertainty and regions of more complex hydroclimatological controls, and these results could be used to target high priority regions for implementation of future $\delta^{18} \mathrm{O}_{\mathrm{ppt}}$ monitoring stations. This would require re-establishment of the CNIP network, however, which was decommissioned in 2010 (alongside many other ventures between Environment Canada and university researchers) as climate-related research was expunged from Environment Canada's mandate. A possible collaboration to reinitiate CNIP 


\section{CHAPTER 6}

could be as a complement to the river isotope monitoring currently being conducted though Water Survey of Canada (Gibson et al., 2010). This additional data could be used to continue iteratively developing the $\delta^{18} \mathrm{O}_{\mathrm{ppt}}$ models for targeted regions of high uncertainty, complex isotope-climate relations, or within Köppen zones that do not currently have models developed within their domains (Appendix B). Another potential application of this research is the continued collaboration between CNIP and USNIP to form a NANIP (North American Network of Isotopes in Precipitation) (Personal communications with J. Welker and S. J. Birks, 2013). This type of collaboration involves generating time series $\delta^{18} \mathrm{O}_{\mathrm{ppt}}$ models and long-term isoscape mapping for the entirety of the North American continent using CNIP, GNIP and USNIP datasets. This would allow for continental-scale climate, hydrology, ecology, and forensics applications (among others) using monthly (or further averaged, if required) time series $\delta^{18} \mathrm{O}_{\mathrm{ppt}}$ as input.

Another limitation of using CNIP and GNIP data to create empirical $\delta^{18} \mathrm{O}_{\mathrm{ppt}}$ prediction models is the monthly time step of the observations. Although many applications can utilize long-term or monthly time series isoscapes as input, other studies will require inputs at a finer temporal resolution (e.g. weekly or daily). Models to estimate $\delta^{18} \mathrm{O}_{\mathrm{ppt}}$ time series at shorter time steps cannot be created from monthly observations. For this reason, isotope-enabled regional climate models show great promise for providing daily (or finer) time series of $\delta^{18} \mathrm{O}_{\mathrm{ppt}}\left(\right.$ and $\delta^{2} \mathrm{H}_{\mathrm{ppt}}$ ) for applications that require higher resolution forcing. However, there is a need for enhanced collaboration between Canadian researchers and isotope-climate modellers to further apply and validate these models throughout Canada. As documented in Chapter 5 and through the work completed by Dr. S. Jean Birks and Dr. K. Sturm, REMOiso exhibits a strong positive bias and 


\section{Chapter 6}

will continue to need correction before use in Canadian studies (Personal communication with $\mathrm{S}$.

J. Birks, 2016). This brings up a strong need for more research to examine the differences between $\delta^{18} \mathrm{O}_{\mathrm{ppt}}$ observations and REMOiso simulations throughout Canada to better understand the nature of this bias, and the most appropriate bias correction methods; which can be done using observations from the CNIP and GNIP databases. Studies which characterize and correct isotope-enabled climate model bias should extend beyond REMOiso. The suitability and performance of other isotope-enabled RCMs for use in Canada should be also explored (e.g. isoRSM, COSMOiso).

There is also a need for time series estimates of $\delta^{2} \mathrm{H}_{\mathrm{ppt}}$ (Holmes, In preparation). This will allow for simultaneous simulation of both $\delta^{18} \mathrm{O}_{\mathrm{ppt}}$ and $\delta^{2} \mathrm{H}_{\mathrm{ppt}}$, and therefore the simulation of $d$-excess as well. Time series of $d$-excess will both act as an additional means of validation of the model simulations in addition to providing insight into controls on $\delta^{18} \mathrm{O}_{\mathrm{ppt}} / \delta^{2} \mathrm{H}_{\mathrm{ppt}}$ - particularly with regards to secondary kinetic effects such as secondary evaporation, snow formation processes, or continental moisture recycling. Companion $\delta^{2} \mathrm{H}_{\mathrm{ppt}}$ models have been developed for the Köppen regionalization using the same parameterizations as the $\delta^{18} \mathrm{O}_{\mathrm{ppt}}$ models in Delavau et al. (2015); however, they have not undergone the intensive quality control and diagnostic testing that the $\delta^{18} \mathrm{O}_{\mathrm{ppt}}$ models have and should therefore be used with caution until their validity has been confirmed. Once complete, these $\delta^{2} \mathrm{H}_{\mathrm{ppt}}$ models can be coupled with isoWATFLOOD and both tracers $\left(\delta^{2} \mathrm{H}\right.$ and $\left.\delta^{18} \mathrm{O}\right)$ can be simulated within the model (Holmes, In preparation).

As identified based on the findings in Chapter 5, WATFLOOD is a complex hydrologic model with a large amount of parameters, and therefore struggles with equifinality issues. The work 


\section{Chapter 6}

summarized in Chapter 5 is a first step towards understanding how various types of $\delta^{18} \mathrm{O}_{\mathrm{ppt}}$ model forcing impact model simulations and the resulting parameterizations. Although the study is able to show how the selection of $\delta^{18} \mathrm{O}_{\mathrm{ppt}}$ impacts model simulations and parameterization within the Fort Simpson Basin, it is limited by sporadic and discontinuous $\delta^{18} \mathrm{O}_{\mathrm{SF}}$ observations for model calibration, in addition to a lack of $\delta^{18} \mathrm{O}_{\mathrm{ppt}}$ observations from which to compare the usefulness of $\delta^{18} \mathrm{O}_{\mathrm{ppt}}$ estimates as model forcing. This is characteristic, however, of the data availability throughout most of Canada, further reinforcing the need to better understand how estimates $\delta^{18} \mathrm{O}_{\mathrm{ppt}}$ and a lack of calibration data impact model simulations and uncertainty in tracer-aided hydrological modelling. This again points to the importance of implementing additional (or enhancing current) hydro-meteorological monitoring networks. Additionally, given the hydrologic regime of the study area (snowmelt dominated, wetland dominated, high relief), these findings may not be applicable in watersheds of differing dominant hydrological processes and physiography.

Due to these limitations, it is recommended that a comprehensive study focusing on $\delta^{18} \mathrm{O}_{\mathrm{ppt}}$ input uncertainty and parameter identifiability be conducted once data availability has improved. If funding permits, data availability could be improved by initiating a sampling campaign within a strategically selected watershed. This watershed must be located in a region that is accessible enough to sample $\delta^{18} \mathrm{O}_{\mathrm{ppt}}$ and $\delta^{18} \mathrm{O}_{\mathrm{SF}}$ at a daily or weekly resolution over an extended period. Having a dataset of this temporal frequency would allow for a 'baseline' model calibration (using both complete time series of $\delta^{18} \mathrm{O}_{\mathrm{SF}}$ and $\delta^{18} \mathrm{O}_{\mathrm{ppt}}$ observations) from which deviations in parameter distributions due to estimated $\delta^{18} \mathrm{O}_{\mathrm{ppt}}$ input could be more intensely explored. This type of parameter identifiability study would allow further investigation regarding if $\delta^{18} \mathrm{O}_{\mathrm{ppt}}$ 


\section{Chapter 6}

estimations are adequate alternatives in place of observations. Additionally, this additional data would permit exploring if a specific subset of model parameters are more sensitive to estimated $\delta^{18} \mathrm{O}_{\mathrm{ppt}}$ input, and how (if at all) these parameters compensate for compounding error stemming from estimated $\delta^{18} \mathrm{O}_{\mathrm{ppt}}$ input. These studies will be a significant step forward regarding assessing the usefulness of $\delta^{18} \mathrm{O}_{\mathrm{ppt}}$ estimates in tracer-aided hydrological modelling, and the model's applicability in regions of sparse $\delta^{18} \mathrm{O}$ observations.

Additionally, it is recommended that future studies examining parameter identifiability in WATFLOOD incorporate at least 100,000 model evaluations (Personal communication with T. Stadnyk and M. Asadzadeh, 2016) if utilizing the GLUE approach (or similar MC techniques). Due to the large computational requirements of Monte Carlo sampling, this will require additional computing resources than what were available when conducting this thesis research. Although the study summarized in Chapter 5 used a multi-objective approach to model calibration, a more intensive analysis of uncertainty estimation should be employed in future studies to develop a more comprehensive understanding of the uncertainty surrounding WATFLOOD simulations. This type of study might include aims such as comparing different objective function combinations and evaluation thresholds, or exploring multiple uncertainty estimation methods (e.g., Shafi et al., 2015). Although a version of this type of analysis is conducted as a part of the work done in Chapter 5, there needs to be a more thorough analysis completed in future studies whose primary focuses are uncertainty quantification and parameter identifiability. These types of studies will provide valuable insight into which are the most efficient and robust methods for providing uncertainty estimates for model simulations and parameter and model structure identification within WATFLOOD. 


\section{CHAPTER 6}

Finally, there are some isoWATFLOOD improvements that would be beneficial to implement before conducting the suggested parameter identifiability studies. These include the following:

- Development of a snowpack fractionation module to track and evolve the isotopic composition of the snowpack throughout the winter, including fractionation from sublimation. Additionally, determination of snowpack and melt offsets (from field studies) and enhancement of isoWATFLOOD's cryospheric dynamics needs to be completed. Research into this recommendation is currently ongoing (Personal communication with T. Stadnyk, 2016), and;

- Inclusion of uncertainty quantification methods within the WATFLOOD model code. The uncertainty assessment conducted in Chapter 5 was completed by writing external scripts in Matlab to automate the process of conducting Monte Carlo random sampling, generating parameter sets, executing the model and summarizing the output. This approach, albeit functional, was inefficient and not easily accessible for future WATFLOOD users wanting to incorporate parameter and model structure uncertainty.

The work completed for this thesis makes significant steps forward in both the development and application of long-term and time series $\delta^{18} \mathrm{O}_{\mathrm{ppt}}$ isoscapes for the Canadian domain, while concurrently provides new insight into isotope-climate relations across Canada. Implementation of these isoscapes within isoWATFLOOD now allows for a multi-objective modelling approach in poorly-gauged Canadian basins, where in the past a lack of $\delta^{18} \mathrm{O}_{\mathrm{ppt}}$ observations for model forcing prohibited using such methods. Findings from this thesis also provide insight into how estimates of $\delta^{18} \mathrm{O}_{\mathrm{ppt}}$ impact hydrological model output and parameterization, thus informing the over-arching goal of quantifying and reducing uncertainty (and equifinality) in isoWATFLOOD streamflow simulations. Limiting equifinality, particularly in operational applications of 


\section{Chapter 6}

hydrological models, is critical for proper management of water resources now and into the future.

\subsection{References}

Bowen, G. J., and J. Revenaugh (2003), Interpolating the isotopic composition of modern meteoric precipitation, Water Resour. Res., 39(10), 1299-1311, doi: 10.1029/2003WR002086.

Bowen, G. J., and B. H. Wilkinson (2002), Spatial distribution of $\delta 180$ in meteoric precipitation, Geology, 30(4), 315-318, doi: 10.1130/0091-7613(2002)030<0315:SDOOIM>2.0.CO;2.

Delavau, C., K. P. Chun, T. Stadnyk, S. J. Birks, and J. M. Welker (2015), North American precipitation isotope $(\mathrm{d} 180)$ zones revealed in time series modeling across Canada and northern United States, Water Resour. Res., 51, doi:10.1002/2014WR015687.

Delavau, C., T. A. Stadnyk, and S. J. Birks (2011), Model based distribution of oxygen-18 isotopes in precipitation across Canada, Cdn. Water Resour. J., 36(4), 313-330, doi: 10.4296/cwrj3604875.

Holmes, T. L. (In preparation), Assessing the values of stable water isotopes in hydrologic modeling: A dual-isotope approach. M.Sc. Thesis, University of Manitoba, Winnipeg, 198 pp.

Shafii, M., B. Tolson, and L. S. Matott (2015), Addressing subjective decision-making inherent in GLUE-based multi-criteria rainfall-runoff model calibration, J. Hydrol., 523, 693-705, doi: 10.1016/j.jhydrol.2015.01.051.

Gibson, J.J., S. J. Birks, and T. Stadnyk (2010), A national isotope monitoring strategy for the Water Survey of Canada: a draft proposal for comment, submitted to Water Survey of Canada, a Branch of the Meteorological Service of Canada, Saskatoon, Saskatchewan, 21 pp. 


\section{Appendix A:}

AUXILIARY MATERIAL FOR NORTH AMERICAN PRECIPITATION ISOTOPE ( $\delta 18 O)$ ZONES

REVEALED IN TIME-SERIES MODELLING ACROSS CANADA AND THE NORTHERN UNITED

STATES 
Auxiliary material for

North American precipitation isotope $\left(\delta^{18} \mathrm{O}\right)$ zones revealed in time-series modelling across Canada and the northern United States

${ }^{1}$ Delavau, C., ${ }^{2}$ Chun, K.P., ${ }^{1}$ Stadnyk, T., ${ }^{3}$ Birks, S.J., and ${ }^{4}$ Welker, J.M.

( ${ }^{1}$ University of Manitoba, Department of Civil Engineering (Water Resources), EITC E1-368A Engineering, 15 Gillson Street, Winnipeg, MB, Canada, R3T 5V6.

${ }^{2}$ Global Institute for Water Security, University of Saskatchewan, Saskatoon, SK, Canada.

${ }^{3}$ Alberta Innovates- Technology Futures, Calgary, AB, Canada.

${ }^{4}$ University of Alaska Anchorage, Anchorage, AK, United States.)

Water Resources Research

Introduction

The following auxiliary material provides information on the precipitation oxygen-18 $\left(\delta^{18} \mathrm{O}_{\mathrm{ppt}}\right)$ data used for empirical model development. Two tables are included, the first, "ts01.txt" details additional CNIP/GNIP/USNIP station information to better understand the temporal and spatial distribution of the $\delta^{18} \mathrm{O}_{\mathrm{ppt}}$ data, and the second table "ts02.txt" provides a summary of the amount of measurements within the calibration and validation data subsets used to develop the empirical models for each of the regionalization schemes.

1. ts01.txt Supplementary information for CNIP, GNIP and USNIP measurement stations.

1.1 Column "Station number", the number used to label each $\delta^{18} \mathrm{O}_{\mathrm{ppt}}$ measurement station. This station number is used throughout the manuscript to identify stations, and is shown on Figures 1, 3 and 4.

1.2 Column "Name", Name for each $\delta^{18} \mathrm{O}_{\mathrm{ppt}}$ measurement station. These names are referenced throughout the manuscript for specific stations, some of which are referenced on Figure 4.

1.3 Column "Province/State", Acronym of the Canadian province or US state for each $\delta^{18} \mathrm{O}_{\mathrm{ppt}}$ measurement station.

1.4 Column "Latitude", degrees, latitude for each $\delta^{18} \mathrm{O}_{\mathrm{ppt}}$ measurement station.

1.5 Column "Longitude" ", degrees, longitude for each $\delta^{18} \mathrm{O}_{\mathrm{ppt}}$ measurement station.

1.6 Column "Altitude", meters, for each $\delta^{18} \mathrm{O}_{\mathrm{ppt}}$ measurement station. 
1.7 Column Record length", the start year and end year of $\delta^{18} \mathrm{O}_{\mathrm{ppt}}$ collection for each $\delta^{18} \mathrm{O}_{\mathrm{ppt}}$ measurement station.

1.8 Column "Isotope Zone: SSC", The Synoptic Scale Classification (SSC) zone number corresponding to each $\delta^{18} \mathrm{O}_{\mathrm{ppt}}$ measurement station. This indicates which SSC zone (i.e., model) a particular station belongs to.

1.9 Column "Isotope Zone Kpn", The Koeppen-Geiger Classification (Kpn) zone number corresponding to each $\delta^{18} \mathrm{O}_{\mathrm{ppt}}$ measurement station. This indicates which Kpn zone (i.e., model) a particular station belongs to.

1.10 Column "Isotope Zone: RCWIP", The Regionalized Climatic Water Isotope Prediction (RCWIP) zone number corresponding to each $\delta^{18} \mathrm{O}_{\mathrm{ppt}}$ measurement station. This indicates which RCWIP zone (i.e., model) a particular station belongs to.

2. ts02.txt Number of observations included in calibration and validation subsets for each seasonal model within the five regionalization schemes.

2.1 Column "Isotope Zone", the regionalization scheme (i.e., SSC, Kpn, RCWIP, 2-Zone or 1Zone) followed by the isotope zone number or zone indicator (e.g. SSC4 represents the model for the Synoptic Scale Classification regionalization scheme in isotope zone four). "SUM" represents the summation of the number of $\delta^{18} \mathrm{O}_{\mathrm{ppt}}$ observations utilized within each season for calibration.

2.2 Column "Number of Measurements: Calibration, DJF", the number of monthly $\delta^{18} \mathrm{O}_{\mathrm{ppt}}$ observations used for calibration of the DJF (winter: December-January-February) models.

2.3 Column "Number of Measurements: Calibration, MAM", the number of monthly $\delta^{18} \mathrm{O}_{\mathrm{ppt}}$ observations used for calibration of the MAM (spring: (March-April-May) models.

2.4 Column "Number of Measurements: Calibration, JJA", the number of monthly $\delta^{18} \mathrm{O}_{\mathrm{ppt}}$ observations used for calibration of the JJA (summer: June-July-August) models.

2.5 Column "Number of Measurements: Calibration, SON", the number of monthly $\delta^{18} \mathrm{O}_{\mathrm{ppt}}$ observations used for calibration of the SON (fall: September-October-November) models.

2.6 Column "SUM" represents the summation of the number of $\delta^{18} \mathrm{O}_{\mathrm{ppt}}$ observations utilized within each isotope zone for calibration throughout all seasons. 
2.1 Column "Isotope Zone", the regionalization scheme (i.e., SSC, Kpn, RCWIP, 2-Zone or 1Zone) followed by the isotope zone number or zone indicator (e.g. SSC4 represents the model for the Synoptic Scale Classification regionalization scheme in isotope zone four). "SUM" represents the summation of the number of $\delta^{18} \mathrm{O}_{\mathrm{ppt}}$ observations utilized within each season for validation.

2.2 Column "Number of Measurements: Validation, DJF", the number of monthly $\delta^{18} \mathrm{O}_{\mathrm{ppt}}$ observations used for validation of the DJF (winter: December-January-February) models.

2.3 Column "Number of Measurements: Validation, MAM", the number of monthly $\delta^{18} \mathrm{O}_{\mathrm{ppt}}$ observations used for validation of the MAM (spring: (March-April-May) models.

2.4 Column "Number of Measurements: Validation, JJA", the number of monthly $\delta^{18} \mathrm{O}_{\mathrm{ppt}}$ observations used for validation of the JJA (summer: June-July-August) models.

2.5 Column "Number of Measurements: Validation, SON", the number of monthly $\delta^{18} \mathrm{O}_{\mathrm{ppt}}$ observations used for validation of the SON (fall: September-October-November) models.

2.6 Column "SUM" represents the summation of the number of $\delta^{18} \mathrm{O}_{\mathrm{ppt}}$ observations utilized within each isotope zone for validation throughout all seasons. 
APpendix A

Table A-1: Supplementary information for CNIP, GNIP and USNIP measurement stations

\begin{tabular}{|c|c|c|c|c|c|c|c|c|c|c|}
\hline \multirow{2}{*}{$\begin{array}{l}\text { Station } \\
\text { Number }\end{array}$} & \multirow{2}{*}{ Name } & \multirow{2}{*}{$\begin{array}{c}\text { Province/ } \\
\text { State }\end{array}$} & \multirow{2}{*}{$\begin{array}{c}\text { Latitude } \\
\left({ }^{\circ}\right)\end{array}$} & \multirow{2}{*}{$\begin{array}{c}\text { Longitude } \\
\left({ }^{\circ}\right)\end{array}$} & \multirow{2}{*}{$\begin{array}{l}\text { Altitude } \\
\text { (m) }\end{array}$} & \multirow{2}{*}{$\begin{array}{l}\text { Record } \\
\text { Length }\end{array}$} & \multirow{2}{*}{$\begin{array}{c}\mathbf{n} \\
\text { (monthly) }\end{array}$} & \multicolumn{3}{|c|}{ Isotope Zone Number ${ }^{a}$} \\
\hline & & & & & & & & SSC & Kpn & RCWIP \\
\hline 1 & Alert & $\mathrm{NU}$ & 82.2 & -62.3 & 62 & $1989-2001$ & 149 & 4 & 62 & 17 \\
\hline 2 & Atikokan & $\mathrm{ON}$ & 48.75 & -91.62 & 393 & $1975-1982$ & 75 & 31 & 42 & 18 \\
\hline 3 & Bay D'Espoir & NL & 47.98 & -55.82 & 190 & $1997-2010$ & 163 & 8 & 42 & 23 \\
\hline 4 & Bonner Lake & $\mathrm{ON}$ & 49.38 & -82.12 & 245 & $1997-2010$ & 161 & 31 & 42 & 23 \\
\hline 5 & Bratt's Lake & SK & 50.12 & -104.42 & 580 & 2003-2010 & 87 & 32 & 42 & 18 \\
\hline 6 & Calgary & $\mathrm{AB}$ & 51.02 & -114.02 & 1049 & $1992-2001$ & 116 & 32 & 43 & 18 \\
\hline 7 & Cambridge Bay & $\mathrm{NU}$ & 69.06 & -105.07 & 23 & 1989-2002 & 148 & 4 & 62 & 17 \\
\hline 8 & Chapais & $\mathrm{QC}$ & 49.82 & -74.95 & 382 & 1997-2010 & 165 & 31 & 43 & 23 \\
\hline 9 & Churchill & $\mathrm{MB}$ & 58.45 & -94 & 28 & 1989-1999 & 119 & 31 & 43 & 18 \\
\hline 10 & Edmonton & $\mathrm{AB}$ & 53.57 & -113.52 & 671 & 1961-1966 & 51 & 32 & 42 & 18 \\
\hline 11 & Egbert & ON & 44.23 & -79.77 & 224 & 1997-2002 & 60 & 31 & 42 & 23 \\
\hline 12 & ELA & ON & 49.67 & -93.72 & 369 & 1997-2010 & 162 & 31 & 42 & 18 \\
\hline 13 & Esther & ON & 51.67 & -110.2 & 707 & 1997-2003 & 64 & 32 & 42 & 18 \\
\hline 14 & Eureka & $\mathrm{NU}$ & 80 & -85.56 & 10 & 1989-2001 & 146 & 4 & 62 & 17 \\
\hline 15 & Fort Smith & NT & 60.02 & -111.97 & 203 & 1961-1965 & 40 & 4 & 43 & 18 \\
\hline 16 & Gimli & MB & 50.62 & -96.98 & 223 & 1975-1982 & 72 & 31 & 42 & 18 \\
\hline \multirow{2}{*}{17} & \multirow{2}{*}{ Goose Bay } & \multirow{2}{*}{ NL } & \multirow{2}{*}{53.32} & \multirow{2}{*}{-60.42} & \multirow{2}{*}{46} & 1961-1969; & \multirow{2}{*}{216} & \multirow{2}{*}{8} & \multirow{2}{*}{43} & \multirow{2}{*}{23} \\
\hline & & & & & & 1997-2010 & & & & \\
\hline 18 & Hall Beach & $\mathrm{NU}$ & 68.47 & -81.15 & 8 & 1989-1993 & 55 & 4 & 62 & 17 \\
\hline 19 & Harcourt & NB & 46.5 & -65.27 & 40 & 1997-2010 & 162 & 31 & 42 & 23 \\
\hline 20 & Inuvik & NT & 68.18 & -133.29 & 59 & 1986-1989 & 14 & 4 & 43 & 16 \\
\hline 21 & Mayo & $\mathrm{YT}$ & 63.62 & -134.13 & 504 & 1985-1989 & 37 & 4 & 47 & 16 \\
\hline 22 & Mould Bay & NT & 76.14 & -119.2 & 15 & 1989-1993 & 58 & 4 & 62 & 17 \\
\hline 23 & Ottawa & ON & 45.32 & -75.67 & 114 & 1979-2007 & 331 & 31 & 42 & 23 \\
\hline 24 & Pond Inlet & $\mathrm{NU}$ & 72.4 & -78 & 55.2 & 1990-1992 & 20 & 4 & 62 & 17 \\
\hline 25 & Resolute Bay & $\mathrm{NU}$ & 74.72 & -94.98 & 67 & 1989-1993 & 59 & 4 & 62 & 17 \\
\hline 26 & Saskatoon & SK & 52.1 & -106.43 & 504 & 1997-2001 & 35 & 32 & 42 & 18 \\
\hline 27 & Saturna Island & $\mathrm{BC}$ & 48.78 & -123.13 & 178 & 1997-2010 & 165 & 8 & 35 & 19 \\
\hline 28 & Simcoe & ON & 42.85 & -80.27 & 240 & 1975-1982 & 79 & 31 & 42 & 23 \\
\hline 29 & Snare Rapids & NT & 63.52 & -116 & 241 & 1997-2010 & 148 & 4 & 43 & 16 \\
\hline 30 & Ste. Agathe & $\mathrm{QC}$ & 46.05 & -74.28 & 395 & 1975-1982 & 76 & 31 & 42 & 23 \\
\hline
\end{tabular}


Appendix A

\begin{tabular}{|c|c|c|c|c|c|c|c|c|c|c|}
\hline 31 & The Pas & MB & 53.97 & -101.1 & 272 & $1975-1982$ & 70 & 31 & 43 & 18 \\
\hline 32 & Truro & NS & 45.37 & -63.27 & 40 & $1975-1983$ & 91 & 8 & 42 & 23 \\
\hline 33 & Victoria & $\mathrm{BC}$ & 48.65 & -123.43 & 20 & $1975-1982$ & 70 & 8 & 35 & 19 \\
\hline 34 & Whitehorse & $\mathrm{YT}$ & 60.72 & -135.07 & 702 & 1961-1989 & 91 & 6 & 47 & 16 \\
\hline 35 & Wynyard & SK & 51.77 & -104.2 & 561 & $1965-1982$ & 72 & 32 & 42 & 18 \\
\hline 36 & Yellowknife & NT & 62.28 & -114.27 & 205 & 1989-1997 & 97 & 4 & 43 & 18 \\
\hline 37 & Poker Creek & $\mathrm{AK}$ & 65.155 & -147.491 & 230 & $2001-2004$ & 35 & 4 & 43 & 16 \\
\hline 38 & $\begin{array}{l}\text { Denali National Park- } \\
\text { Mt. McKinley }\end{array}$ & AK & 63.7232 & -148.9676 & 661 & 1989-2004 & 104 & 4 & 43 & 16 \\
\hline 39 & $\begin{array}{l}\text { Craters of the Moon } \\
\text { National Monument }\end{array}$ & ID & 43.45683 & -113.55283 & 1807 & 1987-2004 & 98 & 32 & -9999 & -9999 \\
\hline 40 & Smith's Ferry & ID & 44.292 & -116.05817 & 1442 & 1989-2004 & 121 & 32 & -9999 & -9999 \\
\hline 41 & Douglas Lake & MI & 45.5565 & -84.67367 & 238 & 1989-2004 & 117 & 31 & 42 & 23 \\
\hline 42 & $\begin{array}{ll}\text { Morcell Experimental } \\
\text { Forest }\end{array}$ & MN & 47.52533 & -93.46783 & 431 & 1989-2004 & 105 & 31 & 42 & 18 \\
\hline 43 & Lamberton & $\mathrm{MN}$ & 44.23567 & -95.30033 & 343 & 1989-2004 & 107 & 31 & -9999 & -9999 \\
\hline 44 & $\begin{array}{lr}\text { Little } & \text { Bighorn } \\
\text { Battlefield } & \text { National } \\
\text { Monument } & \\
\end{array}$ & MT & 45.56783 & -107.43583 & 957 & 1989-2004 & 79 & 32 & -9999 & -9999 \\
\hline 45 & $\begin{array}{l}\text { Glacier National Park - } \\
\text { Fire Weather Station }\end{array}$ & MT & 48.5103 & -113.9958 & 980 & 1989-2004 & 101 & 32 & 43 & -9999 \\
\hline 46 & Lost Trail Pass & MT & 45.6917 & -113.9656 & 2414 & 1990-2004 & 103 & 32 & 42 & -9999 \\
\hline 47 & $\begin{array}{l}\text { Theodore Roosevelt } \\
\text { National Park }\end{array}$ & ND & 47.6014 & -103.2642 & 611 & 1989-2000 & 46 & 32 & 42 & 18 \\
\hline 48 & Icelandic State Park & ND & 48.77617 & -97.7525 & 306 & 1989-2004 & 100 & 31 & 42 & 18 \\
\hline 49 & Aurora Research Farm & NY & 42.73367 & -76.65583 & 249 & $1989-2004$ & 131 & 31 & 42 & 23 \\
\hline 50 & Chautauqua & NY & 42.293 & -79.39117 & 488 & 1989-2004 & 126 & 31 & 42 & -9999 \\
\hline 51 & West Point & NY & 41.3505 & -74.0425 & 201 & 1989-2004 & 132 & 31 & -9999 & -9999 \\
\hline 52 & $\begin{array}{lll}\text { Alsea } & \text { Guard } & \text { Ranger } \\
\text { Station } & & \\
\end{array}$ & OR & 44.38467 & -123.60917 & 104 & 1989-2004 & 120 & 8 & 35 & 19 \\
\hline 53 & $\begin{array}{l}\text { H.J. Andrews } \\
\text { Experimental Forest }\end{array}$ & OR & 44.208 & -122.252 & 436 & 1989-2004 & 130 & -9999 & 35 & 19 \\
\hline 54 & $\begin{array}{ll}\text { Starkey } & \text { Experimental } \\
\text { Forest } & \\
\end{array}$ & OR & 45.22133 & -118.50683 & 1253 & 1989-2004 & 131 & 32 & 35 & -9999 \\
\hline 55 & Underhill & VT & 44.52367 & -72.868 & 399 & 1989-2004 & 166 & 31 & 42 & 23 \\
\hline 56 & $\begin{array}{l}\text { Olympic National Park- } \\
\text { Hoh Ranger Station }\end{array}$ & WA & 47.8597 & -123.9325 & 182 & 1989-2004 & 134 & 8 & -9999 & 19 \\
\hline
\end{tabular}


APPENDix A

\begin{tabular}{|c|c|c|c|c|c|c|c|c|c|c|}
\hline 57 & $\begin{array}{l}\text { Palouse Conservation } \\
\text { Farm }\end{array}$ & WA & 46.75633 & -117.18417 & 766 & 1989-2004 & 130 & -9999 & 35 & -9999 \\
\hline 58 & Trout Lake & WI & 46.05167 & -89.65183 & 501 & 1989-2004 & 130 & 31 & 42 & 23 \\
\hline 59 & Lake Geneva & WI & 42.57417 & -88.50033 & 288 & 1989-2004 & 128 & 31 & -9999 & -9999 \\
\hline 60 & Pinedale & WY & 42.924 & -109.78533 & 2388 & 1989-2004 & 97 & 32 & 42 & -9999 \\
\hline 61 & $\begin{array}{l}\text { Yellowstone National } \\
\text { Park Tower Falls }\end{array}$ & WY & 44.917 & -110.41883 & 1912 & 1989-2004 & 100 & 32 & 43 & -9999 \\
\hline 62 & Brooklyn Lake & WY & 41.3647 & -106.2408 & 3212 & 1993-2004 & 89 & 32 & 43 & -9999 \\
\hline 63 & Newcastle & WY & 43.8733 & -104.1922 & 1466 & $1989-2004$ & 95 & 32 & -9999 & -9999 \\
\hline
\end{tabular}

${ }^{a}$ A zone number of -9999 indicates that the specified station was outside the geographical extents of the isotope zones within the regionalization scheme and was therefore not included in model development. 
Table A-2: Number of observations ( $n$ ) included in: (a) calibration and, (b) validation subsets for each seasonal model within the five regionalization schemes.

(a)

\begin{tabular}{|c|c|c|c|c|c|}
\hline \multirow{2}{*}{ Isotope Zone } & \multicolumn{5}{|c|}{ Number of Measurements: Calibration } \\
\hline & DJF & MAM & JJA & SON & SUM \\
\hline SSC4 & 211 & 200 & 221 & 216 & 848 \\
\hline SSC6 & \multicolumn{4}{|c|}{34} & 34 \\
\hline SSC8 & 156 & 169 & 165 & 161 & 651 \\
\hline SSC31 & 508 & 560 & 591 & 553 & 2212 \\
\hline SSC32 & 285 & 327 & 325 & 298 & 1235 \\
\hline SUM & 1169 & 1265 & 1311 & 1237 & 4980 \\
\hline Kpn35 & 134 & 144 & 136 & 133 & 547 \\
\hline Kpn42 & 498 & 544 & 567 & 540 & 2149 \\
\hline Kpn43 & 253 & 255 & 261 & 254 & 1023 \\
\hline Kpn47 & \multicolumn{4}{|c|}{69} & 69 \\
\hline Kpn62 & 149 & 147 & 155 & 155 & 606 \\
\hline SUM & 1051 & 1107 & 1136 & 1099 & 4394 \\
\hline RCWIP16 & 48 & 35 & 51 & 46 & 180 \\
\hline RCWIP17 & 149 & 147 & 155 & 155 & 606 \\
\hline RCWIP18 & 218 & 240 & 252 & 230 & 940 \\
\hline RCWIP19 & 102 & 113 & 107 & 105 & 427 \\
\hline RCWIP23 & 369 & 395 & 400 & 392 & 1556 \\
\hline SUM & 886 & 930 & 965 & 928 & 3709 \\
\hline 2-Zone: North & 1075 & 1176 & 1212 & 1140 & 4603 \\
\hline 2-Zone: South & 155 & 150 & 157 & 158 & 620 \\
\hline SUM & 1230 & 1326 & 1369 & 1298 & 5223 \\
\hline 1-Zone & 1230 & 1326 & 1369 & 1298 & 5223 \\
\hline
\end{tabular}


(b)

\begin{tabular}{|c|c|c|c|c|c|}
\hline \multirow{2}{*}{ Isotope Zone } & \multicolumn{5}{|c|}{ Number of Measurements: Validation } \\
\hline & DJF & МАM & JJA & SON & SUM \\
\hline SSC4 & 18 & 13 & 22 & 17 & 70 \\
\hline SSC6 & \multicolumn{4}{|c|}{12} & 12 \\
\hline SSC8 & 45 & 50 & 37 & 42 & 174 \\
\hline SSC31 & 87 & 97 & 92 & 92 & 368 \\
\hline SSC32 & 34 & 46 & 40 & 39 & 159 \\
\hline SUM & 187 & 209 & 194 & 193 & 783 \\
\hline Kpn35 & 41 & 44 & 34 & 41 & 160 \\
\hline Kpn42 & 96 & 115 & 113 & 103 & 427 \\
\hline Kpn43 & 35 & 24 & 31 & 28 & 118 \\
\hline Kpn47 & \multicolumn{4}{|c|}{24} & 24 \\
\hline Kpn62 & 9 & 8 & 9 & 3 & 29 \\
\hline SUM & 187 & 197 & 193 & 181 & 758 \\
\hline RCWIP16 & 10 & 5 & 13 & 16 & 44 \\
\hline RCWIP17 & 9 & 8 & 9 & 3 & 29 \\
\hline RCWIP18 & 23 & 35 & 39 & 28 & 125 \\
\hline RCWIP19 & 39 & 42 & 32 & 38 & 151 \\
\hline RCWIP23 & 77 & 84 & 81 & 78 & 320 \\
\hline SUM & 158 & 174 & 174 & 163 & 669 \\
\hline 2-Zone: North & 181 & 202 & 185 & 194 & 762 \\
\hline 2-Zone South & 9 & 8 & 9 & 3 & 29 \\
\hline SUM & 190 & 210 & 194 & 197 & 791 \\
\hline 1-Zone & 190 & 210 & 194 & 197 & 791 \\
\hline
\end{tabular}




\section{Appendix B:}

\section{ISOP PROGRAM DEVELOPMENT AND IMPLEMENTATION}




\section{APPENDIX B}

Before isoWATFLOOD simulations could be forced using time series $\delta^{18} \mathrm{O}_{\mathrm{ppt}}$ input, development and implementation of a program to read in and use $\delta^{18} \mathrm{O}_{\mathrm{ppt}}$ input within the existing WATFLOOD and isoWATFLOOD code is required. This program will hereafter be referred to as $i s o P$. Development and implementation of $i s o P$ consists of two main objectives:

1. Creation of a pre-processing routine and corresponding user manual that allows users to easily generate monthly time series gridded $\delta^{18} \mathrm{O}_{\mathrm{ppt}}$ simulations within specified watershed extents using the KPN models developed in Delavau et al., 2015;

2. Development and alteration of current WATFLOOD and isoWATFLOOD source code to read in monthly time series gridded $\delta^{18} \mathrm{O}_{\mathrm{ppt}}$ simulations in the format as output in (1);

This Appendix outlines the development of a pre-processing routine that automates the process of creating gridded oxygen-18 in precipitation text file output that is compatible for use in isoWATFLOOD. A manual for new users has been written and is available at: G:SPLlisoP_CodeWocumentation and online. Although this application pertains to isoWATFLOOD, additional code could be developed to couple the KPN models from Delavau et al. (2015) to any isotope-enabled hydrological model.

\section{Background Information and Folder Structure}

Building off the existing WATFLOOD folder structure (shown below in Figure B-1, adapted from Kouwen, 2014), the isoP code and required files are housed under the main SPL directory in a folder titled isoP_Code. Within the same directory level is the main watershed folder (e.g. lnrb, simpson_ef, etc). 


\section{APPENDIX B}

Figure B-1: Incorporation of isoP folder within overall WATFLOOD folder structure.

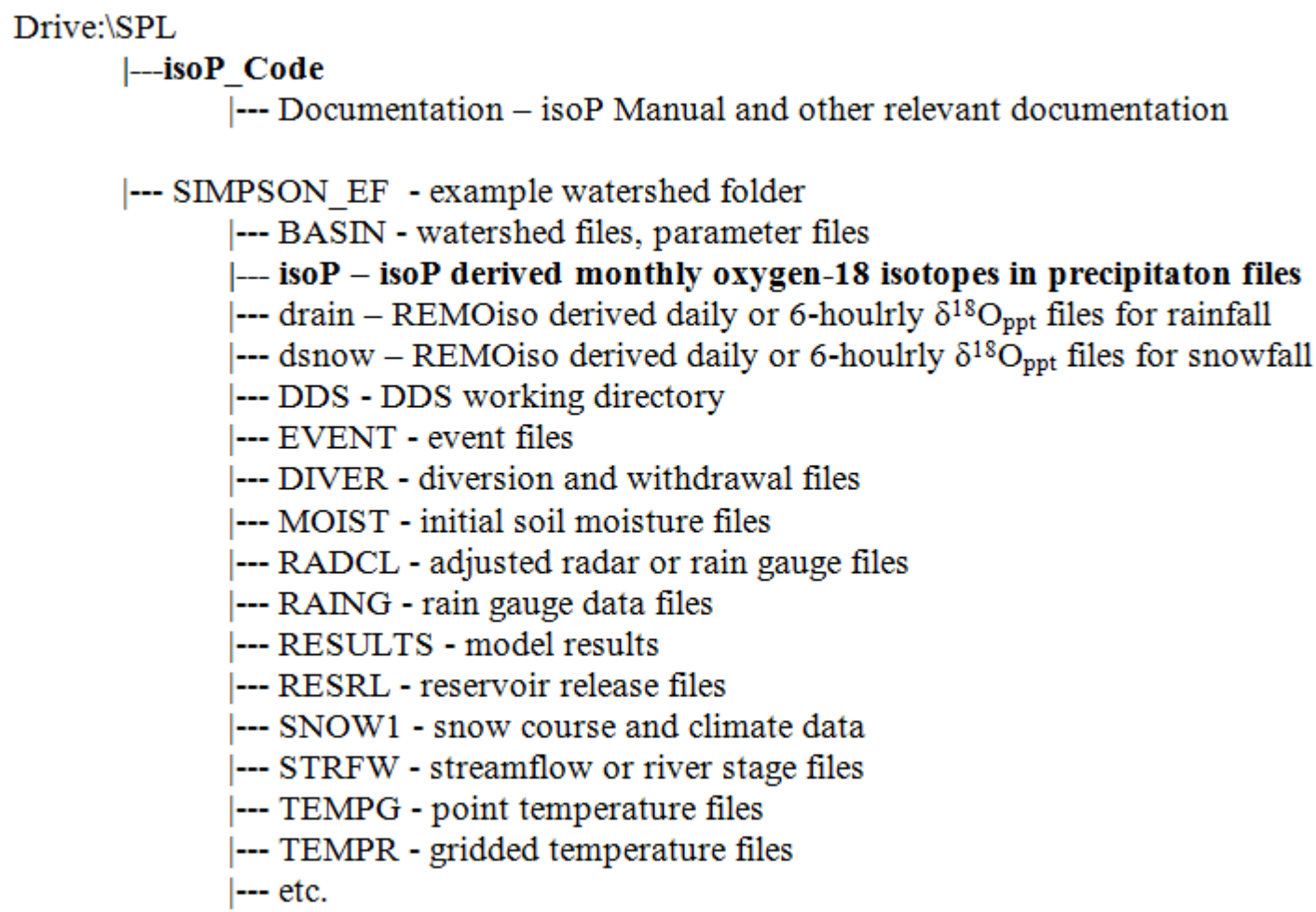

Moving down one level into the watershed folder, isoP requires a folder structure as detailed on the left portion of Figure B-2. This includes an SPL\watershed Nbasin folder with the _shd.r2c file, and a SPL\watershed $i s o P$ folder. For watersheds that have been previously setup, the basin folder and _shd.r2c file will already exist and only the $i s o P$ folder and sub-folders must be created.

If the user plans on simulating upper and lower prediction intervals, they are required to include two empty folders within the SPL\watershed and lower_PI. As the isoP program runs, it will eventually fill the $i s o P$ folder (and upper_PI and lower_PI folders, if applicable) with monthly yyyymmdd_drn.r2c files. R2C stands for 2D rectangular cell format. All gridded WATFLOOD inputs are in this particular format (Kouwen, 


\section{APPENDIX B}

2014), therefore for both simplicity and consistency, the yyyymmdd_drn.r2c files are produced in this format as well.

Figure B-2: Folder structure required by the isoP program, and the files housed in the isoP_Code folder on local drive:LSPLIisoP_Code.

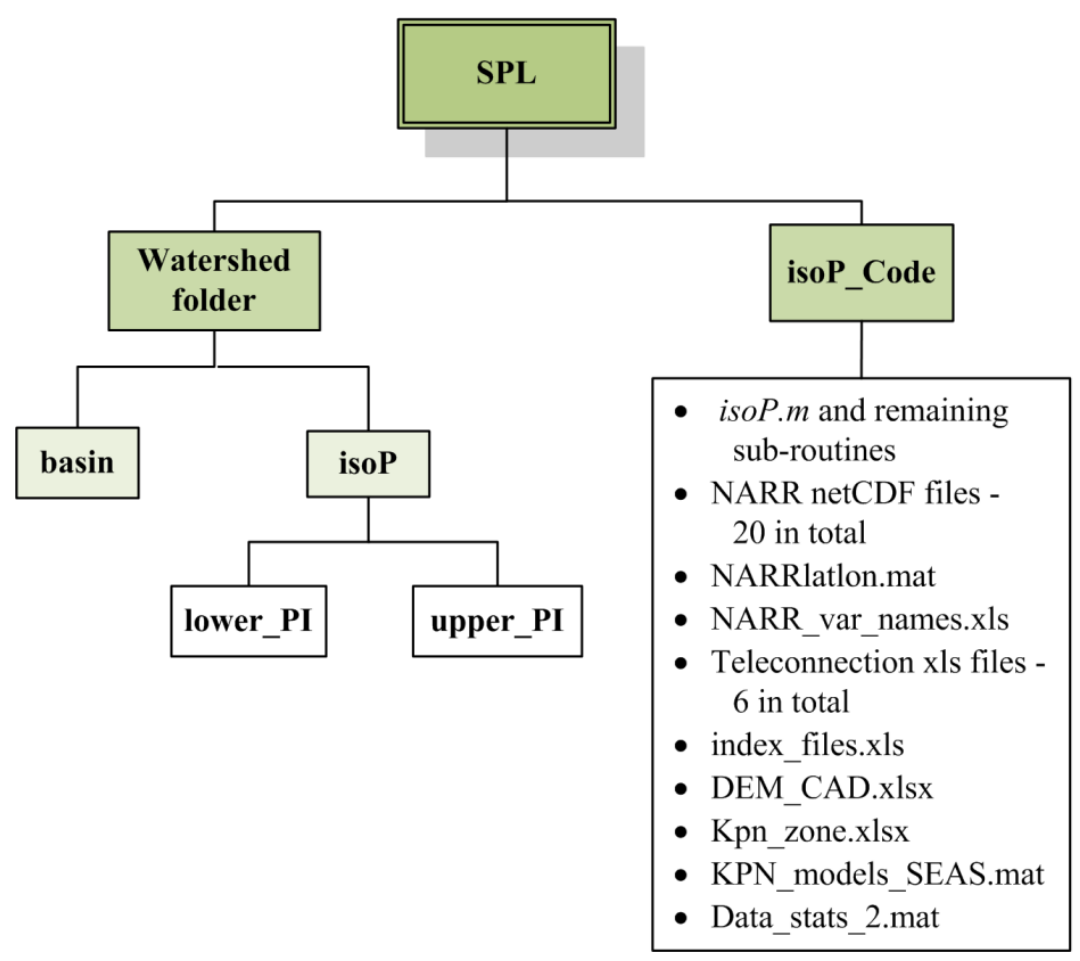

Within the SPLlisoP_Code folder are a series of files that are utilized by the isoP program. The first, and most important, are nine Matlab m-files that constitute the isoP code, which include the isoP.m main program module and remaining sub-routines. These are described in detail below and can be seen on

Figure B-6. The code for each of the aforementioned sub-routines can be found in Appendix C.

The next set of files relate to NARR climate data. Twenty netCDF files (one for each climate variable described in Delavau et al., 2015) are included within this directory. Access to all NARR climate data is freely accessible through an FTP site (NOAA, 2016b). For this particular 


\section{APPENDIX B}

application, time series monthly mean climate variables are required. The remaining two NARR related files (NARR_var_names.xls and NARRlatlon.mat) are used to determine which NARR variables to read in, and what location to read these data from. NARR climate data does have some limitations. Firstly, the data is not available for prior to 1979 , therefore limiting the use of isoP from 1979 onwards. Secondly, although studies have shown adequate performance of NARR at the monthly timescale across the Unites States (e.g. Radhakrishna et al., 2015), there are also known deficiencies with NARR such as changes to the assimilation system to stop including Canadian precipitation from 2003 onwards (Mesinger et al., 2006; West et al., 2006) resulting in discontinuity in Canadian Arctic precipitation after 2003 (Rapaic et al., 2015). Given the high correlation between $\delta^{18} \mathrm{O}_{\mathrm{ppt}}$ and precipitable water (prwtr; Delavau et al., 2015), we wanted to investigate if NARR simulated prwtr was comparable to that of other reanalysis products.

As a means of validating NARR prwtr with other reanalysis products, a comparison between NARR and ERA-interim at 13 locations across Canada is conducted (Figure B-3). ERA-interim daily prwtr was extracted from the European Centre for Medium-Range Weather Forecasts website (ECHMWF, 2016) and was summed to total monthly prwtr for comparison to NARR prwtr. The results are displayed in a series of proportionality plots below (Figure B-4). 


\section{APPENDIX B}

Figure B-3: Locations of comparison between NARR and ERA-40 data.

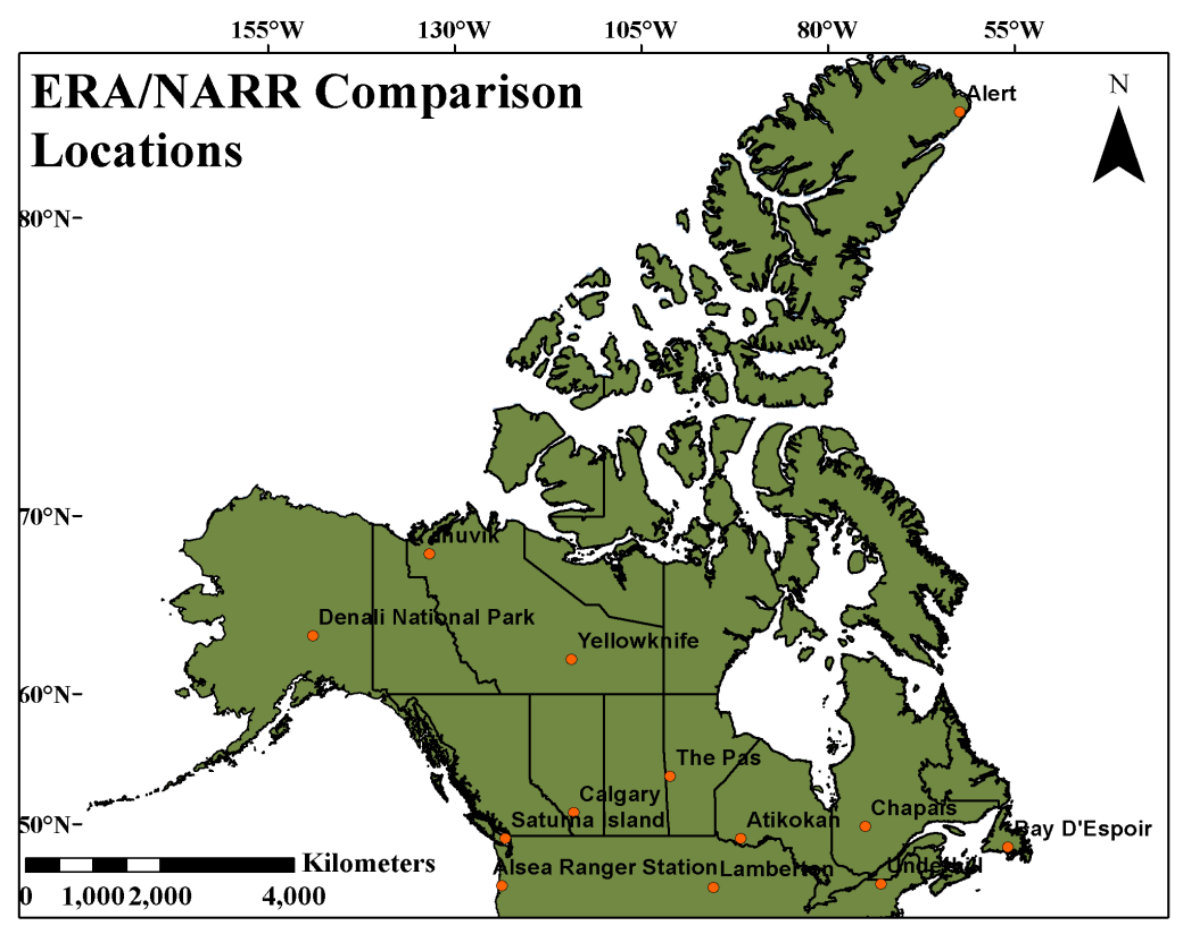

Results show that there is very good agreement between NARR and ERA-40 at almost all of the stations included in the analysis. The Two south-western Pacific Stations (Saturna Island and Alsea Guard Station) show moderate discrepancies between each other, whereby NARR overpredicts relative to ERA-40. This discrepancy may be partially responsible for poor correlation between $\delta^{18} \mathrm{O}_{\mathrm{ppt}}$ observations and prwtr within the south Pacific isotope zones (Delavau et al., 2015). However, before such a conclusion can be drawn, both NARR and ERA-40 should be validated with observed prwtr data at this location to see which reanalysis product shows higher accuracy in this region. At the remaining stations, NARR and ERA-40 prwtr proportionality plots show very strong agreement. The high correlation gives us confidence in NARR's prwtr simulations within this region and for their use in current and future applications. 


\section{APPENDIX B}

Figure B-4: Proportionality plots of NARR (x-axis) vs. ERA-40 (y-axis) precipitable water at 13 locations located throughout the study domain.
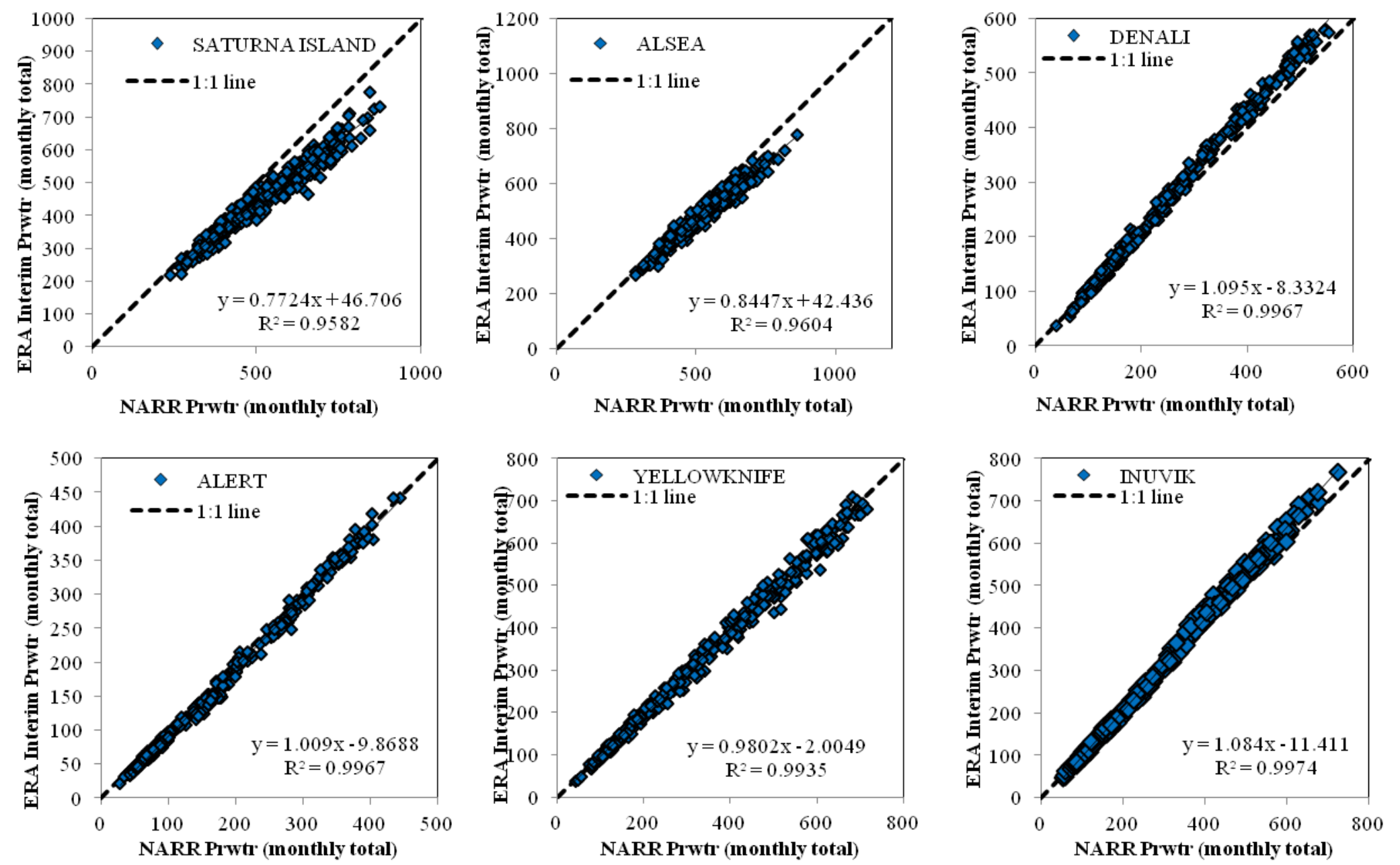


\section{APPENDIX B}
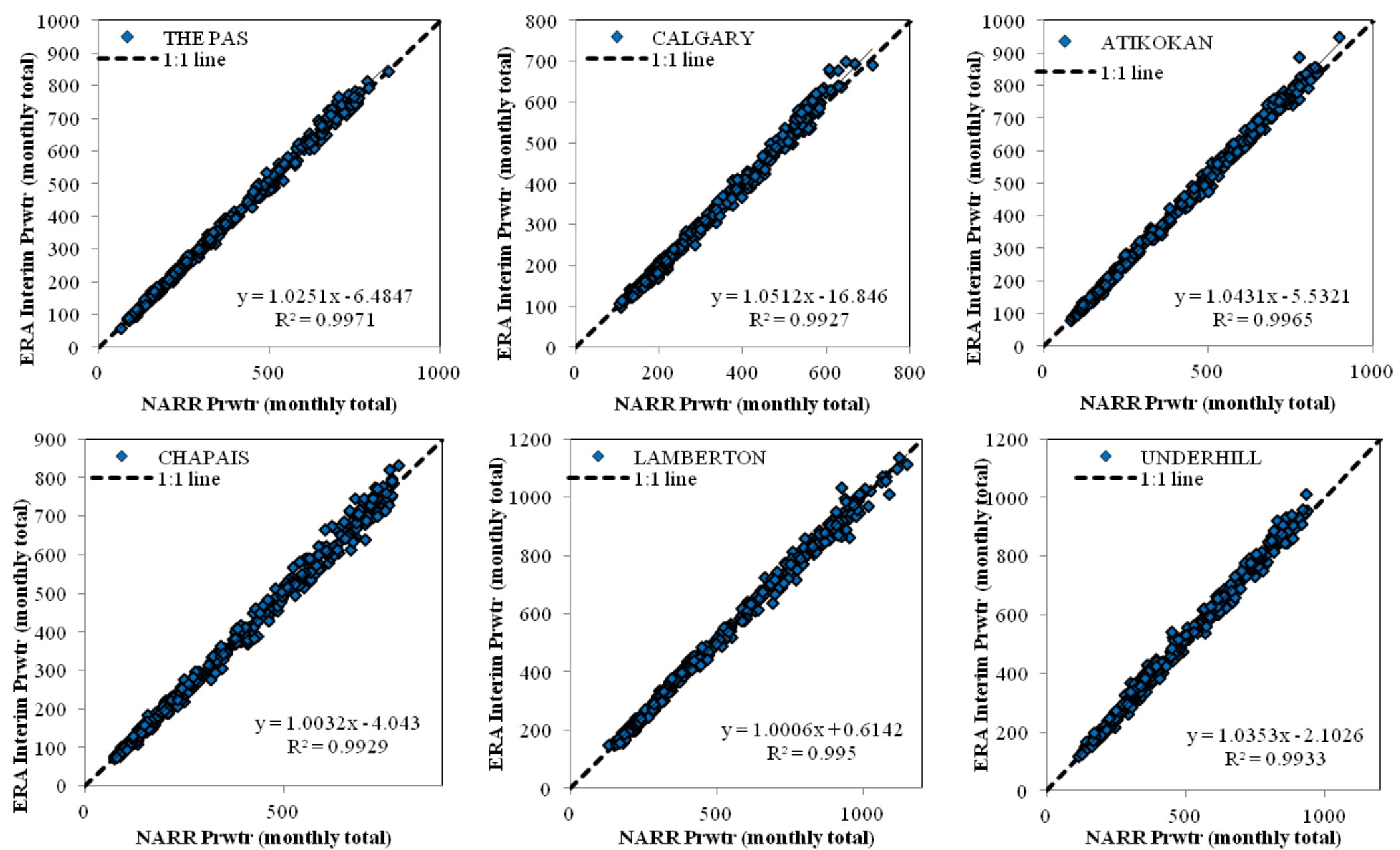


\section{APPENDIX B}

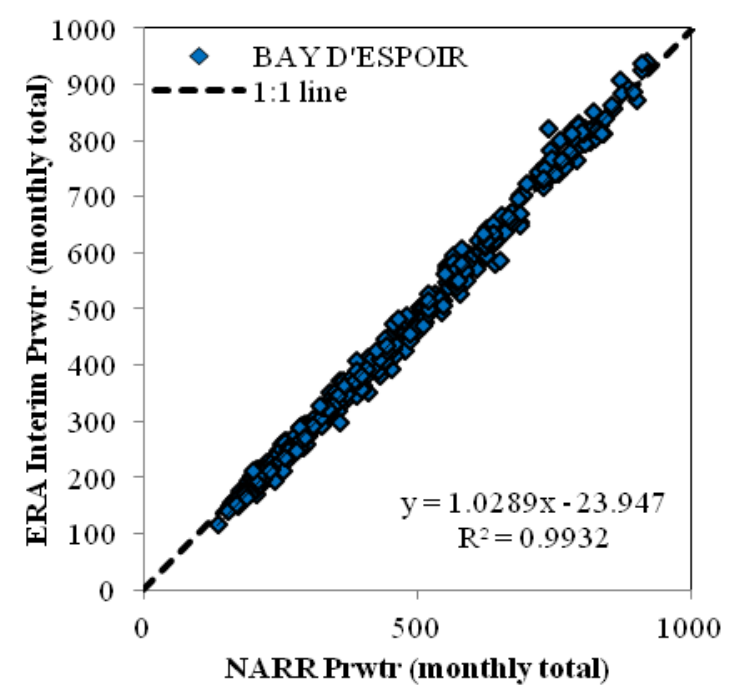

The teleconnection excel files (AMO, AO, NAO, PDO, PNA, SOI) store monthly teleconnection indices from January 1950 until December 2014. All of the indices, with the exception of the PDO index, can be found on the National Oceanic and Atmospheric Administration (NOAA) website (NOAA, 2016a). PDO is available through the University of Washington's Joint Institute for the Study of Atmosphere and Ocean (JISAO) website (JISAO, 2016). Index_files.xls stores the list of teleconnection indices to read into the isoP.m program. Currently, this list contains all six of the aforementioned indices up to 2014, and can be updated as required as more recent data becomes available.

DEM_CAD.xls is a file of latitude and longitude coordinates with an estimate of the elevation at each xy grid. Elevations are obtained from the GTOPP30 digital elevation model (DEM) at a resolution of 30 arc seconds (approximately $1 \mathrm{~km}$ ). This mapping product is from a collaborative effort lead by the United States Geological Survey (USGS) and is freely available on their website (USGS, 1997). Kpn_zone.xls is a similar type of coordinate file and contains the Köppen-Geiger zone number at each point of a 17 arc-second grid, derived from a publically 


\section{APPENDIX B}

available global ACSII file of Köppen-Geiger climate classifications (Institute for Veterinary Public Health, 2011).

As previously described, empirical $\delta^{18} \mathrm{O}_{\mathrm{ppt}}$ models are developed for five of the $10 \mathrm{Köppen} \mathrm{zones}$ that exist in Canada $(35,42,43,47$ and 62; Figure B-5a), which account for almost 95\% of Canada's contributing drainage area. It should be noted that outside of the Köppen zones outlined above, $\delta^{18} \mathrm{O}_{\mathrm{ppt}}$ cannot be simulated using the isoP modelling approach due to a lack of $\delta^{18} \mathrm{O}_{\mathrm{ppt}}$ data within these climate regions to develop empirical prediction models. If more data become available and/or the need exists, $\delta^{18} \mathrm{O}_{\mathrm{ppt}}$ prediction models may be developed in the additional unmodelled regions outlined on Figure B-5b (Köppen zones 26, 32, 41, 46, 61) Conversely, one of the existing models could be applied outside of the zone of development; however this is not recommended as the models have not been tested or applied outside of their respective zones. Regions of Canada currently without a KPN model include some transboundary watersheds (Skagit and Milk Rivers), the downstream portions of the Bow and Red Deer Rivers, a section of the South Saskatchewan River near the Alberta/Saskatchewan border, the northern portion of Vancouver Island, and regions of Ellesmere and Axel Heiberg Islands in the Arctic Archipelago (Figure B-5b). 
Figure B-5: (a) The five Köppen Zones for which $\delta^{18} O_{p p t}$ prediction models are developed, and (b) the ten Köppen Zones located within Canadian river basins.
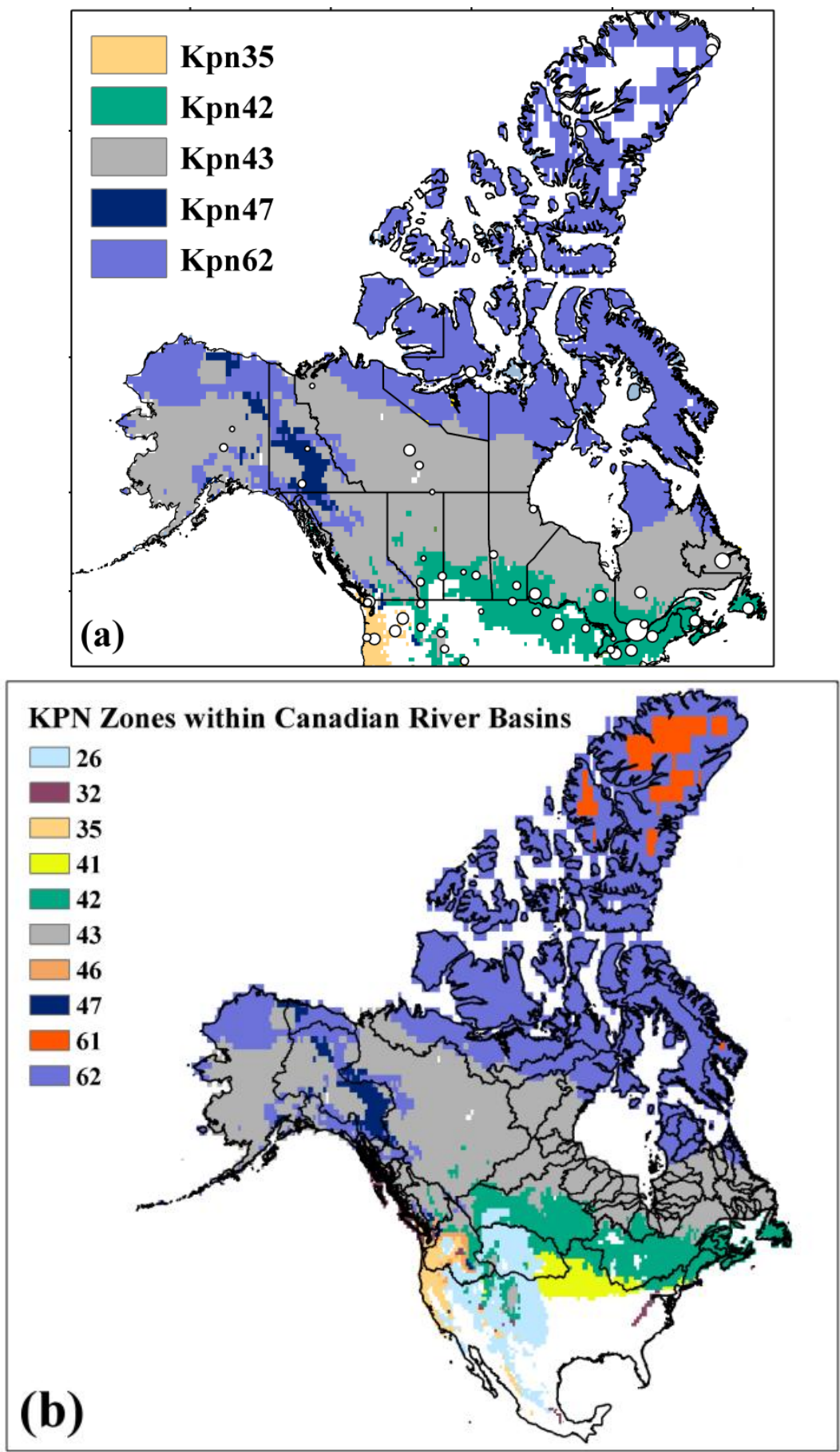

Finally, KPN_models_SEAS.mat is a Matlab workspace storing the 12 empirical models for the Köppen Zone regionalization (as outlined in Delavau et al., 2015). The models are stored in a 


\section{APPENDIX B}

LinearModel format (Mathworks, 2016a) and the details of the models can be viewed (but not changed) in Matlab if required.

\section{The isoP Program}

The isoP program is a series of eight Matlab scripts ( $m$-files) that are called from the main program module, isoP.m (Figure B-6). The code was developed in version R2013a, however has been tested and successfully executed in version R2014b. provides a summary of the structure of the isoP code, and the inputs and outputs passed from one sub-routine to the next. The following section provides an overview of each of the eight sub-routines, as well as the main executing module, isoP.m.

Figure B-6: IsoP program code structure.

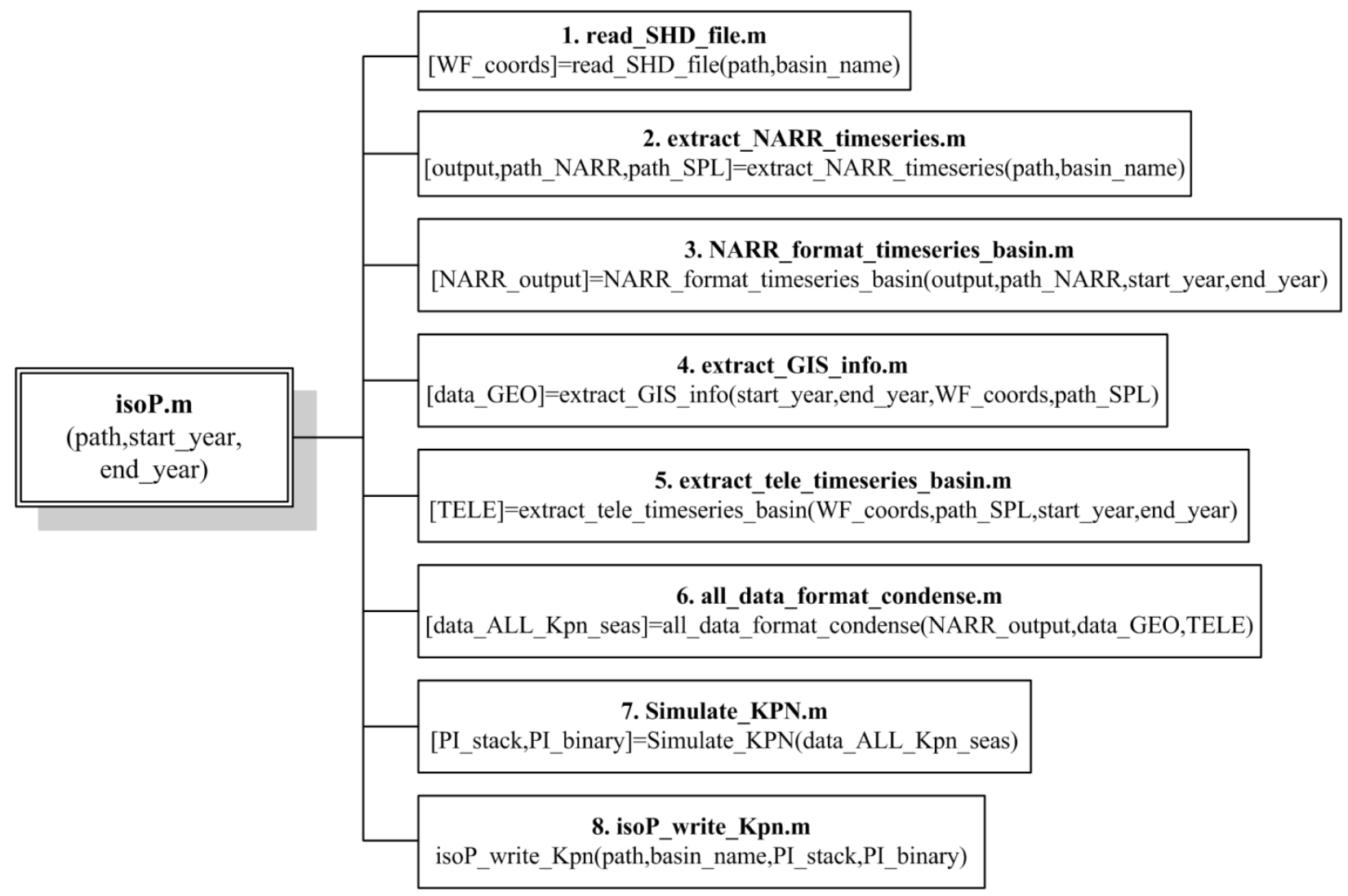




\section{APPENDIX B}

\section{isoP.m}

isoP.m is the main module for the creation of time series gridded $\delta^{18} \mathrm{O}_{\mathrm{ppt}}$ simulations. All other sub-routines are called from this main module in the order listed on Figure B-6, beginning with reading in the _shd.r2c file, and finishing by writing out the yyyymmdd_drn.r2c text files for input into isoWATFLOOD.

To execute the isoP program, the user must first open Matlab and browse to the SPL $\backslash$ isoP_Code folder. Once in this folder, from the command window the user calls the isoP program, and is required to provide the path of the main watershed directory in the form of a text string (e.g. 'G: $\backslash s p \Lambda$ simpson_ef') and the start year and end year of the simulation they would like to carry out at that time, for example:

isoP('G: \SPL\simpson_ef',2009,2012)

From this point forward, the program will provide updates as it progresses through each subroutine, and the user will be prompted for input at least on one occasion (dependent on the coordinate system of the watershed and the type of simulation the user would like to carry out). As previously mentioned, at the end of program execution, gridded $\delta^{18} \mathrm{O}_{\mathrm{ppt}}$ files will be placed within the SPL\watershed $i s o P$ folder.

read_SHD_file.m

read_SHD_file.m uses the provided folder path (e.g. 'G: Isphsimpson_ef'), reads in the WATFLOOD_shd.r2c file, and extracts the geographic information required to locate the basin; such as the $\mathrm{x}$ - and $\mathrm{y}$-origins of the watershed setup, and the number and size of grids. This information is used to construct a grid of latitude and longitude pairs. These coordinates 


\section{APPENDIX B}

represent the isoP "WATFLOOD grid", and are located at the centre of each grid point within the WATFLOOD model of interest (Figure B-7).

Figure B-7: The WATFLOOD grid for the Lower Nelson River watershed.

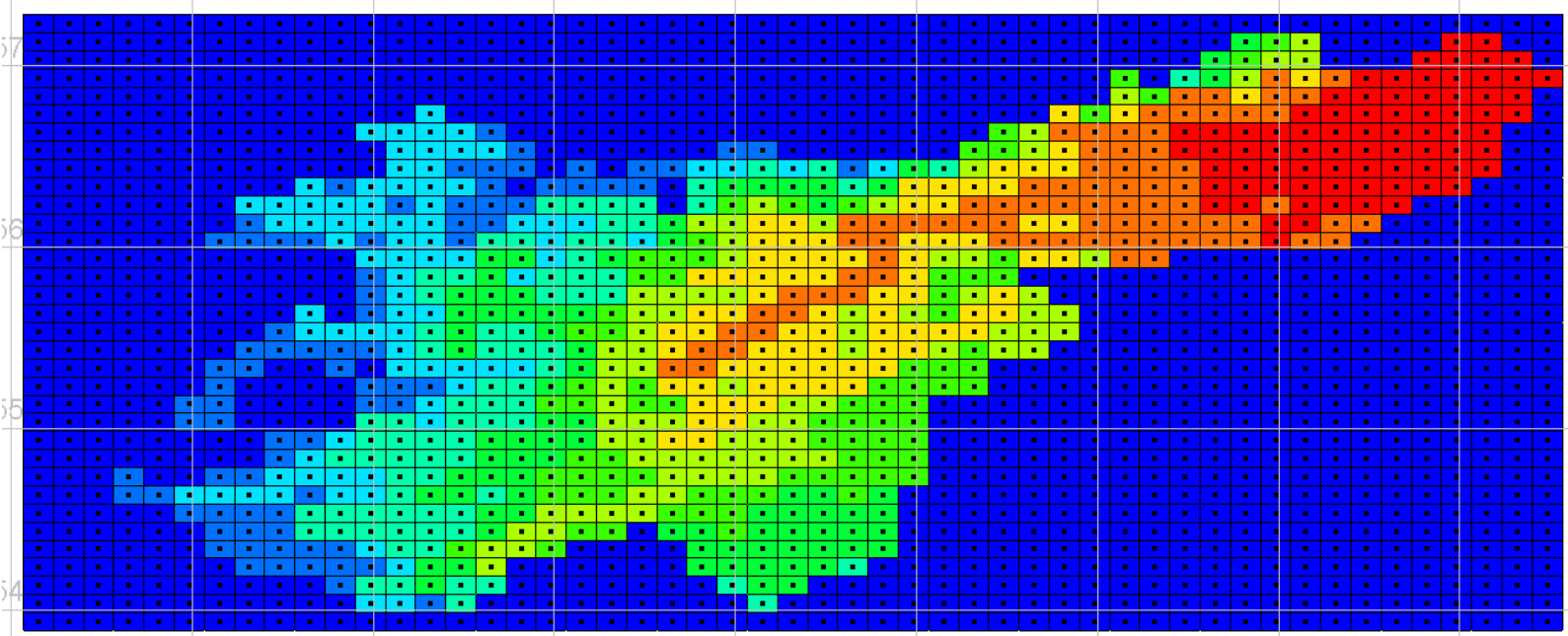

This is the first sub-routine that may prompt the user for feedback. If the watershed coordinate system is in Cartesian or UTM, then the user will be prompted to select what UTM zone the basin in located within. If the coordinate system is specified as lat/long, then there will be no user feedback required. The isoP program uses these coordinates as the locations to extract geographic and climate data, and to carry out all further computations, eventually simulating a time series of monthly $\delta^{18} \mathrm{O}_{\mathrm{ppt}}$ at each grid point. Upon completion of read_SHD_file.m, the program passes the WATFLOOD grid onto extract_NARR_timeseries.m.

\section{Extract_NARR_timeseries.m}

Extract_NARR_timeseries.m reads in the list of NARR climate variable names (NARR_var_names.xls) from the SPLIisoP_Code directory and using the coordinate grid established in read_SHD_file.m, it extracts all 20 NARR variables at the specified grid locations for the entirety of the time series within the netCDF (.nc extension) files $(1979-2014)$. NARR 


\section{APPENDIX B}

data are provided in netCDF format, which is a multi-dimensional format where data are stored in layers made of up several dimensions (in this case, $x, y$ and time). Once extract_NARR_timeseries.m has completed extracting the climate time series at each of the WATFLOOD grids, it passes that output, along with two folder paths to NARR_format_timeseries_basin.m.

\section{NARR_format_timeseries_basin.m}

NARR_format_timeseries_basin.m formats the NARR climate variables into metric units, and for some variables, calculates monthly totals from monthly averages. The NARR output is then passed to all_data_format_condense.m.

\section{extract_GIS_info.m}

extract_GIS_info.m uses a nearest neighbour method (Mathworks, 2016b) to find the DEM grid point (from the previously described DEM_CAD.xls) that is closest to each WATFLOOD grid point. Once located, the program extracts the elevation from that grid and assigns it to the corresponding WATFLOOD grid. extract_GIS_info.m uses this same procedure to extract the Köppen Zone identifier $(35,42,43,47$, or 62, as stipulated within the Kpn_zone.xls file) at each grid point as well. This identifier tells the program which zone(s) the watershed is in, and which seasonal regression models to utilize at each grid point. This program then passes the geographic output to all_data_format_condense.m. 


\section{APPENDIX B}

extract_tele_timeseries_basin.m

extract_tele_timeseries_basin.m reads in the six teleconnection index time series as stipulated in index_files.xls (AMO.xls, AO.xls, NAO.xls, PDO.xls, PNA.xls, SOI.xls). These indices are not spatially variable, and therefore are the same at each WATFLOOD grid point; however they do change throughout time on a monthly basis. Currently, within index_files.xls, these indices have been updated until December 2014.

\section{All_data_format_condense.m}

All_data_format_condense.m brings the three major data sources together (NARR, geographic, and teleconnection), standardizes and condenses them into a single Matlab cell structure, which stores a matrix of data for each grid point. This sub-routine reads in Data_stats_2.mat, which is a workspace with the averages and standard deviations for all predictor variables used in model development. All_data_format_condense.m uses this information to standardize these data before $\delta^{18} \mathrm{O}_{\mathrm{ppt}}$ simulations commence. This is required as the Köppen zone models are developed based on standardized data (for stability purposes), and use of these models requires data to be standardized, and is then converted back to normal reporting convention after $\delta^{18} \mathrm{O}_{\mathrm{ppt}}$ simulation.

\section{Simulate_KPN.m}

Simulate_KPN.m uses these data output by the previous sub-routine, alongside the KPN_models_SEAS.mat workspace to simulate a monthly time series of $\delta^{18} \mathrm{O}_{\mathrm{ppt}}$ at each WATFLOOD grid for the specified time frame. As each grid point is now associated with a Köppen zone number, this sub-routine utilizes that number to determine which regression model to employ. This sub-routine also prompts the user for feedback regarding if they would like to 


\section{APPENDIX B}

simulate $\delta^{18} \mathrm{O}_{\mathrm{ppt}}$ prediction intervals (i.e., account for input data uncertainty) utilizing the bootstrapping methodology outlined in Delavau et al. (2015). It should be mentioned that bootstrapping prediction intervals adds significant time to your simulation- this is especially true for larger basins and longer time periods.

\section{isoP_write_Kpn.m}

isoP_write_Kpn.m reads in simulated $\delta^{18} \mathrm{O}_{\mathrm{ppt}}$ (and prediction intervals, if specified by the user required), and utilizing the standard WATFLOOD header, creates monthly yyymmdd_drn.r2c files for the specified time period. Upon completion of the program, the main files are exported into the SPL\watershedisoP folder. An example of the program output is included in Appendix D. If upper and lower prediction intervals are simulated, these files will be output to the SPL\watershedupper_PI and SPL\watershedNower_PI folders, respectively. The naming convention of the files will still follow the aforementioned format (yyyymmdd_drn.r2c), as this is the file name isoWATFLOOD searches for when reading time series $\delta^{18} \mathrm{O}_{\mathrm{ppt}}$ forcing. However, within the WATFLOOD header of each file, the upper and lower prediction interval $\delta^{18} \mathrm{O}_{\mathrm{ppt}}$ simulations are named 180ppt_KPN_90percentile and 180ppt_KPN_10percentile, respectively.

\section{Changes Required to WATFLOOD Files}

Minimal changes are required to the existing WATFLOOD/isoWATFLOOD files to enable the inclusion of time series $\delta^{18} \mathrm{O}_{\mathrm{ppt}}$ forcing. In addition to the required folder structure (Figure B-2), one line of text must be added to the yyyymmdd.evt and event.evt files, as highlighted below.

$\begin{array}{ll}\# & \\ \text { :filetype } & \text {.evt } \\ \text { :fileversionno } & 9.3 \\ \text { :year } & 1997 \\ \text { :month } & 04 \\ \text { :day } & 01\end{array}$




\section{APPENDIX B}

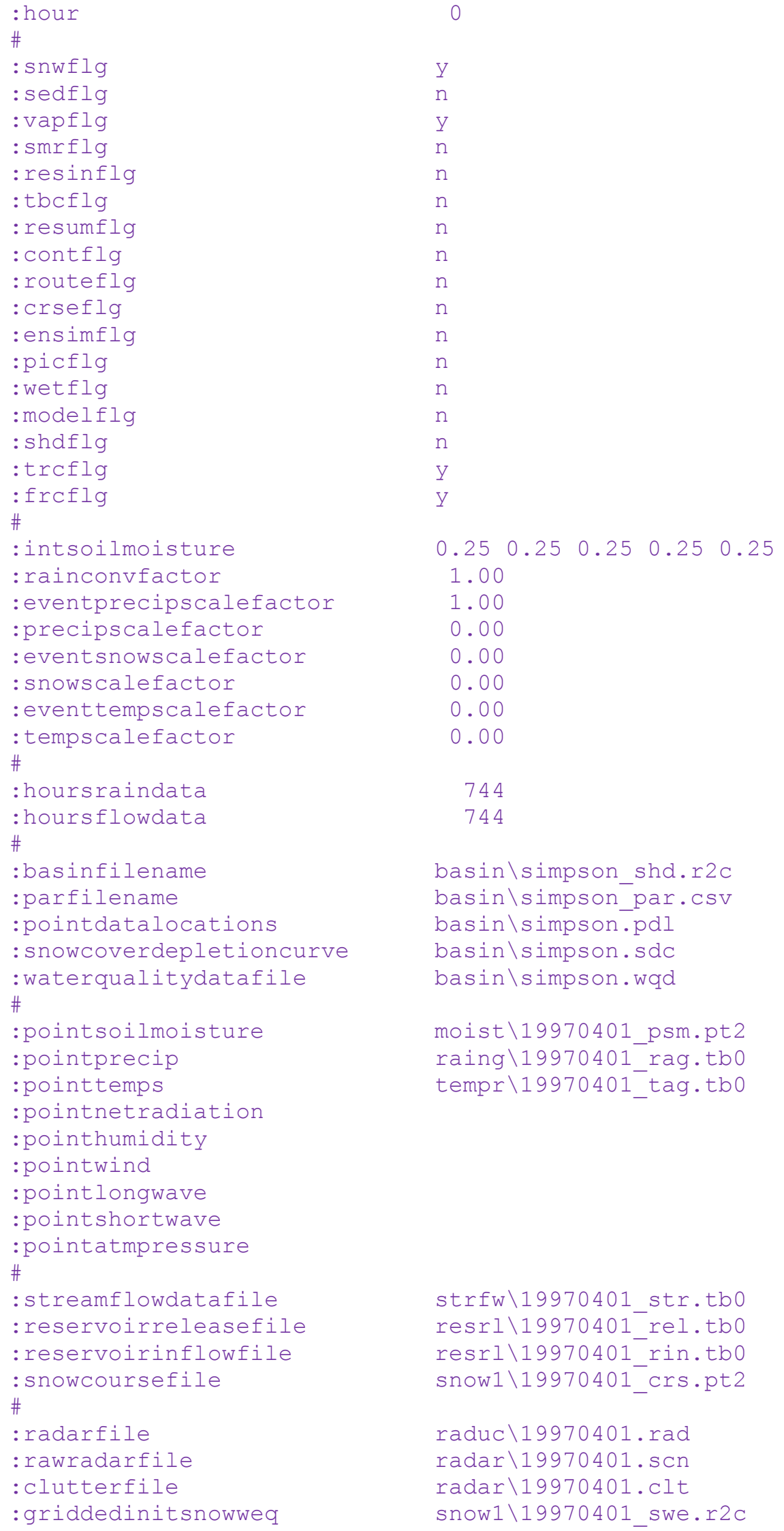




\section{APPENDIX B \\ :griddedinitsoilmoisture \\ :griddedinitlzs \\ :griddedrainfile \\ :griddedsnowfile \\ : griddedtemperaturefile \\ :griddednetradiation \\ : griddedhumidity \\ : griddedwind \\ :griddedlongwave \\ : griddedshortwave \\ :griddedatmpressure \\ : griddedrunoff \\ : griddedrecharge \\ : griddedleakage \\ :griddeddrain \\ \# \\ : noeventstofollow \\ \# \\ event \19970501.evt \\ event \19970601.evt \\ event\19970701. evt \\ eof

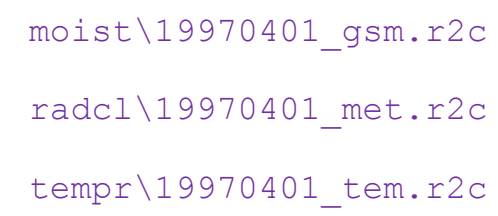 \\ runof \19970401 rff.r2c \\ rchrg \19970401-rch.r2c \\ lkage $19970401^{-} 1 \mathrm{~kg} \cdot r 2 \mathrm{C}$ \\ isoP\19970401_drn.r2c \\ 03}

Additionally, the frcflg must be set to ' $\mathrm{y}$ ' in the event files and in the parameter file itrace must be set to 4 . If the isoP folder exists and if the monthly yyyymmdd_drn.r2c files are within the folder for the period of simulation, then isoWATFLOOD will utilize the isoP files as model input. The user can change the name of the isoP folder or remove the isoP reference in the event file to revert to the default $\delta^{18} \mathrm{O}_{\mathrm{ppt}}$ static forcing.

\section{New isoWATFLOOD Outputs}

Additional variables of $d R A I N \_r a w . c s v$ and $d S N O W \_r a w . c s v$ are now output alongside the existing isoWATFLOOD process output in the Results folder (Figure B-1). These files are generated when running isoWATFLOOD, regardless of $\delta^{18} \mathrm{O}_{\mathrm{ppt}}$ forcing type (i.e., static, KPN or REMOiso). There are two different files, one for rainfall $\delta^{18} \mathrm{O}_{\mathrm{ppt}}$ (dRAIN_raw) and one for snowfall $\delta^{18} \mathrm{O}_{\mathrm{ppt}}$, each reporting hourly simulations. The threshold that isoWATFLOOD uses to determine rainfall versus snowfall is $+4^{\circ} \mathrm{C}$. This threshold is only applicable for the REMOiso 


\section{APPENDIX B}

and static inputs as their input files stipulate both rainfall and snowfall $\delta^{18} \mathrm{O}_{\mathrm{ppt}}$ compositions. Conversely, for the KPN input, both $d R A I N \_r a w . c s v$ and $d S N O W \_r a w . c s v$ are identical, as just a single input file is provided.

\section{References}

Delavau, C., K. P. Chun, T. Stadnyk, S. J. Birks, and J. M. Welker (2015), North American precipitation isotope $(\mathrm{d} 18 \mathrm{O})$ zones revealed in time series modeling across Canada and northern United States, Water Resour. Res., 51, doi:10.1002/2014WR015687.

ECHMWF, (2016), ERA-40, Daily, Retrieved 07/11, 2016, from: http://apps.ecmwf.int/datasets/data/era40-daily/levtype=sfc/

Institute for Veterinary Public Health, (2011), World Map of the Köppen-Geiger climate classification updated, Retrieved 07/11, 2016, from: http://koeppen-geiger.vuwien.ac.at/present.htm

JASAO, (2016), PDO index, Retrieved 07/11, 2016, from: http://jisao.washington.edu/pdo/PDO.latest.

Kouwen, N., (2014), WATFLOOD/WATROUTE Hydrological Model Routing and Flood Forecasting System. User's Manual, University of Waterloo, Waterloo, ON. www.watflood.ca.

Mathworks, (2016a), LinearModel class, Retrieved 07/11, 2016, from: http://www.mathworks.com/help/stats/linearmodel-class.html.

Mathworks, (2016b), NearestNeighbor, Retrieved 07/11, 2016, from: http://www.mathworks.com/help/matlab/ref/triangulation.nearestneighbor.html

Mesinger, F., et al. (2006), North American regional reanalysis, Bull. Am. Meteorol. Soc, 87, 343-360, doi: 10.1175/BAMS-87-3-343.

NOAA, (2016a), Teleconnections - Spatially and temporally large-scale anomalies that influence the variability of the atmospheric circulation, Retrieved 07/11, 2016, from: http://www.ncdc.noaa.gov/teleconnections/

NOAA, (2016b), NCEP North American Regional Reanalysis: NARR, Retrieved 07/11, 2016, from: http://www.esrl.noaa.gov/psd/data/gridded/data.narr.monolevel.html.

Radhakrishna, B., F. Fabry, J. J. Braun, and T. Van Hove, (2015), Precipitable water from GPS over the continental United States: diurnal cycle, intercomparisons with NARR, and link with convective initiation, J. Clim., 28, 2584, 2599, doi: 10.1175/JCLI-D-14-00366.1. 


\section{APPENDIX B}

Rapaić, M., R. Brown, M. Markovic and D. Chaumont, (2015), An evaluation of temperature and precipitation surface-based and reanalysis datasets for the Canadian Arctic, 1950-2010, Atmos. Ocean, 53(3), 283-303, doi: 10.1080/07055900.2015.1045825.

USGS, (1997), Global 30 Arc-Second Elevation (GTOPO30) - Computational and Information Systems Laboratory Research Data Archive, Retrieved 07/11, 2016, from: https://lta.cr.usgs.gov/GTOPO30.)

West, G. L., W. J. Steenburgh, and W. Y. Y. Cheng, (2007), Spurious grid-scale precipitation in the North American regional reanalysis, Mon. Weather Rev., 135(6), 2168-2184, doi: 10.1175/MWR3375.1. 
Appendix C:

ISOP MATLAB CODE 


\section{APPENDIX C}

for $n=1: x$ Count

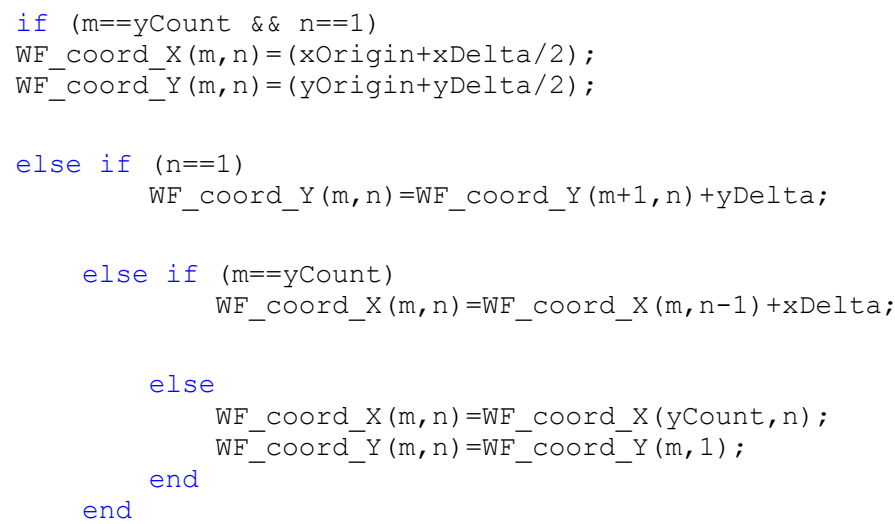




\section{APPENDIX C}

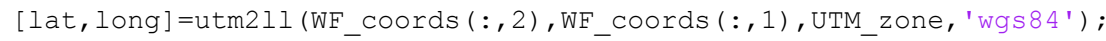

WF_coords=horzcat (lat, long) ;

end

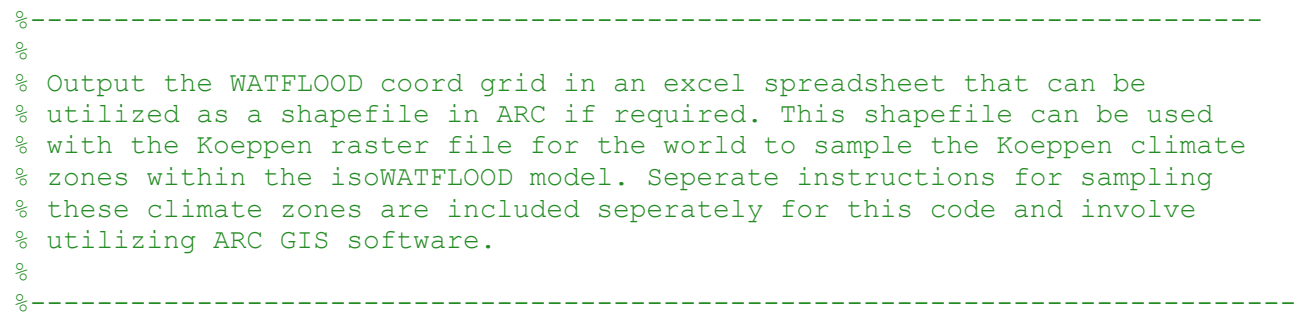

path2=strcat (path, '\isoP \', basin_name, '_coords.xls') ;

[status, message] = xlswrite (path2, WF coords, 'WF coords');

\% at this point, you must use the WF_coords excel file, convert it to a

\% shapefile, and then import that shapefile into ARC GIS software to obtain

\% the Koeppen cliamte classification for the WATFLOOD basin grids.

UPDATE=strcat(basin_name, '.SHD file was successfully read in!')

end 


\section{APPENDiX C}

\section{extract_NARR_timeseries.m}

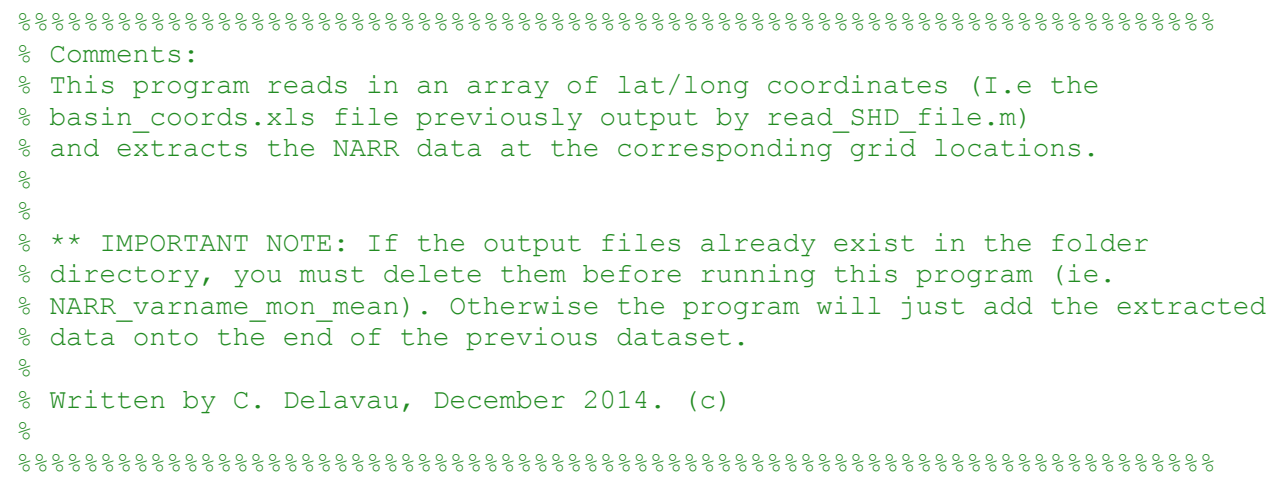

function [output, path NARR, path SPL]=extract NARR timeseries (path, basin name)

oxtract all NARR data at the WATFLOOD grid coords.

oThis is accomplished through reading in an excel file with the names of othe NARR monthly mean files. These files names utilize the naming oconvention of the NARR repository. Therefore, if the data files need to be oupdated to include additional years, they can be directly downloaded form othe NARR server and the names should still be relevant to this program. oThis requires reading in an xls file called "filename". This file must be ostored in the NARR directory. The PATH vairable below will need to be ochanged depending on where the isop file strcuture is stored.

ofrom the path name input by the user, backtrack to the main SPL directory oto access the isoP MAIN folder where the NARR netCDF files are stored.

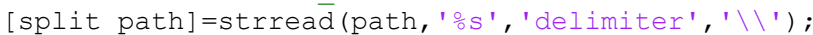
[col, rows]=size (split path);

for $i=1:(\operatorname{col}-1)$

if $i==1$

else path_SPL=split_path $\{1\}$; end

path_SPL=strcat (path_SPL, '\', split_path $\{i\})$;

end

\%Read in the .xls file called 'NARR var names' which is stored in the oisoP MAIN \Code folder. This file is a $\bar{l}$ ist of all the NARR climate ovariables to read in. If you don't want to read all of the NARR variables \%in, you can delete them form this list. Or, conversely, if you would like oto read more variables in, put the netCDF file for a monthly mean climate ovaribale in this folder, add it's name to the .xls file and augment this ocode to read it in.

path NARR=strcat (path SPL, '\isoP Code \NARR var names.xls');

[empty, filename] =xlsread (path NA $\bar{R} R)$;

[num cli par,width1]=size(filename);

\% Read in the WATFLOOD pairs of long/lats (Longitude is in the first column, \% latitude is in the second column). These were output from read SHD file.m \% to the SPL \basin\isoP folder earlier.

path2=strcat (path, '\isoP\', basin name, ' coords.xls');

[WF_coords, empty] =xlsread (path2, 'WF_coords' ) ;

o Find the number of WATFLOOD points that NARR data needs to be

oxtracted at.

[num pts, width2] =size (WF coords);

\% This next portion of code uses latitude and longitude pairs (from in the form [lat, long]) 
APPENDix C

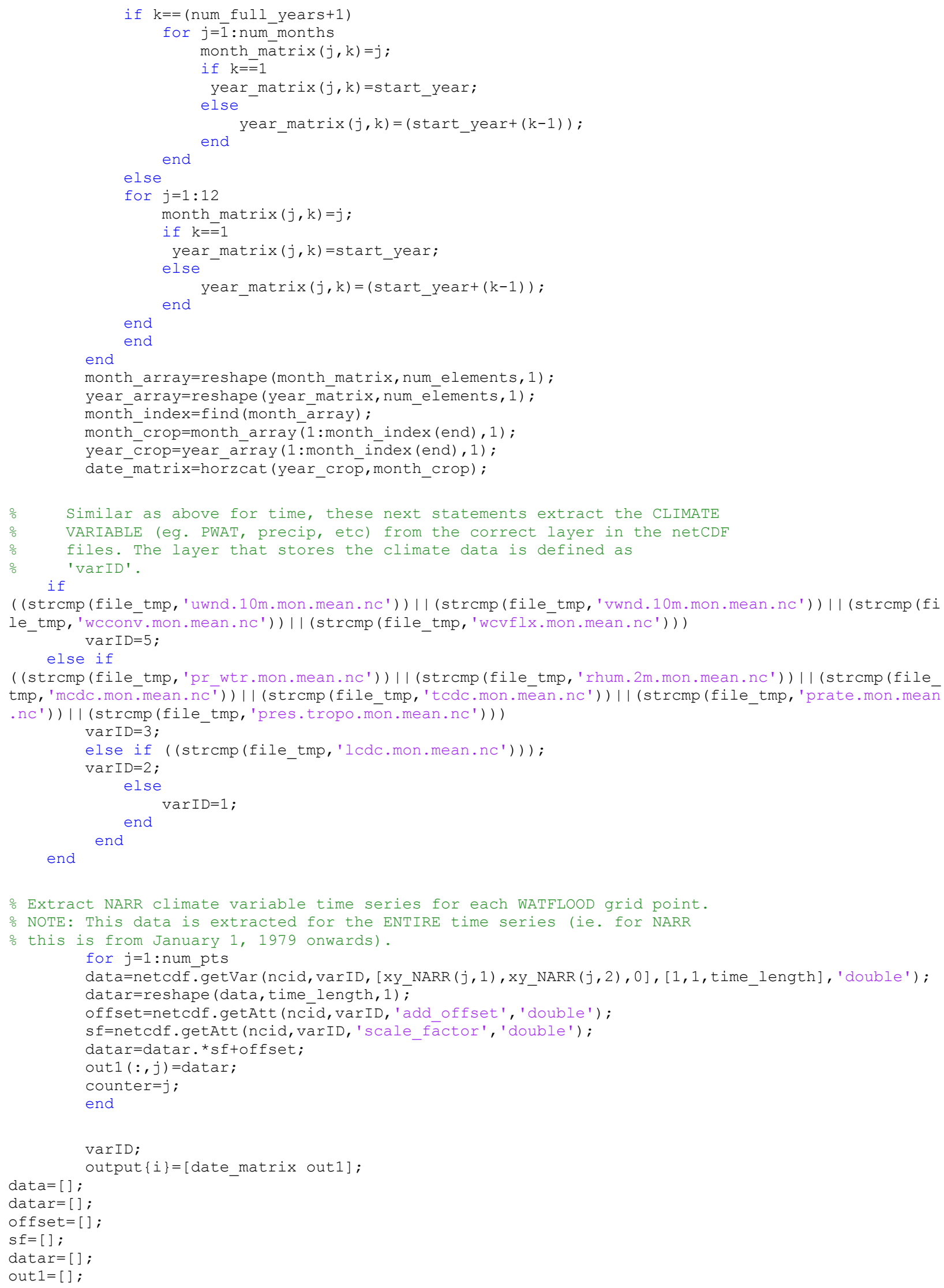


APPENDIX C

end

UPDATE='NARR climate variables successfully read in for specified WATFLOOD grids!'

end 
APPENDix C

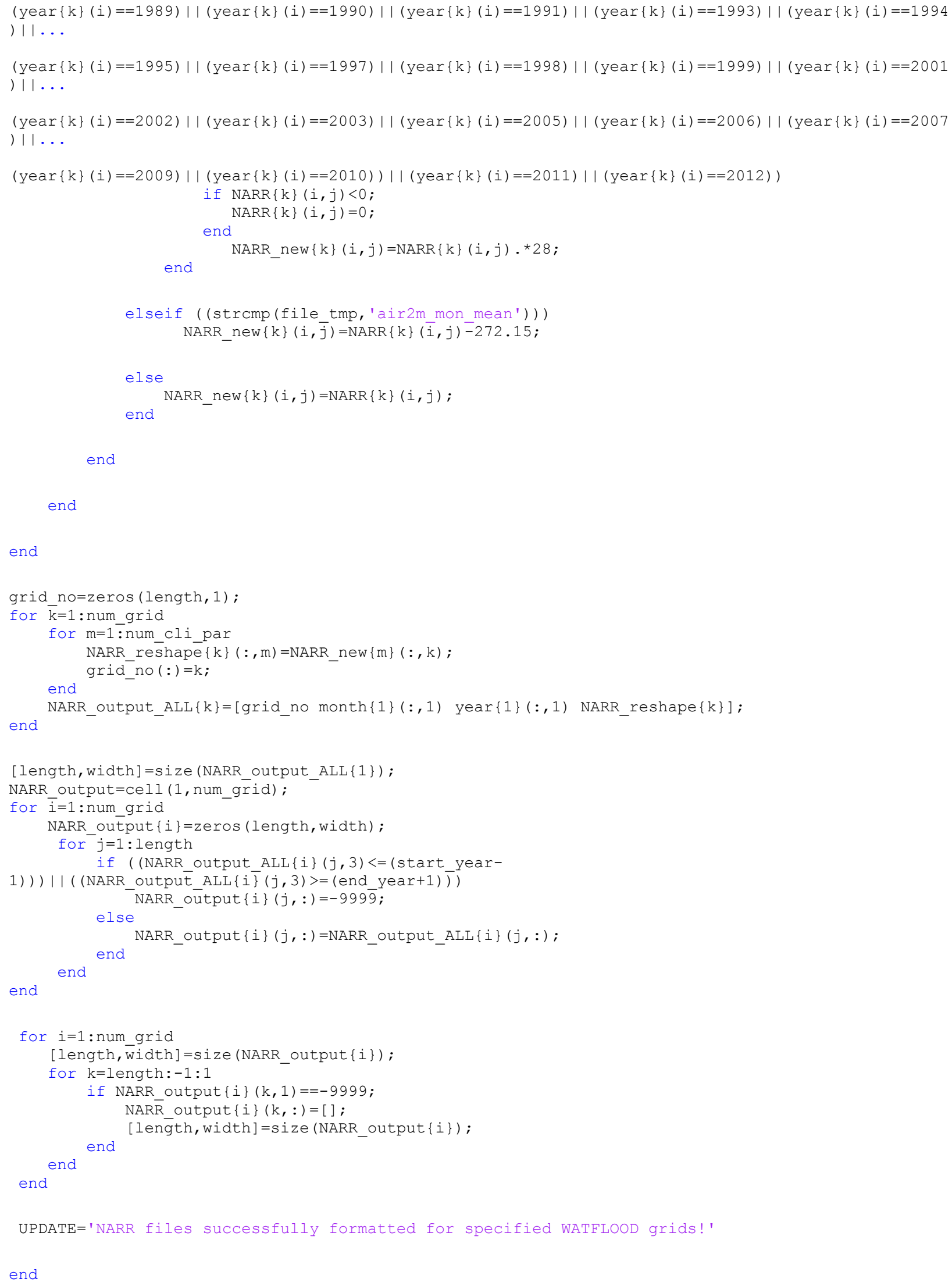


APPENDix C

for $\mathrm{k}=1$ : num grids

data_GEO\{k\} (1: length, 1) =LAT $(\mathrm{k}, 1)$;

data $\operatorname{GEO}\{\mathrm{k}\}(1:$ length, 2$)=\operatorname{LONG}(\mathrm{k}, 1)$;

data_GEO $\{\mathrm{k}\}(1:$ length, 3) =DEM_basin $(\mathrm{k}, 3)$;

end

data_GEO $\{\mathrm{k}\}(1:$ length, 4$)=\operatorname{Kpn}{ }_{-} b a \sin (\mathrm{k}, 3)$;

UPDATE='GIS information successfully read in for specified WATFLOOD grids!'

end 
APPENDiX C

end ${ }^{\text {end }}$

UPDATE='Teleconncetion indices successfully read in for the specified WATFLOOD gird'

end 


\section{APPENDiX C}

\section{all_data-format_condense.m}

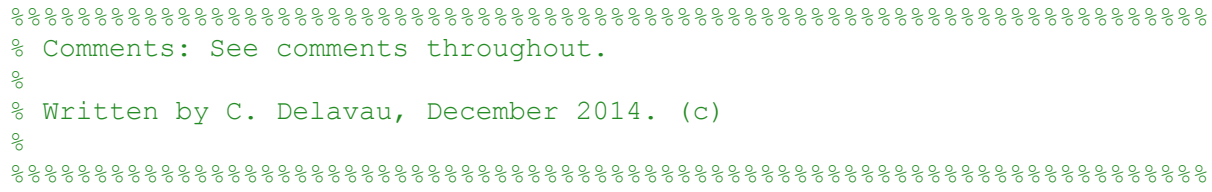


APPENDix C

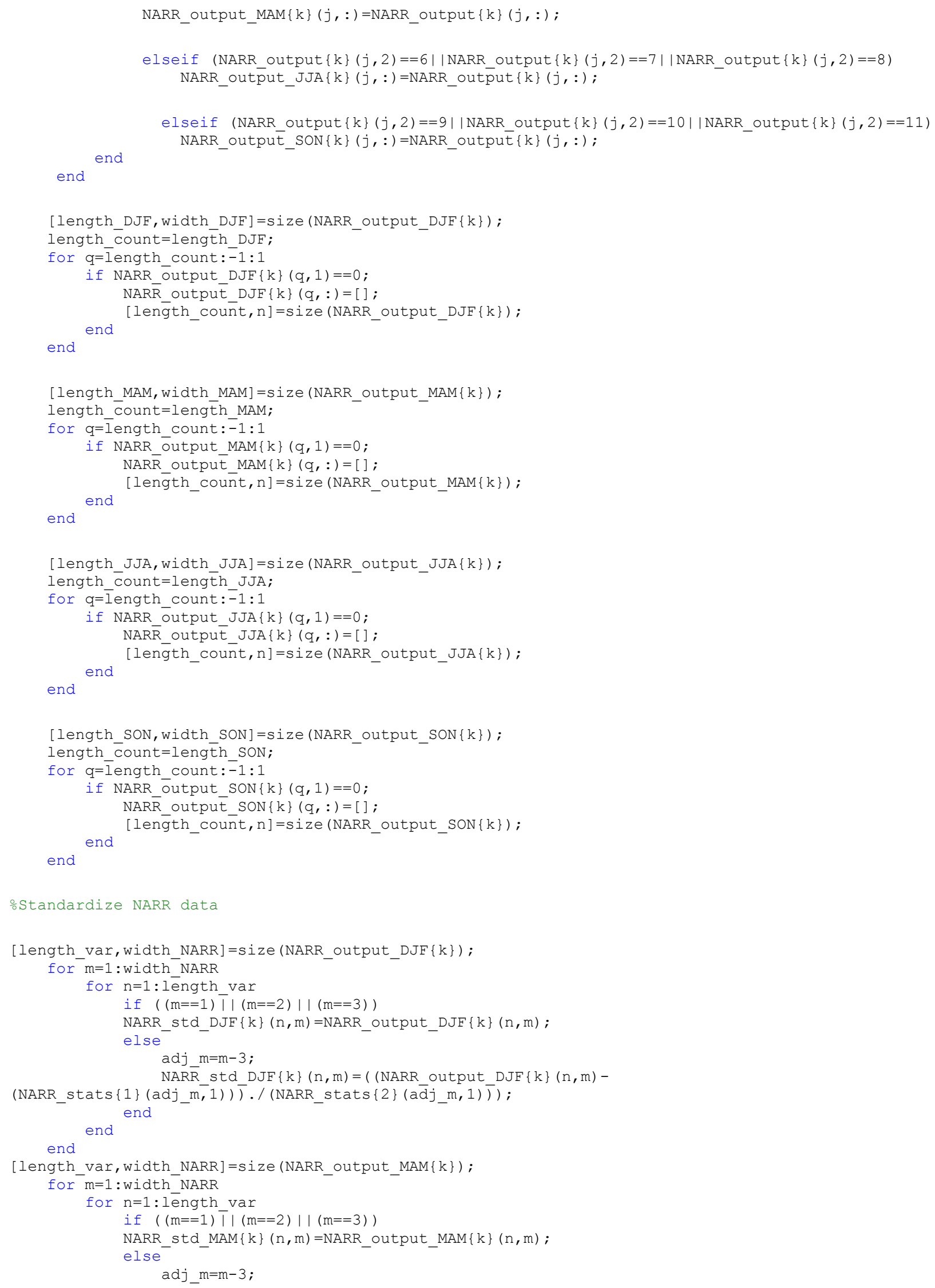


APPENDix C

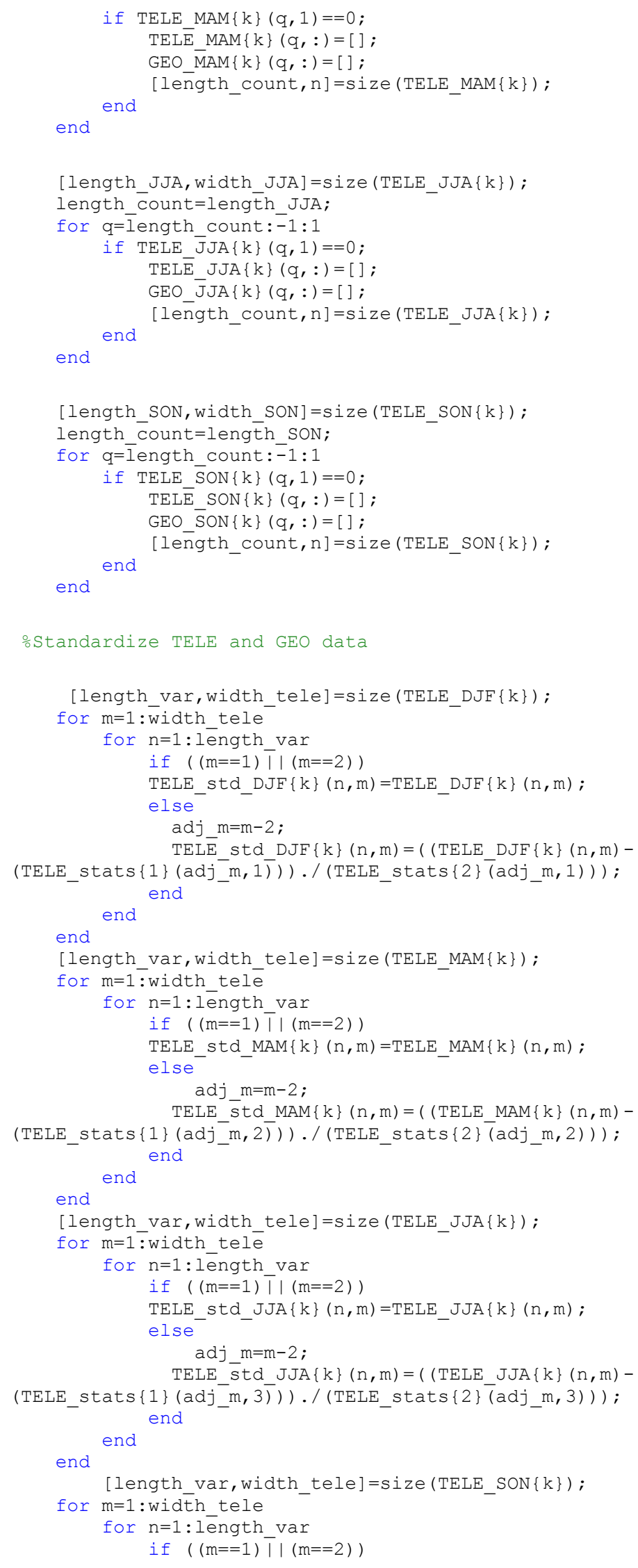


APPENDix C

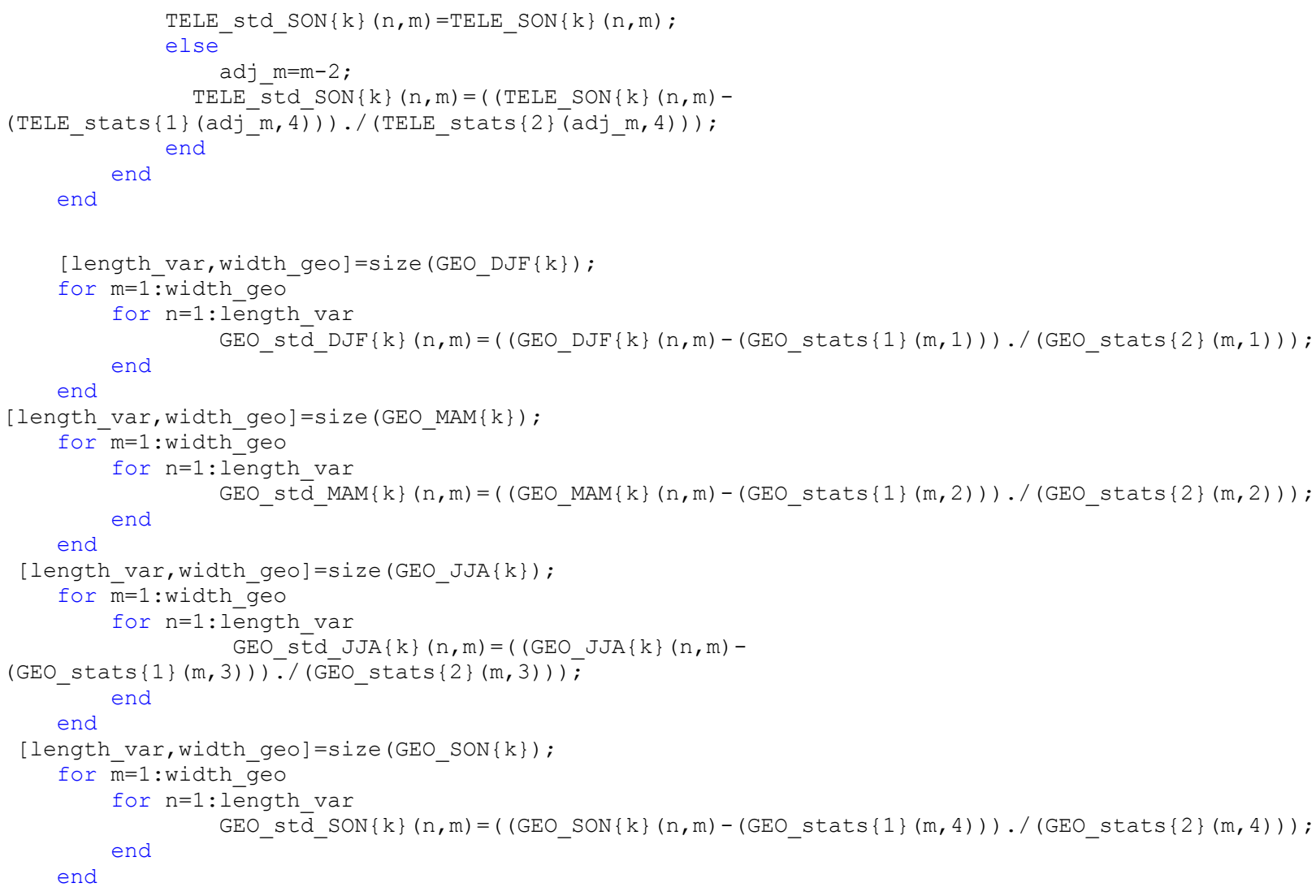


APPENDix C

oSort Data and put into corresponding KPN Zone ㅁJE

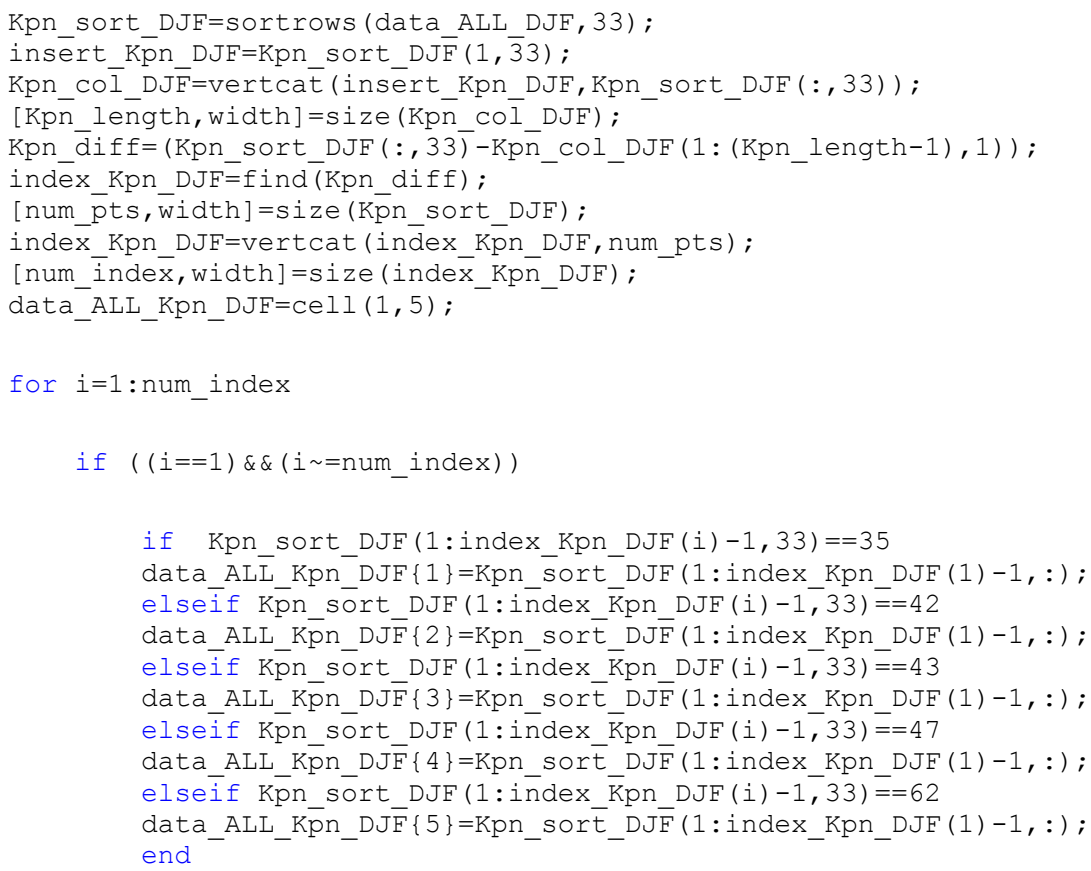

if Kpn sort DJF(index Kpn DJF (i-1) : index Kpn DJF(i) $-1,33$ ) ==35

data_ALI_Kpn_DJF $\{1\}=\operatorname{Kp} \bar{L} \_$Sort_DJF (index_Kpn_DJF $(i-1):$ index_Kpn_DJF (i) -1, : ) ;

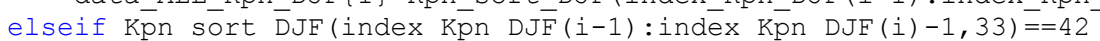

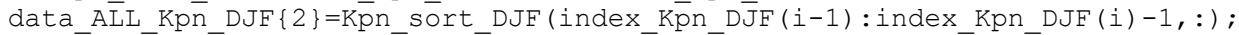

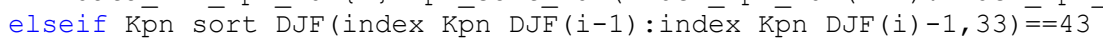

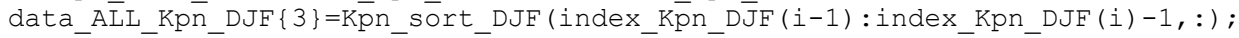

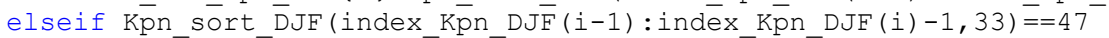
data_ALL_Kpn_DJF $\{4\}=$ Kp n _sort_DJF (index_Kpn_DJF (i-1) : index_Kpn_DJF (i) -1, : ) ;

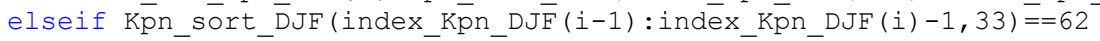

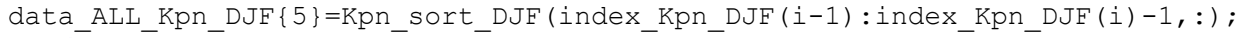
end

elseif $((i>=2) \& \&(i==$ num_index $))$

if Kpn sort DJF(index Kpn DJF (i-1) : index Kpn DJF(i), 33)==35

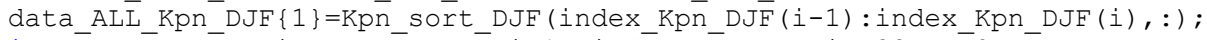

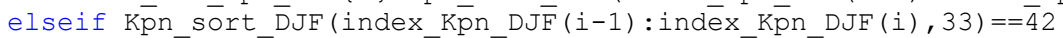

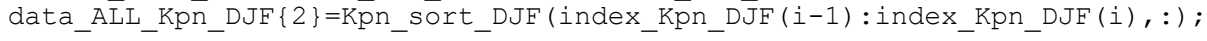


APPENDix C

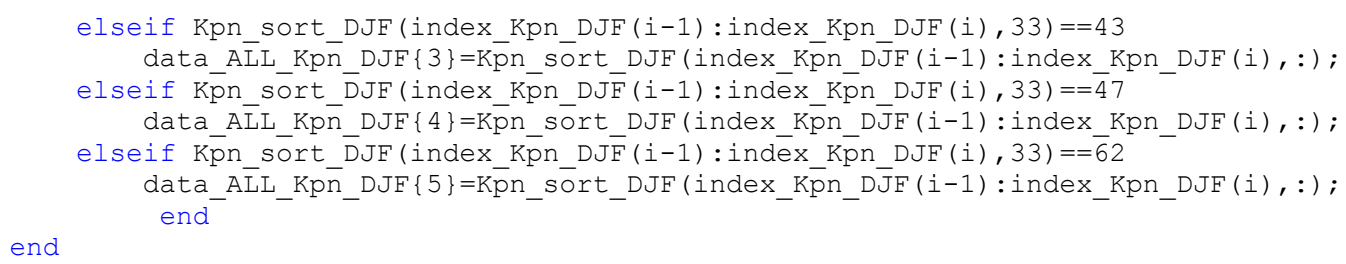




\section{APPENDIX C}

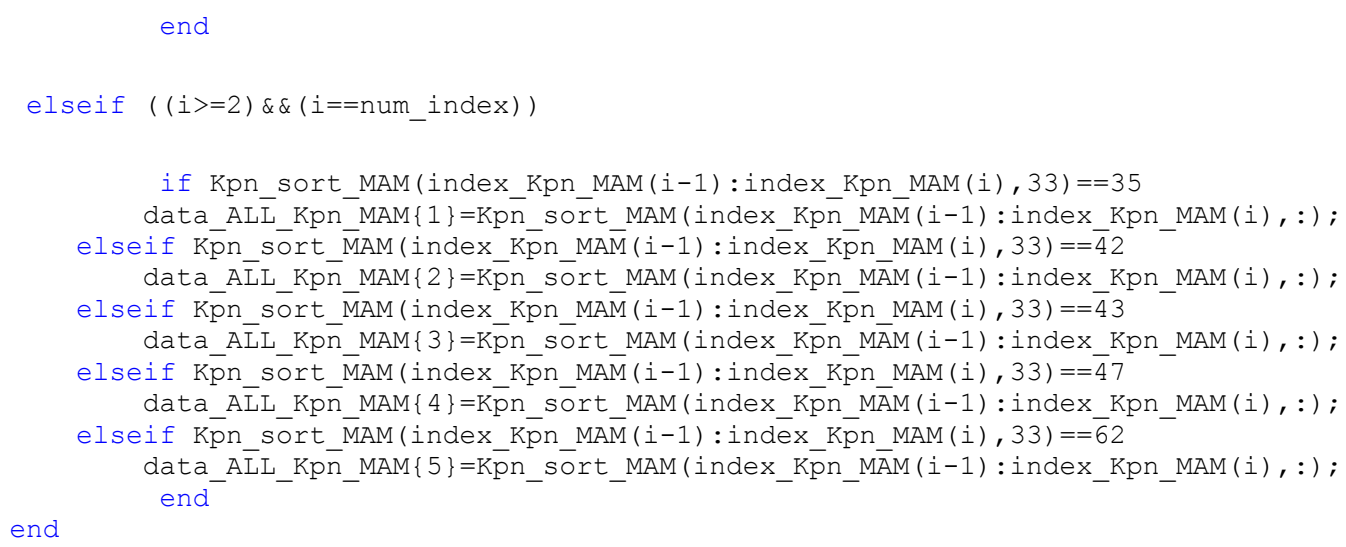


APPENDix C

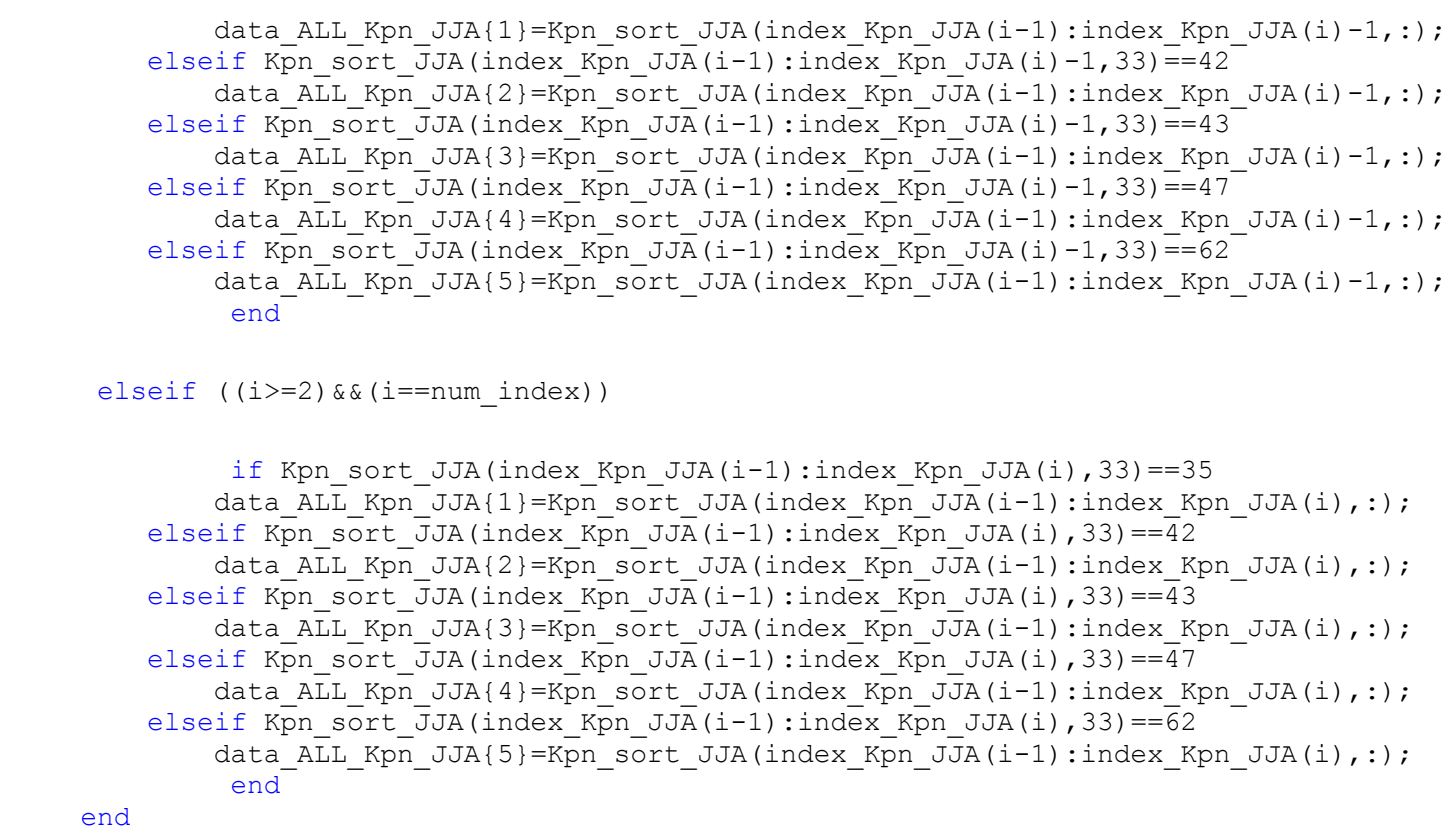

end

Kpn sort SON=sortrows (data ALL SON, 33) ;

insert_Kpn_SON=Kpn_sort_SON $(1, \overline{3} 3)$;

Kpn_co $\overline{1} \_S O \bar{N}=$ vertcat (insēert_Kpn_SON, Kpn_sort_SON $(:, 33)$ ) ;

[Kpn_length, width] =size (Kpn_CoI_SON) ;

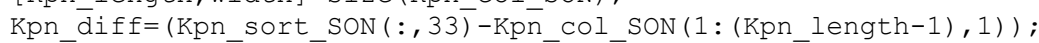

index_Kpn_SON=find (Kpn_diff);

[num_pts, width]=size (Kp̄n_sort_son) ;

index_Kpn_SON=vertcat (index_Kpn_SON, num_pts) ;

[num_index, width] =size (index_Kpn_soN) ;

data_ALL_Kpn_SON=Cell $(1,5)$;

for $i=1$ :num_index

if $((i==1) \& \&(i \sim=$ num_index $))$

if Kpn_sort_SON (1: index_Kpn_SON (i) $-1,33)==35$

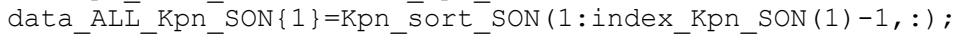

elseif Kpn_sort_SON (1:iñdex_Kpn_SON $(i)-1,33)==42$

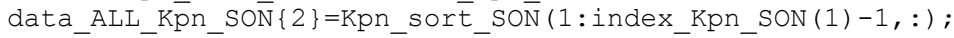

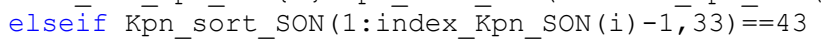

data_ALL_Kpn_SON $\{3\}=K p n \_s o r t \_S O N(1:$ index_Kpn_SON $(1)-1,:)$;

elseíf Kp̄n_sort_SON (1:iñdex_K̄pn_SON (i) $-1,33)==47$

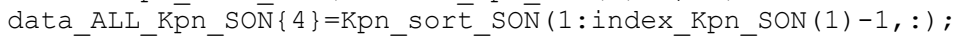

elseiff Kpn_sort_SON (1:iñdex_K̄pn_SON (i) $-1,33)==62$

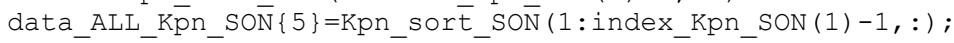
end

elseif $((i==1) \& \&(i==$ num_index $))$

if Kpn_sort_SON (1:index_Kpn_SON (i), 33) ==35

data ALI Kpn SON $\{1\}=\operatorname{Kpn} \operatorname{Sort}_{\text {SON }}(1$ : index Kpn SON (1) , : ) ;

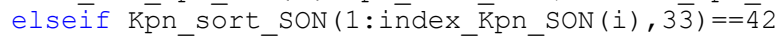

data_ALL_Kpn_SOÑ $\{2\}=K p n \_s o r t \bar{t}$ SON $(1$ : index_Kpn_SON (1) , : );

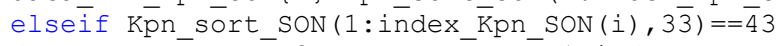

data ALL Kp̄n SON $\{3\}=K p n$ sort $\operatorname{SON}(1$ : index $\operatorname{Kpn} \operatorname{SON}(1),:$ ) ;

elseif Kpn_sort_SON (1:index_Kpn_SON $(i), 3 \overline{3})==\overline{4} 7$ 
APPENDix C

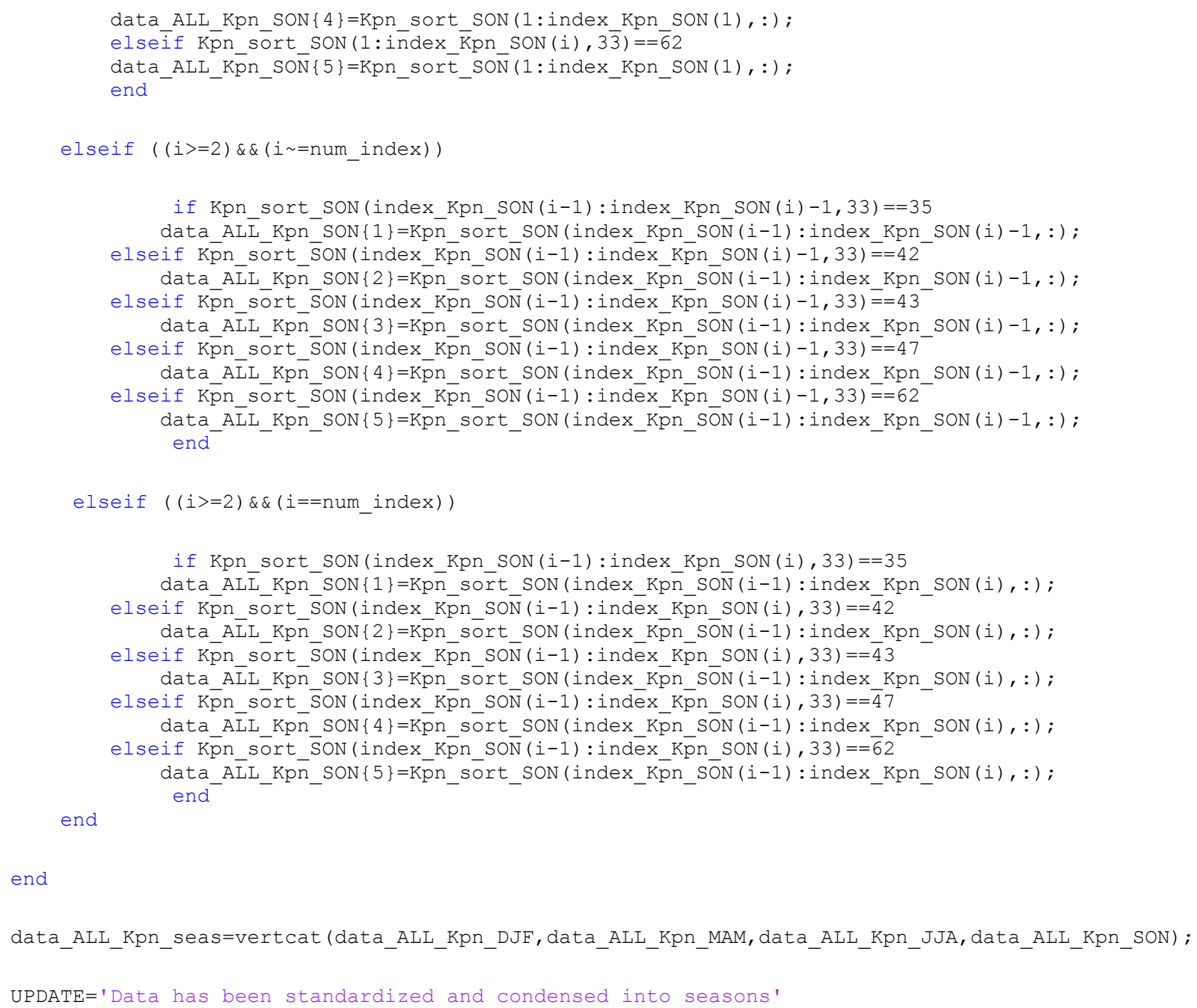

end 


\section{APPENDix C}

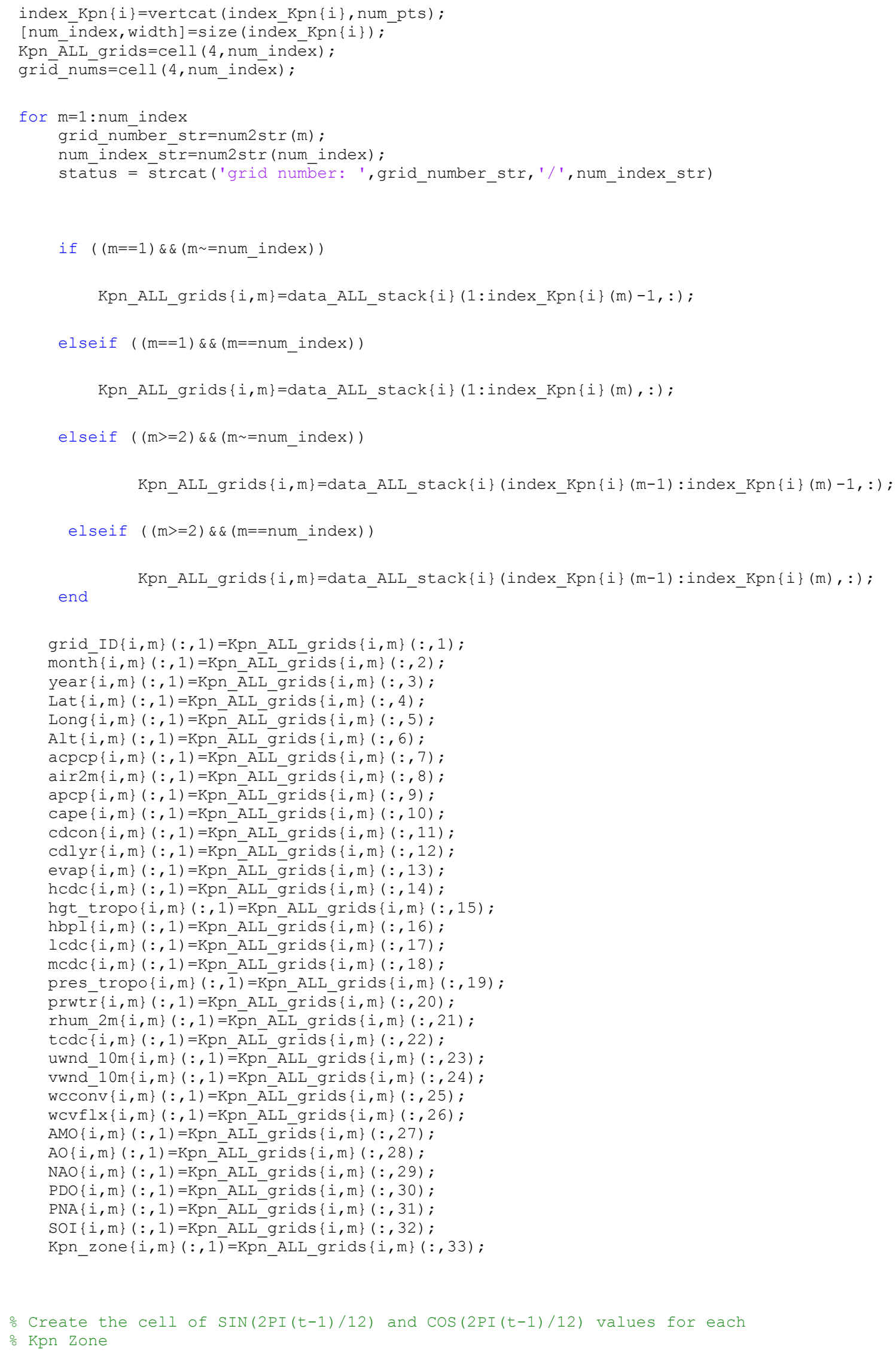


APPENDix C

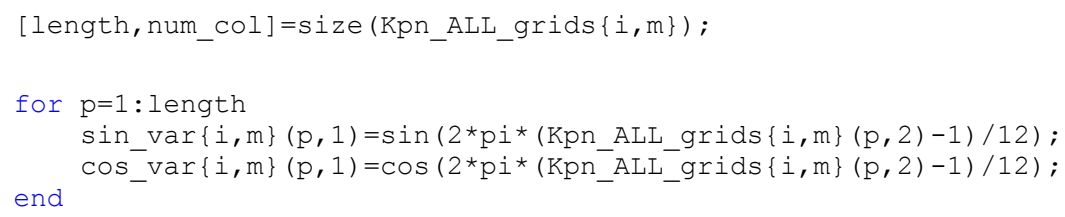


APPENDix C

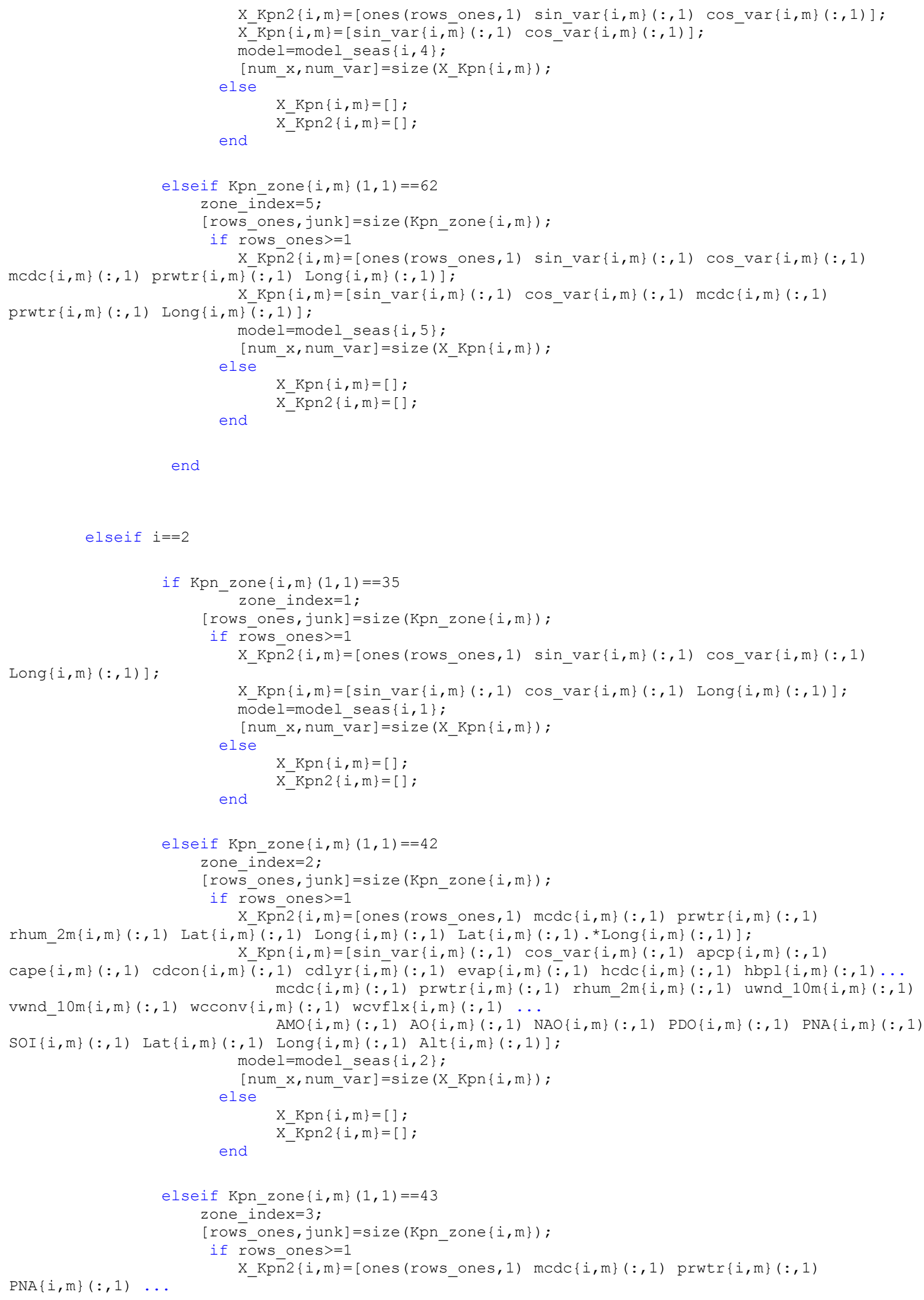


APPENDix C

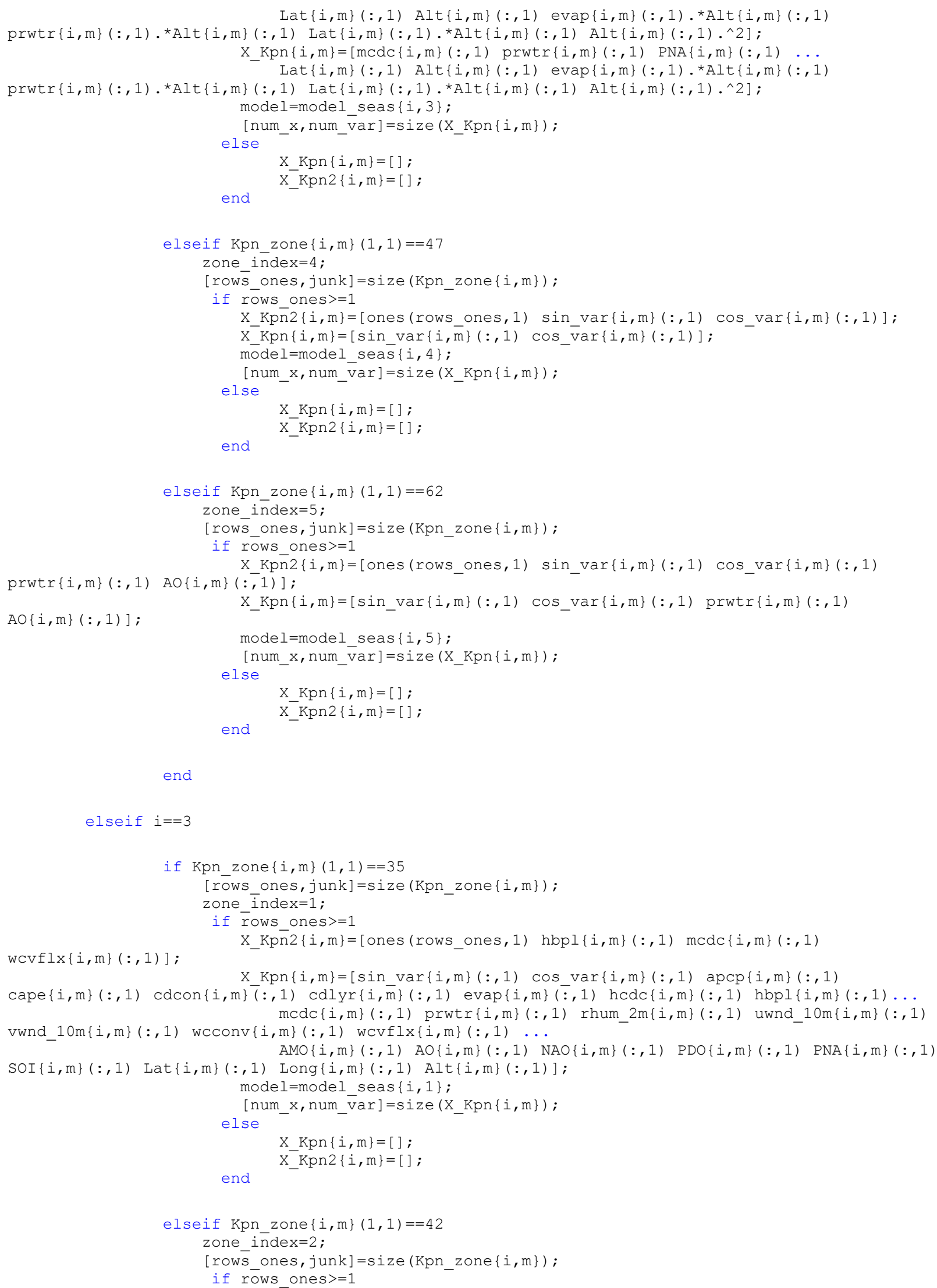


APPENDix C

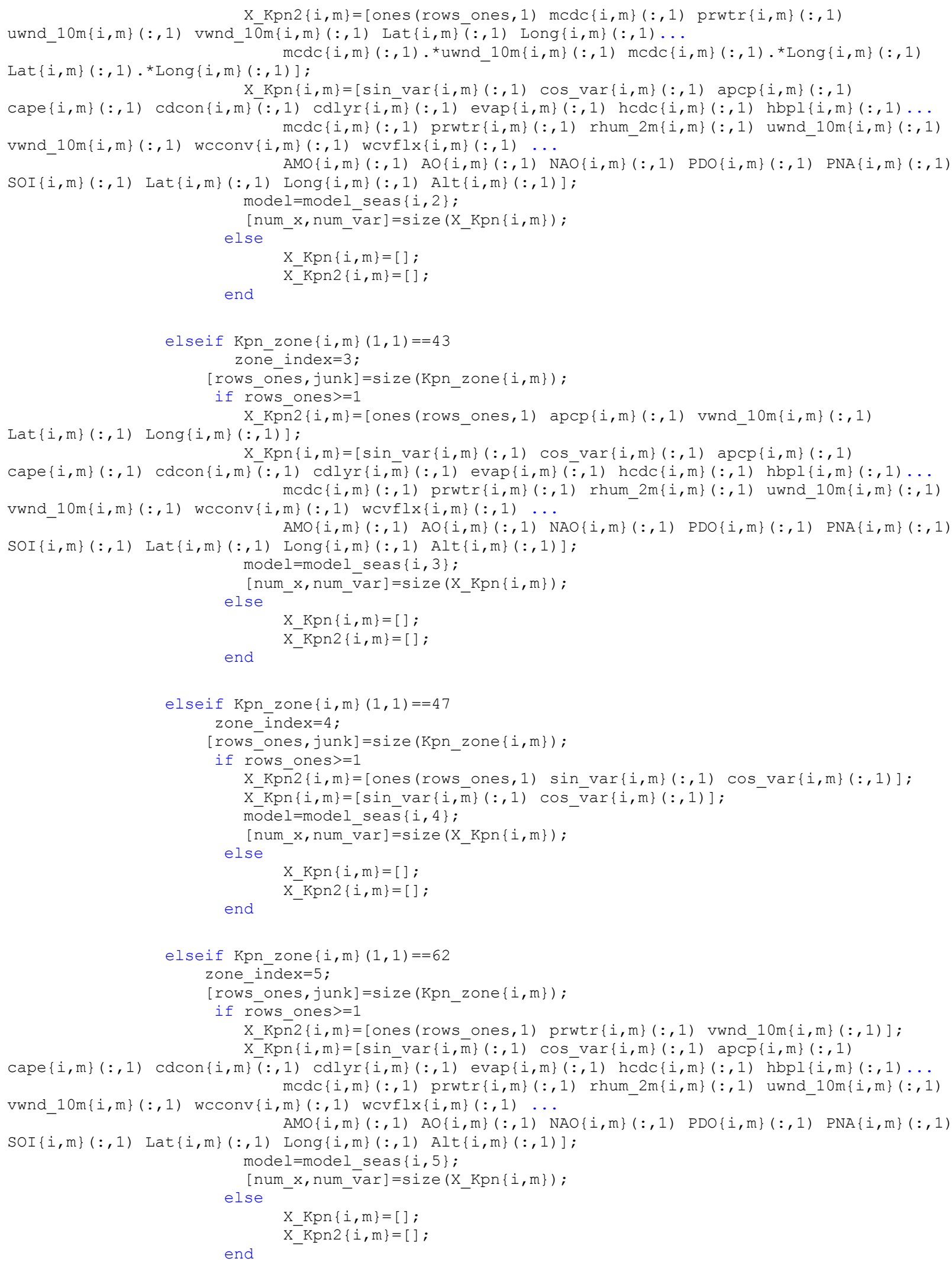


APPENDix C

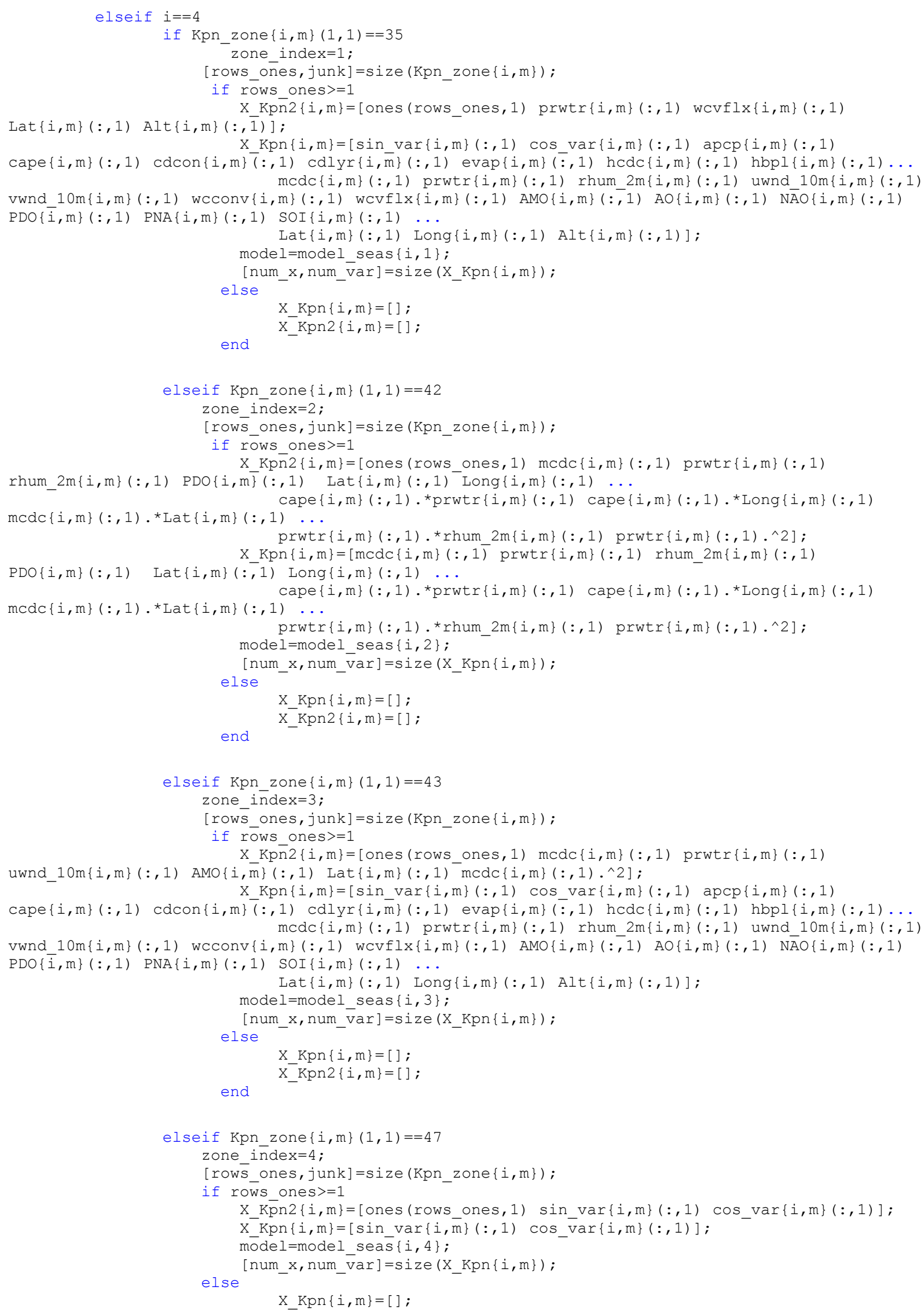


APPENDix C

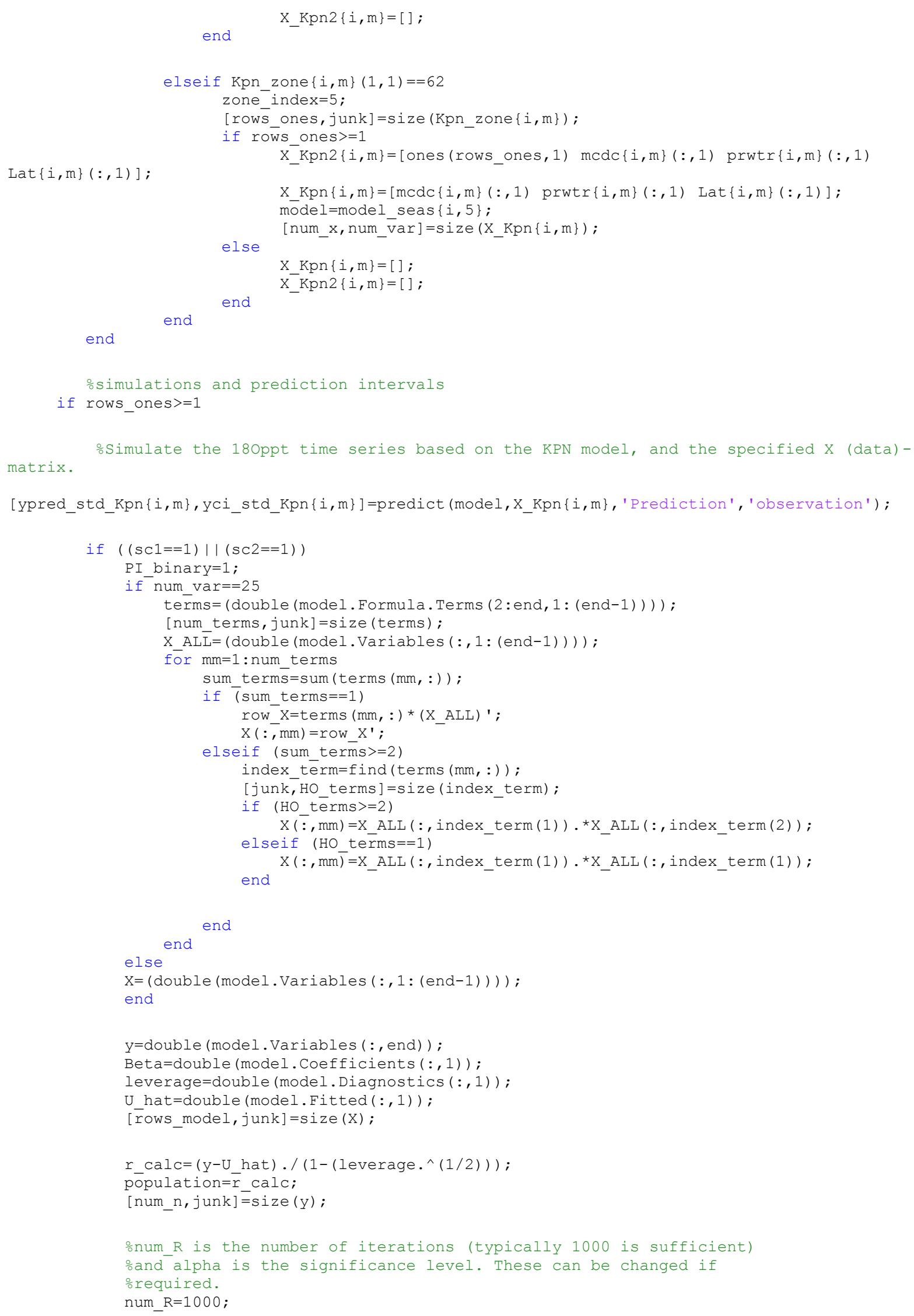


APPENDix C

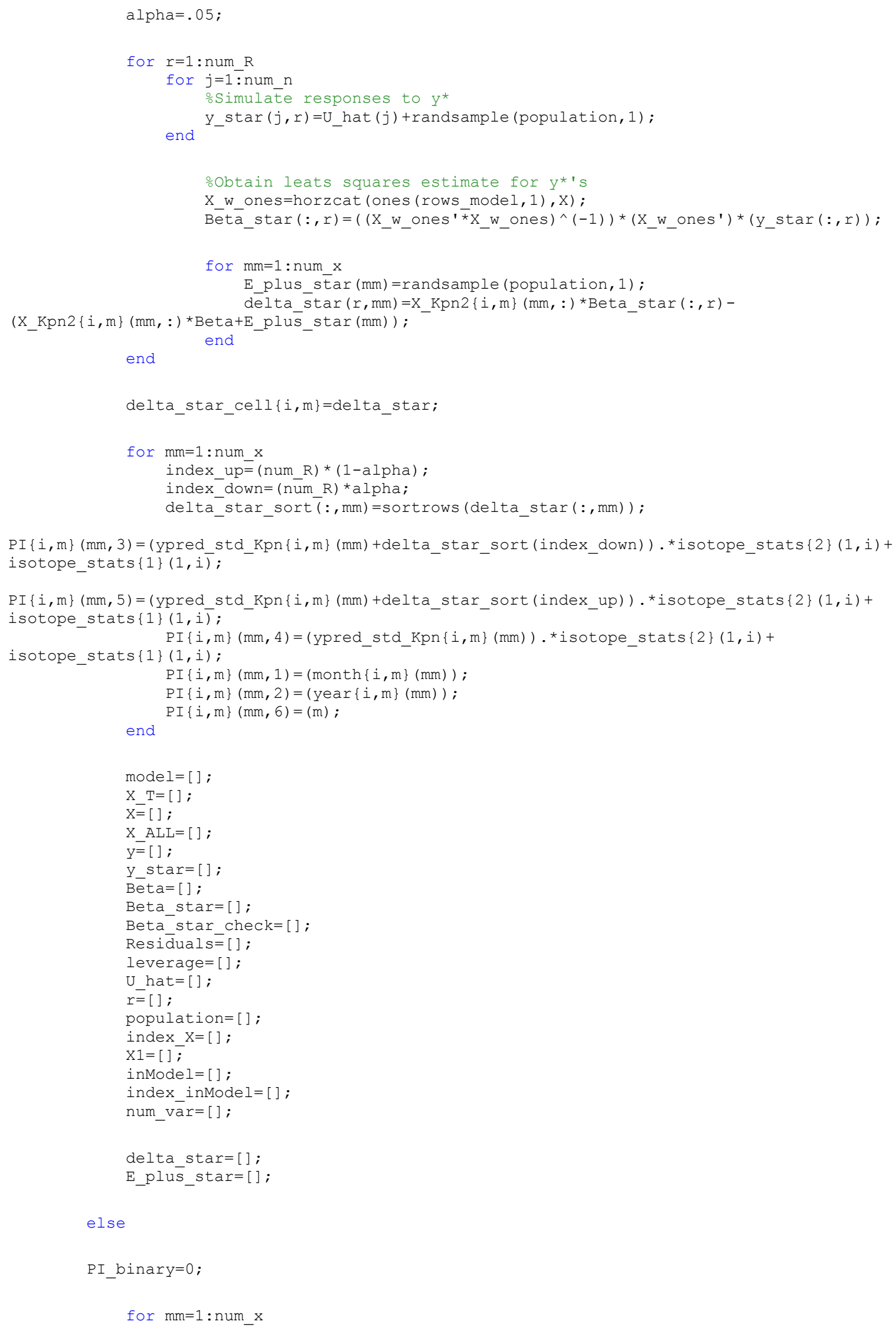


APPENDix C

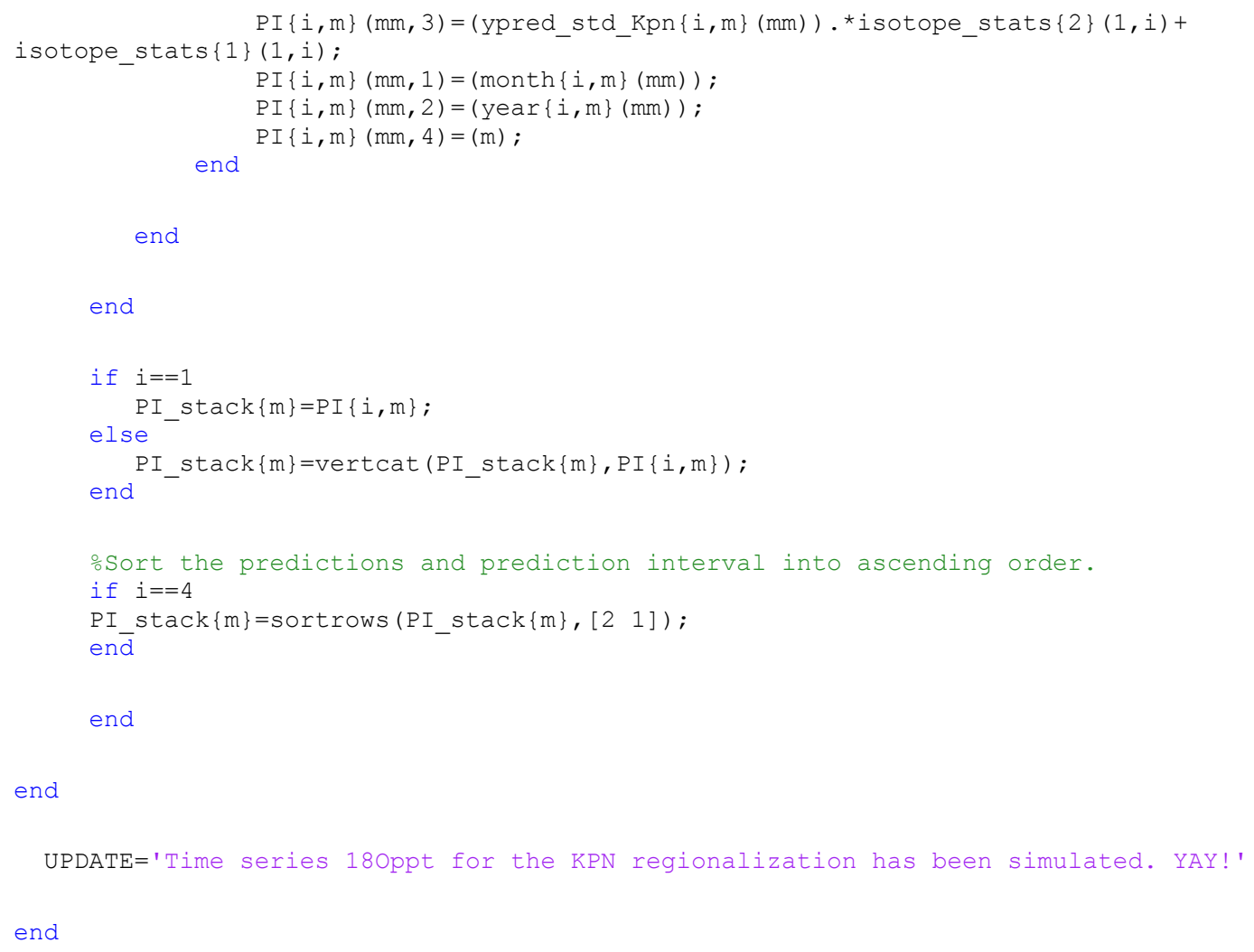


APPENDix C

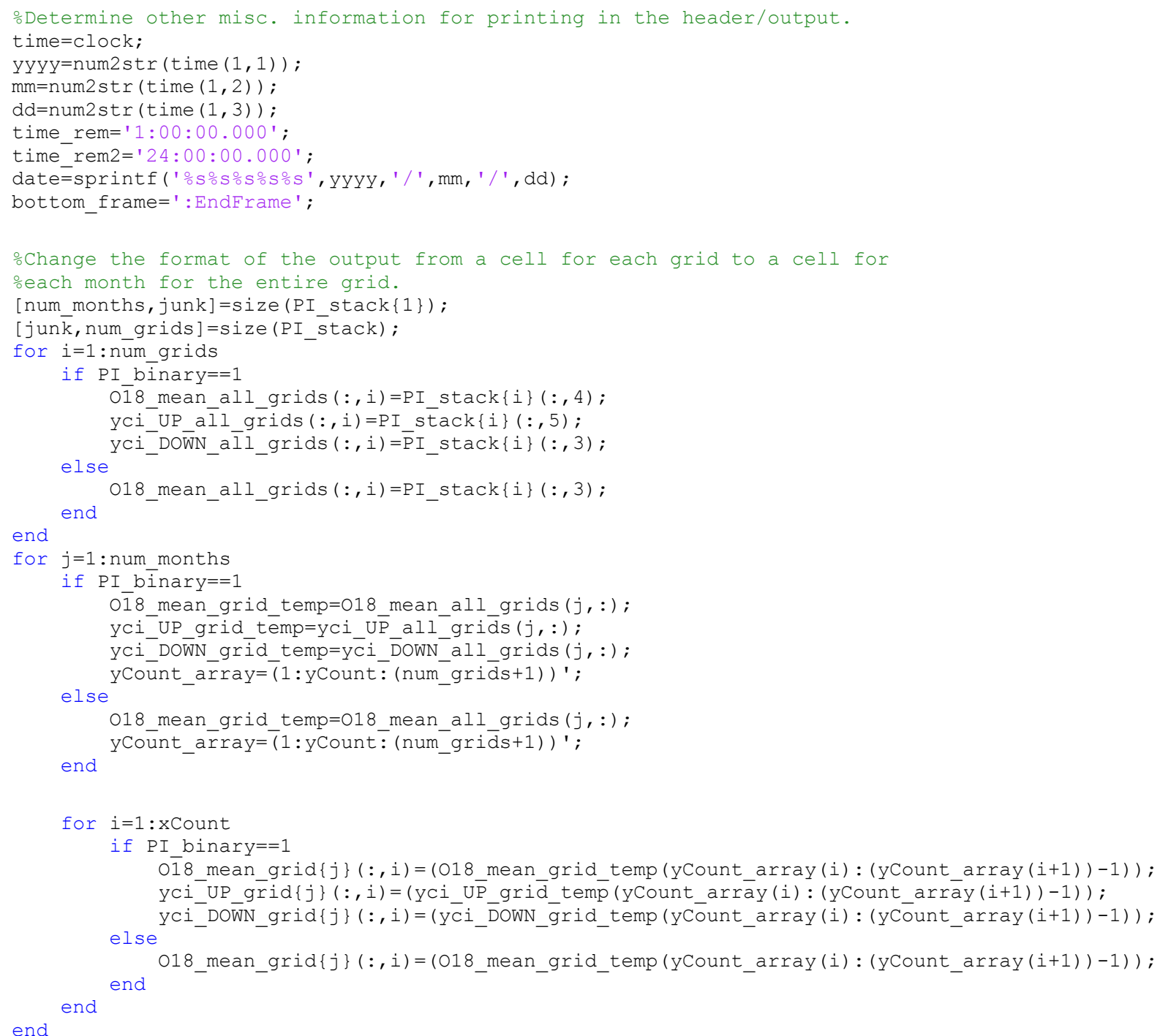

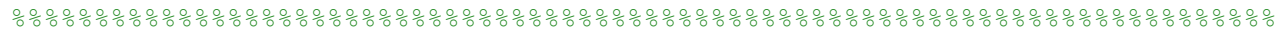

\%---------------- 180ppt Kpn mean-------------------------------------------

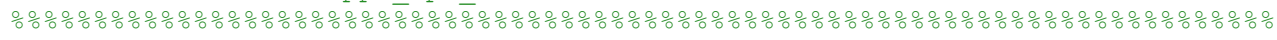

for $j=1$ :num_months

\%Construct the defined lines of text required for the .r2c file header.

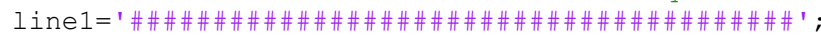

line2=':FileType r2C ASCII EnSim 1.0'.

line3='\#' ;

line4='\# DataType 2D Rect Cell';

line5='\#' ;

line6=' : Application EnSimHydrologic';

line $7=$ ': Version 1.0';

line $8={ }^{\prime}:$ WrittenBy CJD' :

line $9=$ ' : CreationDate';

line10='\#' ;

line11='\#--

line12='\#';

line13=': Name 180ppt KPN mean';

line14='\#';

line15=' : Projection' ;

line16=' : Ellipsoid';

line17='\#';

line18=' :xOrigin'; 
APPENDix C

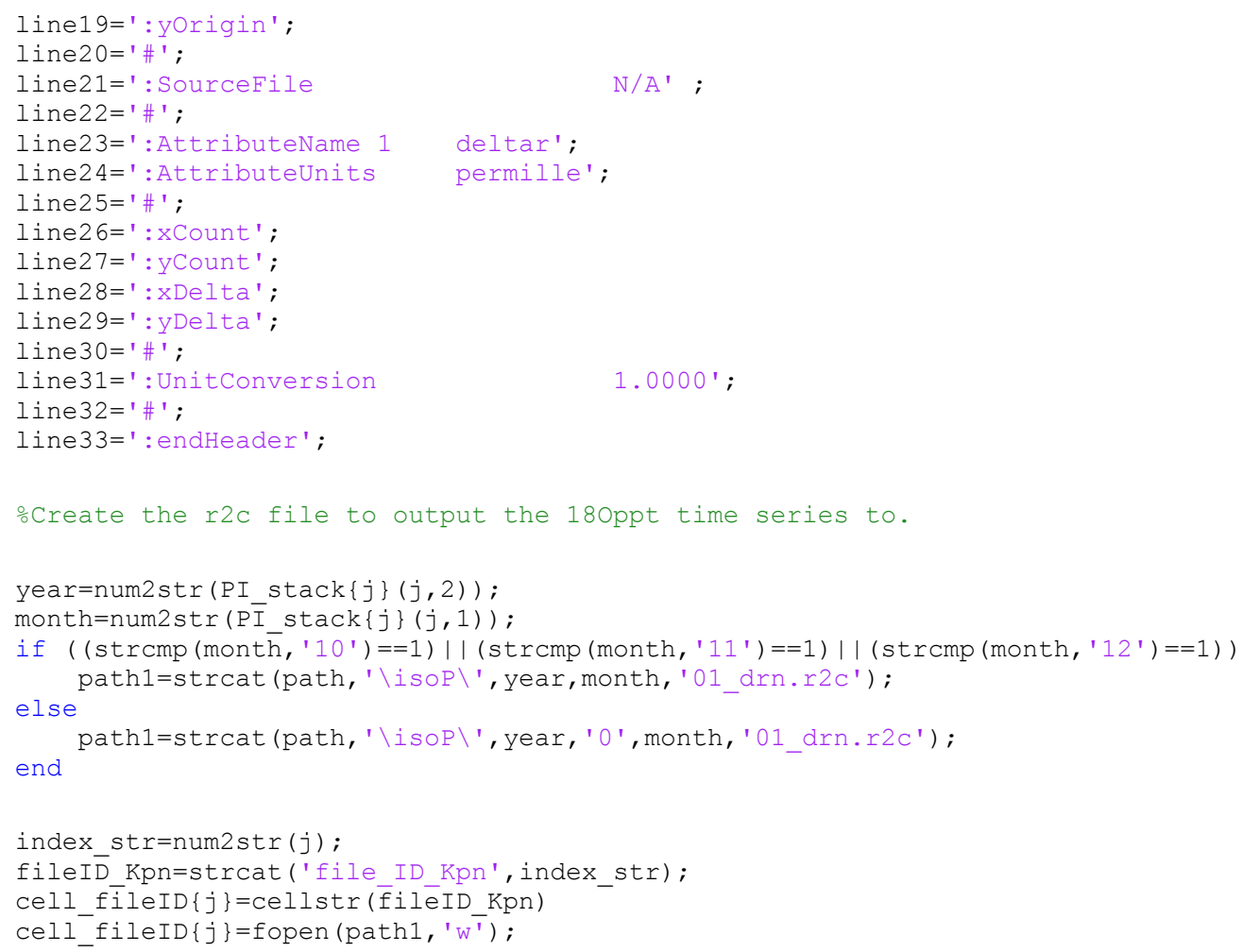


APPENDiX C

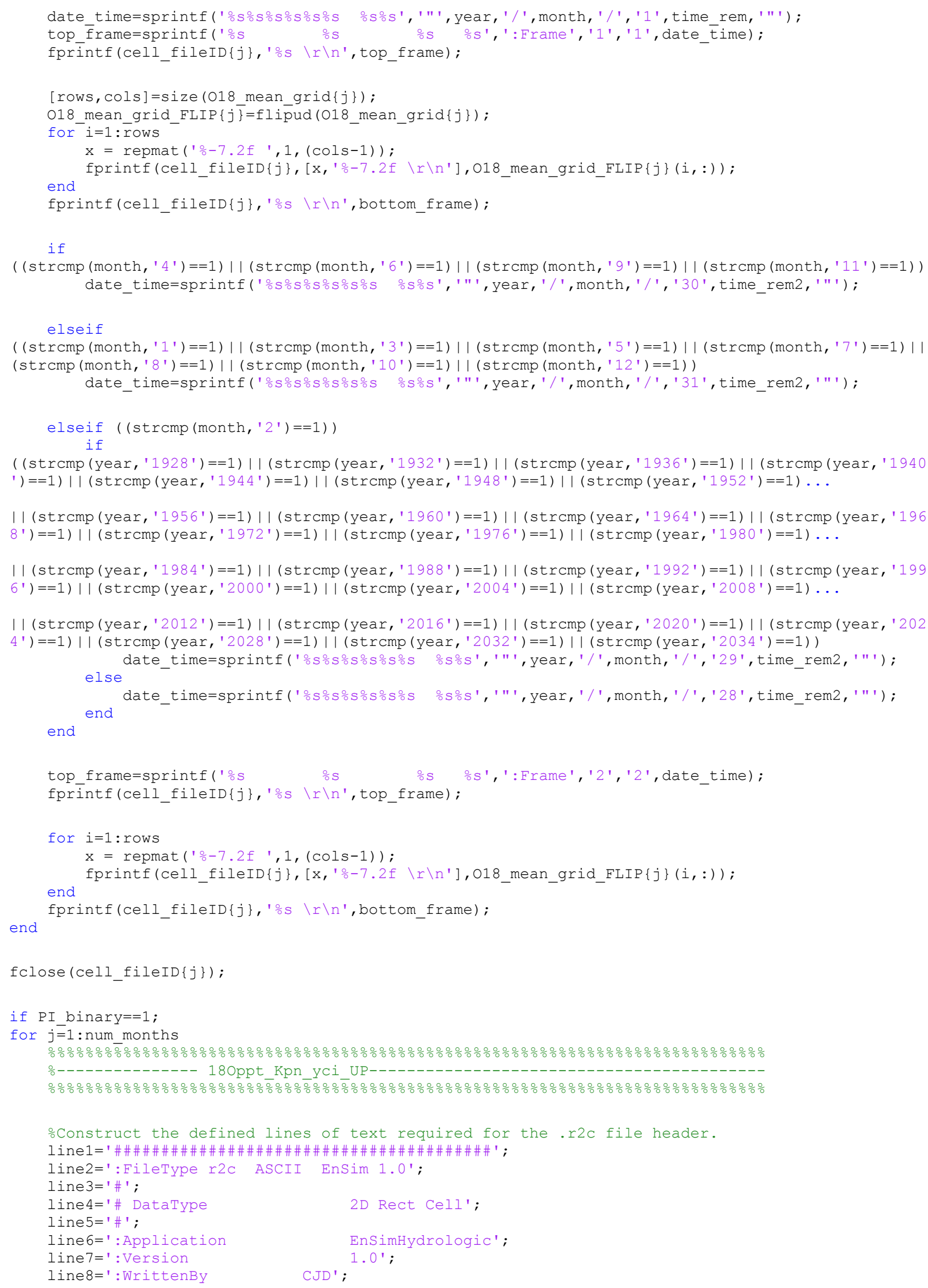


APPENDix C

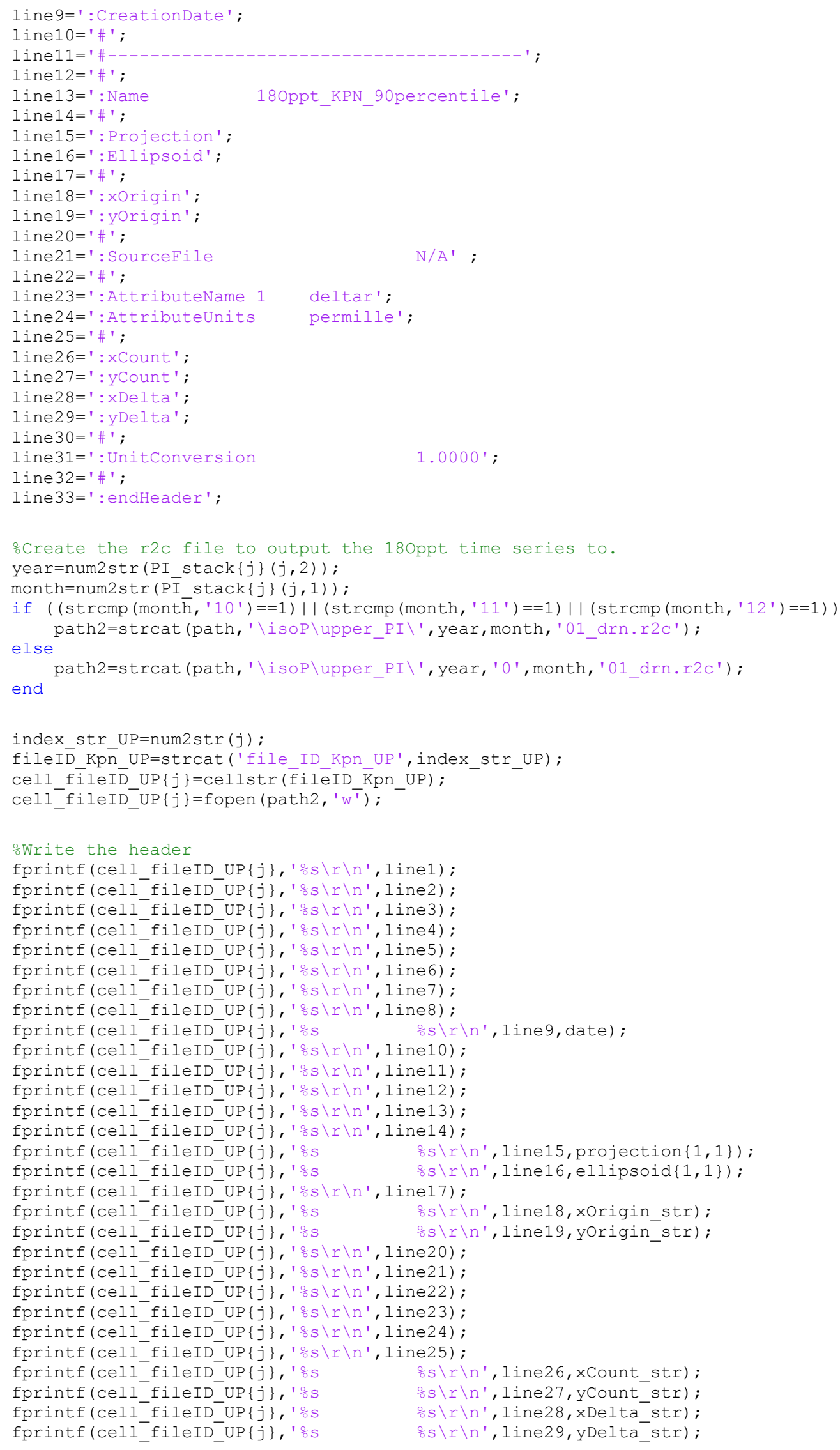


APPENDix C

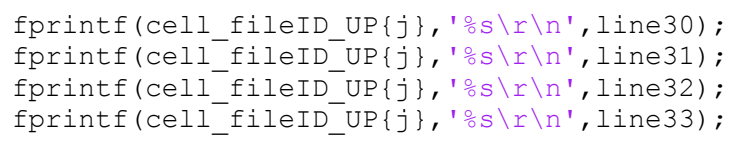

\%Write the gridded 180ppt in monthly blocks.

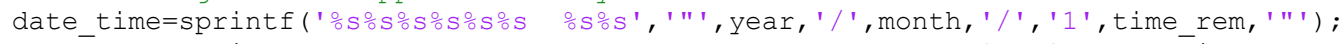

top frame=sprintf('os os os \%s', ':Frame','1',' '1', date_time);

fprintf(cell_fileID_UP $\{j\}, ' \div S \backslash r \backslash n^{\prime}$, top_frame);

[rows, cols] =size (yci UP grid $\{j\})$;

yci_UP_grid_FLIP $\{j\}=\bar{f} l i \overline{p u d}\left(y c i \_U P \_g r i d\{j\}\right)$;

for $i=\overline{1}$ :rows

$\mathrm{x}=\operatorname{repmat}\left({ }^{\circ} \mathrm{o}-7.2 \mathrm{f}, \mathrm{1},(\mathrm{col} \mathrm{s}-1)\right)$;

end

fprintf(cell_fileID_UP $\left.\{j\},\left[x, ' \frac{\circ}{0}-7.2 f \backslash r \backslash n '\right], y c i \_U P \_g r i d \_F L I P\{j\}(i,:)\right)$;

fprintf(cell_fileID_UP $\{j\}, ' \frac{\circ}{\circ} \backslash r \backslash n^{\prime}$, bottom_frame) ;

if

$\left(\left(\operatorname{strcmp}\left(\operatorname{month}, \mathbf{\prime}^{\prime} \mathbf{\prime}^{\prime}\right)==1\right)||\left(\operatorname{strcmp}\left(\operatorname{month}, \mathbf{6}^{\prime}\right)==1\right)||\left(\operatorname{strcmp}\left(\operatorname{month}, \mathbf{\prime}^{\prime} \mathbf{\prime}^{\prime}\right)==1\right)||\left(\operatorname{strcmp}\left(\operatorname{month}, \mathbf{\prime}^{\prime} 11^{\prime}\right)==1\right)\right)$

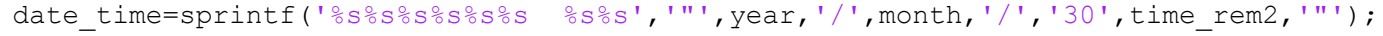

elseif

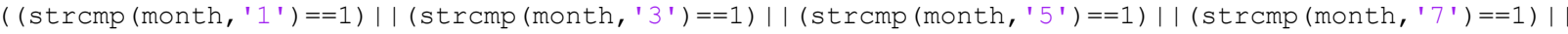

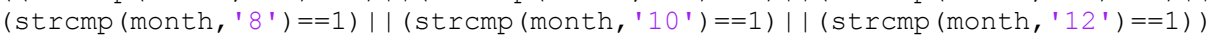

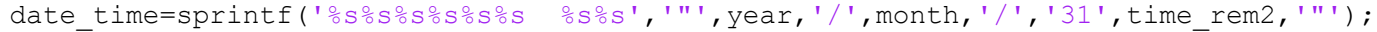

elseif ( (strcmp (month, '2')==1))

if

( ( $\operatorname{strcmp}($ year, '1928')==1)|| (strcmp (year, '1932')==1)|| (strcmp (year, '1936')==1) || (strcmp (year, '1940 ') ==1)||( $\operatorname{strcmp}($ year, '1944' $)==1)||(\operatorname{strcmp}($ year, '1948')==1)||( $\operatorname{strcmp}($ year, '1952' $)==1) \ldots$

|| (strcmp (year, '1956')==1)|| (strcmp (year, '1960')==1) || (strcmp (year,'1964')==1)|| (strcmp (year, '196 $\left.\left.8^{\prime}\right)==1\right)||(\operatorname{strcmp}($ year, '1972')==1)|| (strcmp (year, '1976')==1)||( $\operatorname{strcmp}($ year, '1980' $)==1) \ldots$

|| (strcmp (year, '1984')==1)|| (strcmp (year, '1988')==1)|| (strcmp (year, '1992')==1)|| (strcmp (year, '199

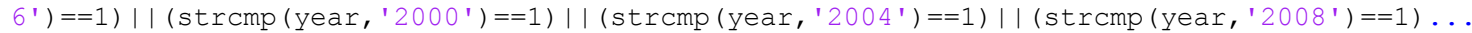

|| (strcmp (year, '2012')==1)|| (strcmp (year, '2016')==1)|| (strcmp (year, '2020')==1)|| (strcmp (year, '202 $\left.\left.4^{\prime}\right)==1\right)||(\operatorname{strcmp}($ year, '2028')==1)|| (strcmp (year, '2032')==1)||( $\operatorname{strcmp}($ year, '2034' $)==1))$ else

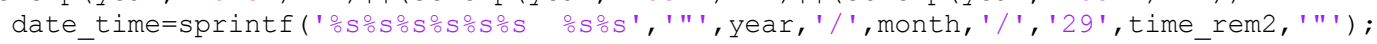
end

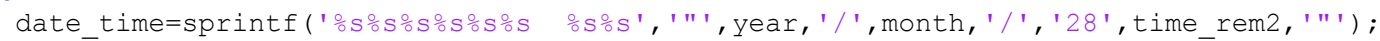

end

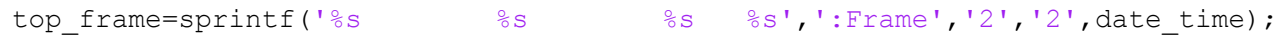

fprintf(cell_fileID_UP $\{j\}, '$ os $\backslash r \backslash n '$, top_frame);

for $i=1$ : rows

$\mathrm{x}=\operatorname{repmat}\left({ }^{\circ} \mathrm{o}-7.2 \mathrm{f}, \mathrm{1},(\operatorname{cols}-1)\right)$;

end

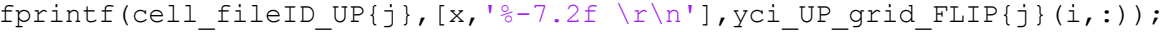

end

fprintf(cell fileID UP $\{j\}, ' \frac{\circ}{\circ} \backslash r \backslash n$ ', bottom frame);

fclose (cell fileID UP $\{j\})$;

for $j=1$ : num_months

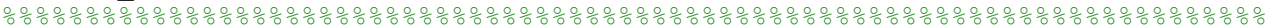

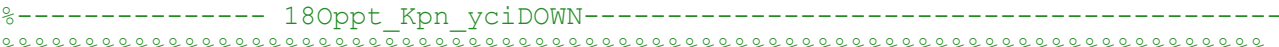

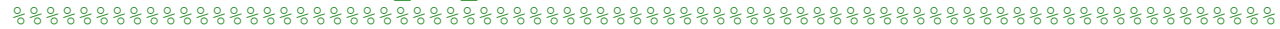

oconstruct the defined lines of text required for the.r2c file header.

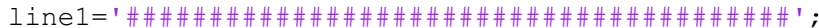

line2=':FileType r2C ASCII EnSim 1.0'; 
APPENDix C

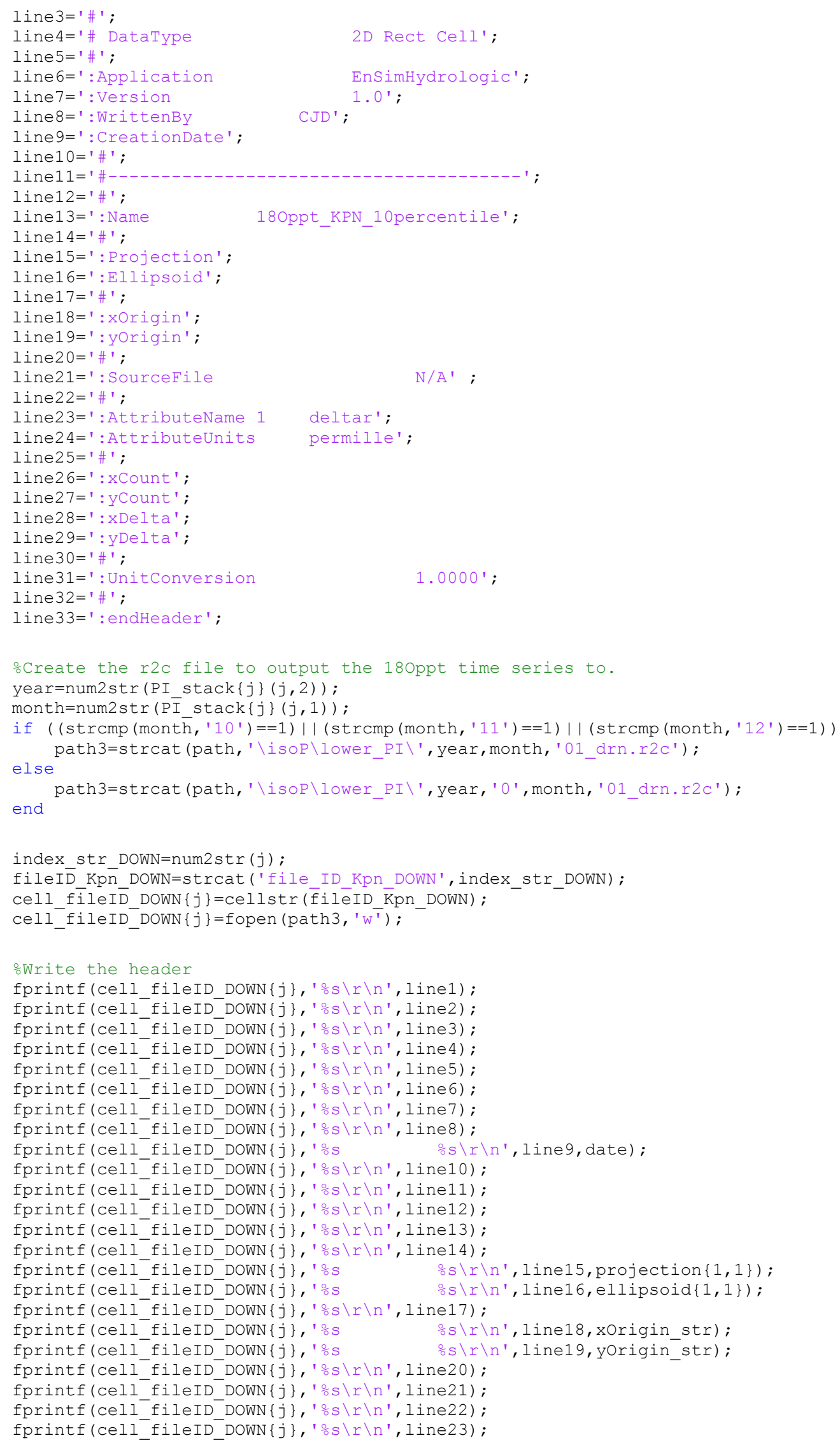


APPENDix C

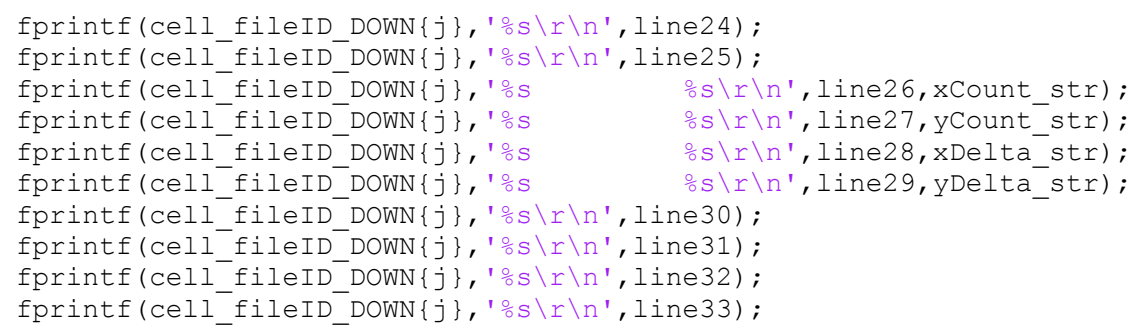


APPENDIX C

UPDATE='Your 180ppt KPN files are written in the SPL \basin \isoP file!'

end 
Appendix D:

ISOP PROGRAM OUTPUT 


\section{APPENDiX D}

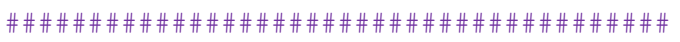

:FileType r2C ASCII EnSim 1.0

\#

\# DataType

2D Rect Cell

:Application

:Version

:WrittenBy

EnSimHydrologic

:CreationDate

CJD

$\#$

: Name

180ppt_KPN_mean

:Projection

:Ellipsoid

:xOrigin

:yorigin

:Sourcefile

:AttributeName

:AttributeUnits

490000

6730000

:xCount $\quad 17$

:ycount 16

:xDelta $\quad 10000$

:yDelta $\quad 10000$

:UnitConversion

:endHeader

\begin{tabular}{|c|c|c|c|c|c|c|c|c|c|c|c|c|c|c|c|c|}
\hline & 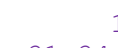 & & 1 & & & & & & & & & & & & & \\
\hline & .34 & 34 & 31.34 & -31.14 & & -31.1 & & & 3 & & 96 & 998 & -30.98 & -30.99 & -30.99 & -30 . \\
\hline & & & & & & & & & & & & & & & & \\
\hline & & & & & & & & & & & & & & & & \\
\hline & & & & & & & & & & & & & & & & \\
\hline & & 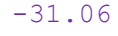 & & - & & & & & & & & & & & & \\
\hline & & & & & & & & & & & & & & & & \\
\hline & 20 & -31 & & & & & & & & & & & & & & \\
\hline & 20 & 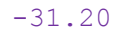 & & & & & & & & & & & & & & \\
\hline & & - & & & & & & & & & & & & & & \\
\hline & -31 & -30 & & & & & & & & & & & & & & \\
\hline & -3104 & 20 & & & & & & & & & & & & & & \\
\hline & -31 & 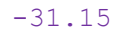 & & & & $-3-3<$ & & & & & & & & & & \\
\hline & -31 & - & & -3 & & -3 & 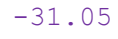 & & & & & & & & & -3 \\
\hline & & & & & & & & & & & & & & & & \\
\hline & & & & & & & & & & & & & & & & \\
\hline & 08 & & & 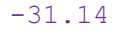 & & - & & & & & & & . & 31.26 & $31 . \angle 6$ & ( \\
\hline
\end{tabular}




\section{APPENDIX D}

:EndFrame

:Frame 22 "1996/1/31 24:00:00.000"

$131.34-31.34-31.34-31.14-31.14-31.14$

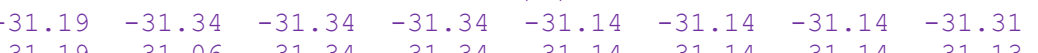

$\begin{array}{lllllll}-31.19 & -31.06 & -31.06 & -31.34 & -31.01 & -31.14 & -31.14\end{array}$

$\begin{array}{llllllll}-31.21 & -31.06 & -31.06 & -31.06 & -31.01 & -31.00 & -31.14 & -30.95\end{array}$

$\begin{array}{llllllll}-31.20 & -31.06 & -31.06 & -31.06 & -31.01 & -31.00 & -31.00 & -30.95 \\ -31.20 & -31.20 & -31.06 & -30.92 & -31.01 & -31.00 & -31.00 & -30.95\end{array}$

$\begin{array}{llllllll}-31.20 & -31.20 & -31.20 & -30.92 & -30.92 & -31.00 & -30.95 & -30.95\end{array}$

$\begin{array}{lllllll}-31.20 & -31.20 & -31.20 & -30.92 & -30.92 & -30.92 & -30.95\end{array}$

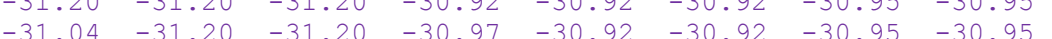

$\begin{array}{llllllll}-31.04 & -31.04 & -30.97 & -30.97 & -30.97 & -30.92 & -31.05 & -30.95\end{array}$

$\begin{array}{lllllll}-31.04 & -31.04 & -30.97 & -30.97 & -30.97 & -30.96 & -31.05\end{array}$

$\begin{array}{llllllll}-31.04 & -31.04 & -31.15 & -30.97 & -30.97 & -31.06 & -31.05 & -31.05\end{array}$

$\begin{array}{llllllll}-31.07 & -31.07 & -31.15 & -31.15 & -31.14 & -30.93 & -30.93 & -31.05\end{array}$

$\begin{array}{llllllll}-31.07 & -31.07 & -31.15 & -31.15 & -31.14 & -30.93 & -30.93 & -30.93\end{array}$

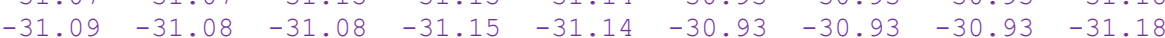

:EndFrame 


\section{Appendix E:}

Publications, Presentations AND Other Works 


\section{Articles Submitted or Published in Refereed Journals}

1. Delavau, C., Stadnyk, T., and Holmes, T.. Examining the impacts of estimated precipitation isotope $\left(\delta^{18} \mathrm{O}\right)$ inputs on distributed tracer-aided hydrological modelling. Submitted to Hydrology and Earth System Sciences, October 2016, manuscript number: hess-2016-539.

2. Delavau, C., Chun, S., Stadnyk, T., Birks, S.J., Welker, J. (2015). North American precipitation isotope (delta O-18) zones revealed in time series modeling across Canada and northern United States. Water Resources Research. 51(2): 1284 - 1299. DOI: 10.1002/2014WR015687 (*Featured article.)

3. Smith, A., Delavau, C., Stadnyk, T. (2015). Identification of geographical influences and flow regime characteristics using regional water isotope surveys in the lower Nelson River, Canada. Canadian Water Resources Journal. 40(1): 23-35. DOI: 10.1080/07011784.2014.985512.

4. Stadnyk, T.A., Delavau, C., Kouwen, N., Edwards, T.W.D. (2013). Towards hydrological model calibration and validation: simulation of stable water isotopes using the isoWATFLOOD model. Hydrological Processes. DOI: 10.1002/hyp.9695.

5. Delavau, C., Stadnyk, T.A., Birks, S. J. (2011). Model based distribution of oxygen-18 isotopes in precipitation across Canada. Canadian Water Resources Journal 36(4): 313-330. DOI: $10.4296 /$ cwrj3604875.

\section{Select Conference Presentations (non-refereed)}

1. Delavau, C., Chun, S.*, Stadnyk, T., Birks, S.J., Welker, J. (December 2014). Time-series Oxygen-18 Precipitation Isoscapes for Canada and the Northern United States. Annual meeting of the American Geophysical Union, San Francisco, CA.

2. Delavau, C., Chun, S., Stadnyk, T., Birks, S.J., Welker, J. (April 2014). Time-series Oxygen18 Precipitation Isoscapes for Canada and the Northern United States. Annual meeting of the European Geophysical Union, Vienna, Austria.

3. Delavau, C., Smith, A., Stadnyk, T., \& Koenig, K. (December 2012). Identifying hydrological controls in the lower Nelson River basin utilizing stable water isotopes. Annual meeting of the American Geophysical Union, San Francisco, CA.

4. Smith, A., Delavau, C.*, Stadnyk, T. \& Koenig, K. (June 2012). The effects of land cover on the composition of stable water isotopes in streamflow within the lower Nelson River basin. Poster presented at the Canadian Water Resources Association/ Canadian Geophysical Union National Conference, Banff, Alberta, Canada.

5. Delavau, C., Stadnyk, T., Birks, S.J., Yi, Y., \& Gibson, J.J. (December 2011). Towards simulating streamflow in ungauged basins utilizing isoWATFLOOD: time-series distribution 
of oxugen-18 and deuterium across Canada. Poster presented at the annual meeting of the American Geophysical Union, San Francisco, CA.

6. Delavau, C., \& Stadnyk, T. (June 2011) Towards Simulating Streamflow in Ungauged Basins utilizing the isoWATFLOOD Hydrological Model: Distribution of Stable Water Isotopes across Canada. Canadian Water Resources Association National Conference, St. John's, Newfoundland, Canada.

7. Stadnyk, T.* \& Delavau, C. (June 2011) The Nelson River Water Isotope Monitoring Network. Canadian Water Resources Association National Conference, St. John's, Newfoundland, Canada.

8. Jasechko, S.*, Yi, Y., Delavau, C., Gibson, J.J. \& Birks, S.J. (June 2011) Tracing air mass sources applying a temperature-independent model to stable water isotopes in precipitation. Canadian Meteorological and Oceanographic Society (CMOS) Congress 2011, Victoria, British Columbia, Canada.

9. Birks, S.J.*, Delavau, C., Yi, Y., Jasechko, S., Gibson, J.J., Stadnyk, T. \& Edwards, T.W.D. (March 2011). Canadian Network for Isotopes in Precipitation: Regional Controls on Isotope-Climate Relations. The Roles of Stable Isotopes in Water Cycle Research, Keystone, Colorado, USA.

10. Delavau, C., Stadnyk, T.* \& Birks, S.J. (March 2011) Towards Simulating Streamflow in Ungauged Basins utilizing the isoWATFLOOD Hydrological Model: Distribution of Stable

Water Isotopes Across Canada. Canadian Water Resources Association Manitoba Conference, Winnipeg, Manitoba, Canada.

11. Delavau, C., Stadnyk, T., Birks, S.J., Gibson, J.J., Yi, Y., \& Kouwen, N. (June 2010) Towards Simulating Streamflow in Ungauged Basins utilizing the isoWATFLOOD Hydrological Model: Analysis of Distribution Methods for Stable Water Isotopes within the Mackenzie River Basin. Poster presented at the Canadian Water Resources Association National Conference, Vancouver, British Columbia, Canada.

12. Slota, P.*, Delavau, C., Stadnyk, T, Kouwen, N. \& Koenig, K. (June 2010) Modelling the Odei river basin: forecasting streamflow for hydroelectric power management. Poster presentation at Canadian Water Resources Association National Conference, Vancouver, British Columbia, Canada.

13. Delavau, C., Stadnyk, T., Gibson, J.J., Sturm, K., Kouwen, N., \& Segleneiks, F. (May 2009) Towards simulating climate change using an RCM-driven hydrological model: coupling REMOiso with isoWATFLOOD in the Mackenzie River basin. International Joint Session of AGU-CGU, Toronto, Ontario, Canada. 


\section{Other Select Non-Refereed Contributions}

1. Edwards, T.W.D., Birks, S.J., Stadnyk, T., Delavau, C., and Smith, A. (November 2013). $50+$ years of monitoring, mapping, and modelling stable isotopes in Canadian precipitation. Sitzung der Expertengruppe "Isotope und Umwelt", Bundesamt für Umwelt, Bern, Switzerland.

2. Stadnyk, T.A., Koenig, K., Bohrn, S., Delavau, C., Smith, A. (June 2013). Development of a stable water isotope monitoring network (SWIMN): phase II and III. Presentation for Manitoba Hydro Research and Development Board. Department of Civil Engineering, Winnipeg: University of Manitoba.

3. Stadnyk, T.A., Delavau, C., Smith, A. (2012). Development of a stable water isotope monitoring network: year 3 progress report (G290). Report prepared for Manitoba Hydro. Department of Civil Engineering, Winnipeg: University of Manitoba.

4. Delavau, C. (2012). Hydrological modelling of large-scale Canadian basins utilizing stable water isotope tracers. Proposal document prepared for the University of Manitoba, Faculty of Graduate Studies. Department of Civil Engineering, Winnipeg: University of Manitoba.

5. Stadnyk, T.A., \& Delavau, C. (2011). Development of a stable water isotope monitoring network: year 2 progress report (G290). Report prepared for Manitoba Hydro. Department of Civil Engineering, Winnipeg: University of Manitoba.

6. Gibson, J.J., Yi, Y., Stadnyk, T., \& Delavau, C. (2010) Evaluating the potential role of stable isotopes in Canada's water survey: examples from the Mackenzie River basin. Alberta Innovates Technology Futures, Project Report: 24 pages. 